INRA Prod. Anim., 2006, 19 (3), 151-240

\title{
Hormones et promoteurs de croissance en productions animales : de la physiologie à l'évaluation du risque
}

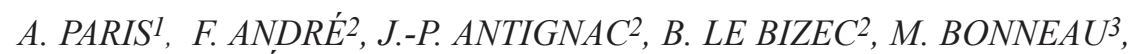

C. BRIANT ${ }^{4}$, A. CARATY, Y. CHILLIARD 5 , Y. COGNIE' ${ }^{4}, Y$. COMBARNOUS, J.-P. CRAVEDI ${ }^{1}, C$. FABRE-NYS $^{4}$, A. FERNANDEZ-SUAREZ ${ }^{6}$, A. FOSTIER ${ }^{7}$, P. HUMBLOT ${ }^{8}$, V. LAUDET ${ }^{9}$, B. LEBOEUF'10, I. LOUVEAU ${ }^{3}$, B. MALPAUX ${ }^{4}$, F. MARTINAT-BOTTÉ 4 , M.-C. MAUREL 4 , M.-T. PELICER-RUBIO 4 , N. PICARD-HAGEN ${ }^{11}$, L. PINAULT ${ }^{12}$,

G. PINEL ${ }^{2}$, C. PONSART ${ }^{8}$, M.-A. POPOT ${ }^{13}$, P. SCHMIDELY14, P.-L. TOUTAIN ${ }^{11}$, D. ZALKO'.

IINRA, ENVT, UMR 1089, Xénobiotiques, 180 chemin de Tournefeuille, BP 3, F-31931 Toulouse Cedex 9

Courriel : aparis@toulouse.inra.fr

2 LABERCA, ENV Nantes, BP 50707, F-44087 Nantes Cedex 03

3 INRA, Agrocampus Rennes, UMR 1079, SENAH, F-35590 Saint-Gilles

4 INRA, CNRS,UMR 6175, Physiologie de la Reproduction et des Comportements, F-37380 Nouzilly

5 INRA, UR 1213, Unité de Recherche sur les Herbivores, F-63122 Saint-Genès Champanelle

6 INTA, CC 77 B1708WAB-Morón Pcia., Buenos-Aires, Argentine

7 INRA, SCRIBE, UR 1037, IFR 140, Campus de Beaulieu, F-35000 Rennes

8 UNCEIA, Département de Recherche et Développement, 13 rue Jouët, F-94704 Maisons-Alfort Cedex ${ }^{9}$ INRA, CNRS, UMR 5161, Laboratoire de Biologie Moléculaire de la Cellule, IFR 128 BioSciences Lyon-Gerland, ENS Lyon, 46 Allée d'Italie, F-69364 Lyon Cedex 07

10 INRA, UE 88, Insémination Caprine et Porcine, F-86480 Rouillé 11 INRA, ENV Toulouse, UMR 181, Physiopathologie et Toxicologie Expérimentales, 23 chemin des Capelles, BP 87614, F-31076 Toulouse Cedex 3

12 Pr Emérite de l'ENV Nantes, 152 rue Paul Bellamy, F-44000 Nantes

13 Laboratoire des Courses Hippiques, 15 rue de Paradis, F-91370 Verrières le Buisson

14 INA Paris-Grignon, UMR 791, Physiologie de la Nutrition et Alimentation, Département des Sciences Animales, 16 rue Claude Bernard, F-75231 Paris

\section{1 / Les principales fonctions physiologiques d'intérêt zootechnique}

\section{1 / La reproduction}

La fonction de reproduction se met en place chez les mammifères au moment de la puberté. De façon la plus manifeste, les individus acquièrent durant cette période un format adulte sous l'action du système GH/IGF-I (Growth Hormone/Insuline-like Growth Factor-I) et des stéroïdes d'origine gonadique (androgènes et œstrogènes) qui jouent un rôle anabolisant. C'est cette stature quasi adulte qui permet la réalisation des comportements mâles et femelles durant la période de reproduction (cours, affrontement, domination, accouplement), mais aussi la réalisation des conditions de maturation des gamètes au moment de l'œstrus et de l'accouplement et, après fécondation, le déroulement de la gestation, de la mise bas et de l'allaitement du ou des jeunes pour assurer le renouvellement des populations et le maintien de l'espèce. Les caractères génétiques les plus favorables au déroulement de la croissance, à la mise en place des différentes phases caractérisant la fonction de reproduction et à sa réalisation seront ainsi plus probablement transmis à la descendance. Cette réalisation de la reproduction des espèces est fortement conditionnée par l'environnement dans lequel se trouvent les populations (figure 1). Chez certaines espèces présentant une activité sexuelle saisonnière, l'intégration au niveau du système nerveux central des changements de photopériode au cours de l'année permet d'expliquer en partie les stratégies d'adaptation à la disponibilité alimentaire.

Les contrôles endocriniens de ces différentes phases caractérisant la fonction de reproduction sont nombreux mais peu sont réellement accessibles à une maîtrise zootechnique simple.

\subsection{1 / La puberté}

Contrairement à l'homme chez qui elle est tardive, dans bon nombre d'espèces l'acquisition de l'aptitude à la reproduction est effective quand le jeune atteint 30 à $70 \%$ du poids adulte. Chez le jeune impubère, l'absence de sécrétion pulsatile de GnRH (Gonadotropin Releasing Hormone) explique le défaut de stimulation hormonale des gonades.

Le début de la période pubertaire est lié au poids corporel et à la masse adipeuse. Le système GH/IGF-I et la leptine sont les facteurs principaux impliqués dans la croissance, mais seule la leptine serait directement liée au déclenchement de la puberté en agissant au niveau du système nerveux central. La sécrétion pulsatile de la $\mathrm{GnRH}$ se met en place progressivement, 
Figure 1. Les différentes interactions possibles entre environnement et fonction de reproduction. Le cycle œstrien caractérise les femelles présentant une activité sexuelle et peut être représenté par les profils hormonaux qui reflètent le dialogue entre ovaires et système nerveux central. Les profils hormonaux présentés ici sont ceux de la brebis. $E_{2}$ : œstradiol, $P_{4}:$ progestérone (Martin et al 2004, Driancourt et Levasseur 2001).

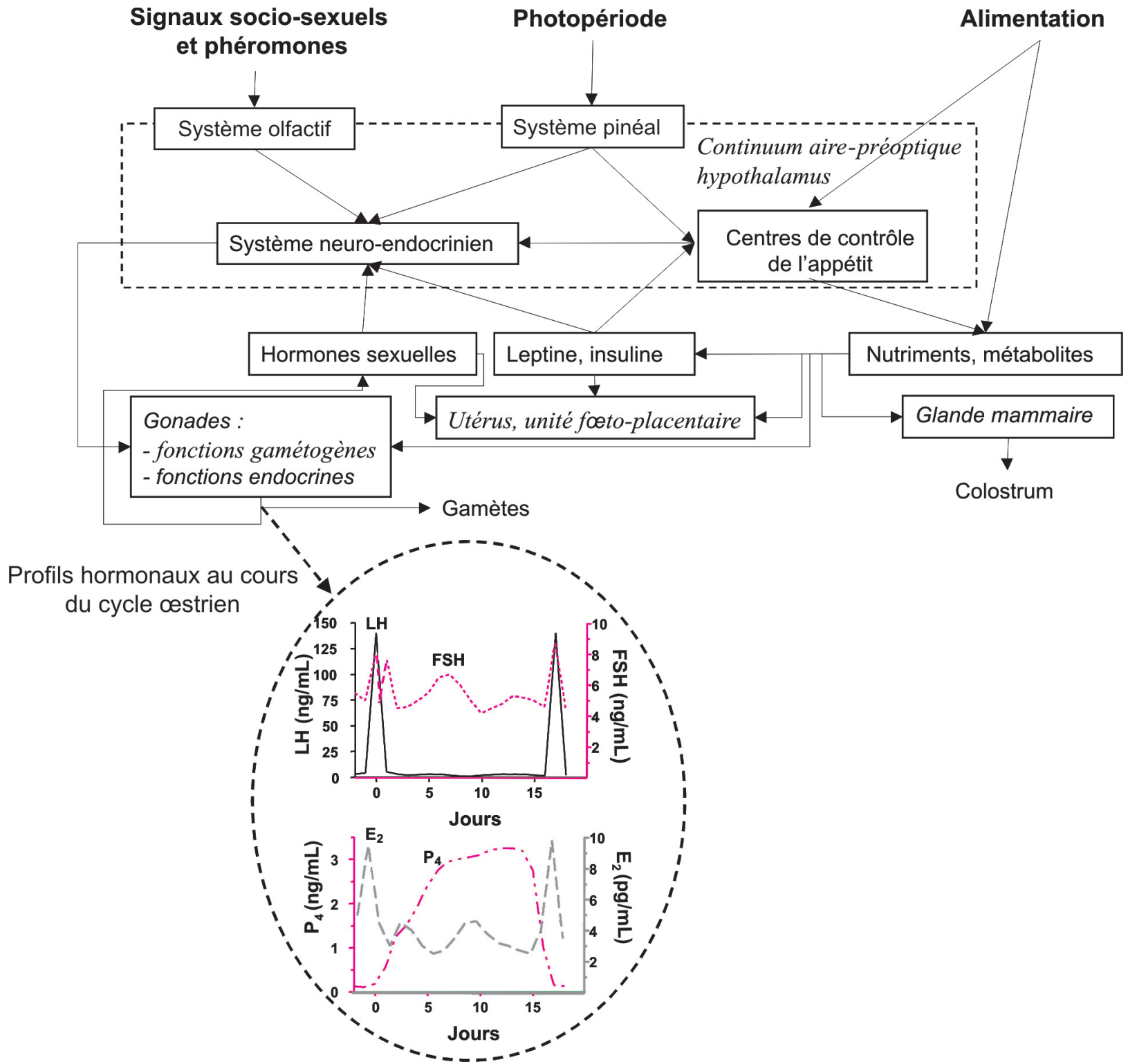

entraînant la reprise de la synthèse et de la sécrétion des gonadotropines : l'hormone lutéinisante (LH) et l'hormone folliculo-stimulante (FSH) (Nicolino et Forest 2001).

Les sécrétions prépubertaires de stéroïdes (testostérone, œstradiol) sont faibles bien que mesurables. Les taux plasmatiques augmentent au cours de la puberté et s'accompagnent d'une diminution progressive de la capacité de liaison de la SHBG (Sex Hormone Binding Globulin), une protéine de transport des stéroïdes sexuels. La mise en place du rétrocontrôle positif des gonadotropines exercé par l'œstradiol qui permet la décharge ovulante apparaît tardivement chez les femelles (Nicolino et Forest 2001).
L'âge à la puberté dépend de facteurs génétiques et environnementaux. Les restrictions alimentaires retardent l'âge à la puberté, même si le développement du système nerveux central et des gonades se poursuit. Chez les espèces à activité sexuelle saisonnière, il est plus difficile de déterminer précisément l'âge à la puberté manifestée, celui-ci étant largement dépendant de la date de naissance.

En pratique, la mise en place de l'aptitude des individus à se reproduire n'offre réellement pas de prise à une manipulation hormonale. Les approches génétiques et alimentaires peuvent néanmoins permettre quelques moyens d'en mieux contrôler les conditions d'apparition.

\subsection{2 / Les gonades}

\section{- Fonctionnement ovarien}

L'activité ovarienne se déroule de façon cyclique tant que l'ovulation n'est pas suivie de la fécondation. Le cycle œstrien correspond à la succession de la phase folliculaire, période durant laquelle les follicules sont recrutés et sélectionnés, pour aboutir à la fin de cette période à un petit nombre de follicules dominants qui ovulent, et la phase lutéale qui couvre la période ovulation/mise en place du corps jaune et régression fonctionnelle du corps jaune (Driancourt et Levasseur 2001).

Cette succession cyclique de structures folliculaires se traduit par l'évolu- 
tion parallèle et coordonnée de profils hormonaux qui reflètent le «dialogue endocrinien» entre ovaires et système nerveux central (figure 1). Une description simple peut en être donnée d'après les observations réalisées chez la brebis et la vache, espèces généralement monoovulantes à phase folliculaire courte (Driancourt et Levasseur 2001). En début de phase folliculaire, la concentration plasmatique en œstradiol est très faible et la pulsatilité de LH réduite. L'augmentation de la pulsatilité de LH à un pulse par heure en fin de phase folliculaire entraîne l'augmentation de la production d'œstradiol par les cellules de la granulosa du follicule préovulatoire, celle-ci augmentant dans des proportions variant de 5 à 10 dans les 24 à 36 heures avant l'ovulation. Ce pic d'œstradiol déclenche par rétrocontrôle positif au niveau hypothalamohypophysaire la décharge ovulante de gonadotropines ( $\mathrm{LH}$ et $\mathrm{FSH}$ ) qui marque le début de la phase lutéale. Un second pic de FSH 24 heures après le pic ovulatoire de gonadotropines apparaît. Durant la phase lutéale, le corps jaune produisant essentiellement la progestérone se met en place, les concentrations maximales en progestérone apparaissant vers le $8 \mathrm{e}$ jour suivant le pic préovulatoire de gonadotropines. A ce moment, la pulsatilité de LH est faible : 1 pic toutes les $6 \mathrm{~h}$ en moyenne. En fin de phase lutéale, l'endomètre sécrète de façon pulsatile la prostaglandine $\mathrm{F}_{2 \alpha}\left(\mathrm{PgF}_{2 \alpha}\right)$ dont l'augmentation progressive induit la régression du corps jaune (lutéolyse), ce qui permet d'initier un nouveau cycle folliculaire (Driancourt et Levasseur 2001).

Chez la jument, espèce monoovulante à phase folliculaire longue, la durée de cette phase est très variable : de 3 à 15 jours. La secrétion de LH semble peu ou pas pulsatile; elle augmente progressivement dès le début de l'œstrus, atteint des valeurs maximales $24 \mathrm{~h}$ après l'ovulation qui chutent 3-4 jours après. Les concentrations en FSH durant la phase folliculaire diminuent par rétroaction négative de l'œstradiol et de l'inhibine. Les concentrations plasmatiques en progestérone augmentent $24 \mathrm{~h}$ après l'ovulation, et ce pendant 5 jours pour se maintenir à un plateau pendant encore 5 jours. Peu avant la lutéolyse, la FSH augmente à nouveau, assurant ainsi le recrutement des follicules pour le cycle suivant (Driancourt et Levasseur 2001).

Chez la truie, espèce polyovulante et à cycle long, les profils de sécrétion des stéroïdes (œstradiol et progestérone) sont peu différents de ceux décrits chez la brebis et la vache. Cette espèce semble se caractériser par un pic ovulatoire de gonadotropines peu élevé (Driancourt et Levasseur 2001).

Le déterminisme de la durée du cycle ovarien est fonction de la durée de la croissance terminale du ou des follicules dominants après lutéolyse et de la durée de vie du corps jaune; elle dépend peu de l'ensemble hypothalamo-hypophysaire.

Chez les femelles cycliques, la maîtrise hormonale des cycles aura donc pour but :

- de mimer la phase lutéale et de maîtriser le moment de l'ovulation en utilisant la progestérone ou ses analogues puisqu'ils bloquent la décharge préovulatoire de la GnRH qui induit la décharge ovulante de LH (Caraty et al 2001). Ces traitements utilisant un progestagène seul doivent être d'une durée comparable à celle d'une phase lutéale vraie. Chez les bovins, équins et caprins, ces traitements progestatifs de longue durée peuvent affecter négativement la fertilité ;

- d'amplifier le recrutement des follicules destinés à ovuler dans le cas de traitement de superovulation, en utilisant la FSH ou un analogue naturel, la gonadotropine chorionique équine (eCG) ;

- de déclencher l'ovulation à un moment prédéterminé en utilisant l'hCG ou des agonistes de la GnRH chez la jument qui présente une phase folliculaire de durée très variable avec l'impossibilité de relier le moment d'apparition du pic préovulatoire de LH au début des chaleurs.

\section{Elle devra se faire en :}

- limitant la durée d'administration des progestines par le recours, en milieu de traitement, à $\mathrm{PgF}_{2 \alpha}$ ou ses analogues. Ils induisent une régression du corps jaune au-delà du 5 e jour du cycle chez les équins, bovins, caprins et ovins et au-delà du $12^{\mathrm{e}}$ jour chez les porcins. Deux injections dont l'intervalle varie selon les espèces sont couramment utilisées pour contrôler les cycles de l'ensemble des femelles ;

- et en utilisant de façon complémentaire les œstrogènes pour leurs propriétés lutéolytiques ou lutéotrophiques selon l'espèce et le stade du cycle considérés. Chez les bovins, ils sont souvent associés à un traitement progestatif de façon à inhiber l'ovulation et empêcher le développement d'un corps jaune.

Chez les femelles prépubères et chez celles en anœstrus saisonnier ou de lac- tation, la maîtrise hormonale des cycles consistera, compte tenu de la faible activité de l'axe hypothalamohypophysaire, à provoquer l'ovulation en induisant le pic préovulatoire de LH. A l'exception de la jument, l'administration de l'eCG permet d'obtenir ce résultat chez de nombreuses espèces en induisant une augmentation importante de la sécrétion d'œstradiol (Cognié 1988).

\section{- Fonctionnement testiculaire}

Tout comme les ovaires, les testicules assurent une double fonction : gamétogène et endocrine. Le siège de la spermatogenèse se situe au niveau des tubes séminifères qui produisent à partir de la puberté un grand nombre de spermatozoïdes à partir des cellules germinales que sont les spermatogonies, les spermatocytes et les spermatides, cellules qui sont associées aux cellules de Sertoli pour constituer l'épithélium séminal. Le cycle spermatogénétique ne peut se définir qu'en un point du tube séminifère et correspond à la succession des différents stades de maturation d'une génération de cellules germinales (Dadoune et Demoulin 2001). La durée du cycle est constante pour chaque espèce. La production continue de spermatozoïdes résulte de la superposition des différents cycles évoluant à des stades de maturation différents.

Les cellules de Sertoli contrôlent la maturation des cellules germinales et synthétisent nombre de protéines dont certaines spécifiques comme l'ABP (Androgen Binding Globulin), l'inhibine et l'hormone antimullérienne et des stéroïdes comme la testostérone et l'œstradiol. Les cellules de Leydig synthétisent des facteurs de croissance (IGF-I) ainsi que des hormones comme l'ocytocine, la vasopressine et la testostérone qui, chez les espèces ovine et porcine, est transformée en œstradiol.

La spermatogenèse est régulée de façon complexe par les signaux endocrines et paracrines. Elle est stimulée par la LH et la FSH, elles-mêmes sous le contrôle de la sécrétion pulsatile de GnRH. La LH stimule au niveau des cellules de Leydig la production de testostérone qui diffuse au niveau des tubules séminifères. Les cellules de Sertoli y possèdent des récepteurs à la FSH ou à la testostérone qui interviennent dans le contrôle de la spermatogenèse.

Chez l'homme, le contrôle hormonal de la spermatogenèse fait l'objet de nombreuses recherches afin de mieux maîtriser la contraception masculine. 
L'administration d'esters de testostérone réduit la stimulation de la spermatogenèse par les gonadotropines. L'oligospermie est renforcée par l'administration combinée d'antagonistes de GnRH ou de progestines (Nieschlag et Behre 1998).

Chez les animaux de rente, le contrôle hormonal de la production de sperme ne fait pas l'objet de recherches à visée appliquée. Celles-ci portent plutôt sur le contrôle de la maturation des spermatozoïdes dans l'épididyme et les modes de dilution et de conservation du sperme.

Des études sont conduites chez l'homme pour comprendre les effets de certains xénobiotiques présents dans l'environnement qui sont considérés comme autant de perturbateurs endocriniens pouvant expliquer la baisse de la fertilité masculine constatée par différents auteurs au cours de ces trente dernières années (Auger et al 1995, Toppari et al 1996, Jouannet et al 2001). Néanmoins, ces études ne semblent trouver que peu d'écho auprès des équipes se préoccupant de l'étude de la fertilité mâle chez les espèces domestiques (Rhind 2002), vraisemblablement parce qu'aucun indice sur un possible déclin de la production spermatique n'a pu être clairement révélé jusqu'à présent (Setchell 1997), ceci en dépit d'une baisse constatée de la fertilité en élevage laitier chez les vaches hautes productrices qui est estimée à $0,5-1 \%$ par an et qui est mise sur le compte du progrès génétique constant réalisé au cours des trente dernières années (Royal et al 2000).

\subsection{3 / L'utérus et l'unité foeto-placen- taire}

La productivité numérique en élevage est calculée comme le nombre de jeunes nés par reproductrice. Ce score est dépendant du nombre d'ovulations et du nombre d'ovules fécondés, mais aussi des pertes embryonnaires. Le début de gestation constitue une période durant laquelle les pertes peuvent être importantes; chez les brebis Mérinos, elles peuvent osciller entre 7 et $45 \%$ (Restall et al 1976). Une cause réside dans les problèmes de sousnutrition des mères, mais paradoxalement un excès alimentaire durant les deux premières semaines de la gestation peut aussi entraîner des pertes embryonnaires en favorisant la clairance de la progestérone. Chez la brebis, un apport en progestérone durant les quelques jours qui suivent la saillie ou l'insémination pourrait améliorer, dans certaines conditions, la taille des portées (Kleemann et al 1994).

\subsection{4 / Le contexte photopériodique}

Chez les ovins, les caprins et les équins, le contrôle de l'activité saisonnière de reproduction est dépendant de la photopériode. Chez ces espèces, la photopériode détectée au niveau rétinien est le principal élément déclenchant la mise en place de l'activité sexuelle via la synthèse nocturne de mélatonine par la glande pinéale (Malpaux 2001). Chez les espèces ayant une activité de reproduction très marquée par les saisons, la mélatonine agit sur l'hypothalamus avec des répercussions sur l'activité gonadotrope hypophysaire. Chez les ovins, la sensibilité à la rétroaction négative des stéroïdes (testostérone, œstradiol) est forte pendant la période de repos sexuel et faible pendant la saison sexuelle (Malpaux 2001)

Pour les espèces animales concernées, la maîtrise du décalage dans l'année des périodes de reproduction peut donc s'appuyer sur un contrôle artificiel de la photopériode ou sur une modification des teneurs circulantes en mélatonine par le biais d'implants.

\subsection{5 / Le contexte nutritionnel}

La qualité et la quantité d'aliment peuvent avoir un effet sur la taille des portées chez la brebis (Martin et al 2004), ce qui laisse supposer que des paramètres endocriniens autres que ceux qui relèvent strictement de la fonction de reproduction peuvent aussi avoir une influence. Parmi ceux-ci, l'insuline, des facteurs de croissance et la leptine pourraient affecter le développement des follicules ovariens et réfléter un état du métabolisme énergétique particulier (figure 1).

\section{2 / La croissance et l'engraisse- ment}

\subsection{1 / Aspects généraux}

- Mise en place et développement des tissus

La croissance pondérale de l'organisme animal rend compte de l'évolution de la masse corporelle depuis la formation de l'œuf jusqu' au stade adulte. Elle est classiquement distinguée du développement qui correspond à la mise en place des tissus, des organes et de leurs fonctions. Pour englober ces deux notions complémentaires mais difficiles à dissocier, la croissance peut être redéfinie comme la succession de variations de masse, de forme, de struc- ture et de composition chimique de l'organisme.

Le tissu musculaire et le tissu adipeux blanc sont les deux tissus les plus abondants de l'organisme dont les proportions relatives évoluent avec l'âge. La masse musculaire représente près de la moitié de la masse corporelle des animaux. Le muscle squelettique est essentiellement constitué de fibres musculaires (75 à $90 \%$ du volume musculaire) qui présentent différentes propriétés contractiles et métaboliques acquises pendant les phases embryonnaires, fotales ou périnatales (Picard et al 2003). Les muscles squelettiques du tronc et des membres dérivent des somites embryonnaires. Les précurseurs myogéniques donnent naissance, après multiplication, aux myoblastes qui fusionnent pour donner des cellules allongées et plurinucléées, les myotubes. Il existe au moins deux générations de myotubes, une qui se met en place au stade embryonnaire et une autre qui se met en place au stade fotal. La croissance et la maturation des myotubes conduisent à la formation des fibres musculaires qui vont ensuite croître par fusion des cellules satellites, les précurseurs myogéniques présents à la périphérie des fibres. Le nombre et la taille des fibres musculaires déterminent la taille du tissu musculaire. Pour la plupart des espèces d'intérêt zootechnique, le nombre total de fibres n'évolue plus après la naissance. En revanche, chez certains poissons, l'hyperplasie musculaire persiste tout au long de la vie. En ce qui concerne l'hypertrophie musculaire, elle se poursuit durant la phase postnatale. Ces processus de prolifération, de différenciation et de croissance cellulaire sont sous la dépendance de facteurs myogéniques (Myo D, myogénine, Myf 5 et MRF4), d'hormones et de facteurs de croissance tels que les IGFs, FGFs et TGF- $\beta$ (Cassar-Malek et al 1998, Oksbjerg et al 2004). Un facteur de la famille du TGF- $\beta$, la myostatine ou GDF-8, agit comme inhibiteur de la croissance du muscle squelettique. L'altération du gène codant la myostatine se traduit par le caractère culard sélectionné dans quelques races bovines comme la race Bleu Belge ou la race Piémontaise (Grobet et al 1997, Kambadur et al 1997).

Le tissu adipeux blanc existe sous forme de dépôts localisés dans différents sites anatomiques. Les dépôts les plus importants sont sous-cutanés et péri-viscéraux. Il existe aussi sous une forme diffuse constituée de cellules plus ou moins isolées comme dans le muscle squelettique. Dans la plupart 
des espèces, le tissu adipeux se met en place avant la naissance, la chronologie d'apparition variant selon l'espèce et les dépôts adipeux considérés. L'augmentation de la masse adipeuse se produit essentiellement après la naissance et peut se poursuivre tout au long de la vie de l'individu. Elle est liée à l'augmentation de la taille et/ou du nombre d'adipocytes. L'augmentation de leur nombre dépend de la différenciation des précurseurs adipocytaires, les préadipocytes. La différenciation adipocytaire a été bien caractérisée in vitro à partir de lignées cellulaires de rongeurs (Grégoire et al 1998). Après une phase de prolifération, les préadipocytes commencent à exprimer les caractéristiques du phénotype adipocytaire sous l'influence de plusieurs hormones et facteurs de croissance comme l'IGF-I et l'hormone de croissance (Louveau et Gondret 2004). L'adipocyte ainsi formé peut contribuer au recrutement de cellules précurseurs.

\section{- Contrôles endocriniens}

Les caractéristiques de la croissance et la composition corporelle varient selon l'espèce considérée. Le sexe de l'embryon détermine aussi des caractères propres de poids, de composition corporelle des animaux à la naissance et de vitesse de croissance postnatale. D'une manière générale, les mâles à la naissance sont plus maigres que les femelles, ce qui est à mettre en relation avec la biosynthèse de testostérone du fœtus mâle en fin de gestation. Chez les bovins, des femelles androgénisées in utero montrent une vitesse de croissance supérieure à celle des femelles témoins qui s'accompagne d'une meilleure efficacité alimentaire et d'un dépôt de graisse moindre (DeHaan et al 1988, Reiling et al 1995). Dans les différentes espèces domestiques, le dimorphisme sexuel dans la croissance pubertaire et dans le format à l'âge adulte est déterminé par la nature et les taux de sécrétion des stéroïdes sexuels. Les androgènes jouent un rôle primordial qui explique que les performances de croissance des mâles castrés sont moindres que celles des mâles entiers et que leur composition corporelle est modifiée par une augmentation relative du tissu adipeux (Lawrence et Fowler 2002). Androgènes et glucocorticoïdes ont des actions opposées sur le métabolisme azoté, les premiers améliorant la rétention azotée, les seconds ayant une action catabolique.

De nombreux promoteurs de croissance peuvent être utilisés pour améliorer les performances de croissance des animaux domestiques (Sillence 2004). L'hormone de croissance (Growth Hormone, GH) ou somatotropine (ST) et les hormones sexuelles ont été les plus étudiées. Des agonistes des récepteurs $\beta$-adrénergiques, proches structuralement de l'adrénaline ou de la noradrénaline, peuvent jouer un rôle complémentaire dans le contrôle physiologique de la croissance. Enfin, une régulation de l'activité de certaines de ces hormones est possible par les protéines de transport (Binding Proteins) de ces hormones, ainsi que par le nombre et l'affinité de leurs récepteurs tissulaires.

La plupart des molécules utilisées permettent de manipuler le rapport tissu maigre/tissu gras. L'augmentation de la masse musculaire peut être obtenue par une augmentation du nombre ou de la taille des fibres. Au cours de la gestation, la modification de l'environnement endocrinien de la mère peut influencer les caractéristiques du développement musculaire chez l'embryon ou le fœtus : un traitement de la truie en début de gestation par la GH se traduit par une augmentation du nombre de fibres musculaires chez le fotus (Rehfeldt et al 1993) tandis qu'un traitement en fin de gestation permet d'obtenir des porcelets plus lourds à la naissance.

In vitro, les IGFs stimulent la prolifération et la différenciation terminale des myoblastes (Florini et al 1996, Oksbjerg et al 2004), ce qui se traduit par des activités d'anabolisme protéique importantes. In vivo, chez la souris, la surexpression du gène codant pour l'IGF-I dans le tissu musculaire entraîne une hypertrophie musculaire (Coleman et al 1995). Ces observations soulignent l'importance des actions autocrines et paracrines de l'IGF-I, ouvrant ainsi la possibilité d'un contrôle endocrinien des cellules myogéniques en élevage pour augmenter la masse musculaire des animaux.

Après la naissance, le rôle des hormones hypophysaires dans le contrôle physiologique de la croissance est bien établi (Wray-Cahen et al 1998). Les principaux tissus placés sous le contrôle de la GH sont le muscle, le tissu adipeux et aussi le foie et le tissu osseux (figure 2). Même si la sécrétion de la $\mathrm{GH}$, pulsatile, rend difficile l'établissement de corrélations simples avec les effets tissulaires observés, il semble que chez les ovins, bovins et porcins la sécrétion journalière de GH soit corrélée positivement avec la proportion de tissu maigre dans les carcasses et néga- tivement avec la proportion de tissu adipeux (Lawrence et Fowler 2002). D'une manière générale, la GH favorise l'anabolisme protéique et réduit l'anabolisme lipidique.

L'utilisation des différents promoteurs de croissance dépend de l'espèce considérée, de l'état physiologique de l'animal et du type de production. Au cours des trois dernières décennies, l'évaluation de ces promoteurs effectuée chez les ruminants et le porc en terme de performance de croissance et de qualité des carcasses produites a permis de les classer. La GH est considérée comme un agent de répartition efficace chez les porcs en fin d'engraissement tandis que les $\beta$-agonistes sont plus efficaces chez les ruminants. GH, IGFs ou $\beta$-agonistes sont néanmoins interdits d'emploi dans l'UE. Les stéroïdes anabolisants naturels (œstradiol, testostérone, progesterone) ou de synthèse (zéranol, acétate de trenbolone, acétate de mélengestrol) sont utilisés essentiellement en élevage bovin, mais hors UE.

\subsection{2 / Particularités propres à l'es- pèce bovine}

Les cinétiques d'accrétion protéique et d'augmentation du compartiment adipeux sont contrastées, le stockage des lipides dans le tissu adipeux s'accélérant avec l'âge au contraire de l'accrétion protéique (Owens et al 1995). La GH favorise l'accrétion protéique et retarde le dépôt de graisse (Dalke et al 1992). Des facteurs génétiques comme le format adulte des animaux, des facteurs liés à la maturité physiologique ou simplement au niveau de la restriction alimentaire imposée influencent aussi la composition des carcasses des animaux en croissance (Owens et al 1995). Chez le jeune ruminant, le taux de synthèse protéique représente 5 à 10 fois celui de l'accrétion protéique. La diminution du turnover protéique induite par un traitement par des $\beta$-agonistes ou par des androgènes se traduira par une augmentation de l'accrétion protéique (Owens et al 1995).

Afin d'améliorer l'efficacité de l'accrétion protéique, on cherchera à augmenter le format adulte des animaux, à limiter la consommation d'énergie en période de croissance et d'engraissement, enfin à abattre les animaux à un stade plus précoce dès que la maturité sera atteinte.

En élevage bovin, pour de meilleures facilités de manipulation des animaux, il était d'usage, jusqu'à la première moitié du $20^{\mathrm{e}}$ siècle, de castrer les 
Figure 2. Diagramme d'interactions entre les signaux endocriniens et des facteurs produits par le système immunitaire et les organes qui interviennent dans la régulation de la croissance (Wray-Cahen et al 1998, Meyer 2001). L'équilibre entre ces systèmes détermine le niveau d'utilisation des nutriments pour la fonction de croissance. En réponse à une sensibilité à l'insuline réduite et à une inhibition de la lipogenèse dans le foie et le tissu adipeux, les concentrations plasmatiques en glucose augmentent ; le métabolisme hépatique des acides aminés $(A A)$ est réduit. Une meilleure utilisation de l'énergie favorise les synthèses de protéines et stimule la croissance et la prolifération cellulaires. GHRH, growth hormone releasing hormone ; SRIF, somatostatine ; CRF, corticotropinreleasing factor ; GH, growth hormone ; ACTH, adrenocorticotropic hormone ; IGF-I, insulin-like growth factor I ; IGFBP, IGF-binding proteins.

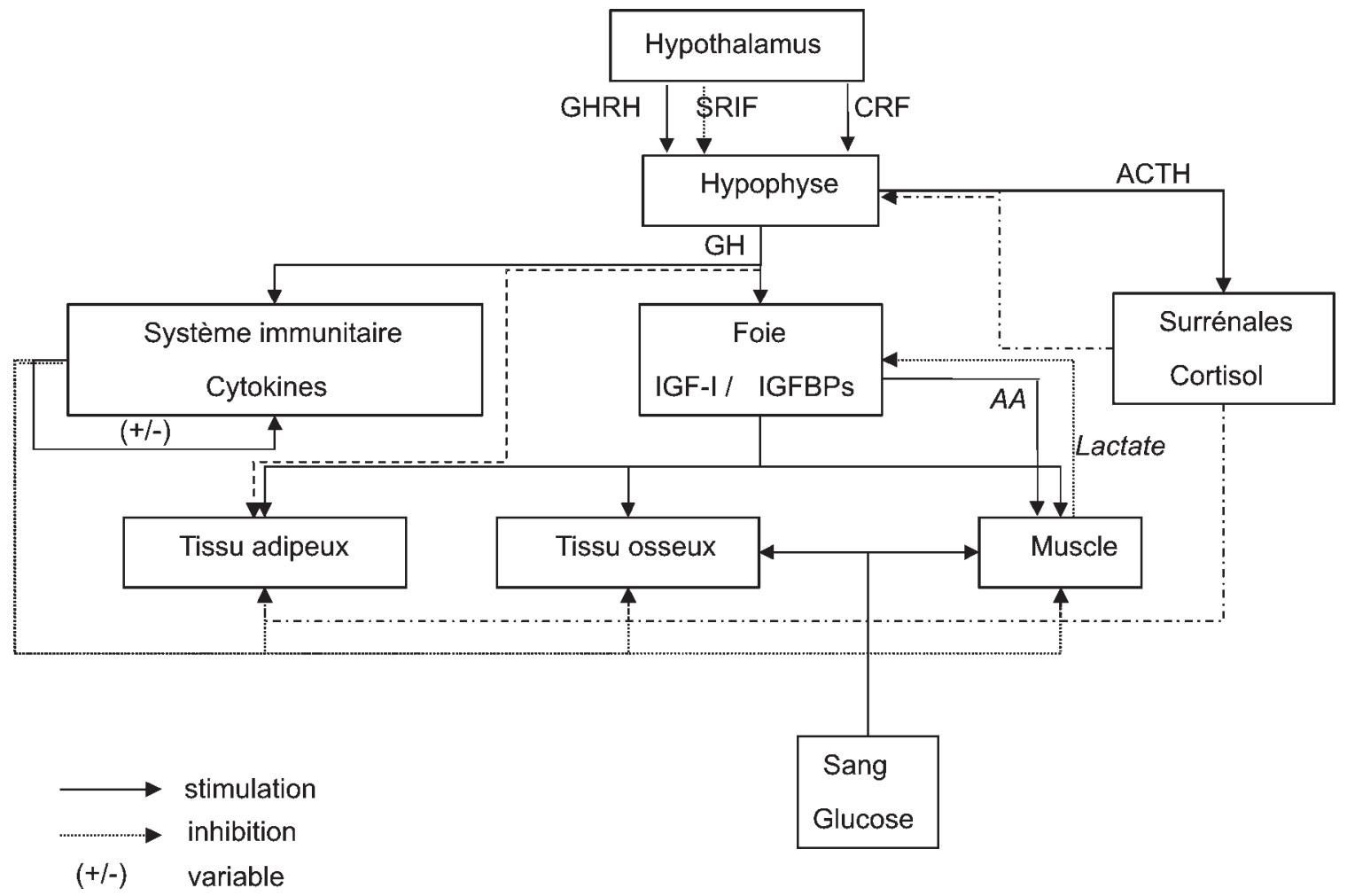

mâles pour produire des bœufs utilisés pour la traction attelée. Ce type d'élevage permettait aussi d'obtenir des bœufs engraissés de façon optimale quand ils étaient abattus vers l'âge de 3 ans. La découverte des stéroïdes anabolisants a permis de rétablir les effets d'une stimulation hormonale améliorant, en fin de période d'engraissement, la croissance des bouvillons destinés à la boucherie ou même de l'adapter aux génisses placées en engraissement.

\subsection{3 / Particularités propres à l'es- pèce porcine}

Chez le porc, la croissance a fait l'objet de revues détaillées (Delpech et Lefaucheur 1986, Reeds et al 1993). Pendant la gestation, la courbe de croissance pondérale des foetus présente une allure exponentielle croissante avec une accélération particulièrement importante durant le dernier tiers de la gestation. A la naissance, le porc se distingue des autres mammifères par son poids qui représente une faible proportion de son poids adulte ; le rapport poids adulte/poids à la naissance est de l'ordre de 300 alors qu'il n'est que de 20 à 40 chez de nombreux autres mammifères. La vitesse de crois- sance postnatale est donc élevée dans cette espèce. L'évolution de la masse corporelle avec l'âge est de type sigmoïdal entre la naissance et 300 jours (Whittemore et al 1988). Elle peut être influencée par de nombreux facteurs sans que l'allure générale de la courbe de croissance soit modifiée. L'effet du type génétique est illustré par les différences de format adulte entre les races européennes et les races chinoises, ces dernières se caractérisant par un format adulte plus petit. L'influence du type sexuel est aussi bien documentée. Ainsi les mâles entiers croissent plus vite que les femelles. Aucune différence de vitesse de croissance globale n'est observée entre les femelles et les mâles castrés nourris à volonté.

L'étude de la croissance pondérale montre des variations d'allométrie contrastées. Le pourcentage représenté par le squelette décroît dès la naissance alors que la part de la masse musculaire augmente et atteint un maximum entre 60 et $80 \mathrm{~kg}$ de poids vif. Le pourcentage de lipides passe de $1,7 \%$ à la naissance à $11,3 \%$ à 21 jours d'âge et peut dépasser $20 \%$ de la carcasse à $100 \mathrm{~kg}$. Les effets du génotype et du type sexuel sur la composition corporelle se manifestent essentiellement au niveau des dépôts musculaire et adipeux. On distingue des génotypes à fort développement musculaire comme le porc de race Piétrain et à faible développement musculaire comme le porc de race Meishan, le pourcentage de muscle dans la carcasse étant respectivement de 60 et $25 \%$ (Noblet 1994). Les mâles se caractérisent par une adiposité plus faible et des teneurs en muscle plus élevées que les femelles alors que la castration des mâles favorise leur engraissement. Même si les performances de croissance des mâles entiers sont plus élevées que celles des mâles castrés, il est d'usage dans la plupart des pays européens de castrer les porcs mâles destinés à la production de viande (Bonneau 1998). Cette pratique résulte de la présence chez certains porcs mâles entiers d'odeurs sexuelles dans la viande ; celle-ci exhale intensément ces odeurs lors de la cuisson, au désagrément évident du consommateur.

\section{3 / La sécrétion lactée}

La fonction de lactation, en permettant une meilleure adaptation des mam- 
mifères nouveau-nés dans des milieux variés et parfois hostiles, peut être considérée comme la dernière étape de la fonction de reproduction. Ces deux fonctions sont donc étroitement imbriquées : la glande mammaire se développe (mammogenèse) notamment autour de la puberté et durant la gestation ; la lactation se déclenche (lactogénèse) durant les quelques jours qui précèdent la parturition ; et le maintien d'une sécrétion lactée abondante (galactopoïèse) s'accompagne d'un blocage ou d'un retard de la fonction ovarienne (anœstrus de lactation).

Les différentes étapes de la mise en place et du maintien de la fonction mammaire sont sous étroit contrôle hormonal, mais aussi métabolique et nutritionnel.

\subsection{1 / La mammogenèse}

La mammogenèse dépend dans un premier temps de sécrétions successives d'œstrogènes et de progestérone durant les cycles ovariens. Durant la phase folliculaire, les œstrogènes favorisent la croissance des canaux mammaires. Durant la phase lutéale, la progestérone stimule la mise en place du système lobulo-alvéolaire, tout en inhibant la mise en place d'une activité sécrétoire (Jammes et Djiane 1988). Les œstrogènes agissent notamment en stimulant la sécrétion du facteur de croissance TGF- $\alpha$ par les cellules épithéliales mammaires, avec des effets autocrines et paracrines sur ces cellules et sur la matrice extracellulaire, qui stimulent les divisions cellulaires (Houdebine 1997). Ces actions s'amplifient ensuite durant la gestation, notamment du fait de la sécrétion d'œstrogènes et de progestérone par l'unité fœto-placentaire. Le système lobulo-alvéolaire se développe rapidement à partir du sixième mois de gestation et se substitue progressivement au tissu adipeux mammaire.

\subsection{2 / La lactogenèse}

La lactogenèse ou montée laiteuse est déclenchée par un ensemble de bouleversements hormonaux qui ont lieu chez les bovins durant les dix derniers jours de la gestation : augmentation des œstrogènes et chute brutale de la progestéronémie, qui entraînent des décharges de glucocorticoïdes, de prolactine et de GH (Jammes et Djiane 1988). Les cellules épithéliales s'hypertrophient et acquièrent les structures spécifiques d'une activité sécrétoire intense de glucides, protéines et lipides ayant des propriétés caractéristiques et spécifiques du lait (par exemple : lactose, caséines et triglycérides ayant un profil particulier d'acides gras).
Simultanément, les régulations métaboliques dans les tissus extra mammaires commencent à être modifiées pour faciliter les adaptations métaboliques du début de lactation (mécanismes téléophorétiques, cf $\S$ 1.3.3). Par exemple, l'expression dans le foie du gène du récepteur $1 \mathrm{~A}$ de la $\mathrm{GH}$ est diminuée (Radcliff et al 2003), ce qui entraînera une résistance à la $\mathrm{GH}$ de la production d'IGF-I en début de lactation (cf $\S 2.2 .4$ ).

\subsection{3 / La galactopoïèse}

La galactopoïèse (entretien de la sécrétion lactée) dépend en premier lieu d'une vidange régulière du lait qui s'accumule dans les canaux et la citerne mammaire. Cette vidange est permise par la sécrétion réflexe d'ocytocine par l'hypophyse, qui stimule la contraction des cellules myoépithéliales entourant les alvéoles mammaires. Par ailleurs, la prolactine, la $\mathrm{GH}$, les glucocorticoïdes et l'insuline sont indispensables au bon fonctionnement des cellules sécrétrices de lait (Houdebine 1997). Il semble toutefois, chez les ruminants, que seule la $\mathrm{GH}$ soit limitante pour maximiser le potentiel sécrétoire ( $\mathrm{cf} \S 2.2 .4$ et 3.1.4 pour les mécanismes d'action et les effets zootechniques de cette hormone et Veerkamp et al (2003) pour les effets de la sélection génétique). Une fourniture abondante de nutriments (glucose, acides aminés, acétate, acides gras longs, minéraux et micronutriments) permise par un flux sanguin mammaire et une nutrition ad hoc de la vache sont indispensables au maintien d'un niveau élevé et durable de production laitière.

Outre la fourniture accrue de nutriments permise par l'accroissement des quantités d'aliments ingérés et digérés qui favorise la sécrétion lactée, celle-ci est facilitée par la mise en place de mécanismes téléophorétiques (transport orienté vers une fin) ou homéorhétiques (flux uniformes) (Chilliard 1999, Bauman 2000). Ces mécanismes modifient les points de consigne des régulations homéostatiques du métabolisme des tissus extramammaires et permettent ainsi d'assurer une priorité relative au métabolisme mammaire, notamment durant les 4 à 6 premières semaines de lactation, période de transition qui permet un accroissement de la production laitière plus rapide que celui du niveau d'ingestion. Toutefois, une sous-alimentation trop poussée ou de trop longue durée s'accompagne d'une diminution rapide du niveau de production laitière, ce qui évite d'épuiser de façon irréversible les réserves corporelles maternelles, protéiques notamment (Chilliard et al 1998a). La lactation, probablement via la sécrétion d'ocytocine, entraîne une diminution de la sécrétion de leptine, et ceci indépendamment d'effets connexes sur l'adiposité ou le bilan énergétique des animaux (Bonnet et al 2005). Cette hypoleptinémie permet probablement de stimuler l'appétit, mais aussi de réduire la production de chaleur et d'accroître l'efficacité énergétique, favorisant ainsi la reconstitution des réserves corporelles pendant la phase décroissante de la lactation (Chilliard et al 2005).

\subsection{4 / Décroissance de la sécrétion lactée et involution du tissu secrétoire}

La décroissance de la sécrétion lactée après le pic de lactation résulte dans un premier temps de la diminution du nombre de cellules sécrétrices (mort cellulaire alors que la multiplication des cellules sécrétrices est terminée). Cette décroissance s'accélère à partir $\mathrm{du}$ quatrième mois de gestation environ, en raison de l'effet négatif des stéroïdes fœto-placentaires sur le fonctionnement et la survie des cellules sécrétoires.

Enfin, une involution brutale du tissu sécrétoire lobulo-alvéolaire fait suite à l'arrêt de la traite (ou de la tétée), en raison de l'accumulation du lait et de l'augmentation de la pression intra mammaire. L'involution n'est toutefois pas complète lorsque le tarissement a lieu en fin de gestation (septième mois, généralement), du fait de sa superposition avec une nouvelle vague de mammogenèse qui prépare la future mise bas. L'involution mammaire s'accompagne d'une perte d'étanchéité de l'épithélium mammaire, d'une diminution du flux sanguin, d'une dégradation de la matrice extra cellulaire, de l'activation de gènes codant pour des protéines bactériostatiques, ainsi que d'un envahissement du tissu par des macrophages (Houdebine 1997).

\section{2 / Les principales molécu- les utilisées et les mécanis- mes d'action associés}

\section{1 / Les hormones stéroïdiennes}

\subsection{1 / Mécanismes et modes d'action des hormones stéroüdiennes : aspects généraux}

Les hormones stéroïdiennes sont de petites molécules hydrophobes déri- 
vées du cholestérol et qui passent librement les membranes biologiques pour entrer dans la cellule, même si l'existence de mécanismes actifs facilitant leur entrée ne peut être exclue. Si certaines hormones comme la progestérone ou les œstrogènes peuvent exercer des effets rapides via des récepteurs membranaires (effets dits «non génomiques», Kousteni et al 2001), il est clair que l'essentiel des effets biologiques de ces hormones passe par des récepteurs particuliers : les récepteurs nucléaires d'hormones. Ces récepteurs forment une superfamille de facteurs de transcription ligand-dépendents qui régulent directement la transcription de gènes cibles en fonction de la présence ou de l'absence de leur ligand. Outre les récepteurs des stéroïdes «classiques» comme la progestérone (PR), les androgènes (AR), les œstrogènes (ER) ou les glucocorticoïdes (GR), cette superfamille regroupe également les récepteurs aux hormones thyroïdiennes (TR), les récepteurs des rétinoïdes (RAR et RXR) mais aussi de nombreux récepteurs dits «orphelins» parce que la nature de leur ligand, si ligand ils ont, n'est pas connue. L'existence des récepteurs nucléaires orphelins est particulièrement intéressante puisque ces molécules offrent la possibilité de mettre en évidence l'existence de nouvelles classes de molécules hormonales. C'est ainsi que toute une série de récepteurs orphelins ont récemment trouvé leur ligand. C'est le cas des récepteurs PPARs (Peroxysome Proliferator Activated Receptor) qui répondent aux acides gras et à certains de leurs dérivés, de CAR et PXR qui fixent une très vaste gamme de xénobiotiques et même des stéroïdes et interviennent dans les processus de détoxification, dans le foie notamment, de LXR et FXR qui fixent des métabolites du cholestérol et interviennent dans le maintien de l'homéostasie du cholestérol. Citons enfin, les récepteurs de type ERR (Estrogen Receptor-Related) qui sont capables de fixer le diéthylstilbœstrol (DES) et qui pourraient intervenir dans les effets biologiques complexes de cette molécule (Gronemeyer et al 2004).

Comment agissent les récepteurs nucléaires d'hormones ? Grâce à des études fonctionnelles détaillées mais aussi grâce à la détermination de la structure tridimensionnelle de certaines parties de ces récepteurs, on commence à bien connaître leur mode d'action. Les récepteurs nucléaires possèdent deux domaines conservés essentiels à leur fonction. Le premier de ces domaines, véritable signature de la superfamille est le domaine $\mathrm{C}$ ou DBD (DNA
Binding Domain) impliqué dans la fixation à des séquences spécifiques sur l'ADN (appelée HRE ou Hormone Responsive Element) et dans la dimérisation des récepteurs qui se fixent le plus souvent sous forme de dimères à l'ADN. Le second domaine est le domaine E ou LBD (Ligand Binding Domain) qui intervient dans la fixation du ligand, la dimérisation et la régulation de la transcription. Deux autres domaines peu conservés, le domaine $\mathrm{A} / \mathrm{B}$ en $\mathrm{N}$-terminal impliqué également dans la régulation de la transcription et le domaine $\mathrm{D}$, qui joue le rôle d'une charnière flexible entre les domaines $\mathrm{DBD}$ et LBD, sont également présents.

On sait à présent que la fixation du ligand au sein d'une poche hydrophobe localisée dans le LBD induit un changement de conformation important de ce domaine. En ce qui concerne les récepteurs des hormones stéroïdiennes, ce changement de conformation permet le recrutement de co-activateurs qui induisent une acétylation des histones et donc une ouverture de la chromatine, ce qui la rend disponible pour la transcription active du gène cible. De façon très intéressante, certaines molécules de synthèse comme le tamoxifène pour le récepteur des œstrogènes ou le célèbre RU486 pour les récepteurs des glucocorticoïdes induisent une conformation différente du LBD qui ne recrute alors plus des co-activateurs mais des co-répresseurs qui induisent une désacétylation des histones et donc une répression de l'expression des gènes cibles. Une pharmacologie complexe dont les bases structurales et fonctionnelles sont assez bien comprises a donc été développée, notamment sur les récepteurs des œstrogènes. Notons que pour de nombreux récepteurs nucléaires comme les TR et les RAR mais pas les récepteurs stérö̈diens, le récepteur en l'absence d'hormone (aporécepteur) est fixé en permanence à l'ADN et réprime activement la transcription de ses gènes cibles en recrutant des co-répresseurs. La fixation du ligand induit le relargage de ces derniers et la fixation de co-activateurs à leur place. Au contraire des autres membres de la superfamille, les aporécepteurs des stéroïdes semblent être présents dans le cytoplasme, sous forme de complexes associant des protéines de choc thermique (hsp90, notamment). La fixation du ligand permet le relargage des protéines hsp, la migration dans le noyau et l'activation des gènes cibles.

La description ci-dessus de ce mode d'action des récepteurs des stéroïdes est nécessairement très schématique et simplifiée : il existe en effet de nombreux co-activateurs et co-répresseurs différents. La dynamique complexe de l'interaction de ces molécules avec les récepteurs nucléaires et les effets induits sur la chromatine sont de mieux en mieux compris, bien que de nombreuses recherches restent à faire dans ce domaine. De même, il a été bien démontré que des communications («cross-talk») importantes existent avec d'autres voies de signalisation. Ainsi, il a été démontré depuis plusieurs années que certains récepteurs comme GR ou ER inhibent l'expression de gènes cibles des facteurs AP-1 ou NF- $\mathrm{KB}$ alors qu'en retour des facteurs de transcription peuvent inhiber l'action de GR ou ER sur leurs propres gènes cibles. Dans d'autres cas (GRfacteurs STAT), des synergies ont été mises en évidence entre récepteurs nucléaires et facteurs de transcription «classiques». Les bases moléculaires et les mécanismes impliqués dans ces interactions sont encore loin d'être expliqués.

\subsection{2 / Stéroïdes : aspects spécifiques dans le domaine de la physiologie de la reproduction}

- Rôle de la progestérone et de ses analogues

a) Effets sur le système nerveux central

Le rôle de la progestérone et des progestagènes dans la maîtrise des cycles sexuels est assez simple et les applications zootechniques résultent essentiellement du blocage de la sécrétion des hormones gonadotropes et par conséquent de l'ovulation. Ce blocage est induit par l'administration en continu de progestérone ou d'un progestatif et l'ovulation n'est permise que lors de l'arrêt de ce traitement.

Au niveau du système nerveux central, la progestérone module la sécrétion de GnRH et de LH en induisant une diminution de la fréquence des pulses de GnRH, ce qui entraîne une accumulation de FSH dans les cellules hypophysaires gonadotropes et évite la survenue d'un second pic de LH. Ces effets de la progestérone nécessitent une imprégnation préalable du système nerveux par l'œstradiol (ChabbertBuffet et al 2000).

\section{b) Effets sur le corps jaune}

Le pic préovulatoire de LH entraîne la lutéinisation des cellules folliculaires, ce qui se caractérise par une 
augmentation de la stéroïdogenèse et une orientation vers la synthèse de progestérone accompagnée d'un arrêt de la production d'œstradiol. Cette production de progestérone est stimulée par la LH. La progestérone a des effets autocrines et paracrines sur le corps jaune en début de phase lutéale (Schams et Berisha 2004). Elle inhibe la sécrétion de $\mathrm{PgF}_{2 \alpha}$, serait lutéotrophique en stimulant la synthèse de récepteurs à la LH et réprimerait l'orientation apoptotique des cellules lutéales. Plus tard dans le cycle, la sensibilité de l'endomètre à la progestérone se réduirait et, ainsi, l'inhibition de la sécrétion utérine de $\mathrm{PgF}_{2 \alpha}$, facteur lutéolytique, serait levée (Schams et Berisha 2004). La progestérone conditionnerait la durée de vie du corps jaune.

\section{c) Effets sur l'endomètre utérin}

Dans le cas d'une ovulation suivie d'une fécondation, la progestérone produite par le corps jaune sous l'action de la LH induit dans l'endomètre la transcription de gènes spécifiques impliqués dans l'implantation du blastocyste. La progestérone serait considérée, d'après les études dynamiques des mécanismes impliquant les récepteurs nucléaires de la progestérone, comme une «lutéotrophine» critique agissant localement pour promouvoir le développement et le maintien de fonctions lutéales au cours du cycle ou en début de gestation (Stouffer 2003).

- Rôle de l'ostradiol sur la croissance et le devenir des follicules ovariens

a) Régulation de la croissance folliculaire et interaction avec les progestagènes

De nombreux articles ont montré chez la vache le rôle important de l'œstradiol dans la régulation de la croissance folliculaire et l'émergence de vagues de croissance folliculaire. Le follicule dominant d'une vague de croissance folliculaire supprime la croissance d'autres follicules subordonnés de la même vague et empêche la croissance d'une nouvelle vague jusqu'au moment où il régresse ou ovule. Le follicule dominant produit de grandes quantités de stéroïdes (androgènes et œstrogènes) et d'autres facteurs non stéroïdiens.

L'œstradiol joue un rôle tout à fait particulier dans le rétrocontrôle négatif de la sécrétion de la FSH ; l'œstradiol peut induire la régression de follicules de 4 à $8 \mathrm{~mm}$ de diamètre sensibles à l'action de la FSH. De plus, chez les femelles cyclées, l'œstradiol peut agir en synergie avec la progestérone. Ceci peut induire des changements de sensibilité à la LH des follicules de plus de $9 \mathrm{~mm}$ de diamètre. Ces effets de rétroaction négative servent de base physiologique à la mise en œuvre des stratégies de synchronisation recherchées pour la maîtrise des cycles.

L'œstradiol administré de façon exogène induit une régression folliculaire après traitement (Hutz et al 1988), en particulier celle du follicule dominant chez des bovins préalablement traités avec des progestagènes. L'œstradiol inhibe la croissance des follicules de taille inférieure (subordonnés) (Bo et al 1995a, 1995b, 2000), ce qui conduit à la naissance et à la croissance d'une nouvelle cohorte de follicules 3 à 5 jours après suppression du follicule dominant (Burke et al 1998). Cet effet de l'œstradiol utilisé en association avec des progestagènes permet d'éviter que ne persiste le follicule dominant comme lorsque les progestagènes sont utilisés seuls ou avec des prostaglandines, ce qui conduit alors à l'ovulation d'un ovocyte trop âgé et subfertile (Mihm et al 1994, Ahmad et al 1995, Kinder et al 1996), expliquant ainsi des taux de gestation faibles.

Ces effets favorables de l'administration d'œstradiol en début de traitement progestatif pour inhiber la croissance $\mathrm{du}$ follicule dominant préexistant et initier une nouvelle vague de croissance folliculaire sont utilisés dans la synchronisation des chaleurs, mais aussi dans les traitements de superovulation réalisés pour la collecte et le transfert d'embryons.

b) Régulation et stimulation de la croissance folliculaire chez les femelles en anœstrus

Chez de nombreuses espèces domestiques, l'œstradiol induit une augmentation du nombre de récepteurs folliculaires des autres hormones. Ainsi chez la vache cyclée, l'œstradiol pourrait avoir un rôle régulateur sur l'apparition et la fonction des récepteurs des hormones gonadotropes présents sur les follicules de la vague de croissance suivante. Chez les vaches en anœstrus, la croissance folliculaire est souvent inexistante ou irrégulière avant l'application des traitements associant progestagènes et œstrogènes (Grimard et al 1995). L'administration d'œstradiol au début d'un traitement progestatif pourrait donc contribuer à inhiber l'effet négatif de gros follicules éventuellement présents et à stimuler la croissance de nouveaux follicules en favorisant l'apparition de récepteurs des hormones gonadotropes lorsque la sécrétion de ces dernières est bloquée par le progestagène. Ceci peut induire l'ovulation d'un ovocyte mature provenant d'un follicule normal présent dans cette nouvelle vague. Ceci expliquerait l'effet favorable de l'utilisation de l'œstradiol chez les femelles en anœstrus profond.

c) Effets de l'administration d'œstradiol au moment du retrait d'un traitement progestatif

Chez la vache, le traitement par l'œstradiol pourrait provoquer une augmentation synchronisée de la sécrétion d'œstradiol endogène et du pic de LH déclenchant l'ovulation d'un follicule nouvellement recruté (Ryan et al 1999). Ainsi, une dose faible d'œstradiol $(1 \mathrm{mg})$ administrée 10 à 24 heures après le retrait d'un progestagène réduit l'intervalle entre l'œstrus et l'ovulation (Ryan et al 1995, Burke et al 2001). Cette dose est aussi efficace pour induire l'ovulation chez des femelles en anœstrus (Mc Dougall et al 1994, Burke et al 2001). Ceci pourrait expliquer pourquoi, dans une étude incluant environ 2000 vaches laitières, le traitement avec $1 \mathrm{mg}$ de benzoate d'œstradiol 10 heures après le retrait du progestagène a conduit à de meilleurs résultats en termes de détection et de synchronisation de l'œstrus ainsi qu'à de meilleurs taux de gestation (Ryan et al 1999).

Cependant, au contraire des observations réalisées chez les génisses cyclées ou chez les vaches allaitantes en anœstrus la maturité du follicule dominant au moment de l'arrêt du traitement progestatif est un élément déterminant de l'ovulation et du développement ultérieur du corps jaune. Ainsi, l'administration d'œstradiol après le retrait du progestagène chez des femelles non cyclées peut conduire à observer l'œstrus sans que l'ovulation ait lieu et/ou que la fonction lutéale mise en place soit normale. La fréquence de ce dysfonctionnement ovarien serait d'environ $10 \%$ (Rhodes 1999), mais présente avec une variabilité très importante.

\section{d) Actions lutéolytique et antilutéo-} trope

Chez bon nombre d'espèces domestiques, il est possible de synchroniser efficacement l'œstrus avec des traitements à base de progestérone ou de progestagènes utilisés seuls. Cependant, chez l'espèce bovine, la fertilité à l'œstrus induit est faible. En effet, la durée du traitement progestagène, trop 
longue, superposable à la durée de la phase lutéale, induit une dégradation de la fertilité. Les actions antilutéotrope et lutéolytique de l'œstradiol ont été utilisées pour obtenir une synchronisation similaire de l'œstrus et de l'ovulation en réduisant la durée de vie du corps jaune (Wiltbank 1971, Lemon 1975). Ces effets de l'œstradiol sont augmentés en utilisant une injection simultanée de progestagènes. L'association progestagène-œstrogène, du fait des effets lutéolytique et lutéotrope des œstrogènes, a permis de réduire la durée du traitement progestagène.

Ces propriétés de l'œstradiol représentent actuellement la base physiologique principale de l'utilisation de cette molécule en association avec les progestagènes, ce qui permet une synchronisation de femelles cyclées chez lesquelles un traitement progestatif de courte durée (9-12 jours) est administré.

- Rôle des androgènes et des œstrogènes sur le comportement sexuel mâle

a) Le contrôle hormonal des comportements

L'expression du comportement sexuel mâle chez les mammifères dépend en grande partie de la présence de stéroïdes gonadiques. Il en est de même, à un degré moindre, pour le comportement territorial et agressif (Balthazart et Fabre-Nys 2001).

La castration provoque une diminution jusqu'à, éventuellement, la disparition de l'activité sexuelle. Cependant, l'effet obtenu varie suivant l'espèce considérée et entre individus : de quelques jours à plusieurs mois, voire des années chez certains boucs. Le moment de la castration est un facteur important : faite avant la puberté, la castration est plus efficace pour empêcher l'expression des comportements sexuels et agressifs que si elle est effectuée en période postpubertaire. Ceci est en partie dû au rôle positif joué par l'expérience antérieure de l'individu sur le comportement. La diminution du niveau d'expression du comportement sexuel après castration est progressive. Les éléments moteurs de type consommatoire, éjaculation ou intromission, sont affectés en premier lieu puis les comportements de cour dits «précopulatoires» et, enfin, les éléments de type appétitif tels que les approches ou flairages.

A l'inverse, il est possible chez un animal castré ou hypogonadique de stimuler l'expression du comportement sexuel par administration de stéroïdes. Pour être efficaces, les stéroïdes doivent être administrés de façon chronique pendant plusieurs semaines. Chez la plupart des ongulés, un traitement journalier par 100 à $300 \mu \mathrm{g}$ de testostérone/kg de poids vif induira l'apparition du comportement sexuel en 2 à 5 semaines. Cependant, le délai varie en fonction du mode d'administration, du composé administré, de l'individu et également du moment de l'année chez les espèces à reproduction saisonnière. L'effet du traitement stéroïdien est progressif, comme l'est celui de la castration. Les premiers éléments de comportement qui apparaissent sont les derniers à avoir disparu : flairages, approches puis comportement de cour et enfin intromission puis éjaculation. Chez les mâles de la plupart des espèces : cerf, bélier, verrat, taureau, la testostérone peut être remplacée par l'œstradiol qui doit être également administré de manière répétée mais qui est efficace à des concentrations 10 fois moindres. Un traitement par la $5 \alpha$-dihydrotestostérone, le métabolite de la testostérone actif sur le tractus génital, est en revanche le plus souvent inefficace sur le comportement sexuel.

Que le comportement soit stimulé par un traitement par la testostérone ou qu'il le soit par l'œstradiol, l'effet dépend de la dose ; la limite maximale correspond à une valeur «plateau» audelà de laquelle aucun effet additionnel n'est obtenu. Chez l'animal non castré, les concentrations circulantes sont en général au-dessus de ce plateau, ce qui explique par exemple qu'un traitement additionnel chez un animal peu actif sexuellement reste inefficace.

b) La manipulation des comportements

Chez la plupart des mammifères, il est possible d'induire artificiellement un comportement de type mâle chez les femelles par les traitements stéroïdiens mentionnés ci-dessus. De tels traitements ont été utilisés chez les bovins ou les ovins pour aider à la détection de l'œstrus ou pour jouer le rôle de mâle dans l'induction de la cyclicité de femelles en anœstrus. Comme chez le mâle, l'apparition du comportement est progressive, elle dépend de l'expérience «acquise». En effet, la femelle répondra plus vite si elle a déjà été traitée et a déjà présenté un comportement de type mâle. Plusieurs travaux ont montré que de telles femelles étaient aussi efficaces que des mâles tout en étant plus faciles à manipuler.

\subsection{3 / Stéroïdes : aspects spécifiques dans le domaine de la physiologie de la croissance}

Outre son implication dans les aspects de physiologie biomécanique (mouvement et intégrité physique de l'organisme), le tissu musculaire sert de «réservoir» pour mobiliser les protéines en cas de stress, en particulier dans les périodes de jeûne prolongé, de gestation ou de lactation (Meyer 2001). Ces fonctions sont modulées par les stéroïdes anabolisants et les glucocorticoïdes. En période de stress, les glucocorticoïdes ont un rôle inhibiteur sur la synthèse de protéine et favorisent le catabolisme des acides aminés, ce qui entraîne une fonte musculaire pouvant impliquer, en cas de stress prolongé, une mobilisation du pool protéique hépatique et plasmatique (Meyer 2001). Aussi, l'anabolisme protéique dépendra de la balance entre les apports en nutriments et les niveaux circulants en glucocorticoïdes, cette balance variant d'un sexe à l'autre. En effet, les génisses présentent des concentrations en récepteurs aux glucocorticoïdes dans le muscle au double de celles trouvées chez le veau mâle. Ceci laisse supposer l'existence d'une plus faible sensibilité aux glucocorticoïdes circulants chez le jeune taurillon qui pourrait expliquer un catabolisme des protéines réduit, une accrétion protéique et une vitesse de croissance augmentée. Cet anabolisme sera renforcé par les stéroïdes sexuels de façon différentielle en fonction de l'âge et du sexe de l'animal. Parmi ces stéroïdes, les androgènes, les œstrogènes et, indirectement, les progestines ont un effet anabolisant. Androgènes et œstrogènes se lient aux récepteurs présents dans le tissu musculaire mais aussi dans le foie, le rein, le rumen et l'épithélium intestinal, le tissu osseux et au niveau hypothalamohypophysaire (Meyer 2001, figure 3). Indirectement, les stéroïdes anabolisants stimuleraient la sécrétion d'hormone de croissance et d'IGF-I.

\section{- Les androgènes}

En tant qu'anabolisants, les androgènes sont réputés être moins actifs chez les bovins ou les ovins que chez l'homme, traduisant une concentration en récepteurs aux androgènes dans le muscle plus faible, de l'ordre de 0,1$0,5 \mathrm{fmol} / \mathrm{mg}$ de protéine (Sauerwein et Meyer 1989).

La trenbolone fait partie des stéroïdes anabolisants les plus efficaces (figure 4), ce qui s'expliquerait par des propriétés de liaison de type agoniste au 
Figure 3. Mécanismes physiologiques décrivant l'effet anabolisant provoqué par les androgènes et œstrogènes (Meyer 2001).

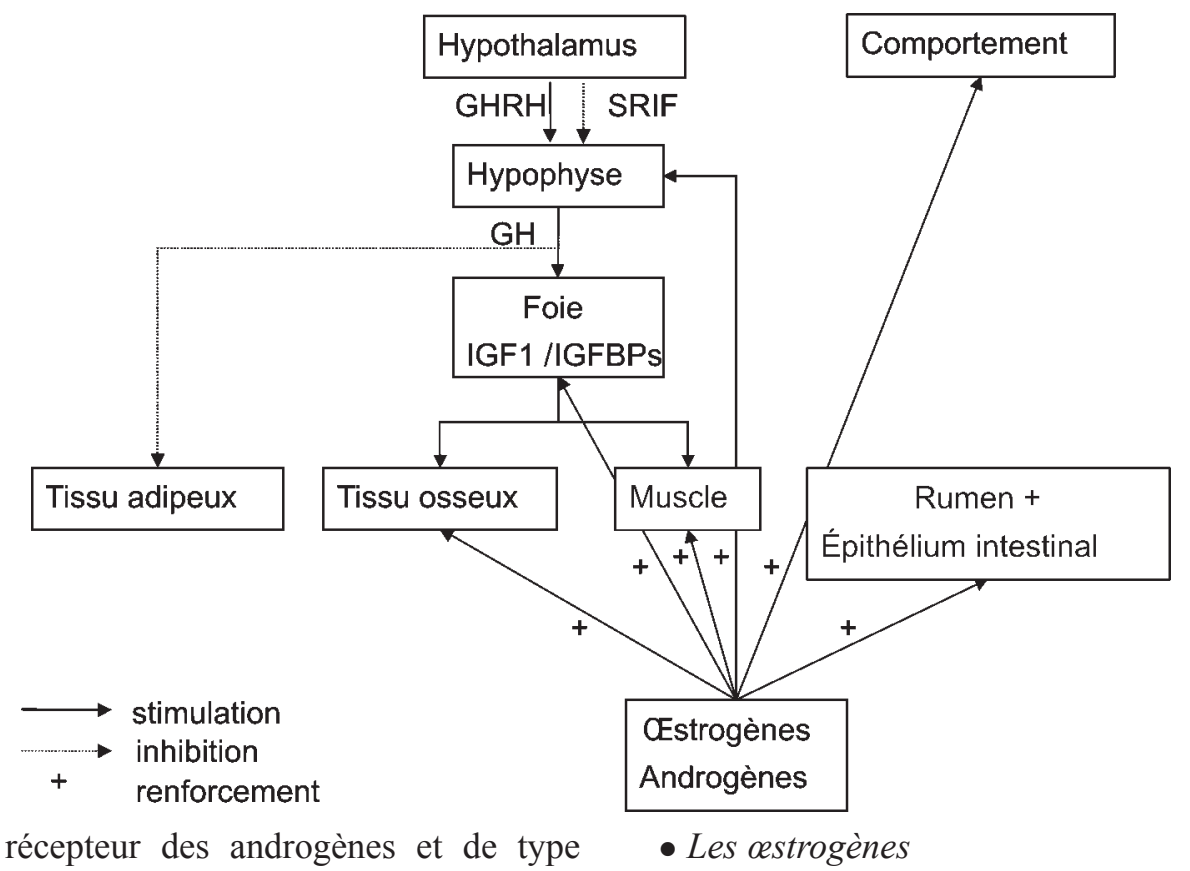

antagoniste au récepteur des glucocorticoïdes (Bauer et al 2000). En effet, ces propriétés s'accompagnent d'une inhibition de l'activité tyrosine aminotransférase, une enzyme-clé de la dégradation des acides aminés examinée sur hépatocytes de rat, qui est quasi complète en présence de trenbolone, mais non en présence de testostérone ou de nortestostérone (Danhaive et Rousseau 1986, 1988).
Le jeune ruminant (veau, génisse, bouvillon, agneau) avec une production endogène d'œstrogènes faible présente vitesses de s'explique par un accroissement de l'accrétion protéique dans le muscle.

L'œstradiol et le zéranol ( $\alpha$-zéarala- molécules utilisables comme anabolisant œstrogénique en élevage aux USA et au Canada notamment, mais non dans l'UE. Les stilbènes, en particulier le DES, sont partout interdits d'utilisation. Les capacités d'induction des réponses œstrogéniques de l'œstradiol, du DES et de l'éthinyl-œstradiol (un analogue de l'œstradiol) qui sont mesurées sur levure exprimant artificiellement la forme $\alpha$ du récepteur des œstrogènes sont comparables, celle du zéranol représentant simplement 1,7\% de celle de l'œstradiol mesurée dans ce système mais près de $16 \%$ quand cette même activité est mesurée sur hépatocytes de truite (Le Guével et Pakdel 2001). Les données concernant l'activation œstrogénique de la forme $\beta$ du récepteur des œstrogènes induite par le zéranol sont absentes.

Les concentrations en récepteurs (forme $\alpha$ ) des œstrogènes dans le muscle de bovin atteignent des valeurs de l'ordre de 0,5 à $2 \mathrm{fmol} / \mathrm{mg}$ de protéine et représentent environ $1 \%$ de celles mesurées dans l'utérus (Meyer et Rapp 1985). Des variations dans les concentrations en récepteurs (Sauerwein et Meyer 1989) ou en ARN messagers correspondants (Pfaffl et al 2001) sont en rapport avec les variations allométriques notées dans la croissance de différents muscles.

Fonctionnellement, l'anabolisme gravidique est en relation avec une stimu-

Figure 4. Principaux stéroïdes ou analogues stérö̈diens utilisés comme anabolisants.

\section{Androgènes}

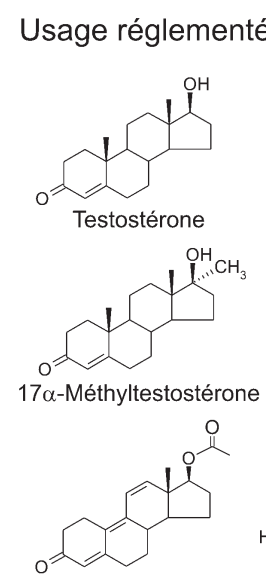

Acétate de trenbolone

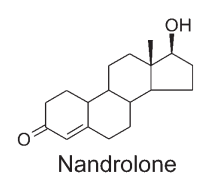

Noréthandrolone
Usage interdit
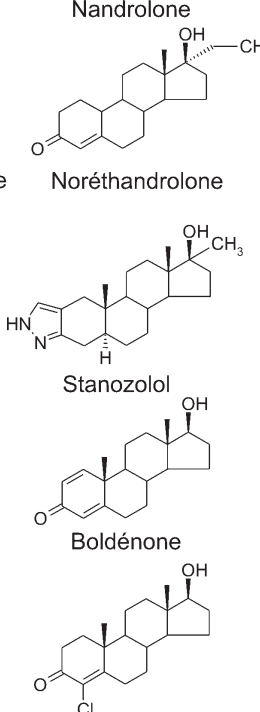

\section{CEstrogènes}

Usage réglementé Usage interdit
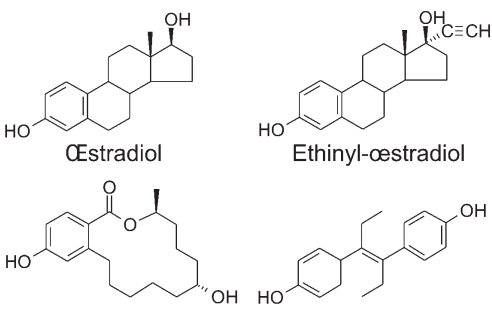

Zéranol ( $\alpha$-Zéaralanol)

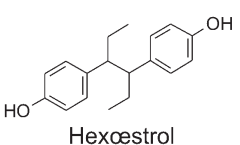

Ethylestrénol

Allylestrénol

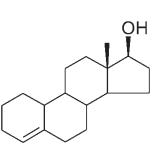

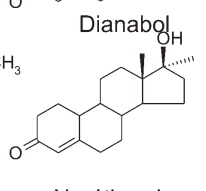

.


lation d'origine œstrogénique qui permet d'expliquer l'importance de l'accrétion protéique et minérale $(\mathrm{Ca}, \mathrm{P})$. Ce stokage se résorbe progressivement au cours de la lactation. Chez le mâle, l'association androgèneœstrogène se traduit par l'acquisition d'une morphologie favorisant les comportements de dominance pendant les périodes de reproduction. Chez le jeune en croissance, de faibles doses d'œstradiol stimulent l'activité des cartilages de conjugaison impliqués dans la croissance des os longs comme lors de la puberté tandis que de fortes doses arrêtent la croissance staturale (Karg 1969).

Chez le jeune bovin, l'utilisation réglementée aux USA ou au Canada d'anabolisants associe dans la plupart des cas l'œstradiol et un androgène, l'acétate de trenbolone ou la testostérone libre ou estérifiée (tableau 1). Chez le taurillon, le bouvillon ou la génisse en engraissement, la même association œstrogène-androgène est utilisée dans les implants, le dosage d'œstrogène apporté étant le plus souvent relativement plus faible pour les femelles que pour les mâles (tableau 1). Chez les femelles cyclées, un androgène, l'acétate de trenbolone, peut aussi être utilisé seul. Dans l'UE, des cas de fraude par injection d'une solution huileuse d'androgène ou d'ester d'androgène utilisé seul ne sont pas rares chez des vaches de réforme.

\section{- Les progestines}

Aux USA et au Canada, la progestérone (figure 4) peut être utilisée comme anabolisant en association à un œstrogène, l'œstradiol ou son dérivé benzoate. A l'heure actuelle, les mécanismes biochimiques pouvant expliquer un effet direct de la progestérone sur le métabolisme sont inconnus.

L'acétate de mélengestrol (MGA) (figure 4), une progestine de synthèse, peut être utilisé comme additif à l'alimentation des génisses pour calmer les animaux et renforcer les paramètres de croissance en supprimant l'œstrus (Lauderdale 1983). Le MGA stimulerait aussi la production d'œstrogènes d'origine ovarienne (Henricks et al 1997), ce qui aurait un effet direct sur la croissance des femelles. En effet, la dose journalière de $0,5 \mathrm{mg}$ de MGA par animal suffit à inhiber le feed-back positif des œstrogènes sur l'axe hypothalamo-hypophysaire et l'ovulation. La croissance continue des follicules ovariens se traduit par des niveaux en œstradiol circulant de l'ordre de $5 \mathrm{pg} / \mathrm{mL}$ de plasma, concentration suf- fisante pour induire un effet sur la croissance des génisses (Daxenberger et al 1999, Meyer 2001). A des concentrations plus élevées, le MGA est considéré comme une progestine conventionnelle (Hageleit et al 2000). Au contraire de l'acétate de médroxyprogestérone (MPA), le MGA ne peut être considéré comme un agoniste partiel des androgènes, la liaison au récepteur des androgènes étant négligeable (Bauer et al 2000).

\subsection{4 / Stéroüdes : aspects spécifiques à leur utilisation dans le domaine de la médecine vétérinaire}

Les hormones stéroïdiennes utilisées en médecine vétérinaire (œstrogènes, progestagènes et glucocorticoïdes) présentent de multiples applications thérapeutiques chez les espèces de rente (Barragry 1994, Squires 2003, Carruthers 1986).

Les œstrogènes, de par leurs effets utérotoniques et immunostimulants, sont recommandés pour ouvrir le col de l'utérus et pour provoquer l'expulsion d'un contenu utérin pathologique lors de métrite, de pyomètre ou de momification fotale.

Outre l'utilisation zootechnique de dispositifs à base de progestines pour la synchronisation des chaleurs (cf $\S 3.1 .1$ ), ces hormones sont indiquées pour traiter les kystes folliculaires ovariens chez la vache associés ou non à un comportement nymphomane.

La testostérone a été recommandée pour stimuler la libido chez le mâle ou pour améliorer sa fertilité, mais son usage est interdit en France chez les espèces de rente.

Les glucocorticoïdes (dexaméthasone et fluméthasone) à effet rapide sont utilisés pour induire l'avortement chez les ruminants ou pour induire la parturition lors de disproportion fœtomaternelle ou de souffrance fotale. Ils sont utilisés généralement après le $5^{\mathrm{e}}$ mois de gestation chez la vache, seuls ou associés à la $\mathrm{PgF}_{2 \alpha}$ ou ses analogues.

\section{2 / Les hormones peptidiques et protéiques}

\subsection{1/ Hormones peptidiques : struc- tures et mécanismes d'action, aspects généraux}

Les hormones peptidiques sont de tailles et de structures très diverses (Combarnous 2004). Les plus petites sont des polypeptides courts : la TRH,
3 acides aminés (aa); l'ocytocine et la vasopressine, 9 aa ; la GnRH, 10 aa. Les extrémités C-terminales de ces peptides sont amidés et leurs extrémités $\mathrm{N}$-terminales sont souvent des pyroGlu (TRH, GnRH). Ces modifications stabilisent leurs structures en évitant leur protéolyse par des exopeptidases. D'autres hormones sont également de simples polypeptides de longueurs supérieures (MSH : 17 aa, glucagon : 29 aa, ACTH : 39 aa, etc.) tandis que d'autres présentent deux chaînes suite à des coupures protéolytiques d'un précurseur codé par un gène unique (insuline : 21 et 30 aa pour les chaînes A et B liées par des ponts disulfures). D'autres hormones de plus de 50100 aa sont plutôt des holoprotéines telles la GH et la prolactine (PRL) qui sont constituées d'une seule chaîne polypeptidique de près de 200 aa.

D'autres protéines hormonales sont beaucoup plus complexes car elles sont formées de chaînes polypeptidiques de taille importante qui en outre, pour certaines d'entre elles, portent des chaînes polysaccharidiques. Ainsi les hormones de la famille du TGF- $\beta$ sont des molécules très apparentées entre elles constituées de deux chaînes polypeptidiques, identiques ou différentes selon les cas et liées par des ponts disulfures. Les principales hormones de cette famille sont l'inhibine, l'activine, l'hormone anti-müllérienne, les BMP (Bone Morphogenic Proteins), etc. Certaines isoformes de ces hormones peuvent en outre être glycosylées. La famille des hormones glycoprotéiques proprement dite comprend les gonadotropines hypophysaires, LH et FSH, et placentaires, CG (seulement chez les primates et les équidés), ainsi que la TSH (hypophysaire). Ces hormones sont toutes formées de deux sous-unités glycoprotéiques différentes $\alpha$ et $\beta$ liées de manière non-covalente. Dans chaque espèce, la sous-unité $\alpha$ est commune à toutes ces hormones tandis que les sous-unités $\beta$ sont spécifiques de chacune des hormones et codées par des gènes distincts.

Les récepteurs des hormones peptidiques mais aussi ceux des facteurs de croissance, des cytokines, des neurotransmetteurs et des phéromones sont membranaires et la stimulation initiale des cellules cibles s'effectue donc à ce niveau. Les récepteurs membranaires peuvent être grossièrement classés en deux grandes familles sur une base structurale : les récepteurs à sept domaines transmembranaires (R7TM) et les récepteurs à un seul domaine transmembranaire. Les R7TM consti- 
Tableau 1. Description des différentes préparations hormonales pouvant être utilisées ou ayant été utilisées comme substances anabolisantes à des fins zootechniques dans un cadre réglementaire en dehors de l'UE.

\begin{tabular}{|c|c|c|c|c|c|}
\hline Nom Commercial & Composition & $\begin{array}{c}\text { Mode } \\
\text { d'adminis- } \\
\text { tration }\end{array}$ & Animaux cibles & \begin{tabular}{|c|} 
Durée de \\
Traitement \\
(jours)
\end{tabular} & Origine \\
\hline Revalor ${ }^{(}-\mathrm{H}$ & TBA (140 mg) $+E_{2}(14 \mathrm{mg})$ & \multirow{32}{*}{$\begin{array}{l}\text { Implant } \\
\text { sous-cutané } \\
\text { à la base } \\
\text { de l'oreille }\end{array}$} & \multirow{2}{*}{ Génisses } & $<130$ & \multirow{11}{*}{ Intervet } \\
\hline Revalor $^{\circledR}-\mathrm{IH}^{1}$ & TBA $(80 \mathrm{mg})+\mathrm{E}_{2}(8 \mathrm{mg})$ & & & $>130$ & \\
\hline Revalor $^{\circledR}-\mathrm{S}$ & TBA $(120 \mathrm{mg})+\mathrm{E}_{2}(24 \mathrm{mg})$ & & \multirow{2}{*}{ Bouvillons } & $<130$ & \\
\hline Revalor $^{(\otimes}-$ IS $^{1}$ & TBA $(80 \mathrm{mg})+\mathrm{E}_{2}(16 \mathrm{mg})$ & & & $>130$ & \\
\hline Revalor $^{(2)}-G$ & TBA $(40 \mathrm{mg})+\mathrm{E}_{2}(8 \mathrm{mg})$ & & Broutards & & \\
\hline Revalor $^{(\circledast)}$ & TBA $(140 \mathrm{mg})+\mathrm{E}_{2}(20 \mathrm{mg})$ & & Veaux mâles et femelles & $90-100$ & \\
\hline Revalor $^{(\mathbb{2}}-200$ & TBA $(200 \mathrm{mg})+\mathrm{E}_{2}(20 \mathrm{mg})$ & & \begin{tabular}{|l|} 
Bouvillons \\
\end{tabular} & $90-100$ & \\
\hline Torelor $^{(\mathbb{B}}$ & TBA (200 mg) $+E_{2}(40 \mathrm{mg})$ & & Bouvillons & $90-120$ & \\
\hline Finaplix ${ }^{\circledR}-\mathrm{H}$ & TBA (200 mg) & & Génisses & $<100$ & \\
\hline Finaplix ${ }^{(3}-S$ & TBA (140 mg) & & Bouvillons & $126(2 \times 63)$ & \\
\hline Forplix $^{\circledR}$ & $\begin{array}{l}\text { TBA (140 mg) + zéranol } \\
(36 \mathrm{mg})\end{array}$ & & Bouvillons, génissses & & \\
\hline Component $^{T M}$ TE-S & TBA $(120 \mathrm{mg})+\mathrm{E}_{2}(24 \mathrm{mg})$ & & Bouvillons $(250-450 \mathrm{~kg})$ & $90-120$ & \multirow{14}{*}{$\begin{array}{l}\text { Ivy Laboratories } \\
\text { (Ivy Animal } \\
\text { Health) }\end{array}$} \\
\hline Component $^{T M}$ TE-H & TBA $(140 \mathrm{mg})+\mathrm{E}_{2}(14 \mathrm{mg})$ & & Génisses (300-450 kg) & $90-120$ & \\
\hline Component $^{\mathrm{TM}}$ TE-G & TBA (40 mg) $+E_{2}(8 \mathrm{mg})$ & & \begin{tabular}{|l|} 
Bouvillons, Génisses \\
\end{tabular} & 60 & \\
\hline Component $^{T M}$ TE-ID & TBA $(120 \mathrm{mg})+\mathrm{E}_{2}(24 \mathrm{mg})$ & & Génisses & & \\
\hline Component $^{\mathrm{TM}}$ TE-IS & TBA (80 mg) $+E_{2}(16 \mathrm{mg})$ & & Bouvillons & & \\
\hline Component $^{\mathrm{TM}} \mathrm{T}-\mathrm{S}$ & TBA (140 mg) & & Bouvillons & & \\
\hline Component $^{\mathrm{TM}} \mathrm{T}-\mathrm{H}$ & TBA (200 mg) & & Génisses & & \\
\hline Component $^{\mathrm{TM}}$ TE-200 & TBA $(200 \mathrm{mg})+\mathrm{E}_{2}(20 \mathrm{mg})$ & & Bouvillons & & \\
\hline Component $^{\mathrm{TM}} \mathrm{E}-\mathrm{H}$ & $\begin{array}{l}\text { T-propionate }(200 \mathrm{mg})+ \\
\text { E}_{2} \text {-benzoate }(20 \mathrm{mg})\end{array}$ & & Bouvillons $(185-450 \mathrm{~kg})$ & & \\
\hline Component $^{\mathrm{TM}} \mathrm{E}-\mathrm{C}$ & $P_{4}(100 \mathrm{mg})+E_{2}(10 \mathrm{mg})$ & & Broutards & & \\
\hline Component $^{\mathrm{TM}} \mathrm{E}-\mathrm{S}$ & $\mathrm{P}_{4}(200 \mathrm{mg})+\mathrm{E}_{2}(20 \mathrm{mg})$ & & Bouvillons (185-450 kg) & & \\
\hline Implus- $C^{(B)}$ & $\begin{array}{l}P_{4}(100 \mathrm{mg})+E_{2} \text {-benzoate } \\
(10 \mathrm{mg})\end{array}$ & & Broutards & $70-120$ & \\
\hline Implus- $\mathrm{H}^{\circledR}$ & $\begin{array}{l}T(100 \mathrm{mg})+\mathrm{E}_{2} \text {-benzoate } \\
(10 \mathrm{mg})\end{array}$ & & Génisses & $70-120$ & \\
\hline Calf-oid $^{\circledR}$ & $\begin{array}{l}P_{4}(100 \mathrm{mg})+E_{2} \text {-benzoate } \\
(10 \mathrm{mg})\end{array}$ & & Broutards & $70-120$ & \\
\hline Synovex ${ }^{(\pi-H}$ & $\begin{array}{l}\text { T-propionate }(200 \mathrm{mg})+ \\
\mathrm{E}_{2} \text {-benzoate }(20 \mathrm{mg})\end{array}$ & & Génisses (> $180 \mathrm{~kg}$ ) & $90-120$ & \multirow{4}{*}{$\begin{array}{l}\text { Fort Dodge } \\
\text { Animal Health }\end{array}$} \\
\hline Synovex ${ }^{\circledR}$-Plus & $\begin{array}{l}\text { TBA (200 mg) }+\mathrm{E}_{2^{-}} \\
\text {benzoate }(28 \mathrm{mg})\end{array}$ & & Bouvillons & $120-150$ & \\
\hline Synovex ${ }^{(B)}-C$ & $\begin{array}{l}\mathrm{P}_{4}(100 \mathrm{mg})+\mathrm{E}_{2} \text {-benzoate } \\
(10 \mathrm{mg})\end{array}$ & & Broutards mâles & $70-90$ & \\
\hline Synovex ${ }^{\circledR}-S$ & $\begin{array}{l}\mathrm{P}_{4}(200 \mathrm{mg})+\mathrm{E}_{2} \text {-benzoate } \\
(20 \mathrm{mg})\end{array}$ & & Bouvillons (> $180 \mathrm{~kg}$ ) & & \\
\hline Compudose $^{(囚)}$ & $\mathrm{E}_{2}(24 \mathrm{mg} / 45 \mathrm{mg})$ & & $\begin{array}{l}\begin{array}{l}\text { Veaux mâles, génisses, } \\
\text { bouvillons }\end{array} \\
\end{array}$ & $60-90$ & \begin{tabular}{|l|} 
Elanco Animal \\
Health (Eli-Lilly)
\end{tabular} \\
\hline Ralgro $^{\circledR}$ & Zéranol (36 mg) & & \begin{tabular}{|l|} 
Broutards femelles \\
\end{tabular} & $70-120$ & \multirow{2}{*}{$\begin{array}{l}\text { Schering- } \\
\text { Plough Animal } \\
\text { Health Corp. }\end{array}$} \\
\hline Ralgro ${ }^{\circledR}$ Magnum & Zéranol (72 mg) & & \begin{tabular}{|l|} 
Bouvillons \\
\end{tabular} & $70-120$ & \\
\hline MGA & $\begin{array}{l}\text { Acétate de mélengestrol } \\
(0,5 \mathrm{mg} / \text { animal/jour })\end{array}$ & Alimentation & Génisses & 140 & $\begin{array}{l}\text { Pharmacia \& } \\
\text { Upjohn Co. }\end{array}$ \\
\hline
\end{tabular}

1 Implantations uniques ou répétées.

tuent une famille homogène par le fait qu'au-delà de leur parenté structurale, ils partagent un mécanisme d'action commun par leur couplage fonctionnel à des protéines $\mathrm{G}$ hétérotrimériques. De ce fait, ils sont communément dénommés récepteurs couplés aux protéines $G$
(GPCR : G Protein-Coupled Receptors). A l'inverse, les récepteurs à un seul domaine transmembranaire ne constituent pas une famille homogène.

Le mécanisme de transduction transmembranaire du signal hormonal des
R7TM est consécutif à la liaison des ligands (GnRH, ACTH, LH, FSH par exemple) du côté extracellulaire qui provoque un changement d'orientation des segments transmembranaires du récepteur. Ceci conduit à une interaction, du côté intracellulaire du récep- 
teur avec la sous-unité $\alpha$ d'une protéine $\mathrm{G}$ hétérotrimérique (Gs ou $\mathrm{Gi}$ ou $\mathrm{Gq}$ ou Go, etc., selon le récepteur). Cette interaction provoque l'échange GDP/GTP au niveau de cette sous-unité $\alpha$ et sa séparation d'avec le complexe des sous-unités $\beta \gamma$. Les sous-unités $\alpha_{\mathrm{GTP}}$ ainsi libérées sont les principales responsables de l'activation des effecteurs en aval (adénylate cyclase pour $\alpha$ s et $\alpha i$, phospholipase C $\beta$ pour $\alpha q$, etc.). Les sous-unités $\alpha$ possèdent en outre une activité GTPasique conduisant à l'hydrolyse du GTP en GDP, à leur inactivation et à la réassociation des sous-unités $\alpha_{\mathrm{GDP}}$ avec le complexe $\beta \gamma$. Le complexe $\alpha_{\text {GDP }} \beta \gamma$ est ainsi disponible pour être à nouveau activé par le récepteur.

Les effecteurs que sont l'adénylate cyclase et la phospholipase C synthétisent des seconds messagers intracellulaires. L'adénylate cyclase catalyse la biosynthèse d'AMP cyclique (AMPc) dont la dégradation est assurée par des nucléotide-phosphodiestérases. La phospholipase $\mathrm{C}$ catalyse la biosynthèse de deux seconds messagers, le diacylglycérol et l'inositol triphosphate qui à son tour provoque la sortie d'ion calcium vers le cytoplasme à partir du réticulum endoplasmique. Les seconds messagers stimulent ensuite des protéines kinases spécifiques : la PKA pour l'AMPc et la PKC pour le diacylglycérol en collaboration avec le calcium cytosolique libéré par l'inositol triphosphate. Les protéines kinases phosphorylent ensuite divers substrats spécifiques (enzymes, facteurs de transcription, protéines du cytosquelette, etc.), ce qui entraîne une modification de leurs activités et/ou de leurs structures et, en conséquence, des réponses cellulaires caractéristiques de l'hormone considérée.

Le mécanisme d'action le plus simple pour les récepteurs à un seul domaine transmembranaire est celui observé pour les récepteurs-protéines kinases. La liaison du ligand du côté extracellulaire provoque directement l'activation de l'activité kinase intracellulaire, généralement suite à la dimérisation des récepteurs. Dans le cas de l'EGF, des PDGF ou de l'insuline, il s'agit de récepteurs-tyrosine kinases ; la liaison des ligands à ces récepteurs provoque leur autophosphorylation, le recrutement et la phosphorylation de tyrosines de protéines plateformes (IRS ; Shc) permettant le recrutement d'autres acteurs en aval (par exemple la séquence $\mathrm{SoS}>$ ras $>$ raf $>$ cascade MAPK $>$ multiplication/différenciation cellulaire ou encore $\mathrm{PI} 3 \mathrm{~K}>\mathrm{PDK}>\mathrm{PKB}>$
GLUT > entrée de glucose). Dans le cas de l'inhibine, de l'activine ou des BMPs, il s'agit de récepteurssérine/thréonine kinases. La phosphorylation de sérines et/ou de thréonines des récepteurs de type I par les types II conduit au recrutement et à la phosphorylation de protéines cytosoliques, les Smads, qui forment alors des trimères impliquant obligatoirement la CoSmad (Smad 4), entrent dans le noyau et agissent en tant que facteurs de transcription.

D'autres récepteurs à un seul domaine transmembranaire ne sont pas euxmêmes des protéines kinases mais après liaison de leurs ligands $(\mathrm{GH}$, PRL, EPO, leptine, IL par exemple) recrutent des kinases cytosoliques (JAK, Tyk) qui se phosphorylent sur des tyrosines puis, ainsi activées, phosphorylent les protéines Stat qui comme les Smads sont des facteurs de transcription. D'autres récepteurs ne recrutent qu'indirectement les kinases (récepteurs du TNF et récepteurs TLR, BcR ou TcR).

Enfin, une dernière catégorie de récepteurs à un seul domaine transmembranaire (récepteur de l'ANF) possède une activité guanylate cyclase dans son domaine intracellulaire qui conduit à la production de GMPc qui active alors une protéine kinase spécifique (PKG ou cGK).

\subsection{2 / Hormones peptidiques : aspects spécifiques dans le domaine de la physiologie de la reproduction}

La GnRH et les hormones glycoprotéiques gonadotropes d'origine hypophysaire (LH, FSH) ou placentaire (eCG) sont largement utilisées dans les traitements hormonaux de maîtrise de la reproduction chez les mammifères domestiques, en particulier pour mimer les événements endocriniens du cycle sexuel conduisant à l'induction de l'œstrus et de l'ovulation (cf $\S 1.1$ et $\S 3.1 .1)$.

Selon les doses d'hormone utilisées, on peut induire une ovulation (traitement d'induction et de synchronisation de l'œstrus et de l'ovulation) ou plusieurs (traitement de superovulation). Les hormones utilisées sont des hormones de synthèse (GnRH et ses agonistes) ou des hormones natives extraites du plasma (eCG) ou d'hypophyses (FSH, LH). Pour écarter tout risque sanitaire lié à l'injection d'hormones glycoprotéiques extraites (prion, virus, etc.) et pour disposer d'un système de production des hormones glycopro- téiques mieux contrôlé, plusieurs laboratoires ont essayé de produire des hormones recombinantes. Ainsi, l'eCG a été produite à partir de plusieurs systèmes d'expression (Baculovirus, Pischia pastoris, cellules $\mathrm{CHO}$, etc.). Dans tous les cas, l'hormone recombinante est active in vitro mais ne présente aucune activité in vivo en raison probablement d'une glycosylation incomplète (Legardinier et al 2005). Une eCG monocaténaire (fusion des deux sousunités $\alpha$ et $\beta$ ) a été produite dans le lait de lapine transgénique. Là encore, cette hormone est active in vitro mais ne présente aucune activité in vivo (Galet et al 2000). De même, une FSH bovine a été produite dans le lait de lapine transgénique mais n'a pas développé d'activité biologique détectable in vivo (Coulibaly et al 2002). Outre l'impossibilité de disposer pour l'instant d'une hormone à demi-vie suffisante pour être active in vivo, le coût de production de ces hormones glycoprotéiques recombinantes reste élevé par rapport au coût d'extraction et de purification des hormones natives qui sont encore utilisées aujourd'hui.

Quelle que soit l'espèce cible, le principe du traitement d'induction et de synchronisation de l'œstrus et de l'ovulation est le même : une injection i.m. de eCG (Syncropart PMSG ${ }^{\circledR}$-CEVA, France ; Chronogest PMSG ${ }^{\circledR}$-Intervet, Pays-Bas) induit l'ovulation de façon synchrone chez les femelles traitées après que celles-ci aient été soumises à un traitement progestatif pour synchroniser le cycle sexuel (éponge vaginale chez les ovins ou les caprins, implant sous-cutané ou spirale vaginale chez les bovins). Les doses utilisées varient selon l'espèce cible (tableau 2). En raison de sa demi-vie très longue (2,5 jours chez les ovins, 5 jours chez les bovins) et de sa double activité hormonale de type FSH et $\mathrm{LH}$ chez les espèces non-équines, 1'eCG permet d'induire l'ovulation de façon efficace en une seule injection.

Dans le cadre de la production et du transfert d'embryons, les traitements de superovulation sont indispensables pour obtenir un rendement optimal. La superovulation peut être provoquée par une injection massive de eCG : 1000 à 2000 UI chez les ovins et les caprins deux jours avant la fin du traitement progestatif, $2500 \mathrm{UI}$ chez les bovins au $10^{\mathrm{e}}$ jour du cycle. Mais, l'eCG n'est pratiquement plus utilisée en traitement de superovulation car sa forte activité LH peut entraîner une lutéinisation précoce des follicules chez les petits ruminants et sa longue demi-vie, une lutéo- 
Tableau 2. Utilisation d'eCG dans les principaux traitements d'induction et de synchronisation de l'œstrus et de l'ovulation chez les espèces bovine, ovine et caprine (d'après Chemineau et al 1996a).

\begin{tabular}{|c|c|c|c|c|c|c|c|}
\hline Espèce & Catégorie & $\begin{array}{l}\text { Progestatif } \\
\text { (dose, } \\
\text { durée) }\end{array}$ & $\begin{array}{c}\text { Voie } \\
\text { d'administration }\end{array}$ & $\begin{array}{c}\text { Prostaglandines } \\
\text { oui ou non } \\
\text { (jours avant } \\
\text { retrait) }\end{array}$ & $\begin{array}{l}\text { Dose } \\
\text { de } \\
\text { eCG }\end{array}$ & $\begin{array}{c}\text { Synchronisation de } \\
\text { l'œstrus après retrait } \\
\text { du progestatif }\end{array}$ & $\begin{array}{l}\text { Moments de } \\
\text { saillie ou d'IA } \\
\text { après retrait }\end{array}$ \\
\hline \multirow{3}{*}{ Bovins } & $\begin{array}{l}\text { Vaches } \\
\text { laitières }\end{array}$ & $\begin{array}{l}\text { Norgestomet } \\
3 \mathrm{mg} \text { total } \\
7 \text { à } 11 \text { jours }\end{array}$ & $\begin{array}{c}\text { Implant } \\
\text { sous-cutané } \\
+ \text { surcharge } \\
\text { à la pose } \\
+ \text { œestradiol } \\
\text { à la pose }\end{array}$ & oui (2) & $400 \mathrm{UI}$ & $86 \%$ en $48 \mathrm{~h}$ & $56 \mathrm{~h}(\mathrm{IA})$ \\
\hline & $\begin{array}{l}\text { Génisses } \\
\text { et vaches } \\
\text { rustiques } \\
\text { et viande }\end{array}$ & idem & idem & non & $\begin{array}{l}500 \text { à } \\
700 \mathrm{UI}\end{array}$ & idem & $56 \mathrm{~h}(\mathrm{IA})$ \\
\hline & $\begin{array}{c}\text { Toutes } \\
\text { catégories }\end{array}$ & $\begin{array}{l}\text { Progestérone } \\
1,5 \mathrm{~g} \text { total } \\
12-14 \text { jours }\end{array}$ & $\begin{array}{c}\text { Spirale vaginale } \\
\left(\text { PRID }^{3}\right) \\
+ \text { œstradiol } \\
\text { à la pose } \\
\end{array}$ & non & $\begin{array}{l}400 \text { à } \\
700 \mathrm{Ul}\end{array}$ & $80 \%$ en $48 \mathrm{~h}$ & $\begin{array}{c}56 \mathrm{~h}(\mathrm{IA}) \\
48 \mathrm{~h} \text { et } 72 \mathrm{~h}(\mathrm{IA})\end{array}$ \\
\hline Ovins & & $\begin{array}{c}\mathrm{FGA}^{1} \text { ou } \\
\mathrm{MPA}^{2} \\
30 \text { à } 40 \mathrm{mg} \\
14 \text { jours }\end{array}$ & $\begin{array}{c}\text { Eponge vaginale } \\
\text { (ou implant) }\end{array}$ & non & $\begin{array}{l}400 \mathrm{à} \\
700 \mathrm{Ul}\end{array}$ & $99 \%$ avant $48 \mathrm{~h}$ & $\begin{array}{c}24 \text { à } 48 \mathrm{~h} \\
\text { (saillie) } \\
\text { ou } \\
55 \mathrm{~h}(\mathrm{IA})\end{array}$ \\
\hline Caprins & & $\begin{array}{l}\text { FGA } 45 \mathrm{mg} \\
11 \text { jours }\end{array}$ & Eponge vaginale & $\begin{array}{l}\text { oui (2) } \\
\text { non }\end{array}$ & $\begin{array}{l}500 \text { à } \\
700 \text { Ul }\end{array}$ & $\begin{array}{c}97 \% \text { de } \\
12 \text { h à } 36 \text { h }\end{array}$ & $\begin{array}{c}24 \text { à } 48 \mathrm{~h} \\
\text { (saillie) } \\
\text { ou } 45 \mathrm{~h}(\mathrm{~A})\end{array}$ \\
\hline
\end{tabular}

1 FGA : acétate de fluorogestone.

2 MPA : acétate de médroxyprogestérone.

3 PRID : « progesterone-releasing intravaginal device » ou spirale vaginale à relargage de progestérone.

lyse prématurée et une moindre viabilité des embryons récoltés, ceci du fait d'une forte sécrétion d'œstradiol après l'ovulation des follicules superovulés (Cognié et al 2003, Vos et al 1994). Elle est remplacée par la FSH porcine (Follitropin ND - Vetrepharm, Canada ; Stimufol ${ }^{N D}$ - Mérial, France) ou ovine (OvagenND - Immuno Chemical Products, Nouvelle-Zélande). En raison de sa demi-vie courte, de l'ordre de 30 minutes, la FSH doit être injectée de façon séquentielle en six injections à douze heures d'intervalle et à des doses décroissantes.

L'efficacité des traitements hormonaux peut être altérée chez les ovins et les caprins par la mise en place d'une réponse immunitaire humorale développée contre l'eCG et la pFSH (Roy et al 1999a, 1999b, Baril et al 1993, 1996a, Remy et al 1991). Dans le cas particulier de la pFSH, l'utilisation de la FSH ovine permet de circonvenir le problème de réponse immunitaire visà-vis de la $\mathrm{pFSH}$.

\subsection{3 / Hormones peptidiques : aspects spécifiques dans le domaine de la physiologie de la croissance}

Parmi les nombreuses hormones qui participent au contrôle de la croissance, les hormones de l'axe somatotrope jouent un rôle important. Cet axe endocrinien implique la GH, l'IGF-I et l'IGF-II, leurs récepteurs (RGH et RIGF) et plusieurs protéines de liaison spécifiques (GHBP, IGFBP). La sécrétion et la synthèse de la GH par les cellules somatotropes de l'adénohypophyse sont sous le contrôle du système nerveux central et principalement sous la dépendance de deux peptides hypothalamiques, un peptide inhibiteur, la somatostatine ou SRIF (Somatotropin Release Inhibiting Factor) et un peptide stimulateur, le GHRH (Growth Hormone Releasing Hormone). Ce dernier comporte 44 acides aminés. La portion comportant les 29 premiers acides aminés $\left(\mathrm{GHRH}_{1-29}\right)$ est suffisante à l'expression biologique du GHRH et présente une séquence très bien conservée chez les mammifères ; elle est identique chez l'homme et le porc; les séquences bovine, caprine et ovine se distinguent de cette séquence par un acide aminé. L'administration de GHRH stimule la sécrétion de GH dans plusieurs espèces (Frohman et Jansson 1986). L'action de la GH débute par sa liaison à un récepteur spécifique possédant un seul domaine transmembranaire appartenant à la superfamille des récepteurs aux cytokines de classe I
(Bazan 1990). La formation du complexe hormone-récepteur suivie de la dimérisation du récepteur active une cascade de phosphorylations de protéines intracellulaires (cf $\S 2.2 .1$ ). A ce jour, plusieurs voies de signalisation ont été décrites pour la GH (Frank 2001). Le récepteur à la $\mathrm{GH}$ est fortement exprimé au niveau du foie mais aussi dans de nombreux autres sites comme le muscle ou le tissu adipeux (Louveau et Bonneau 2001). En plus de la liaison à son récepteur, la $\mathrm{GH}$ se lie à une protéine de liaison, la GHBP $(G H$ binding protein) dans le plasma. Cette dernière est générée soit par épissage alternatif de l'ARNm du récepteur à la GH (rongeurs), soit par clivage protéolytique du domaine extracellulaire du récepteur à la $\mathrm{GH}$ [homme, lapin et autres espèces, (Edens et Talamantes 1998)]. Cette protéine augmenterait la demi-vie de la GH et modulerait les effets de la $\mathrm{GH}$ par compétition avec le récepteur (Bauman 2001).

La GH exerce des actions somatogéniques et métaboliques sur de nombreux organes et tissus. Les mécanismes biologiques par lesquels elle opère ne sont pas tous élucidés. L'hypothèse ancienne selon laquelle l'action de la $\mathrm{GH}$ est relayée par l'IGF-I plasmatique 
d'origine hépatique (Salmon et Daughaday 1957) a longtemps été admise. Cependant, la production d'IGF-I par le foie mais également par de nombreux autres organes et tissus associée à la présence du récepteur à la $\mathrm{GH}$ et à l'IGF-I dans de nombreux types cellulaires et à l'existence de plusieurs IGFBPs indiquent que des interactions multiples sont possibles au niveau de ce système (Le Roith et al 2001). La plupart des études décrivant les actions de la $\mathrm{GH}$ ne permettent pas de distinguer les effets propres de la $\mathrm{GH}$ de ceux relayés par l'IGF-I.

Parmi les différentes stratégies qui permettent d'intervenir sur un des maillons de l'axe somatotrope pour modifier la croissance et la composition corporelle des animaux, la stratégie la plus documentée se fonde sur l'augmentation de la concentration plasmatique de $\mathrm{GH}$ à la suite d'une administration de GHRH ou d'une administration de GH exogène spécifique de l'espèce (Etherton 1999). La disponibilité depuis le début des années 80 de grandes quantités de GHRH ou de $\mathrm{GH}$ a permis d'en étudier les effets dans différentes productions animales. A doses administrées équivalentes l'action du GHRH sur les performances de croissance est plus faible que celle de la GH (Bonneau 1992). Chez le porc en croissance, l'administration de GH porcine $(\mathrm{pGH})$ exogène augmente de façon spectaculaire les performances de croissance en augmentant la proportion de tissu maigre et en réduisant le dépôt de tissu gras. Chez le porc, les effets de la $\mathrm{GH}$ sur le métabolisme lipidique du tissu adipeux sont bien documentés (Etherton 2000). La lipogenèse est diminuée, ce qui entraîne une augmentation des concentrations sanguines en glucose et insuline. Dans ces conditions physiologiques à caractère catabolique et diabétogène, la sensibilité du foie et celle du tissu adipeux à l'insuline sont modifiées, ce qui favorise le métabolisme énergétique des tissus musculaire et osseux (Meyer 2001). En ce qui concerne l'adipocyte, la GH s'oppose à l'action de l'insuline, ce qui entraîne une diminution de l'incorporation du glucose et une réduction de la lipogenèse, la lipolyse étant assez peu affectée. La réduction de l'activité des enzymesclés de la lipogenèse est associée à une réduction des ARNm indiquant qu'il s'agit d'une régulation transcriptionnelle. Le mécanisme mis en jeu dans l'interaction entre la $\mathrm{GH}$ et l'insuline demeure toujours inconnu à ce jour. L'action de la GH sur le récepteur à l'insuline ou sur l'activité tyrosine kinase de ce récepteur peut être écartée
(Magri et al 1990). De même, le SREBP-1 (Sterol Response Element Binding Protein-1), facteur de transcription décrit comme jouant un rôleclé dans l'action de l'insuline sur les gènes impliqués dans le métabolisme lipidique hépatique, n'est pas impliqué (Louveau et Gondret 2004).

\subsection{4 / Hormones peptidiques : aspects spécifiques dans le domaine de la physiologie de la lactation}

On connaît depuis plus de 75 ans les effets stimulants d'injections d'extraits hypophysaires sur la sécrétion lactée. Ces effets sont dus essentiellement à l'action de la GH. La GH produite naturellement par l'hypophyse a une séquence de 190 ou 191 acides aminés, avec 4 variants majeurs, en proportions variables selon les races laitières, et un polymorphisme génétique qui semble lié au niveau de production et/ou à la composition du lait. La GH bovine recombinante (rbGH ou rbST), produite par biotechnologie, possède de 191 à 199 acides aminés, selon les procédés de fabrication des différentes firmes productrices.

L'effet premier de la GH chez le ruminant est de stimuler, directement ou indirectement via l'IGF-I ou d'autres messagers, l'activité sécrétoire et/ou la durée de vie des cellules mammaires. Par ailleurs, la GH exerce à court terme des effets de type diabétogène (résistance à l'action périphérique de l'insuline et augmentation de sa sécrétion, réduction de l'utilisation extramammaire du glucose, oxydation accrue des acides gras, etc.) qui augmentent la disponibilité en glucose et permettent l'augmentation importante de la synthèse du lactose par la mamelle. La GH facilite donc à court terme l'adaptation coordonnée (homéorhèse ou téléophorèse) du métabolisme des différents tissus et organes (foie, tissu adipeux, muscle, os, etc.) pour satisfaire la demande en nutriments de la mamelle, tout en maintenant une régulation homéostatique normale (figure 5). Après quelques semaines pendant lesquelles l'animal mobilise ses lipides corporels ou ralentit leur dépôt, l'organisme s'adapte probablement à plus long terme à cette situation physiologique, par une augmentation du niveau d'ingestion qui fournit progressivement les nutriments nécessaires à la mamelle et à la néoglucogenèse hépatique, puis au rétablissement des réserves corporelles (Bauman et Vernon 1993, Chilliard et al 1998b, 2001).

\section{- Glande mammaire, foie et IGF-I}

Le foie est un tissu cible majeur de la $\mathrm{GH}$ et des récepteurs de haute affinité ont été mis en évidence chez les bovins, les ovins et les caprins. La liaison GH-

Figure 5. Mécanismes d'action à court terme de la $\mathrm{GH}$ chez le ruminant en lactation (Bauman et Vernon 1993, Chilliard et al 1998b, 2001).

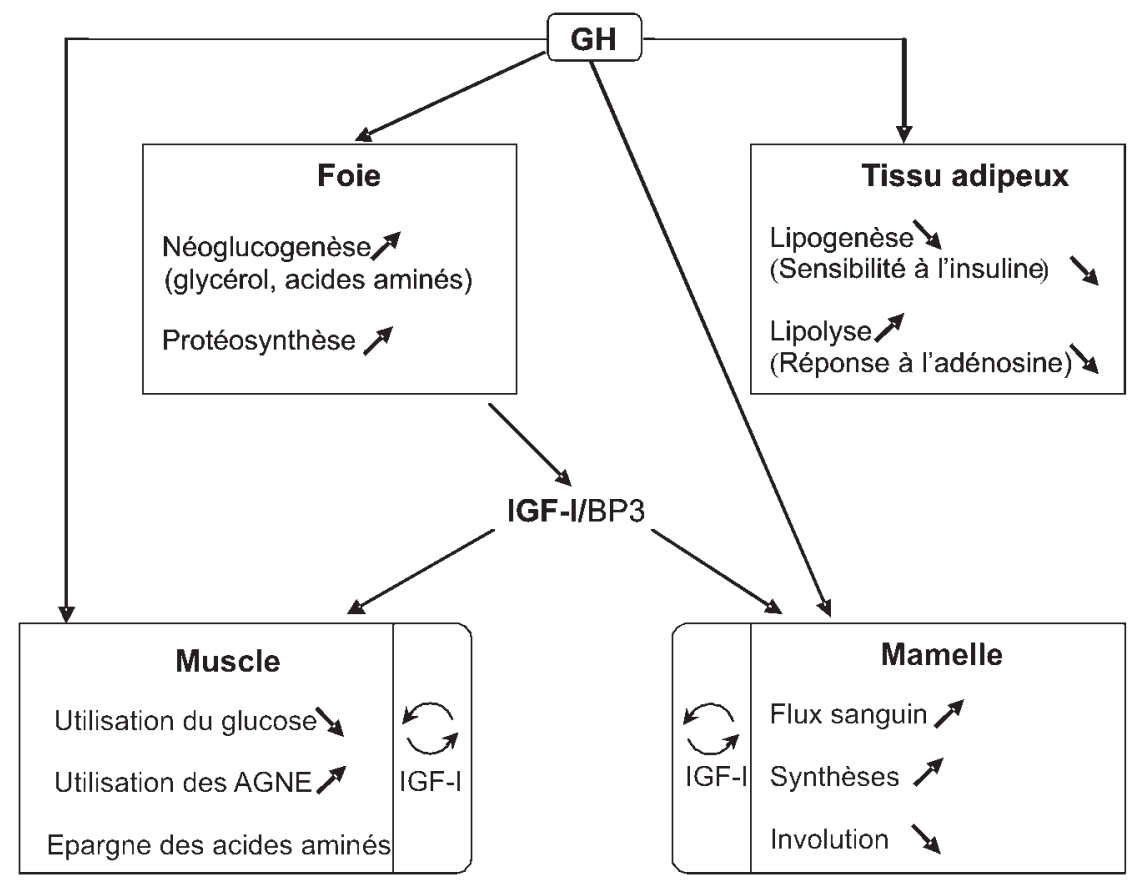

AGNE - acides gars non estérifiés $B P 3=$ protéine de liaison de type 3 IGF-I = insulin like growth factor-I 
récepteur induit l'augmentation de la concentration de l'IGF-I circulant ainsi que de sa protéine de liaison de type 3 (IGFBP3), et la diminution de la protéine de liaison de type 2 (IGFBP2), ce qui accroît la biodisponibilité de l'IGF-I, au niveau mammaire en particulier.

La réalité d'une action directe de la $\mathrm{GH}$ sur la glande mammaire reste controversée. La réceptivité de la mamelle à la $\mathrm{GH}$ est probablement faible car les méthodes classiques n'ont pas permis d'y mettre en évidence des récepteurs pour la $\mathrm{GH}$, bien que la détection d'ARNm codant pour ces récepteurs dans la mamelle de vache et de brebis montre que leur synthèse $\mathrm{y}$ est possible. Toutefois, l'infusion locale de GH n'augmente pas la production laitière et, in vitro, le métabolisme d'explants mammaires bovins en culture n'est que très faiblement affecté par la GH.

L'administration de GH accroît rapidement le flux sanguin mammaire, aussi bien chez des ruminants en lactation que taris, en modifiant les échanges gazeux dans les cellules vasculaires. Par ailleurs, ce traitement ralentit la diminution du nombre de cellules épithéliales mammaires au cours de la lactation et l'involution mammaire. En revanche, chez la chèvre, un traitement de 3 semaines par la rbGH n'a accru les activités des enzymes lipogéniques que dans le cas de 3 traites par jour, et cet effet disparait lors d'un traitement de 22 semaines. Ceci suggère que l'effet galactopoïétique à long terme s'exerce principalement via la longévité, plutôt que via l'activité métabolique des cellules sécrétrices.

De fait, le seul argument décisif en faveur d'une action directe de la GH sur le tissu mammaire des ruminants en lactation est l'augmentation de la synthèse de l'IGF-I par ce tissu, obtenue in vitro, résultat conforté par l'augmentation in vivo des concentrations de l'IGF-I dans la mamelle et le lait de chèvres et de vaches traitées. Aussi, synthétisé dans le foie et/ou dans la glande mammaire, l'IGF-I est considéré comme le médiateur principal de l'action galactopoïétique de la GH. Chez les petits ruminants, l'infusion d'IGF-I au niveau mammaire permet une augmentation de la production laitière. Néanmoins, cette production additionnelle est toujours inférieure à celle observée lors d'injection de $\mathrm{GH}$, probablement en raison de l'absence de synthèse associée de l'IGFBP3. In vitro, l'IGF-I induit une augmentation de la synthèse d'ADN et stimule la prolifération des cellules mammaires bovines.

\section{- Partage des nutriments entre les} différents tissus

Les adaptations métaboliques des tissus extramammaires ont été étudiées jusqu'ici presque exclusivement lors d'essais à court terme, donc dans une situation où l'animal doit satisfaire des besoins mammaires accrus sans avoir modifié son niveau d'ingestion. Si l'administration de $\mathrm{GH}$ ne semble pas changer l'efficacité d'utilisation de la ration, le partage des nutriments entre les différents tissus est en revanche profondément modifié.

Le flux de glucose vers la mamelle croît, en premier lieu par suite d'une forte diminution de l'oxydation extramammaire, notamment dans le muscle, ce qui peut expliquer jusqu'à $30 \%$ de l'accroissement de la sécrétion de lactose. Par ailleurs, la néoglucogenèse hépatique augmente, probablement à partir de précurseurs endogènes tels que le glycérol provenant de la lipomobilisation (27\% des besoins supplémentaires), le lactate ou les acides aminés. En outre, l'administration de GH diminue l'oxydation des acides aminés et l'excrétion d'azote urinaire, ce qui peut expliquer un accroissement du dépôt protéique observé chez les vaches traitées en fin de lactation où le besoin mammaire est faible.

Les effets sur le métabolisme musculaire et osseux sont probablement dus pour partie à l'IGF-I, dont la synthèse est accrue par la $\mathrm{GH}$, en particulier dans le foie, mais aussi dans les tissus périphériques (muscles, os, etc.). Toutefois, les teneurs en IGF-I circulant sont réduites chez l'animal en début de lactation et chez l'animal sous-alimenté, bien que les teneurs en GH soient élevées. Il a été montré récemment que l'hypoinsulinémie du début de lactation limite l'expression hépatique des gènes du récepteur $1 \mathrm{~A}$ de la GH, et de l'IGF-I (Butler et al 2003, Rhoads et al 2004). Cette absence de réponse (résistance) de l'IGF-I à la GH explique que les effets anaboliques de la GH (produits par l'IGF-I) ne sont pas ou très peu observés chez l'animal sous-alimenté ou en début de lactation.

L'administration de GH in vivo diminue les activités lipogéniques et l'oxydation du glucose du tissu adipeux chez les ovins et la vache laitière. Cela a été confirmé in vitro où des concentrations physiologiques de $\mathrm{GH}$ diminuent la sensibilité de la lipogenèse à l'insuline. Le traitement par la GH ne semble pas modifier sensiblement la sécrétion de leptine par le tissu adipeux, si ce n'est indirectement lorsqu'elle diminue l'adiposité et/ou le bilan énergétique des animaux (Chilliard et al 2005).

Chez la vache en lactation recevant de la GH, l'augmentation du taux des AGNE circulants, qui reflète la lipomobilisation, dépend en grande partie des variations de l'état nutritionnel à court (effet repas) et à long terme (effet stade). L'administration de GH accroît la réponse des AGNE circulants à une injection d'adrénaline chez la vache en lactation et en bilan énergétique diminué mais est sans effet chez la vache tarie, qu'elle soit sous- ou suralimentée. L'effet accru chez la vache en lactation semble résulter principalement d'une diminution, par la GH, de l'effet antilipolytique de l'adénosine.

La GH peut donc agir directement sur le tissu adipeux (qui possède des récepteurs à cette hormone) et modifier ses réponses aux régulations homéostatiques de la lipogenèse et de la lipolyse, mais sans abolir ces régulations. L'augmentation de la lipomobilisation sous l'effet de la GH, en début de lactation ou au début d'un traitement par la rbGH, pourrait en outre contribuer à limiter la vitesse d'augmentation du niveau d'ingestion dans ces deux situations. De ce fait, les risques digestifs ou métaboliques accompagnant un accroissement brutal des flux ruminaux, intestinaux ou hépatiques de nutriments seraient diminués (Bareille et al 1997).

Le métabolisme lipidique ne semble pas être notablement altéré dans le foie des vaches laitières traitées par la $\mathrm{GH}$. Les AGNE provenant des tissus adipeux sont plus largement sécrétés par la mamelle et oxydés par les autres tissus, sans accroissement de l'estérification et du stockage en triglycérides dans le foie.

\subsection{5 / Hormones peptidiques : aspects spécifiques à leur utilisation en médecine vétérinaire}

Les hormones peptidiques et protéiques utilisées en médecine vétérinaire sont la GnRH ou ses analogues et les hormones chorioniques (hCG, eCG). La prescription de GnRH ou d'eCG en association avec une progestine est indiquée, à des fins thérapeutiques, dans le traitement de l'anœstrus vrai postpartum (cf $\S 3.1 .1$ et $\S 6.2 .1$ ). La prescription de GnRH ou ses analogues est indiquée lors du syndrome de repeat-breeding chez la vache (vaches infertiles présentant des chaleurs régulières) pour laquelle différents protoco- 
les sont utilisés : administration en milieu du cycle pour contrôler la vague de croissance folliculaire, au moment de l'ovulation ou après insémination artificielle (IA) pour stimuler le développement et le maintien du corps jaune et stimuler la sécrétion de progestérone indispensable à la survie embryonnaire.

Lors de kystes ovariens chez la vache ou la jument, parfois associés à un comportement nymphomane, la GnRH ou l'hCG sont utilisées pour provoquer la rupture du kyste folliculaire ou sa lutéinisation.

Chez le mâle, la GnRH ou ses analogues ou l'hCG stimulent la production d'androgènes et favorisent la descente des testicules chez le jeune, ils sont indiqués lors de comportement sexuel insuffisant ou de cryptorchidie.

\section{3 / Les substances $\beta_{2}$-adréner- giques}

Certaines substances $\beta$-adrénergiques peuvent être utilisées chez l'animal d'élevage à des fins zootechniques. Ces $\beta$-agonistes ne sont pas des hormones, mais leur incorporation à des doses très faibles dans les aliments destinés aux animaux permet la production de viandes moins grasses ainsi qu'une augmentation de la masse musculaire plus ou moins prononcée selon l'espèce considérée. Ces substances sont aussi appelées «agents de répartition». Leurs effets secondaires ne sont pas négligeables. Dans certains cas, des consommateurs de produits animaux (foie, muscle) provenant d'animaux traités ont pu s'en trouver affectés. Leur utilisation est interdite au sein de l'UE (directive 96/22/EC). En dehors de l'UE, seules quelques molécules sont utilisées dans un nombre restreint de pays.

\subsection{1 / Mécanismes et modes d'action des $\beta$-agonistes : aspects généraux}

La composante orthosympathique du système nerveux autonome exerce un contrôle important sur les appareils cardio-vasculaire, respiratoire, génito-urinaire et digestif. Deux catécholamines endogènes, l'adrénaline et la noradrénaline, sont libérées lors de son activation. Ces médiateurs chimiques viennent stimuler des récepteurs spécifiques présents sur la membrane plasmique des cellules cibles : les récepteurs adrénergiques (AR). Sur des bases fonctionnelles, les travaux d'Ahlquist (1948) ont permis de distinguer les $\alpha$-AR (associés à la contraction des muscles lisses) des $\beta$-AR. Pour ces derniers, l'existence de sous-types $\beta_{1}$ et $\beta_{2}$ a été démontrée par Lands et al (1967), le $\beta_{1}$-AR étant à l'origine de la stimulation cardiaque et le $\beta_{2}$ étant responsable de la relaxation de la musculature lisse. L'existence d'un $\beta_{3}$-AR a aussi été mise en évidence (Arch et al 1984) mais non démontrée chez les animaux d'élevage, en particulier les ruminants (Ferlay et al 2001). Ces résultats ont conduit au développement par l'industrie pharmaceutique de molécules capables d'activer (agonistes) ou de bloquer (antagonistes) la réponse des AR. Des études anciennes ont montré que des composés, dont l'adrénaline, sont capables de moduler les concentrations cellulaires en AMPc, ce qui modifie le métabolisme lipidique chez l'animal (Cunningham 1965). Cependant, c'est le développement d'agonistes spécifiques des $\beta$-AR, en particulier le clenbutérol, qui a conduit à envisager l'utilisation des $\beta$-agonistes en élevage pour leurs effets d'agents de répartition, à savoir une diminution de la masse de tissu adipeux et une accrétion protéique (Ricks et al 1984). La stimulation des $\beta_{2}$-AR (et peut-être des $\beta_{3}$-AR, notamment pour les effets lipolytiques) est primordiale pour l'expression des effets zootechniques des $\beta$-agonistes (Hinkle et al 2002, Mills et al 2003), même si des mécanismes endocrines peuvent également être impliqués (Buttery et Dawson 1987). La formation du complexe $\beta$-agoniste/ récepteur entraîne l'activation de la protéine $\mathrm{G}_{\mathrm{s}}$, dont l'unité $\alpha$ active l'adénylate cyclase, conduisant à la production d'AMPc. Par le biais de la protéine kinase A, l'AMPc provoque la phosphorylation de protéines intracellulaires, dont la lipase hormono-sensible. L'augmentation de la concentration intra-cellulaire en AMPc provoque également la phosphorylation de protéines de régulation transcriptionnelle, stimulant la transcription de certains gènes (Mersmann 1998). Les effets des $\beta$-agonistes sur le métabolisme lipidique adipocytaire mettent en jeu à la fois une stimulation de la dégradation des triacylglycérols et une inhibition de la synthèse de ces triacylglycérols et des acides gras. Ces effets sont observés in vitro (adipocytes) et ex vivo. In vivo, l'implication de la lipolyse adipocytaire est également confirmée par l'augmentation de la concentration en acides gras libres constatée chez de nombreuses espèces, après administration de $\beta$-agonistes (Mersmann 1987 , Eisemann et al 1988, Gojmerac et al 2000). Les mécanismes conduisant à une accrétion protéique chez les animaux traités pourraient, de même, résulter d'une augmentation des syn- thèses protéiques et d'une diminution concomitante de leur dégradation (Mersmann 1995, Navegantes et al 2003). Ainsi ont été notées une augmentation des ARNm codant pour la chaîne légère de la myosine et de l' $\alpha$-actine (Smith et al 1989, Grant et al 1993), une élévation de la calpastatine, un inhibiteur de certaines protéases (Killefer et Koohmaraie 1994), et une modulation de l'expression de plusieurs isoformes de la chaîne lourde de la myosine (Beekley et al 2003, Bricout et al 2004).

\subsection{2 / Aspects spécifiques à l'utilisa- tion des $\beta$-agonistes pour l'augmenta- tion des performances de croissance et d'engraissement}

La capacité des $\beta$-agonistes à exercer un effet d'agent de répartition a été évaluée chez de nombreuses espèces animales (Bell et al 1998). C'est chez les ruminants que ces produits sont les plus actifs. Leurs effets ont également été étudiés chez le porc (Bell et al 1998, Stoller et al 2003). Le gain financier consécutif au traitement de veaux par des $\beta$-agonistes est de l'ordre de 5 à $15 \%$ de leur prix de base. Il est dû à une augmentation de la masse protéique produite, mais également à une amélioration de la conformation des carcasses et de l'indice de consommation. Indépendamment des considérations portant sur la qualité des viandes provenant des animaux traités par ces substances, l'usage des $\beta$-agonistes en élevage soulève des problèmes relatifs à l'activité pharmacologique des résidus présents dans les denrées animales, à l'égard du consommateur. Ces effets sont pour partie liés au fait que les $\beta$ agonistes illégalement utilisés chez l'animal, même s'il s'agit d'agonistes préférentiels des $\beta_{2}-\mathrm{AR}$, demeurent capables d'activer les $\beta_{1}$-AR. La structure des $\beta$-agonistes, qui ont en commun un squelette de type phényléthanolamine, est dérivée de celle des catécholamines endogènes (figure 6). Les $\beta$-agonistes diffèrent de l'adrénaline et de la noradrénaline par les substituants du cycle aromatique, ainsi que ceux de la chaîne latérale. Leur métabolisme et leurs propriétés pharmacologiques sont largement influencés par ces modifications. La présence de substituants plus ou moins volumineux sur l'amine de la chaîne latérale diminue la capacité de ces molécules à activer les $\alpha$-AR et, dans une moindre mesure, les $\beta_{1}$-AR et augmente leur spécificité $\beta_{2}$ agoniste. Elle rend également impossible leur désamination par les monoamine oxydases (MAO), enzymes qui prennent en charge le métabolisme des 
Figure 6. Principaux $\beta$-agonistes utilisables en élevage de façon illégale ou réglementée (Ractopamine, Zilpatérol).<smiles>CNCC(O)c1ccc(O)c(O)c1</smiles>

Adrénaline<smiles>CC(C)(C)NCC(O)c1cc(Cl)c(N)c(Cl)c1</smiles>

Clenbutérol<smiles>CC(C)(C)NCC(O)c1cc(Cl)c(N)c(C(F)(F)F)c1</smiles>

Mabutérol<smiles>CC(C)(C)NCC(O)c1ccc(O)c(CO)c1</smiles>

Salbutamol (Albutérol)<smiles>NCC(O)c1ccc(O)c(O)c1</smiles>

Noradrénaline<smiles>CC(C)NCC(O)c1cc(Cl)c(N)c(C#N)c1</smiles>

Cimatérol<smiles>CC(C)NCC(O)c1cc(O)cc(O)c1</smiles>

Métaprotérénol<smiles>CC(Cc1ccc(O)cc1)NCC(O)c1ccc(O)cc1</smiles>

Ractopamine<smiles>OCc1cc(C(O)CNCCOCc2ccccc2)ccc1O</smiles>

Salmétérol<smiles>CC(Cc1ccc(O)cc1)NCC(O)c1cc(O)cc(O)c1</smiles>

Fénotérol<smiles>CC(C)NC1CCn2c(=O)[nH]c3cccc(c32)C1O</smiles>

Zilpatérol catécholamines endogènes. L'absence de structure de type catéchol, qu'elle soit obtenue par substitution (salbutamol, salmétérol), déplacement (résorcinols : fénotérol, métaprotérénol) ou perte d'un groupement hydroxy (ractopamine) empêche par ailleurs la métabolisation de ces molécules par les catéchol-O-méthyltransférases (COMT), avec pour conséquence l'allongement de leur demi-vie dans l'organisme. Actuellement, les seules molécules dont l'utilisation est autorisée en élevage sont la ractopamine et le zilpatérol. La ractopamine dispose d'une autorisation de mise sur le marché pour les USA chez le porc (Paylean ${ }^{\circledR}$ ) et depuis peu chez les bovins (Optaflex ${ }^{\mathrm{TM}}$ ). Le zilpatérol est autorisé au Mexique et en Afrique du Sud, uniquement chez les bovins $\left(\right.$ Zilmax $\left.^{\mathrm{TM}}\right)$. La structure du zilpatérol est différente de celle des autres $\beta$-agonistes, mais il n'en demeure pas moins que cette molécule de «deuxième génération» conserve la partie phényl-éthanolamine commune à tous les $\beta$-agonistes. Le clenbutérol, le mabutérol et le cimatérol portent sur le cycle aromatique un ou plusieurs substituants augmentant considérablement leur caractè- re lipophile, et par conséquent leur biodistribution dans l'organisme, tout en empêchant un métabolisme trop rapide. Ces trois molécules ont également en commun une structure de type arylamine, avec l'existence d'un groupement amine primaire en position para de la chaîne latérale. C'est dans ce groupe que l'on trouve la majeure partie des $\beta$ agonistes utilisés illégalement en élevage (tableau 3).

\subsection{3 / Aspects spécifiques à l'utilisa- tion en médecine vétérinaire}

La plupart des $\beta$-agonistes a été initialement développée en tant que bronchodilatateurs ou agents tocolytiques. C'est le cas du clenbutérol (Engelhardt 1972), mais aussi celui du salbutamol et du mabutérol (figure 6). Les principales pathologies relevant à l'heure actuelle d'un traitement par des $\beta$-mimétiques sont les maladies cardiovasculaires $\left(\beta_{1}\right.$-antagonistes à activité $\beta_{2}$ variable), la bronchodilatation et le contrôle de la parturition ( $\beta_{2}$-agonistes). Les molécules utilisées en médecine vétérinaire sont le clenbutérol, l'isoxuprine et la carazolol. Le clenbutérol est un agoniste relati- vement sélectif des $\beta_{2}-A R$, le ratio d'activation $\beta_{1}-\mathrm{AR} / \beta_{2}-\mathrm{AR}$ étant de l'ordre de $1 / 4$ (Chu 1984). Il est employé comme bronchodilatateur chez le cheval (Ventipulmin ${ }^{\mathrm{TM}}$ ) ainsi que pour ses propriétés tocolytiques chez la vache (Planipart ${ }^{\mathrm{TM}}$ ). Le brevet du clenbutérol est passé dans le domaine public depuis 1984. Les doses contenues dans les deux spécialités vétérinaires actuellement disponibles sur le marché sont faibles et les rendent économiquement inintéressantes si l'on envisage de les utiliser pour traiter des animaux à des fins zootechniques. L'isoxuprine est un agent ayant une composante $\beta$-agoniste, mais également une activité $\alpha$-antagoniste. Elle est utilisée en médecine vétérinaire par voie injectable comme tocolytique chez les bovins, ovins et caprins, ainsi que chez le porc et le cheval (Duphaspamin ${ }^{\circledR}$ ). Ce produit n'est pas utilisé pour des applications zootechniques et il a été considéré qu'il n'était pas nécessaire de fixer de limite maximale de résidus. Le carazolol $\left(\right.$ Suacron $\left.{ }^{\circledR}\right)$, mentionné pour mémoire, est commercialisé chez le porc pour ses propriétés $\beta$-bloquantes et comme anti-stress de transport. 
Tableau 3. Structure des différents $\beta$-agonistes utilisables en élevage de façon illégale ou réglementée.

\begin{tabular}{|c|c|c|c|c|c|}
\hline Molécules & R1 & R2 & R3 & R4 & R5 \\
\hline Clenbutérol & $\mathrm{NH}_{2}$ & $\mathrm{H}$ & $\mathrm{Cl}$ & $\mathrm{Cl}$ & $\mathrm{C}\left(\mathrm{CH}_{3}\right)_{3}$ \\
\hline Clenpropérol & $\mathrm{NH}_{2}$ & $\mathrm{H}$ & $\mathrm{Cl}$ & $\mathrm{Cl}$ & $\mathrm{CH}\left(\mathrm{CH}_{3}\right)_{2}$ \\
\hline Clenpentérol & $\mathrm{NH}_{2}$ & $\mathrm{H}$ & $\mathrm{Cl}$ & $\mathrm{Cl}$ & $\mathrm{C}\left(\mathrm{C}_{2} \mathrm{H}_{5}\right)\left(\mathrm{CH}_{3}\right)_{2}$ \\
\hline Bromoclenbutérol & $\mathrm{NH}_{2}$ & $\mathrm{H}$ & $\mathrm{Cl}$ & $\mathrm{Br}$ & $\mathrm{C}\left(\mathrm{CH}_{3}\right)_{3}$ \\
\hline Mabutérol & $\mathrm{NH}_{2}$ & $\mathrm{H}$ & $\mathrm{Cl}$ & $\mathrm{CF}_{3}$ & $\mathrm{C}\left(\mathrm{CH}_{3}\right)_{3}$ \\
\hline Mapentérol & $\mathrm{NH}_{2}$ & $\mathrm{H}$ & $\mathrm{Cl}$ & $\mathrm{CF}_{3}$ & $\mathrm{C}\left(\mathrm{C}_{2} \mathrm{H}_{5}\right)\left(\mathrm{CH}_{3}\right)_{2}$ \\
\hline Mahéxérol & $\mathrm{NH}_{2}$ & $\mathrm{H}$ & $\mathrm{Cl}$ & $\mathrm{CF}_{3}$ & $\mathrm{C}\left(\mathrm{C}_{3} \mathrm{H}_{7}\right)\left(\mathrm{CH}_{3}\right)_{2}$ \\
\hline 3-Méthyl-mapentérol & $\mathrm{NH}_{2}$ & $\mathrm{H}$ & $\mathrm{Cl}$ & $\mathrm{CF}_{3}$ & $\mathrm{C}\left(\mathrm{CH}_{5}\right)\left(\mathrm{C}_{2} \mathrm{H}_{5}\right)_{2}$ \\
\hline Brombutérol & $\mathrm{NH}_{2}$ & $\mathrm{H}$ & $\mathrm{Br}$ & $\mathrm{Br}$ & $\mathrm{C}\left(\mathrm{CH}_{3}\right)_{3}$ \\
\hline Bromomapentérol & $\mathrm{NH}_{2}$ & $\mathrm{H}$ & $\mathrm{Br}$ & $\mathrm{CF}_{3}$ & $\mathrm{C}\left(\mathrm{C}_{2} \mathrm{H}_{5}\right)\left(\mathrm{CH}_{3}\right)_{2}$ \\
\hline Cimatérol & $\mathrm{NH}_{2}$ & $\mathrm{H}$ & $\mathrm{CN}$ & $\mathrm{H}$ & $\mathrm{CH}\left(\mathrm{CH}_{3}\right)_{2}$ \\
\hline Cimbutérol & $\mathrm{NH}_{2}$ & $\mathrm{H}$ & $\mathrm{CN}$ & $\mathrm{H}$ & $\mathrm{C}\left(\mathrm{CH}_{3}\right)_{3}$ \\
\hline \multirow{13}{*}{$\begin{array}{l}\text { (autres substitutions } \\
\text { possibles du noyau } \\
\text { aromatique) }\end{array}$} & $\mathrm{NH}_{2}$ & $\mathrm{H}$ & $\mathrm{Cl}$ & $\mathrm{F}$ & \\
\hline & $\mathrm{NH}_{2}$ & $\mathrm{H}$ & $\mathrm{Cl}$ & $\mathrm{CN}$ & \\
\hline & $\mathrm{NH}_{2}$ & $\mathrm{H}$ & $\mathrm{Cl}$ & $\mathrm{CH}_{3}$ & \\
\hline & $\mathrm{NH}_{2}$ & $\mathrm{H}$ & $\mathrm{Br}$ & $\mathrm{F}$ & \\
\hline & $\mathrm{NH}_{2}$ & $\mathrm{H}$ & $\mathrm{Br}$ & $\mathrm{CN}$ & \\
\hline & $\mathrm{NH}_{2}$ & $\mathrm{H}$ & $\mathrm{Br}$ & $\mathrm{CF}_{3}$ & \\
\hline & $\mathrm{NH}_{2}$ & $\mathrm{H}$ & $\mathrm{Br}$ & $\mathrm{H}$ & \\
\hline & $\mathrm{NH}_{2}$ & $\mathrm{H}$ & $\mathrm{CN}$ & $\mathrm{F}$ & \\
\hline & $\mathrm{NH}_{2}$ & $\mathrm{H}$ & $\mathrm{F}$ & $\mathrm{H}$ & \\
\hline & $\mathrm{NH}_{2}$ & $\mathrm{H}$ & $\mathrm{F}$ & 1 & \\
\hline & $\mathrm{NH}_{2}$ & $\mathrm{H}$ & $\mathrm{CF}_{3}$ & $\mathrm{H}$ & \\
\hline & $\mathrm{NH}_{2}$ & $\mathrm{H}$ & $\mathrm{CH}_{3}$ & $\mathrm{H}$ & \\
\hline & $\mathrm{NH}_{2}$ & $\mathrm{H}$ & $\mathrm{CH}_{2} \mathrm{OH}$ & $\mathrm{H}$ & \\
\hline Isopropyl-clenbutérol & $\mathrm{NH}-\mathrm{CH}\left(\mathrm{CH}_{3}\right)_{2}$ & $\mathrm{H}$ & $\mathrm{Cl}$ & $\mathrm{Cl}$ & $\mathrm{C}\left(\mathrm{CH}_{3}\right)_{3}$ \\
\hline $\begin{array}{l}\text { Isopropyl-bromoclen- } \\
\text { butérol }\end{array}$ & $\mathrm{NH}-\mathrm{CH}\left(\mathrm{CH}_{3}\right)_{2}$ & $\mathrm{H}$ & $\mathrm{Cl}$ & $\mathrm{Br}$ & $\mathrm{C}\left(\mathrm{CH}_{3}\right)_{3}$ \\
\hline Terbutaline & $\mathrm{H}$ & $\mathrm{H}$ & $\mathrm{OH}$ & $\mathrm{OH}$ & $\mathrm{C}\left(\mathrm{CH}_{3}\right)_{3}$ \\
\hline Métaprotérénol & $\mathrm{H}$ & $\mathrm{H}$ & $\mathrm{OH}$ & $\mathrm{OH}$ & $\mathrm{CH}\left(\mathrm{CH}_{3}\right)_{2}$ \\
\hline Salbutamol & $\mathrm{OH}$ & $\mathrm{H}$ & $\mathrm{CH}_{2} \mathrm{OH}$ & $\mathrm{H}$ & $\mathrm{C}\left(\mathrm{CH}_{3}\right)_{3}$ \\
\hline Tulobutérol & $\mathrm{H}$ & $\mathrm{Cl}$ & $\mathrm{H}$ & $\mathrm{H}$ & $\mathrm{C}\left(\mathrm{CH}_{3}\right)_{3}$ \\
\hline
\end{tabular}

\section{4 / La mélatonine}

\subsection{1 / Mécanismes et mode d'action}

La mélatonine est une substance naturelle découverte en 1958. Elle est présente dans l'organisme de tous les mammifères et est très répandue dans le monde vivant. Elle est synthétisée, principalement dans la glande pinéale, à partir du tryptophane et de la sérotonine selon un rythme jour/nuit bien défini (Arendt 1986). Chez les ovins et les caprins, les taux plasmatiques diur- de la N-acétyl-transférase (NAT) qui catalyse la transformation de la sérotonine en N-acétyl-sérotonine. La mélatonine parvient dans la circulation sanguine par l'intermédiaire de la veine de Galien qui draine la glande pinéale. Elle est également libérée directement dans le liquide céphalo-rachidien où les concentrations sont 100 fois plus élevées que dans la circulation périphérique (Tricoire et al 2003). Chez les mammifères, la mélatonine est métabolisée en 6-hydroxy-mélatonine par le foie et les reins. Ce métabolite est excrété dans l'urine sous forme de conjugués sulphate ou glucuronide. La mélatonine est également métabolisée dans le cerveau en N-acétyl-5méthoxy-kénurénamine (Arendt 1986).

Le rôle principal de la mélatonine est de traduire les effets de la photopériode sur diverses fonctions physiologiques, en particulier la reproduction chez les espèces saisonnées. La mélatonine est en effet secrétée pendant une durée plus longue pendant les jours courts d'automne-hiver que pendant les jours longs de printemps-été et c'est cette différence de durée de présence de l'hormone dans l'organisme qui est responsable des effets inhibiteurs ou stimulants de la photopériode sur la fonction de reproduction. Chez les ovins et les caprins, des espèces dont l'activité de reproduction est stimulée par les jours courts, il est possible d'administrer de la mélatonine de manière continue (implants souscutanés) ou en milieu de journée (injection ou incorporation à la nourriture) pour augmenter la durée de présence de taux élevés de mélatonine. Ces traitements causent une stimulation de l'activité de reproduction chez des brebis ou des chèvres de la même façon que des jours courts, c'est-à-dire après une période de latence d'environ 50 jours (Chemineau et al 1992). La mélatonine agit dans l'hypothalamus postérieur pour contrôler la fréquence de libération de $\mathrm{GnRH}$, ce qui change la fréquence de libération de la LH et l'activité des gonades (Malpaux et al 2001).

\subsection{2 / Aspects spécifiques à l'utilisa- tion de la mélatonine en élevage ovin et caprin}

La mélatonine est commercialisée dans plusieurs pays, dont la France, sous forme d'implants sous les noms de Regulin ${ }^{\circledR}$ (pays anglo-saxons) ou Melovine $^{\circledR}$ (pays latins) pour modifier la date de la saison sexuelle des ovins ou des caprins. L'utilisation de ces implants permet de mimer l'exposition à des jours courts pour stimuler l'acti- 
vité de reproduction. La mélatonine, administrée après une période d'au moins deux mois de jours longs (jours longs naturellement croissants de printemps) avance le début de la saison sexuelle de la brebis. Chez les races originaires de l'Europe du Nord, ayant une saison de reproduction très marquée et dont le début se situe en septembre, la mélatonine permet d'avancer de 1 à 1,5 mois le début de la saison sexuelle. Elle provoque également une augmentation du taux d'ovulation qui conduit à un accroissement sensible de la prolificité. Chez les races «peu saisonnées» telles que la race Mérinos, ce traitement peut être appliqué avec succès pendant toute la période d'anœstrus. Il permet une augmentation de la fécondité, conduisant à un gain de 25 agneaux pour 100 femelles traitées. L'utilisation de la mélatonine peut également être combinée à celle de jours longs artificiels pour induire une activité à contre-saison. Le principe consiste à imposer une période minimale de 2 mois de jours longs pendant l'hiver, suivie par un traitement par la mélatonine pendant le printemps, afin d'aboutir à une activité sexuelle en fin de printemps-début d'été. Ces mêmes traitements permettent d'avancer la puberté chez les jeunes béliers nés à l'automne et provoquent une reprise importante de l'activité spermatogénétique et la production d'une semence utilisable pour l'insémination artificielle chez les béliers adultes (Chemineau et al 1992).

\section{5 / Les anti-thyroïdiens de syn- thèse}

\subsection{1 / Mécanismes et modes d'action : aspects généraux}

La plupart des anti-thyroïdiens de synthèse (ATS) connus aujourd'hui sont des dérivés de la thiourée, molécule utilisée pour la première fois dans le traitement de l'hyperthyroïdie chez l'homme et dont l'activité goitrigène avait été fortuitement mise en évidence (Astwood 1943). Les principaux ATS sont des thionamides qui présentent tous un groupement thiourée, nécessaire à l'activité anti-thyroïdienne (Astwood et al 1945). Ils peuvent être classés en deux groupes : les dérivés du thiouracile (méthylthiouracile, benzylthiouracile, diméthylthiouracile, éthylthiouracile, propylthiouracile, phénylthiouracile) et les dérivés du mercapto-imidazole (carbimazole, mercapto-benzimidazole) (figure 7).

La compréhension du mode d'action des ATS a suscité de nombreuses études

Figure 7. Les anti-thyroïdiens de synthèse dérivés du thiouracile (a) ou du mercaptoimidazole (b).<smiles>O=c1cc[nH]c(=S)[nH]1</smiles>

\section{2,3-dihydro-2-thioxo-4(1H)-pyrimidinone}

sans qu'il soit aujourd'hui encore parfaitement compris. Plusieurs hypothèses sont émises, parmi lesquelles une inhibition de la peroxydase thyroïdienne (TPO) intervenant dans de nombreuses étapes de l'hormonogenèse thyroïdienne. Cette action, démontrée par plusieurs auteurs, serait l'étape-clé de l'activité antithyroïdienne des ATS (Taurog 1976, Michot et al 1979, Engler et al 1982, Shiroozu et al 1983, Taurog et Doris 1989). Cependant, l'inhibition enzymatique ne suffit pas à expliquer le mécanisme qui doit être complété par un deuxième niveau d'action dans lequel les iodures circulants sont rendus non disponibles par complexation avec les ATS (Raby et al 1990, Buxeraud et al 1987, Lagorce et al 1992). Les ATS inhibent donc les premières étapes de la synthèse hormonale mais n'empêchent pas la libération des hormones déjà formées et stockées. Un temps de latence avant l'apparition des effets anti-thyroïdiens est de ce fait observé.

\subsection{2 / Aspects spécifiques à l'utilisa- tion des ATS pour l'augmentation des performances de croissance et d'en- graissement}

Les ATS, en inhibant la production des hormones thyroïdiennes, provoquent une perturbation des différents métabolismes se trouvant sous la dépendance directe de ces hormones. Il en résulte une diminution du métabolisme basal des lipides et des glucides et de la consommation en oxygène, une meilleure utilisation des réserves énergétiques, une rétention d'eau extracellulaire élevée (myxœdème) ainsi qu'un ralentissement du transit intestinal (Kotter et al 1959, Derblom et al 1963, DeRubertis et al 1971). Les ATS ne sont pas véritablement des anabolisants puisqu'ils ne stimulent pas la synthèse protéique et aucune accrétion protéique nette n'est observée.

Les effets décrits ci-dessus provoquent une prise de poids des animaux traités, processus inversé dès que le traitement est suspendu. En effet, aucune augmentation de la masse musculai- b<smiles>Cn1cc[nH]c1=S</smiles>

1,3-dihydro-6-méthyl-2(1H)-imidazole

re proprement dite n'est observée ; il s'agit principalement d'un processus de rétention d'eau par les tissus musculaires et sous-cutanés. La qualité de la viande s'en trouve amoindrie. On peut de plus penser que la présence de résidus de ces substances dans la viande est susceptible de présenter pour le consommateur un risque carcinogène et tératogène. Le mercaptoimidazole ou tapazole, le thiouracile, le méthylthiouracile ainsi que le propylthiouracile sont de puissants antithyroïdiens, peu onéreux et, pour la plupart d'entre eux, aisément accessibles illégalement. Ils peuvent être utilisés frauduleusement, quelques temps avant l'abattage, chez les bovins, porcins, caprins et ovins destinés à la boucherie.

\subsection{3 / Aspects spécifiques à l'utilisa- tion en médecine vétérinaire}

La médecine vétérinaire ne préconise l'utilisation d'ATS que dans des cas d'hyperthyroïdie chez le chat, dysendocrinie la plus fréquente chez ces animaux. Les molécules alors utilisées relèvent de la médecine humaine et sont le benzylthiouracile (Basdène ${ }^{\circledR}$ ) et le carbimazole $\left(\right.$ Neomercazole $\left.^{\circledR}\right)$. Les ATS ne sont en revanche pas utilisés en médecine vétérinaire pour le bétail.

\section{6 / Les prostaglandines}

\subsection{1 / Mécanismes et modes d'action : aspects généraux}

Les prostaglandines agissent comme messagers chimiques locaux. Leur demi-vie est brève. Différentes séries (PgE, PgF, PgI, thromboxanes) sont formées à partir de la postaglandine $\mathrm{H}$ $\left(\mathrm{PgH}_{2}\right)$ qui elle-même dérive de l'acide arachidonique par l'activité $\mathrm{PgH}_{2}$ synthétase (figure 8). Beaucoup de leurs fonctions sont associées au contrôle de la contraction des muscles lisses. Pour les PgE et PgI, les actions impliquent l'activation du système adénylate cyclase. PgI et $\mathrm{TxA}_{2}$ ont des actions antagonistes sur le système plaquettaire, la coagulation sanguine et la vasoconstriction. $\mathrm{PgE}_{2}$ est vasodilatateur et stimule les contractions utérines et 
Figure 8. Voies de biosynthèse des prostaglandines et du thromboxane $A_{2}$

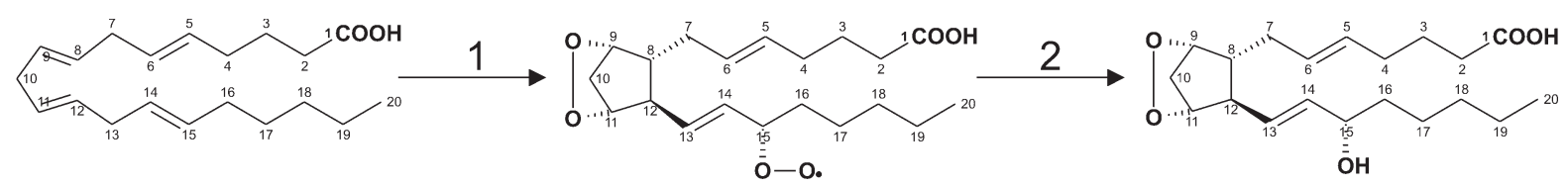

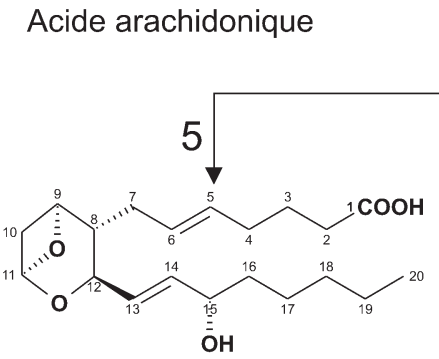

Thromboxane $\mathrm{A}_{2}$

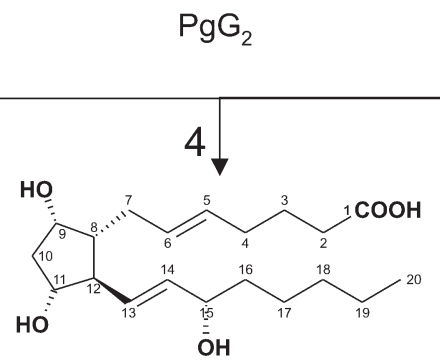

$\mathrm{PgF}_{2 \alpha}$

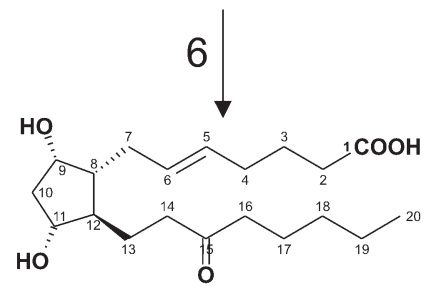

\section{3,14-dihydro-15-céto-PgF2 $\alpha$}

puissant vasoconstricteur, de même que l'angiotensine produite par le corps jaune dont la sécrétion est stimulée par $\mathrm{PgF}_{2 \alpha}$. Ces facteurs renforceraient l'action de $\mathrm{PgF}_{2 \alpha}$ sur la régression lutéale. Les macrophages par leur capacité à produire des espèces réactives de l'oxygène renforcent aussi cette régression (Leymarie et Martal 2001).

\section{tion des prostaglandines pour le contrôle de la lutéolyse}

2.6.2 / Aspects spécifiques à l'utilisa-

$\mathrm{PgF}_{2 \alpha}$ et ses analogues peuvent être utilisés pour induire la lutéolyse et permettre ainsi la croissance de nouveaux follicules ovariens, le plus souvent en association avec un traitement progestatif, le rôle de $\mathrm{PgF}_{2 \alpha}$ comme médiateur endogène de la lutéolyse étant bien établi dans de nombreuses espèces (Olofsson et Leung 1994). $\mathrm{PgF}_{2 \alpha}$ induit l'activité $20 \alpha$-hydroxystéroïde déshydrogénase (Wiest 1968) qui métabolise la progestérone en un composé inactif, cette activité étant considérée comme un marqueur de la lutéolyse (Wiest et al 1968). Ce rôle est corroboré par la présence d'un récepteur spécifique de $\mathrm{PgF}_{2 \alpha}$ sur les membranes des cellules lutéales (Wright et al 1979). Dans les heures qui suivent sa biosynthèse ou son administration, $\mathrm{PgF}_{2 \alpha}$ induit une augmentation de la transcription des caspases 1 et 3 (vache, brebis) qui interviennent dans l'apoptose ainsi que la sécrétion d'endothéline qui inhiberait la production de progestérone par les cellules lutéales (Leymarie et Martal 2001). L'endothéline est un
Chez la vache et la brebis, l'œstradiol administré durant la phase lutéale induit la sécrétion de $\mathrm{PgF}_{2 \alpha}$ par l'utérus et donc une lutéolyse précoce. Dans l'endomètre, l'œstradiol induirait les récepteurs à l'ocytocine et la synthèse de $\mathrm{PgF}_{2 \alpha}$. L'ocytocine est normalement sécrétée par la post-hypophyse, mais aussi par le corps jaune chez la vache et la brebis, sous l'action de $\mathrm{PgF}_{2 \alpha}$ (Leymarie et Martal 2001). Chez les ruminants, l'ocytocine a aussi un rôle lutéolytique en provoquant une sécrétion de $\mathrm{PgF}_{2 \alpha}$ par l'utérus. Un double rétrocontrôle positif existerait de fait entre utérus et ovaire accélérant ainsi la régression lutéale. Chez d'autres espèces, l'ocytocine hypophysaire jouerait un rôle plus important dans la régression lutéale (Leymarie et Martal 2001).

\subsection{3 / Aspects spécifiques à l'utilisa- tion des prostaglandines en médecine vétérinaire}

En dehors de l'utilisation pour la maîtrise des cycles, $\mathrm{PgF}_{2 \alpha}$ et ses analogues peuvent être utilisés à des fins zootechniques pour interrompre des

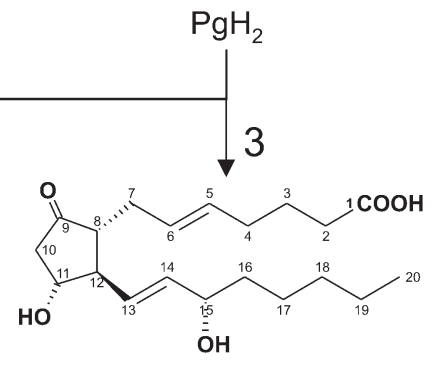

$\mathrm{PgE}_{2}$

$1:$ Cyclooxygénase

2 : Peroxydase

3 : Endoperoxyde $E$ isomérase

4 : Endoperoxyde $F$ isomérase

5: Thromboxane $A_{2}$ isomérase

6 : Inactivation par les activités 15-céto et $\Delta_{13}$-réductase

gestations non désirées à certains stades ou pour induire la parturition, notamment chez les porcins. Leur effet utérotonique est mis à profit pour favoriser l'involution utérine ou provoquer l'expulsion d'un contenu utérin pathologique, lors de métrite, de pyomètre ou de momification fœtale. Ils sont préconisés également, de par leurs effets lutéolytiques, pour traiter l'anœstrus lors de kyste lutéal ou de corps jaune persistant.

\section{3 / Les productions anima- les concernées}

\section{1 / Chez les mammifères domestiques}

\subsection{1 / La maîtrise de la reproduction}

\section{- Aspects généraux}

La maîtrise de la reproduction dans le cadre de l'élevage fait l'objet d'une évolution constante pour optimiser la productivité des troupeaux et répondre aux exigences du marché. De nombreux traitements, hormonaux ou non hormonaux, sont utilisés. Ils permettent principalement de programmer et synchroniser la période de mise bas, de diminuer les périodes improductives, d'optimiser la taille de la portée et, enfin, d'accélérer le progrès génétique. Ils sont en outre le plus souvent néces- 
saires à la pratique de l'IA, qui, en limitant les mouvements d'animaux entre élevages, est un des piliers de la politique sanitaire. Ils sont indispensables également dans la mise au point des biotechnologies appliquées à l'élevage (production d'embryons, clonage, transgenèse).

Le choix de la période de reproduction et donc de mise bas se justifie sur de nombreux points : ajustement aux disponibilités fourragères (ovins transhumants), au système d'élevage (équins et période administrative de monte) ou à la demande de la consommation (caprins laitiers). C'est aussi pour l'éleveur un moyen de simplifier le travail de gestion du troupeau (regroupement des agnelages par exemple) et de trouver le meilleur équilibre entre productivité, adaptation au marché et vie familiale. Le second avantage lié à la maîtrise de la reproduction est de limiter ou supprimer les périodes improductives. Ainsi, certaines espèces présentent au cours de l'année de longues périodes de silence sexuel ou anœstrus, qu'il est souhaitable de réduire. C'est par exemple l'anœstrus saisonnier chez les ovins et les caprins qui limite la productivité des femelles à une seule mise bas par an ou l'anœstrus post-partum chez les bovins allaitants qui allonge l'intervalle intervêlage. Enfin, avancer la puberté des femelles et des mâles accroît leur productivité totale au cours de leur vie (porcins, bovins à viande, ovins). L'optimisation de la taille de la portée chez les espèces polytoques constitue le troisième avantage de la maîtrise de la reproduction. Chez les porcins, la productivité par truie dépend du nombre de porcelets sevrés par portée. Chez les ovins à viande, l'effet est encore plus marqué du fait de la moindre fécondité de cette espèce. Enfin, la maîtrise de la reproduction se révèle indispensable au niveau de la gestion collective du patrimoine génétique, en particulier dans le cadre de l'insémination artificielle (Chemineau et al 2001).

De nombreux traitements sont disponibles pour maîtriser la reproduction des mammifères domestiques et leur indication dépend de l'espèce considérée, de l'état physiologique et du type de production.

\section{- Les ovins et les caprins}

Il existe chez les petits ruminants des variations saisonnières de l'activité sexuelle aussi bien chez les femelles (arrêt des cycles sexuels) que chez les mâles (baisse de la production sperma- tique) qui sont plus ou moins marquées selon les races. L'induction ou le maintien à contre-saison d'une activité ovarienne cyclique et d'une spermatogenèse suffisante est cependant possible par application de traitements photopériodiques basés sur l'alternance des jours courts et de jours longs ( $\mathrm{cf} \S 2.4$ ). Les jours courts peuvent être naturels (obscurité des bâtiments) ou mimés par administration de mélatonine (Malpaux et al 2001).

Chez la brebis et la chèvre, l'induction et la synchronisation hormonale des chaleurs et des ovulations associent un traitement progestagène, la progesterone ou ses analogues comme l'acétate de fluorogestone (FGA, $20 \mathrm{mg} /$ éponge vaginale dans les préparations commerciales Chrono-gest ${ }^{\circledR}$ et Synchro-part ${ }^{\circledR}$ ) ou l'acétate de médroxyprogestérone (MPA, $60 \mathrm{mg}$ /éponge vaginale) (figure 9), utilisée pour maîtriser la durée de la phase lutéale, à une injection i.m. de l'hormone gonadotrope eCG en fin de traitement pour obtenir à travers la stimulation folliculaire une synchronisation de la décharge préovulatoire et de l'ovulation des femelles traitées. Chez les femelles non cyclées, ce traitement progestagèneeCG permet l'expression d'un comportement d'œstrus accompagné d'ovulation(s) et le développement normal du ou des corps jaunes induits. Chez la chèvre, la réduction de la durée du traitement progestagène (11 vs 17 jours) a permis une amélioration significative de la fertilité à l'œstrus induit. La mise en place de ce traitement court nécessite l'injection supplémentaire d'une faible dose de $\operatorname{PgF}_{2 \alpha}$ deux jours avant le retrait de l'éponge.

La saisonnalité de l'activité sexuelle chez les ovins et les caprins a des conséquences sur le type de traitement utilisé pour maîtriser la reproduction dans ces espèces. La première conséquence est que le traitement par la seule $\mathrm{PgF}_{2 \alpha}$ (2 injections avec un intervalle de 9 à 14 jours) induisant la régression lutéale ne peut être appliqué pendant la période d'anœstrus. La seconde particularité est que les doses d'eCG injectées doivent être modulées en fonction de la saison (Chemineau et al 2001).

Chez les ovins et caprins, les traitements hormonaux sont utilisés pour la reproduction en saillie naturelle et IA. Cette dernière technique est indispensable pour le fonctionnement des schémas de sélection des races laitières. Elle permet aussi une réduction des risques sanitaires de transmission de maladies contagieuses entre les éleva- ges (brucellose, tuberculose, chlamydiose, fièvre $Q$, etc.).

La fertilité après l'œstrus induit est identique à celle obtenue après un œstrus naturel, à condition que soient respectées des règles simples concernant l'utilisation des mâles pour la saillie ou la mise en place de l'IA. Toutefois, une réponse immunitaire révélée par la présence d'anticorps anti-eCG a été mise en évidence chez certaines femelles dès le premier traitement reçu. Cette réponse immunitaire s'accentue lors des traitements suivants. Chez ces femelles ayant une réponse immuniatire forte, la diminution de la fertilité après IA à un moment déterminé qui est constatée s'accompagne d'un retard dans l'apparition de l'œstrus et du pic préovulatoire (Roy et al 1999a). Cette diminution serait corrélée à la réponse immunitaire.

En France, ce sont les éleveurs de brebis laitières (région de Roquefort, Pyrénées) qui sont les principaux utilisateurs des traitements hormonaux de contrôle de l'œstrus pour faciliter la mise en place de l'IA dans un programme d'amélioration génétique de ces races : 650000 brebis, soit $50 \%$ du cheptel laitier, sont inséminées chaque année. La fertilité est de $65 \%$ de mises bas après une seule insémination programmée après le retrait de l'éponge vaginale. En ce qui concerne les races à viande, plus des deux tiers des brebis adultes «déssaisonnées» d'avril à juillet sont mises en lutte après traitement hormonal. Sur un cheptel qui compte 5,3 millions de brebis de race à viande, $5 \%$ et $10 \%$ des femelles environ sont respectivement inséminées ou mises en monte naturelle après traitement hormonal (ANIO 2003). L'optimisation de la taille de la portée étant un paramètre important de la rentabilité de ces élevages producteurs de viande, la dose de eCG doit être fixée en tenant compte de l'état physiologique des femelles traitées pour obtenir la prolificité naturelle moyenne des troupeaux en milieu de saison sexuelle. Dans le monde, on estime à 4 ou 5 millions le nombre de brebis mises en reproduction après traitement hormonal.

Chez les caprins laitiers, l'augmentation de l'utilisation des traitements hormonaux est également importante depuis quelques années car ces traitements permettent de déplacer la date de mise bas et donc la production de lait à une période favorable à la vente du lait ou des fromages. Environ $15 \%$ $\mathrm{du}$ cheptel francais de chèvres reproductrices qui compte 1 million de têtes 
Figure 9. Principaux progestagènes utilisés pour la maîtrise des cycles.<smiles>CC(=O)C1CCC2C3CCC4=CC(=O)CC[C@]4(C)C3CCC12C</smiles>

Progestérone<smiles>CC(=O)OC12CCC3C4C[C@H](C)C5=CC(=O)CCC5(C)C4CCC3(C)C1(C(C)=O)CC2</smiles>

Acétate de médroxyprogestérone (MPA)<smiles>CC(=O)OC1CCC2C3CCC4=CC(=O)CCC4C3C(C)CC12C(C)=O</smiles>

Norgestomet<smiles>C=CCC1CCC2C3CCC4=CC(=O)CCC4=C3C=CC12O</smiles><smiles>CC(=O)OC12CC3C4C=C(C)C=CC4(C)C3CCC1(C(C)=O)C2(C)C(C)=O</smiles>

Acétate de mélengestrol (MGA)<smiles>CC(=O)OC1(C(C)=O)CCC2C3C=C(C)C4=CC(=O)CCC4(C)C3CCC21C(C)C</smiles>

Mégestrol-acétate<smiles>CC(=O)O[C@]1(C(C)=O)CCC2C3CCC4=CC(=O)CCC4[C@@]34CC[C@]21C[C@H]4O</smiles>

Acétate de fluorogestone (cronolone, flugestone-acétate, FGA)

\section{Altrenogest (allyltrenbolone, Regumate ${ }^{\circledR}$ )}

(Eurostat 2002) utilisent les traitements hormonaux, soit pour permettre l'IA programmée (80 $000 \mathrm{IA} / \mathrm{an})$ ou, à part égale, pour faciliter la monte en main sur chaleurs synchronisées.

Cependant, il faut noter qu'avec la vente de fromages sous label AOC est apparu le besoin de rechercher des traitements alternatifs pour maîtriser la reproduction sans utilisation d'hormones (cf $\S 6.2)$.

\section{- Les porcins}

En France, dans les élevages, les truies reproductrices sont conduites en bandes, ce qui nécessite une bonne maîtrise de la reproduction des cochettes et des truies. Les cochettes (truies nullipares cyclées) doivent venir en chaleur d'une manière synchrone dans la semaine du tarissement afin de les introduire dans chaque bande.

Deux solutions étaient envisageables pour synchroniser les œstrus chez les cochettes : soit induire la régression des corps jaunes par injection d'analogues de $\mathrm{PgF}_{2 \alpha}$, soit créer artificiellement une phase lutéale par administration d'un progestagène. La seconde solution a été retenue. Des résultats très satisfaisants ont été obtenus avec l'altrenogest (figure 9), le seul progestagène autorisé à la vente depuis 1982 en France en élevage porcin et commercialisé sous le nom de Régumate $^{\circledR}$. Une dose journalière de 20 mg de Régumate ${ }^{\circledR}$ par truie est administrée par voie orale pendant 18 jours. Le traitement progestatif est commencé à n'importe quel moment du cycle. A la dose prescrite, ce progestagène empêche la croissance des follicules mais n'a aucune influence sur la durée de vie des corps jaunes. A l'arrêt du traitement, une phase folliculaire commence. Les cochettes doivent être venues au moins une fois en chaleur car le Régumate ${ }^{\circledR}$ ne déclenche pas la première ovulation. Ceci est essentiel à la réussite du traitement. Environ $95 \%$ des cochettes viennent en œstrus entre le $4^{\mathrm{e}}$ et le $7^{\mathrm{e}}$ jour post-traitement avec un pic important les $5^{\mathrm{e}}$ et $6^{\mathrm{e}}$ jours. Les travaux sur l'utilisation du Régumate ${ }^{\circledR}$ n'ont montré aucune détérioration des performances de reproduction des cochettes. Au contraire, les œstrus induits par le Régumate ${ }^{\circledR}$ sont plus fertiles et aboutissent à une prolificité accrue (Martinat-Botté et al 1989). L'accroissement des tailles de portée s'expliquerait par l'augmentation du taux d'ovulation alors que la survie fœtale reste inchangée (Martinat-Botté et al 1995).

Les retards d'œstrus après le tarissement des truies perturbent la conduite en bandes et sont une des causes de réforme des animaux. Une des solutions proposées est l'emploi du progestagène Régumate $^{\circledR}$ au moment du tarissement, en particulier chez les truies primipares. Différents protocoles d'administration ont été testés chez les primipares (20 mg de Régumate ${ }^{\circledR}$ par jour et par truie). Le traitement le plus efficace commence le jour du tarissement et dure 3 jours (Forgerit et al 1995). Différents protocoles d'administration sont utilisés par les éleveurs à cette période (Boulot et al 2004). Cependant, il faut savoir que le Régumate $^{\circledR}$ est indiqué uniquement pour synchroniser les chaleurs des cochettes. Une enquête récente en France menée auprès de 200 éleveurs montre que $82 \%$ d'entre eux utilisent ce progestagène pour introduire les cochettes dans les bandes (Boulot et al 2004).

\section{- Les bovins}

\section{a) Utilisation actuelle en France}

Chez les bovins, les progestagènes et les œstrogènes sont utilisés de façon combinée pour la synchronisation des chaleurs permettant la réalisation d'IA à des moments prédéterminés. Ces traitements sont utilisés principalement dans les troupeaux de femelles allaitantes utilisant l'IA pour conduire les schémas d'amélioration génétique destinés à améliorer les qualités bouchères et les caractères fonctionnels du cheptel (qualités maternelles, fertilité, etc.). Ces traitements sont également utilisés chez les génisses de race laitière ou à viande et, dans une moindre mesure, chez les vaches laitières présentant un retard de reprise d'activité sexuelle après vêlage (vaches en anœstrus). Ces traitements sont également utilisés dans différents pays d'Europe : en Irlande, en Espagne et, de façon plus limitée, en Italie.

Le traitement consiste en l'administration par voie $i . m$. de $5 \mathrm{mg}$ de valérate d'œstradiol (VOE) associée à un implant auriculaire de progestagène (norgestomet, $17 \alpha$-acétoxy-11 $\beta$-mé- 
thyl-19-norprégn-4-ène-3,20-dione) (figure 9) ou de $10 \mathrm{mg}$ de benzoate d'œstradiol (BOE) sous forme de capsules intra-vaginales avec une spirale en silastic imprégnée de progestérone (tableau 4). L'administration des œstrogènes se fait au moment de la pose du traitement progestatif.

Ces traitements destinés à favoriser la mise à la reproduction et la naissance ultérieure d'un veau sont mis en œuvre longtemps avant l'abattage éventuel de l'animal. Il a été montré que les concentrations de progestérone ne dépassent pas celles observées naturellement au cours du cycle ou de la gestation. Les concentrations d'œstradiol sont doublées pendant 4 ou 5 jours par rapport à $3^{\mathrm{e}}$ mois de gestation.

L'utilisation de ces protocoles est limitée dans le temps : progestérone ou progestagène de synthèse administré pendant 5 à 10 jours, œstradiol administré au moment de l'apport du progestagène. Ces traitements sont employés chez des génisses ou chez des vaches entre 50 et 100 jours après vêlage, ces animaux étant supposés avoir une carrière reproductive normale.

b) Induction/synchronisation des ovulations et taux de gestation suivant l'application de traitements incluant l'œstradiol ou non

Chez les bovins, les avantages zootechniques de l'utilisation de l'œstradiol associé aux progestagènes peuvent être résumés ainsi : une proportion plus élevée de vaches en chaleurs pendant un temps donné est observée et des taux de gestation plus élevés sont constatés avec une administration d'œstradiol au moment de la pose du progestagène (tableau 4). Selon les études et le type de production, laitière ou allaitante, les différences en terme de taux de gestation peuvent varier de 5 à $30 \%$. Chez les vaches de race laitière ou allaitante, les différences sont plus importantes chez les femelles en anœstrus que chez celles ayant repris une activité ovarienne après vêlage. L'absence d'œstradiol ou d'œstrogènes se traduit par de très faibles taux de gestation - la plupart du temps proches de $30 \%$ - qui rendent ce protocole inapplicable dans les conditions de terrain. Chez les bovins en anœstrus de lactation, seuls les traitements stéroïdiens (progestagènes, œstrogènes) ont à ce jour prouvé leur efficacité.

Les effets positifs de l'œstradiol ont été montrés également lorsque le traitement progestatif était associé à une injection de $\mathrm{PgF}_{2 \alpha}$ (Chupin et al 1974). Les actions antilutéotrope et lutéolytique de l'œstradiol peuvent être aussi obtenues par une injection de $\mathrm{PgF}_{2 \alpha}$ à la fin du traitement progestatif.

L'interdiction des traitements par des œstrogènes ou la limitation de leur utilisation en élevage bovin peut favoriser le recours à d'autres molécules comme les prostaglandines ou les analogues de la GnRH.

\section{- Les équins}

La jument présente un rythme de reproduction annuel, avec une période sans ovulation comprise entre les mois d'octobre et avril. Les traitements utilisés permettent d'avancer la reprise de l'activité ovarienne au printemps et de mieux maîtriser le moment de l'ovulation quand la jument est cyclique. Ils ont pour objectif de disposer d'un plus grand nombre de cycles dans l'année, de faciliter la gestion de la reproduction et d'améliorer l'efficacité des différentes interventions liées au transport des juments et de la semence.

La reprise de l'activité ovarienne peut être obtenue par administration d'un traitement photopériodique de 14,5 heures de lumière par jour, commencé vers le 20 décembre, pendant 35 jours. La première ovulation est observée environ 2 mois après le début de la stimulation (Palmer et al 1982, Guillaume 1999).

Quand la jument est cyclée, 2 types de traitements sont disponibles (Ginther 1992) : la synchronisation des chaleurs et l'induction de l'ovulation. Pour la synchronisation des chaleurs, les progestagènes associés ou non aux œstrogènes, par leur effet de rétrocontrôle négatif sur le système hypothala-

Tableau 4. Différences d'efficacité des traitements progestatifs associés ou non à l'œstradiol au moment de la pose de l'implant de progestagène chez les bovins.

\begin{tabular}{|c|c|c|c|c|c|}
\hline $\begin{array}{c}\text { Type de production / } \\
\text { Situation } \\
\text { physiologique }\end{array}$ & Dose d'œstradiol & Références & Pays & $\begin{array}{c}\text { Différences } \\
\text { observées sur la } \\
\text { venue en œstrus }\end{array}$ & $\begin{array}{l}\text { Différences de } \\
\text { taux de gestation } \\
\text { (nombre d'IA ) }\end{array}$ \\
\hline $\begin{array}{l}\text { Système allaitant : } \\
\text { - Cyclées }\end{array}$ & $\begin{array}{c}0 \text { vs } 5 \text { mg OEV } \\
\text { (implant de norgestomet) }\end{array}$ & Non publié 2001 & $\mathrm{~F}$ & & $+5 \%{ }^{1}(2 \mathrm{Al})$ \\
\hline - Non cyclées & $\begin{array}{c}0 \text { vs } 5 \text { mg OEV } \\
\text { (implant de norgestomet) }\end{array}$ & Non publié 2001 & $\mathrm{~F}$ & & $+18 \%^{1}(2 \mathrm{Al})$ \\
\hline \multirow[t]{2}{*}{$\begin{array}{l}\text { - Cyclées / } \\
\text { Non cyclées }\end{array}$} & $\begin{array}{c}0 \text { vs } 5 \text { mg OEV } \\
\text { (implant de norgestomet) }\end{array}$ & Chupin et al 1974 & $\mathrm{~F}$ & & $+19 \%$ \\
\hline & $\begin{array}{l}\text { O vs } 0,75 \mathrm{mg} \mathrm{OEB} \mathrm{OB}^{\mathrm{C}} \\
\text { (progesterone) }\end{array}$ & $\begin{array}{l}\text { Sprott et al } 1984 \\
\text { Smith et al } 1980\end{array}$ & $\begin{array}{l}\text { USA } \\
\text { Aus }^{3}\end{array}$ & $\begin{array}{c}+39 \% \\
-\end{array}$ & $+13 \%$ \\
\hline \multirow[t]{2}{*}{$\begin{array}{l}\text { Système laitier: } \\
\text { - Cyclées }\end{array}$} & $\begin{array}{l}0 \text { vs } 10 \mathrm{mg} \text { OEB } \\
\text { (progesterone) }\end{array}$ & Roche 1977 & $|r|^{3}$ & & $\begin{array}{l}+21,8 \%(1 \mathrm{Al}) \\
+8,7 \%(2 \mathrm{Als})\end{array}$ \\
\hline & $\begin{array}{l}0 \text { vs } 5 \mathrm{mg} \text { OEV } \\
\text { (implant de norgestomet) }\end{array}$ & Non publié 2001 & $\mathrm{Hu}^{3}$ & & $+17 \%^{2}(1 \mathrm{Al})$ \\
\hline - Non cyclées & $\begin{array}{l}0 \text { vs } 5 \mathrm{mg} \text { OEV } \\
\text { (implant de norgestomet) }\end{array}$ & Non publié 2001 & $\mathrm{Hu}^{3}$ & & $+30 \%^{2}(1 \mathrm{Al})$ \\
\hline
\end{tabular}

a IA : insémination artificielle. b OEV : valérate d'œstradiol. c OEB : benzoate d'œstradiol.

1 Deux IA 48-72 heures après retrait du progestagène.

2 Une IA 56 heures après retrait du progestagène.

3 Aus : Australie, Irl : Irlande, Hu : Hongrie. 
mo-hypophysaire, inhibent la croissance folliculaire et bloquent l'ovulation. Ils sont administrés par voie orale (altrenogest) pendant 10 jours ou à l'aide de dispositifs intravaginaux $\left(\mathrm{PRID}^{\circledR}\right)$ pendant environ 12 jours. Les chaleurs apparaissent en moyenne 3 à 5 jours après l'arrêt du traitement mais l'ovulation n'est pas synchronisée. L'administration par injection intramusculaire de $\mathrm{PgF}_{2} \alpha$ permet d'autre part de provoquer la lyse du corps jaune de plus de 5 jours. La synchronisation des chaleurs est obtenue par deux administrations de $\mathrm{PgF}_{2 \alpha}$ séparées de 14 jours associées à une injection d'hCG, 6 jours plus tard. L'association des deux types de traitement en renforce l'efficacité. Il n'existe pas de données statistiques nationales sur l'utilisation de ces produits, les cycles des juments pouvant être suivis par des vétérinaires travaillant en collaboration avec les Haras Nationaux ou en clientèle privée. A titre d'exemple, les Haras Nationaux ont conduit en 2003 sur 9 circonscriptions une campagne de synchronisation des chaleurs avec le Regumate $^{\circledR}$ (altrenogest). 840 juments en ont bénéficié. La fertilité de fin de saison était de $78 \%$ avec une moyenne de 1,59 cycles utilisés par jument (Margat et Martin 2003).

L'induction pharmacologique de l'ovulation est obtenue par l'injection de hCG, hormone à activité LH, ou par l'administration d'un analogue de la GnRH (Briant 1999, Ginther 1992). L'administration des hormones gonadotropes se fait par injection unique intraveineuse, lorsque le follicule dominant atteint la taille préovulatoire (30 à $40 \mathrm{~mm}$ ). L'ovulation est observée entre 24 et 48 heures après injection chez 75 à $85 \%$ des juments. Associée au suivi ovarien par échographie transrectale, cette technique permet une programmation rationnelle des inséminations. En France, seule l'hCG (Chorulon ${ }^{\circledR}, 1500$ UI) est commercialisée. Cependant, son administration répétée sur un même animal entraîne la formation d'anticorps, associée à une baisse d'efficacité. L'administration de peptides de synthèse analogues de la GnRH peut s'effectuer sous différentes formes pharmaceutiques. Seule la buséréline (Réceptal ${ }^{\circledR}$ ) est autorisée en France chez les équins. Le protocole d'administration consiste en plusieurs injections espacées de 12 heures, à partir du moment où le follicule dominant atteint la taille préovulatoire. Quatre injections intraveineuses de $20 \mathrm{mg}$ permettent d'obtenir un taux d'ovulation de $83 \%$ dans les 40 heures. Le deslorelin (Ovuplant ${ }^{\circledR}$ ) est commercialisé dans d'autres pays (Australie, USA). C'est un implant sous-cutané, à libération de courte durée, qui est administré quand le follicule dominant atteint $35 \mathrm{~mm}$ de diamètre. Son efficacité permet d'obtenir $90 \%$ d'ovulations dans les 48 heures. Cependant, du fait d'une libération trop prolongée, il induit une interruption de cyclicité d'une durée variable mais souvent prolongée pendant plusieurs mois.

$\mathrm{Au}$ plan expérimental, des études sont actuellement en cours pour la programmation de l'ovulation à l'aide d'antagonistes de GnRH, associés ou non à hCG (Briant et al 2003).

\subsection{2 / La production d'embryons}

La production et le transfert d'embryons ne peuvent se réaliser sans une maîtrise efficace de la stimulation ovarienne et de la fécondation des espèces concernées. Cette technique appartient à l'ensemble des techniques de reproduction utilisées en élevage dans le cadre de l'amélioration génétique des cheptels. Elle permet une diffusion plus rapide des gènes des reproducteurs et garantit une protection sanitaire élevée. Son coût se raisonne dans un contexte économique concurrentiel où la plusvalue obtenue par la production de géniteurs est importante : $95 \%$ des taureaux laitiers mis en testage proviennent d'embryons transplantés (Chemineau et al 2001).

\section{- Bovins}

La superovulation est obtenue chez les bovins après un traitement hormonal à base d'hormones gonadotropes (FSH porcine ou ovine ou eCG) et représente la première étape de la technique de production d'embryons in vivo. Elle est suivie de l'insémination des femelles donneuses, de la collecte des embryons 6 à 8 jours après insémination et de leur transplantation chez des femelles receveuses (Nibart 1991). En 20 ans d'utilisation, un gain d'environ 2 embryons viables par collecte a été observé, avec un nombre moyen de 5,5 embryons viables par collecte observé ces dernières années. Cette forte augmentation de la réponse à la superovulation a été en partie obtenue grâce à l'utilisation de la pFSH en remplacement de l'eCG (Nibart et Humblot 1997, Ponsart et al 2004). En France, environ 6000 donneuses sont collectées chaque année et 30000 embryons sont transplantés (source IETS 2004). Dans l'hexagone, une seule spécialité à base d'extraits hypophysaires (Stimufol ${ }^{\circledR}$, Mérial) est commercialisée. Dans d'au- tres pays, d'autres spécialités à base d'extraits hypophysaires existent. Ces dernières années, quelques pays dont l'Allemagne ont restreint l'utilisation de $\mathrm{FSH}$, entraînant un recul d'activité important faute de traitement alternatif aussi efficace.

Le nombre d'ovulations obtenu après superovulation dépend à la fois du nombre de follicules stimulés susceptibles d'ovuler et du taux d'ovulation. Ces deux composantes sont très variables, dépendant à la fois de facteurs génétiques, zootechniques, physiologiques (liés à la donneuse) et des modalités de la superovulation (Ponsart et al 2002). La présence d'un follicule dominant au début du traitement de superovulation diminue le nombre de follicules stimulés et par conséquent le nombre d'embryons collectés et viables (Guilbaut et al 1991, Bungartz et Niemann 1994). L'ablation des gros follicules 2 jours avant la première injection de FSH est une méthode permettant en général de gagner entre 0,5 et 1 embryon viable, mais son utilisation en ferme est limitée par son coût de réalisation. Des traitements hormonaux alternatifs ayant pour but d'entrâ̂ner l'atrésie ou l'ovulation du follicule dominant ont été testés : des injections d'œstradiol et de progestérone réalisées à la pose d'un progestagène (Bo et al 1995a) entraînent l'émergence d'une nouvelle vague folliculaire 3-4 jours après injection, mais ne sont pas utilisables en France. Des injections de LH ou d'analogue de GnRH, 2 jours avant superovulation donnent des résultats variables (Kohram et al 1998, Baracaldo et al 2000, Deyo et al 2001).

L'amélioration du taux d'ovulation pourrait être obtenue par un meilleur contrôle du déclenchement du pic préovulatoire de LH. Un traitement constitué d'un traitement progestatif, mis en place 2 jours avant la première injection de FSH et laissé pendant 5 jours, permettrait de mieux synchroniser le pic de LH (Govignon et al 2000, Ménard et al 2000, Lafri et al 2002). D'autres traitements utilisant soit une administration d'un progestagène suivi d'une injection de GnRH (Van de Leemput 1999) soit un agoniste de la GnRH (Deslorelin ${ }^{\circledR}$ ) associé à une injection de LH (D'occhio et al 1999, Lindsey et al 2002) sont les principales pistes de recherche visant à mieux contrôler le pic de LH.

\section{- Ovins et caprins}

Comme chez les bovins, le traitement de superovulation chez les ovins et caprins est mis en place directement à 
la fin du traitement progestatif. Il comprend plusieurs injections de $\mathrm{pFSH}$ réparties sur trois jours et administrées en doses décroissantes.

L'ajout de pLH en concentrations constantes au cours du traitement ou en concentrations croissantes lors des deux dernières injections de $\mathrm{pFSH}$ (rapport FSH/LH égal 0,3-0,4) contribue à améliorer l'efficacité des traitements (Baril et al 1993, 1996b). La variabilité de la réponse ovarienne reste considérable. Elle est expliquée en partie par des différences dans le nombre et la taille des follicules présents sur l'ovaire au moment du traitement, la présence d'un ou de deux gros follicules dominants étant très préjudiciable. Pour s'affranchir de cette difficulté, une première stratégie consiste à administrer de la GnRH (BusérélineReceptal $^{N D}$ - Intervet, Cystorelin ND CEVA) en injection unique afin d'induire de façon synchrone un pic de sécrétion des gonadotropines endogènes. Cette méthode donne des résultats très variables selon qu'un follicule dominant est présent ou non au moment de l'injection, tant chez les ovins que chez les caprins (Walker et al 1989). Elle reste cependant la seule méthode possible utilisée pour la production de zygotes maturés in vivo dans le cadre de la transgenèse ou du clonage.

La stratégie visant à éliminer les gros follicules inhibiteurs par un traitement long de la GnRH ou d'antagoniste de la GnRH afin de ne stimuler au moment du traitement par la FSH que les petits follicules donne de bons résultats chez les ovins. Elle permet d'accroître le nombre de petits follicules en inhibant les sécrétions endogènes de $\mathrm{LH}$ et de FSH par l'injection d'un agoniste de la GnRH $(40 \mu \mathrm{g} / \mathrm{j})$ pendant 2 semaines ou par un antagoniste (Antarélix$0,5 \mathrm{mg} / \mathrm{j}$; Teverelix ND, Europeptides) pendant 10 jours avant le début de la stimulation par FSH. Cette méthode, associée au traitement progestatif, permet de doubler le nombre de petits follicules, de diminuer le taux d'atrésie folliculaire et d'augmenter de $50 \%$ le nombre d'embryons transférables chez la brebis (Brebion et al 1992, Cognié 1999, Cognié et al 2003). A l'inverse, chez les caprins (Cognié et al 2003), comme d'ailleurs chez les bovins, ce traitement entraîne une détérioration de la qualité de la fécondation qui se traduit par une augmentation du nombre d'ovocytes non fécondés et du nombre d'embryons dégénérés.

\subsection{3 / La croissance et l'engraisse- ment}

\section{- Les porcins}

a) L'hormone de croissance

L'utilisation de la GH à des fins zootechniques est interdite au sein de l'UE. Il existe néanmoins une forme commerciale de GH porcine recombinante (rpGH ou rpST) nommée Reporcin ${ }^{\circledR}$. L'utilisation de cette molécule a été autorisée dès 1993 en Australie. Depuis, elle est commercialisée dans quelques pays d'Asie, d'Amérique Centrale ou d'Amérique du Sud. Chez le porc, la plupart des données disponibles sur les effets de la GH proviennent d'études où des injections journalières de rpGH sont effectuées par voie intramusculaire, les données relatives à l'utilisation d'implants assurant un relargage continu et prolongé de $\mathrm{pGH}$ étant peu nombreuses. Il n'existe toujours pas à ce jour de système d'implant adapté au porc. Les effets bénéfiques d'une administration de $\mathrm{pGH}$ pendant la période de finition (de 50-60 à 90-110 kg) sur les performances de croissance et la composition corporelle de porcs nourris à volonté avec un aliment adapté, notamment en ce qui concerne les teneurs en protéines et en lysine, sont clairement démontrés (Bonneau 1992, Louveau et Bonneau 2001). En dépit d'une diminution de l'ingéré alimentaire (2-22\%), une accélération de la croissance (jusqu'à $47 \%$ ) et une amélioration de l'efficacité alimentaire (3-38\%) sont observées chez les porcs traités par la pGH. L'adiposité des carcasses est fortement réduite : de 7 à $44 \%$, avec une augmentation concomitante de la proportion de muscle (de 2 à $23 \%$ ). De façon plus générale, la pGH favorise le déve- loppement de tous les tissus riches en protéines (muscle, peau et os) au détriment du tissu adipeux. En liaison avec le développement accru de certains organes (foie, cœur, rein), le rendement à l'abattage chute de 1 à $4 \%$ après administration de pGH. L'amplitude des effets de la pGH varie avec la dose de pGH administrée (figure 10). Les valeurs mesurées correspondant à l'ingéré alimentaire et au dépôt de gras décroissent presque linéairement avec la dose. Par contre, l'augmentation du gain de poids et la diminution de l'indice de consommation en réponse à la $\mathrm{GH}$ ne sont pas linéaires. La réponse maximale est atteinte pour une dose de $100 \mu \mathrm{g} / \mathrm{kg} /$ jour. Il faut noter que l'administration de $\mathrm{GH}$ à doses élevées entraîne des problèmes sanitaires, en particulier le développement d'ulcères gastro-œsophagiens. Les effets de la pGH varient également avec le génotype, même si des effets favorables sur les performances de croissance sont décrits dans tous les génotypes de porc étudiés jusqu'à présent. L'amélioration des performances est particulièrement spectaculaire chez les porcs de race Meishan, animaux gras à croissance lente, aussi bien en race pure qu'en croisement avec des races conventionnelles. Dans les races très musclées, comme le Piétrain ou le Landrace Belge, le gras sous-cutané disparaît presque, alors que le pourcentage de muscle de la carcasse n'est que légèrement amélioré. En règle générale, on peut considérer que l'amélioration relative des performances apportée par le traitement par la pGH est d'autant plus importante que le potentiel de croissance musculaire de l'animal est plus faible. Le type sexuel influence également la réponse à la $\mathrm{GH}$. Les effets d'une forte dose de $\mathrm{pGH}(100 \mu \mathrm{g} / \mathrm{kg} / \mathrm{jour})$

Figure 10. Influence de la dose de $\mathrm{GH}$ administrée $(\mu \mathrm{g} / \mathrm{kg} / \mathrm{jour})$ sur la consommation alimentaire quotidienne (C), le gain de poids quotidien (GMQ), l'indice de consommation (IC) et l'épaisseur de lard dorsal (ELD) (Louveau et Bonneau 2001).

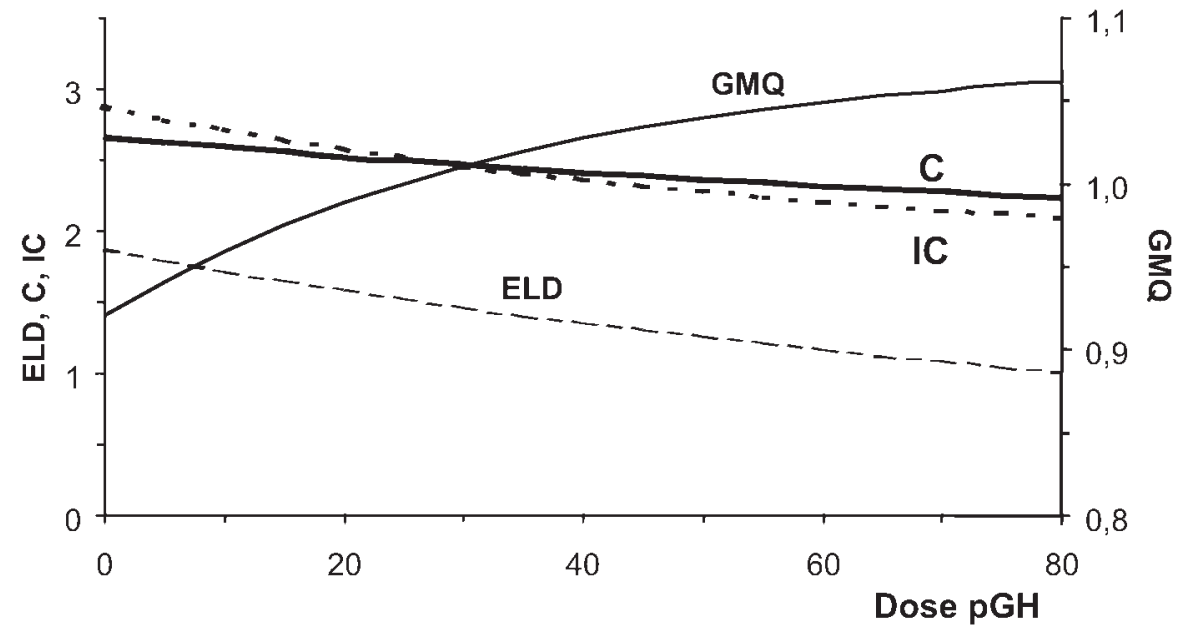


sont plus prononcés chez les mâles castrés que chez les femelles et chez les femelles que chez les mâles entiers, si bien que les différences de performances entre types sexuels sont quasiment gommées chez les porcs traités par la pGH.

La période de finition au cours de laquelle la croissance musculaire atteint sa valeur maximale, alors que le développement du tissu adipeux s'accélère, est en général considérée comme la période la plus favorable à la manifestation des effets de la pGH chez le porc, même si les effets de la pGH administrée à d'autres périodes de la vie de l'animal sont aussi détectés. Un traitement pendant la période de croissance entre $25-30$ et 50-60 kg a des effets similaires à ceux observés chez des porcs plus lourds. Les effets de la pGH s'observent aussi chez des animaux traités au-delà de $100 \mathrm{~kg}$ de poids vif. L'amélioration des performances est similaire, voire plus forte que celle observée chez des porcs traités au cours de la période de finition. A l'inverse, les effets d'une administration de $\mathrm{GH}$ chez le porcelet allaité sont beaucoup moins marqués. L'utilisation d'une dose élevée de GH est nécessaire pour observer une réponse. L'administration de $\mathrm{GH}$ à une dose de $1 \mathrm{mg} / \mathrm{kg} /$ jour durant la période d'allaitement a pour conséquence de réduire l'adiposité de la carcasse à $100 \mathrm{~kg}$ de poids vif (Dunshea et al 2003).

\section{b) Stéroïdes}

La possibilité d'utiliser l'association trenbolone-œstradiol comme anabolisants stéroïdiens en élevage porc a été démontrée dès les années 70 (Grandadam et al 1975), en particulier pour améliorer l'indice de consommation, la vitesse de croissance et réduire le dépôt de gras des mâles castrés en engraissement. Cependant, ces résultats ne sont pas clairement confirmés chez des mâles entiers ou des femelles recevant la même préparation hormonale ou ayant été traités avec une préparation équivalente ou associant progestérone et œstradiol (De Wilde et Lauwers 1984) ou plus récemment chez mâles castrés implantés avec l'association acétate de trenboloneœstradiol (Lee et al 2002). Ces auteurs ont noté une diminution des quantités d'aliments ingérés même si une diminution de l'indice de consommation trahissait un effet anabolisant patent. Ces résultats mitigés expliquent que l'utilisation d'implants de stéroïdes en élevage porc ne soit pas amenée à se développer.

\section{c) $\beta$-agonistes}

Chez le porc, administré dans l'aliment à la dose de 5-20 ppm, la ractopamine améliore l'efficacité alimentaire et le gain de poids tout en abaissant la proportion de tissu adipeux dans la carcasse (Watkins et al 1990, Crome et al 1996, FOIS 1999).

\section{- Les bovins}

\section{a) Stéroïdes}

- Progestagènes, androgènes, corticostéroïdes, associations androgèneostrogène, androgène-progestérone

Les effets zootechniques revendiqués lors de l'utilisation des anabolisants stéroïdiens portent essentiellement sur l'augmentation de la vitesse de croissance, sur les modifications de la composition corporelle (répartition muscleos-gras dans la carcasse, répartition protéines-lipides-eau dans le tissu musculaire) et sur la rétention azotée (Schmidely 1993). De nombreux facteurs animaux (âge, sexe, etc.) ou d'élevage (nature de l'alimentation, type et dose d'hormones, fréquence des traitements) déterminent la variation de réponse à ces traitements (Schmidely 1993).

\section{- Effets sur la vitesse de croissance}

L'accroissement du gain moyen quotidien (GMQ) des animaux traités par les anabolisants stéroïdiens (tableau 1) comparativement aux animaux non traités est compris en moyenne entre 15 et $20 \%$ chez les bovins et les ovins avec une forte dispersion de ces réponses puisque l'écart-type obtenu était de $10 \%$ (soit $60 \%$ de variation résiduelle). Chez les bovins mâles non castrés, les préparations à base d'œstrogènes sont moins efficaces que les associations œstrogènes/androgènes pour accroître le GMQ (+ $4 \% v s+17 \%)$. Chez les femelles bovines non castrées, les associations œstrogènes/androgènes et les androgènes seuls conduisent à des améliorations du GMQ similaires $(+18 \%$ et $+15 \%$, respectivement $)$ et supérieures à l'utilisation des œstrogènes seuls $(+4 \%)$. Chez le bovin mâle castré qui a été l'animal le plus étudié, la hiérarchie d'accroissement des performances s'établit ainsi : œstrogènes $(+12 \%)<$ œstrogènes/progestagènes $(+16 \%)<$ androgènes $(+20 \%)$ $<$ androgènes/œstrogènes ( $30 \%$ ). Chez les ovins castrés, la hiérarchie est équivalente à celle observée chez les bovins castrés. Un des principaux facteurs déterminant l'amplitude de réponse était le niveau de performance initial. Ainsi sur des bovins castrés trai- tés par des associations œstrogènes/androgènes, le GMQ supplémentaire moyen est de $+0,22 \mathrm{~kg} / \mathrm{j}$, avec un gain maximal de $+0,3 \mathrm{~kg} / \mathrm{j}$ pour un niveau initial de GMQ de $1 \mathrm{~kg} / \mathrm{j}$, cet effet s'annulant pour des croissances initiales supérieures à $1,8 \mathrm{~kg} / \mathrm{j}$. Cette amplitude de réponse est également largement déterminée par le niveau d'alimentation des animaux et par la teneur en protéines de la ration pour soutenir le surcroît de croissance ; en pratique des teneurs en protéines jusqu'à $18 \%$ de la matière sèche permettent d'obtenir les réponses les plus fortes. Par ailleurs, il apparaît difficile de montrer si, au sein des associations utilisées, la nature des œstrogènes ou des androgènes utilisés conditionnait l'ampleur de la réponse du GMQ.

\section{- Effets sur la rétention azotée}

L'accroissement de la rétention azotée est significativement plus important chez les bovins castrés traités par les anabolisants stéroïdiens $(+25 \mathrm{~g} \mathrm{~N} / \mathrm{j})$ que chez des bovins mâles entiers $(+15 \mathrm{~g} \mathrm{~N} / \mathrm{j})$. Dans la majorité des cas, elle correspond à une réduction du catabolisme protéique, en particulier chez les animaux pour lesquels l'androgène est 1'acétate de trenbolone (Meyer 2001). La réponse optimale pour la rétention azotée se situe chez les deux sexes entre 4 et 6 semaines après la pose de l'implant, les réponses se réduisant ultérieurement du fait de la diminution des concentrations des hormones dans la circulation sanguine.

- Effets sur la composition corporelle et la composition chimique de la viande

Généralement, l'effet des anabolisants sur le rendement en carcasse est peu prononcé en dépit de l'alourdissement du poids vif, du fait de l'accroissement simultané des autres compartiments corporels (viscères, etc.). Par contre, la conformation musculaire et le pourcentage de muscle dans les carcasses sont légèrement accrus, surtout par les associations œstrogènes/androgènes, mais les effets quantitatifs restent faibles. L'état d'engraissement est généralement réduit par toutes les préparations chez les bovins castrés, alors que chez les mâles entiers, les œstrogènes utilisés seuls accroissent l'adiposité. Les associations œstrogènes/androgènes et, dans une moindre mesure, les androgènes seuls tendent à réduire la teneur en lipides des carcasses des animaux castrés en faveur d'un accroissement de la teneur en protéines et en eau. Les œstrogènes utilisés seuls tendent au contraire à accroître la teneur en lipides des carcasses et de la viande, 
particulièrement chez le mâle entier. Cette diversité de réponse pour la composition chimique apparaît essentiellement liée à la nature des interactions entre le type de muscle, le sexe de l'animal traité et la nature de la préparation hormonale et la dose administrée.

\section{b) $\beta$-agonistes}

La voie d'administration habituelle des $\beta$-agonistes utilisés en élevage est la voie orale, en mélange avec 1'aliment. Le principe actif est distribué au cours des dernières semaines qui précèdent l'abattage. Aucune molécule ne dispose d'une autorisation de mise sur le marché pour l'UE en tant qu'agent de répartition. Lorsque le clenbutérol ou des analogues structuraux sont utilisés, illégalement, on suppose qu'une courte période sans traitement est observée au cours des derniers jours de vie de l'animal, pour permettre l'élimination de la majeure partie des résidus de $\beta$-agoniste présents dans les tissus. Les données scientifiques publiées à ce sujet indiquent que les effets obtenus sont principalement une amélioration de l'efficacité alimentaire (de 10 à $25 \%$ ), une augmentation du poids relatif de la carcasse et celle du rendement en viande (accrétion protéique, avec, simultanément, diminution des dépôts lipidiques) (Hanrahan 1987, Montrade et al 1994). Leur intensité est différente selon les espèces : ils sont prononcés chez les ruminants, faibles chez les volailles et intermédiaires chez le porc (Ricks et al 1984, Schiavetta et al 1990, Mersmann 1998). Les doses nécessaires pour obtenir ces effets zootechniques correspondent environ à dix fois la dose indiquée en thérapeutique vétérinaire, soit pour le clenbutérol 5 à $10 \mu \mathrm{g} / \mathrm{kg}$ deux fois par jour (Meyer 1991). Chez des bovins traités à ces doses, le taux de lipides présents dans la carcasse peut diminuer de plus de $20 \%$ et la masse musculaire augmenter de $10 \%$ (Hanrahan 1987). Selon l'espèce et l'âge des animaux traités, les $\beta$-agonistes réorientent l'utilisation des nutriments en faveur d'une accumulation protéique de +6 à $+30 \%$, au détriment du dépôt adipeux pour lequel on observe une réduction pouvant aller jusqu'à $30 \%$ (Montrade et al 1994). Hors UE, seules deux molécules disposent d'une autorisation de mise sur le marché. Chez le bœuf, le zilpatérol produirait l'ensemble des effets décrits cidessus, bien que peu de résultats aient été rendus publics à ce jour (Plascencia et al 1999, Birkelo 2003, Shelver et Smith 2004). Davantage de données sont disponibles pour la ractopamine.
Chez les bovins, les effets zootechniques de l'utilisation de la ractopamine sont comparables à ceux décrits pour le porc (FOIS 2003).

\subsection{4 / La production laitière}

Les recherches sur les effets galactopoḯtiques de la GH chez la vache laitière se sont très fortement intensifiées au cours des années 80, du fait de la production semi-industrielle de $\mathrm{rbGH}$, puis de la mise au point de formes à action prolongée (rbGH retard) qui ont permis et suscité de très nombreuses études de longue durée et sur de grands effectifs de vaches, en fermes expérimentales ou commerciales (Bauman et al 1985, Chilliard 1988).

Les effets zootechniques spectaculaires de la $\mathrm{GH}$ sont maintenant décrits avec suffisamment de précision (Chilliard et al 1998b). Son utilisation est efficace et sans problèmes majeurs si elle se réalise sur des animaux sains et indemnes d'infections latentes, correctement alimentés, ne recevant pas de traitements médicamenteux, et si le traitement débute après la fécondation. Le traitement des vaches primipares demande une attention particulière sur les plans nutritionnels et de la reproduction.

La plupart des questions techniques concernant l'utilisation de la rbGH en production laitière ont reçu une réponse favorable, que ce soit pour l'efficacité productive, la qualité technologique des produits laitiers ou la sécurité alimentaire pour le consommateur. Toutefois, deux points demandent encore des vérifications : l'effet éventuel de la GH sur la vitesse d'élimination des xénobiotiques par le foie, et ses effets éventuels sur le réveil d'infections latentes par des virus ou autres agents infectieux pathogènes (Chilliard et al 2001). Le risque technique est apparu suffisamment faible aux autorités américaines pour autoriser dès 1993 l'utilisation commerciale de la rbGH aux USA. Un suivi sanitaire systématique des vaches traitées et de leur lait serait cependant nécessaire et pourrait être exigé par les consommateurs, ainsi que la traçabilité du lait produit à moindre coût avec l'aide de rbGH. Toutefois, il n'existe pas à l'heure actuelle de moyens techniques pour contrôler cette traçabilité.

Cette autorisation n'a pas été accordée dans l'UE pour plusieurs raisons socio-économiques puisque dans un système avec quotas laitiers la rentabilité de l'utilisation de la rbGH est limitée, et que son utilisation dans un contexte de libre production conduirait, comme d'autres technologies nouvelles, à accélérer la disparition d'une partie des éleveurs, favorisant ainsi la désertification de certaines zones rurales. De plus, une dégradation de l'image positive des produits laitiers dans l'esprit des consommateurs, dans un contexte général d'inquiétude devant «l'artificialisation» de l'agriculture, pourrait renforcer les problèmes de l'ensemble de la filière laitière. Il faut toutefois être conscient qu'en cas de libéralisation complète des échanges mondiaux les pays utilisant le traitement hormonal pour produire du lait à moindre coût bénéfieraient d'un avantage significatif dans leur compétition avec les producteurs européens.

- Effets sur les performances laitières

\section{a) Production et composition du lait}

Avec des injections journalières de doses croissantes de $\mathrm{rbGH}$, la réponse varie de $+2,8$ à $+5,6 \mathrm{~kg}$ de lait $/ \mathrm{j}$ (figure 11). L'injection de la forme retard de rbGH tous les 14 ou 28 jours donne des résultats inférieurs. La variabilité des réponses entre troupeaux ou essais (comprises entre +1 et $+8 \mathrm{~kg} / \mathrm{j}$ ) est très élevée. La réponse très rapide de la production laitière $(+4,5 \mathrm{~kg} / \mathrm{j}) \mathrm{s}$ 'amenuise au cours de la période de traitement pour atteindre $+2,5 \mathrm{~kg} / \mathrm{j}$ après 30 semaines de traitement. Au total, la production laitière annuelle est accrue de 10 à $30 \%$, et ceci a pu être observé lors de traitements de vaches pendant plusieurs lactations successives (jusqu'à 8 lactations).

La composition du lait ne varie pas en moyenne sur de longues périodes. Toutefois, outre les variations observées en début de traitement, on observe des fluctuations plus ou moins importantes durant l'intervalle de temps séparant deux injections de rbGH retard. En effet, dans le cas d'injections mensuelles, on assiste à des réponses cycliques de la production et la composition du lait, avec généralement un maximum de production laitière et de taux butyreux entre 5 et 10 jours après chaque injection, alors que le taux protéique est minimal dès le lendemain et pendant une semaine environ, puis augmente au cours de la semaine suivante. L'accroissement du taux butyreux s'accompagne d'un enrichissement de la matière grasse du lait en acides gras à longue chaîne provenant de la mobilisation des lipides corporels. La diminution du taux protéique pourrait être liée à l'effet d'épargne azotée de la GH sur 
Figure 11. Effets à long terme de la dose et de la nature de l'hormone de croissance bovine recombinante (rbGH) sur la production laitière des vaches (Chilliard et al 1998b).

\section{Réponse de la production laitière} (rbGH-témoin, $\mathrm{kg} / \mathrm{j}$ )

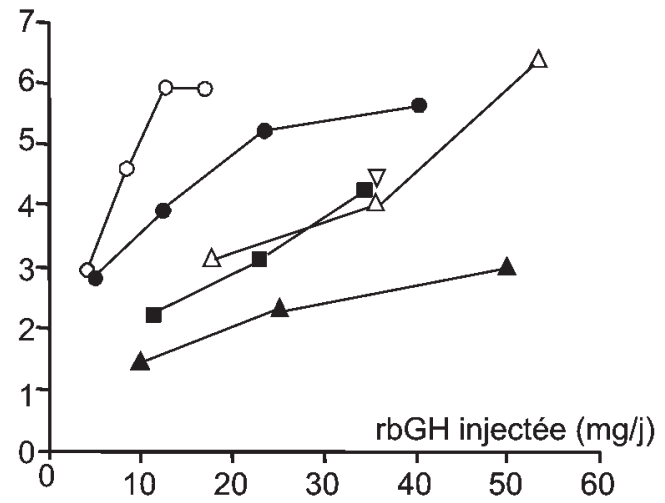

- Injections quotidiennes de rbGH, 969 vaches

- Injections quotidiennes de Somavubove, 598 vaches

$\nabla \quad$ Injections tous les $14 \mathrm{j}$ de Sometribove, 881 vaches

$\triangle$ Injections tous les $14 \mathrm{j}$ de Sometribove, 241 vaches

$\Delta$ Injections tous les $14 \mathrm{j}$ de rbGH-retard, 229 vaches

- Injections tous les $28 \mathrm{j}$ de Somidobrove, 468 vaches

les protéines corporelles et l'oxydation des acides aminés, ce qui serait compatible avec l'augmentation du taux protéique en fin de cycle, lorsque la production laitière diminue rapidement.

b) Ingestion de la ration et bilan énergétique des animaux

L'ingestion augmente significativement après un délai de 6 à 8 semaines. L'augmentation est d'environ $+1,5 \mathrm{~kg}$ $\mathrm{MS} / \mathrm{j}$ dans les essais qui durent 32 semaines, et seulement d'environ $+0,8 \mathrm{~kg} \mathrm{MS} / \mathrm{j}$ dans les essais qui ne durent que 18 semaines, en raison du poids plus important des $6-8$ premières semaines dans la réponse moyenne.

Il résulte de ces évolutions respectives de la production laitière et de l'ingestion de matière sèche que les vaches traitées sont tout d'abord en bilan énergétique plus faible que les vaches témoins (figure 12), comme si une mini-lactation démarrait en superposant ses effets à ceux de la lactation en cours. Le bilan peut toutefois redevenir supérieur lorsque les vaches disposent d'une ration très ingestible de haute valeur nutritionnelle (bons fourrages et proportion élevée de concentrés). Ces calculs sont confirmés, sur l'ensemble des résultats disponibles, par les évolutions de composition corporelle, de poids vif, de notes d'état corporel et de métabolites sanguins. Il faut toutefois souligner que lorsque la ration a une teneur plus faible en énergie, ou lorsque les traitements durent moins de
32 semaines, les vaches traitées sont en moins bon état corporel à la fin de l'expérience, et devront recevoir ultérieurement un supplément d'énergie pour arriver au vêlage suivant dans un état d'engraissement comparable.

Les études effectuées en chambres respiratoires et les essais zootechniques montrent que la $\mathrm{GH}$ ne modifie ni le besoin d'entretien ni l'efficacité d'utilisation digestive et métabolique de l'énergie ingérée lorsque les vaches sont maintenues à poids vif et état corporel constants. Le besoin énergétique total augmente donc normalement avec le supplément de lait produit, et il peut être prédit par les normes habituelles des systèmes d'alimentation.

c) Facteurs de variation des réponses

Des comparaisons indirectes effectuées sur un grand nombre d'essais suggèrent que les réponses sont supérieures (environ $+5 \mathrm{~kg} / \mathrm{j}$ ) avec des rations complètes à base d'ensilage de maïs et riches en concentrés, qu'avec des rations à base d'ensilage d'herbe ou d'herbe pâturée et/ou avec une distribution séparée de concentrés en quantité limitée $(+2,5$ à $+3,5 \mathrm{~kg} / \mathrm{j})$.

Une réponse inférieure de 10 à $45 \%$ est observée chez les primipares par rapport aux multipares (tableau 5). Les primipares, quand elles répondent bien en production laitière, sont particulièrement sensibles à l'effet négatif de la GH sur l'état corporel, probablement
Figure 12. Effets de la rbGH retard (500 mg tous les 14 jours) sur la production laitière, la consommation alimentaire et le bilan énergétique de vaches recevant une ration complète à volonté (Phipps 1988).
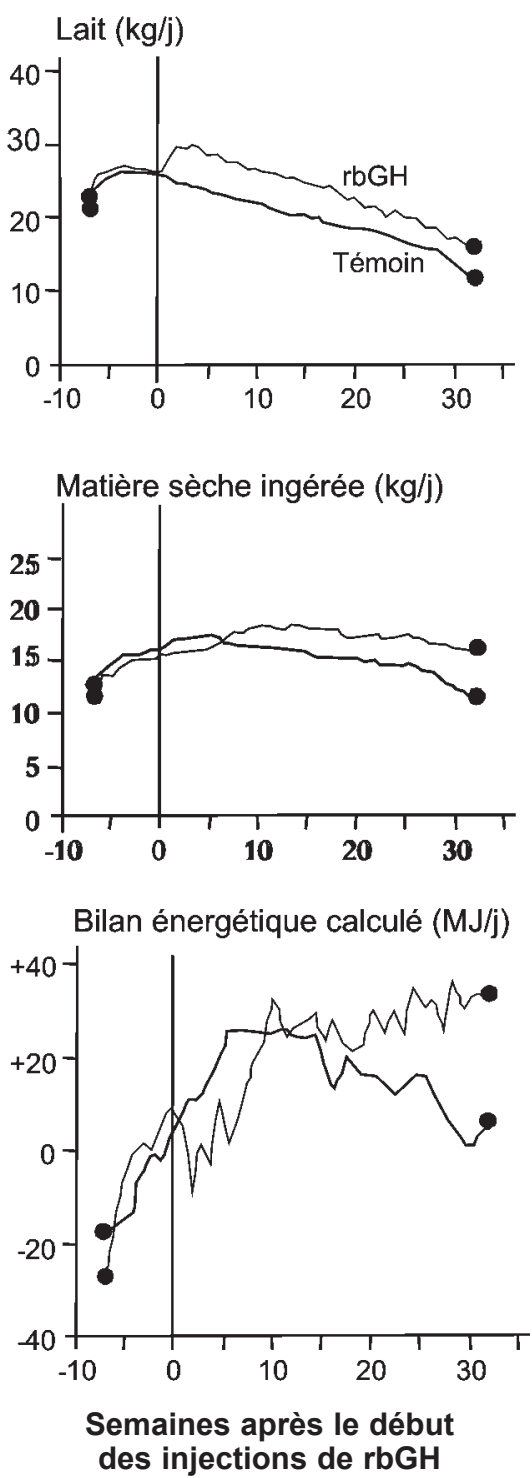

parce qu'elles ont simultanément une faible capacité d'ingestion, une bonne persistance de la production laitière et un dépôt protéique musculaire prioritaire et consommateur d'énergie.

Par ailleurs, les réponses sont plus élevées lorsque le traitement a lieu entre les $3-4^{\mathrm{e}}$ et $5-7^{\mathrm{e}}$ mois de lactation (tableau 5). Ceci est probablement lié à la fragilité de l'équilibre nutritionnel des vaches avant le $3^{\mathrm{e}}$ mois et à la réduction du potentiel sécrétoire (nombre et activité des cellules mammaires, hormones de la gestation) après le $5^{\mathrm{e}}$ mois de lactation.

Les différentes races laitières étudiées, Holstein, Montbéliarde, Normande, Jersiaise, donnent des réponses laitières comparables. La réponse ne 
Tableau 5. Effets du numéro de lactation et du stade de lactation sur la réponse (kg de lait/j) à une administration de rbGH retard (500 mg tous les 14 jours pendant 12 semaines).

\begin{tabular}{|c|c|c|}
\hline $\begin{array}{c}\text { Stade de lactation au } \\
\text { début du traitement }\end{array}$ & $\begin{array}{c}\text { Primipares } \\
\text { (a) } / \text { (b) }\end{array}$ & $\begin{array}{c}\text { Multipares } \\
\text { (a) } / \text { (b) }\end{array}$ \\
\hline $\mathbf{6 0 - 1 0 0 ~ j o u r s ~}$ & $2,1 / 3,2$ & $2,7 / 4,0$ \\
\hline $\mathbf{1 0 0 - 1 4 0 ~ j o u r s ~}$ & $2,5 / 5,2$ & $4,1 / 6,6$ \\
\hline $\mathbf{1 4 0 - 1 8 5}$ jours & $3,9 / 4,2$ & $4,8 / 6,0$ \\
\hline $\mathbf{1 8 5 - 2 2 5}$ jours & $3,8 /-$ & $4,3 /-$ \\
\hline
\end{tabular}

(a) Bruneau et al (1991) - 420 vaches traitées dans 24 élevages français.

(b) Thomas et al (1991) - 445 vaches traitées dans 15 élevages américains.

semble pas varier en fonction du potentiel du troupeau ou des vaches considérées individuellement, bien que certaines études suggèrent que les hautes productrices répondent moins à la $\mathrm{GH}$, peut-être parce que la sécrétion de l'hormone endogène serait moins limitante chez ces animaux.

\section{- Conséquences sur la reproduction}

Initiées avant la fécondation, les injections de $\mathrm{GH}$ dégradent clairement la fécondité et/ou la fertilité des animaux. Un traitement avant la mise à la reproduction s'est traduit par une diminution systématique $(15 \%)$ du taux de gestation, d'autant plus forte que le traitement est précoce et la dose utilisée élevée. Les primipares apparaissent les plus sensibles : le pourcentage de vaches produisant un veau passe de 91 (témoins) à 64 après $\mathrm{GH}$ chez les primipares, et de 81 à 71 chez les multipares. Lorsque le traitement par la GH a débuté postérieurement à la fécondation, on n'observe ni mortalité embryonnaire, ni avortement, ni modification du poids du veau à la naissance, ni difficulté particulière au vêlage suivant.

La GH, administrée in vivo ou ajoutée au milieu de culture in vitro, stimule la production de progestérone des corps jaunes cycliques et de gestation. La réponse lutéale apparaît donc favorable à l'initiation de la gestation. Par ailleurs, on observe une stimulation indirecte de la croissance folliculaire par la GH chez les ruminants non lactants, mais pas lorsqu'ils sont en lactation.

A la lumière des connaissances actuelles, l'action directe de la GH sur la fonction de reproduction stricto sensu apparaît modeste et plutôt favorable (Santos et al 2004). Les effets défavorables sur les performances de reproduction, observés lorsque l'administration de $\mathrm{GH}$ est initiée avant la fécondation, semblent être indirects et associés à l'augmentation de la produc- tion laitière, mais surtout à la diminution du bilan énergétique pendant les premières semaines de traitement, en cohérence avec les effets déjà connus de la sous-nutrition sur la fonction de reproduction. La sensibilité accrue des primipares peut, de même, être reliée aux particularités des flux de nutriments chez ces animaux. Pratiquement, il est donc préférable d'initier les injections de $\mathrm{GH}$ après la fécondation. Néanmoins, lorsque les vaches sont traitées sur l'ensemble de la lactation, les régimes alimentaires classiques en Europe peuvent ne pas toujours permettre un retour à un état d'engraissement suffisant pour assurer une bonne reproduction ultérieure, surtout dans le contexte actuel de désintensification relative de la production laitière.

\section{- Etat sanitaire}

Le profil métabolique des vaches présente une légère tendance à l'acidose et à une baisse de l'albuminémie, comme chez toutes les vaches hautes productrices mobilisant leurs réserves corporelles (Burton et al 1994). L'absence de déviations métaboliques marquées (acétonémie, stéatose hépatique, fièvre vitulaire), c'est-à-dire le bon maintien de l'homéostase de l'animal, peut s'expliquer d'une part par les effets coordonnés (téléophorèse) de la GH sur l'ensemble du métabolisme et, d'autre part, par la moindre réponse de la mamelle en cas de sous-nutrition prolongée. Il n'existe que peu d'études rapportant les effets à long terme du traitement des vaches laitières par la GH. Une étude effectuée aux USA sur 164 troupeaux commerciaux traités pendant 4 ans, ne rapporte pas de modification du taux de réforme des animaux (Bauman et al 1999). Toutefois, deux autres études portant sur un total d'environ 1200 vaches traitées rapportent un accroissement significatif des problèmes de boiteries (Broom et al 1999, Collier et al 2001).

Les différentes cellules de l'organisme impliquées dans l'immunité répon- dent à la GH et à l'IGF-I, et pourraient même produire ces hormones, ce qui suggère une action autocrine ou paracrine de celles-ci sur le système immunitaire (Chilliard et al 2001). Chez les bovins, l'administration de $\mathrm{rbGH}$ ne modifie pas les concentrations d'immunoglobulines dans le sang, ni les titres en anticorps hémagglutinants et la sensibilité cutanée. Par ailleurs, il y a peu de données publiées concernant l'effet de la rbGH sur l'immunité cellulaire, mais les résultats disponibles tendent à confirmer l'effet immunostimulant décrit chez l'homme et les rongeurs (Burton et al 1994). Ils ne permettent cependant pas de savoir précisément si la rbGH augmente ou non la résistance aux maladies infectieuses chez la vache laitière haute productrice recevant cette hormone pendant une longue durée.

Au cours des nombreux essais zootechniques mis en place pour étudier les effets de la rbGH sur les performances des vaches laitières, la fréquence des pathologies infectieuses comptabilisées en nombre de vaches atteintes une ou plusieurs fois pendant la lactation, ne semble pas être modifiée par le traitement (Burton et al 1994). Toutefois la GH pourrait, dans certaines circonstances, modifier plusieurs processus infectieux.

D'une part, l'administration de rbGH augmente l'incidence des mammites (Willeberg et al 1993) et le nombre de cellules somatiques du lait (Bauman et al 1999), mais ceci résulterait plutôt de l'augmentation de la production laitière. Il n'y a pas, en effet, d'observation suggérant que la rbGH diminue les compétences immunologiques des vaches, et l'augmentation des numérations cellulaires observée en début de lactation pourrait même avoir un rôle protecteur contre les infections mammaires (Burvenich et al 1999). En effet, l'afflux précoce de polymorphonucléaires neutrophiles (cellules phagocytaires) du sang est le mécanisme principal de défense de la mamelle contre les agents pathogènes responsables de mammites. Or cette augmentation constitue la base du diagnostic des infections mammaires subcliniques chez la vache laitière ne recevant pas de $\mathrm{GH}$, et les numérations cellulaires du lait sont prises en compte pour le paiement du lait. Compte tenu des enjeux (amélioration de l'efficacité des traitements des mammites, mais fréquence plus élevée de celles-ci et diminution du prix du lait en cas de numérations cellulaires élevées), des études complémentaires utilisant des infections expérimentales dans des conditions bien 
contrôlées sont nécessaires pour mieux comprendre l'effet de la rbGH sur l'état sanitaire de la mamelle ainsi que les mécanismes de la réponse immunitaire éventuellement impliquée.

D'autre part, lorsqu'on l'ajoute dans certains modèles in vitro, à des doses généralement pharmacologiques et en présence d'autres hormones, la $\mathrm{GH}$ peut stimuler la production d'agents pathogènes à développement intracellulaire tels que les virus et les prions (Chilliard et al 2001). Il serait donc logique d'effectuer des études complémentaires in vivo de longue durée, avec de la rbGH administrée à doses physiologiques à des ruminants, avant de pouvoir écarter la possibilité de risques sur l'état sanitaire des troupeaux et la sécurité des consommateurs.

- Aptitude du lait à la transformation et à la consommation

Les modifications de la composition du lait déjà mentionnées sont principalement observées durant les premières semaines d'administration de rbGH et liées à une diminution passagère de l'équilibre nutritionnel des animaux. Elles n'agissent donc que faiblement et temporairement sur les rendements et l'aptitude technologique à la transformation du lait. Ainsi, aucune des études relatives aux principales transformations laitières (laits de consommation ou fermentés, poudres de lait, fromages à pâte molle, demi-dure ou pressée cuite) n'a pu mettre clairement en évidence de différence significative de comportement technologique ou de qualités organoleptiques des produits transformés à partir de laits provenant de vaches traitées par la rbGH (Laurent et al 1992).

A différentes reprises au début des années 90, diverses organisations gouvernementales américaines, auxquelles se sont jointes des organisations mondiales (FAO, OMS 1997), ont conclu à l'innocuité vis-à-vis des consommateurs des produits laitiers provenant de vaches traitées par la rbGH. Toutefois, dans un contexte d'accroissement de la production laitière par l'utilisation de la rbGH, les risques d'augmentation de pathologies liées à la lactation (mammites, etc.) ou à des infections virales latentes ne sont pas nuls de façon certaine. Dans l'éventualité d'une élimination plus lente des xénobiotiques chez les animaux recevant de la rbGH (cf $\S 4.2 .3$ ), les règles d'utilisation des médicaments vétérinaires, notamment les antibiotiques, devraient alors vraisemblablement être modifiées. Ainsi, pour la commercialisation du lait, une attention particulière devrait être apportée aux délais d'attente de façon à respecter les limites maximales résiduelles autorisées pour les médicaments utilisés.

\section{- Amélioration génétique}

Deux stratégies sont possibles pour l'amélioration génétique lorsque la rbGH est utilisée par les éleveurs :

- continuer le perfectionnement des méthodes d'évaluation génétique déjà engagées en ignorant complètement le nouveau facteur de variation que représente la rbGH, avec une diminution prévisible de l'efficacité de la sélection.

- organiser le recueil de l'information mensuelle concernant le traitement des vaches et l'utiliser dans un modèle d'évaluation génétique, plus coûteux, basé non sur la lactation totale mais sur les différents contrôles mensuels (Colleau 1996).

Les USA sont le premier pays à forte production laitière où la rbGH est autorisée et, pour l'instant, c'est la première attitude qui y prévaut. On ne sait pas quelles en seront les conséquences sur l'efficacité de la sélection dans ce pays, celles-ci devant dépendre de l'ampleur et du mode d'utilisation de la rbGH dans les élevages : régulière et concentrée sur toutes les vaches de certains troupeaux, conjoncturelle ou sur une partie seulement des vaches des troupeaux traités.

\section{2 / Chez le poisson}

Une des caractéristiques de l'élevage piscicole tient au fait que la reproduction des espèces est loin d'être totalement maîtrisée, comparativement aux autres animaux de rente. Une grande partie des poissons faisant aujourd'hui l'objet d'une production intensive ne se reproduisent pas spontanément en captivité ou présentent des anomalies de la reproduction en raison de conditions environnementales inappropriées ou du stress inhérent à leur confinement. Dans ces cas, même lorsque les gonades se développent, les femelles ne parviennent pas à achever le dernier stade de maturation des ovocytes ou produisent des ovules de mauvaise qualité (développement embryonnaire conduisant à des malformations ou de fortes mortalités) tandis que les mâles peuvent donner de faibles volumes de laitance ou du sperme de mauvaise qualité. A ces problèmes, il faut ajouter les difficultés liées à un cycle reproducteur saisonnier et une période de ponte limitée qui ne permettent pas de disposer d'alevins tout au long de l'année. Si la manipulation de certains paramètres environnementaux tels que la température et la photopériode permettent souvent de dessaisonner les pontes, les traitements hormonaux restent nécessaires pour obtenir ou synchroniser la reproduction finale des géniteurs.

L'obtention naturelle de gamètes est possible pour les espèces de poissons représentant aujourd'hui la majorité de la production piscicole mondiale, cyprinidés, salmonidés, tilapias, espèces essentiellement d'eau douce, mais seulement quand un environnement optimal pour leur reproduction est assuré, ce qui n'est pas toujours le cas, comme par exemple la carpe chinoise en eau chaude (Glasser et al 2003) ou le saumon Atlantique maintenu en mer (Haffray et al 1995). Par ailleurs, la diversification de la production piscicole conduit à mettre en élevage de nouvelles espèces dont la reproduction n'est pas obtenue spontanément, au moins dans les premières phases de leur domestication, comme par exemple pour la dorade (Zohar et Mylonas 2001). L'exigence de maîtrise de la reproduction de nouvelles espèces peut être plus ou moins forte selon le système d'élevage choisi et les contraintes économiques qu'il doit intégrer. Ainsi, une écloserie spécialisée devra utiliser au mieux son potentiel de production en contrôlant, tout au long de l'année, les périodes et les quantités d'alevins à produire en adéquation avec son marché. Elle peut aussi, pour améliorer son organisation, souhaiter synchroniser les reproductions au sein de lots de géniteurs importants en nombre. Enfin, le développement des schémas d'amélioration génétique tend à privilégier une reproduction sous contrôle d'individus sélectionnés et la fécondation in vitro (Fostier et Chevassus 1991).

Outre l'utilisation des hormones pour permettre ou améliorer la reproduction des espèces, il est apparu très tôt que les traitements hormonaux pouvaient stimuler la croissance des poissons. Ce sont principalement les hormones stéroïdiennes et la $\mathrm{GH}$ qui ont fait l'objet de travaux approfondis, même si quelques études, aux résultats contradictoires, ont porté sur l'effet des hormones thyroïdiennes sur la croissance.

\subsection{1 / La reproduction}

\section{- La maîtrise de la reproduction}

Bien que la maîtrise de la reproduction implique toutes les phases de la gamétogenèse (Jalabert et al 1998), la 
question du contrôle des dernières étapes de l'élaboration des gamètes est la plus fréquemment traitée par voie hormonale (Breton et al 1996, Donaldson 1996). On parle alors «d'induction de ponte» qui se fera le plus souvent par des traitements hormonaux : production d'ovocytes ovulés ayant achevés leur méiose chez la femelle (ovulation), et de spermatozoïdes libérés dans le tractus génital chez le mâle (spermiation).

Les premières préparations à base d'extraits d'hypophyses prélevées sur des poissons sexuellement matures et injectées à des adultes ont permis d'induire la maturation finale des gamètes ou d'obtenir une synchronisation des pontes chez des poissons maintenus en captivité (Fontenele 1955, Pickford et Atz 1957). En général, le protocole consiste à injecter chez les femelles 2 à $10 \mathrm{mg}$ de broyat d'hypophyse par $\mathrm{kg}$ de poisson receveur, l'injection ayant lieu par voie intramusculaire ou intrapéritonéale et consistant en une première administration de 10 à $20 \%$ de la dose totale et d'une seconde apportant les $80-90 \%$ restants 6 à 24 heures plus tard (Breton et al 1980, Lam 1982). Pour les mâles, l'injection d'une seule dose (environ $2 \mathrm{mg} / \mathrm{kg}$ ) peut être pratiquée. Même si elles tendent à disparaître, ces méthodes de traitement sont encore traditionnellement utilisées aujourd'hui pour certaines espèces ou pour des raisons essentiellement socio-économiques. Ce sont aujourd'hui des lyophilisats ou des extraits séchés puis réduits en poudre qui sont employés. Il faut cependant être attentif au fait que cette technique présente des risques de transmission de maladies, en particulier virales, si l'état sanitaire des poissons sur lesquels sont prélevées les hypophyses n'est pas parfaitement contrôlé. Depuis, une hormone gonadotrope homologue de la LH mammalienne a été découverte qui provoque cet effet et plusieurs techniques substitutives ont pu être développées. La première a consisté à utiliser des extraits purifiés d'hypophyse ou des gonadotropines purifiées homologues ou hétérologues (Hunter et al 1981). La relative spécificité des gonadotropines chez les poissons et leur coût limitent néanmoins leur champ d'application (Breton et al 1973a). Plusieurs auteurs ont utilisé avec succès, tant chez les mâles que chez les femelles, l'hCG, seule ou en combinaison avec des extraits hypophysaires de poisson (Lam 1982, Donaldson et Hunter 1983). Plusieurs espèces répondent de manière satisfaisante à $l^{\prime} h C G$ qui, cependant, peut devenir inefficace chez des animaux traités à plusieurs reprises en raison des anticorps anti-hCG produits (Zohar et Mylonas 2001).

D'autres types de traitements hormonaux ont fait l'objet d'expérimentations en laboratoire. En particulier, les hormones stéroïdes telles que les dérivés de la progestérone et les corticostéroïdes permettent, dans une certaine mesure, d'induire l'ovulation surtout si elles sont administrées en association avec des gonadotropines (Jalabert et al 1977, Lam 1982, Donaldson et Hunter 1983). L'utilisation d'une progestine a également été proposée pour son action comme phéromone sur la stimulation de la spermiation chez les cyprinidés (Stacey et al 1994). Plus récemment, l'administration d'inhibiteurs de la production d'œstrogènes à des mâles et à des femelles a permis d'avancer, respectivement, les périodes d'ovulation et d'entrée en spermiation (Afonso et al 1999, 2000). D’une manière générale, ces traitements par des stéroïdes, relativement complexes et d'efficacité irrégulière, ne font pas l'objet d'applications à grande échelle en raison de résultats hétérogènes ou de protocoles délicats à mettre en œuvre.

Des recherches ont aussi été menées sur l'efficacité d'une hormone hypothalamique, la gonadolibérine $(\mathrm{GnRH}$, ou encore LH-Releasing Hormone) pour induire la maturation sexuelle des poissons (Breton et Weil 1973b, Breton et al 1993, Peter 1997). Ces peptides, ainsi que leurs analogues de synthèse, sont mieux adaptés au contrôle de la ponte et de la gamétogénèse que les autres composés utilisés (Weil et al 1986, Peter et al 1988). Outre le fait que la structure des GnRHs de poisson ne varie que très peu d'une espèce à l'autre, ce qui permet d'en faire une utilisation non spécifique contrairement à l'hormone gonadotrope, celles-ci sont faciles à obtenir par synthèse, ce qui favorise l'obtention de formes hautement purifiées à un coût relativement faible. En raison d'une demi-vie courte d'environ 5 minutes, l'administration de GnRH native ne permet pas toujours d'obtenir un résultat satisfaisant sur la reproduction (Zohar et al 1990). C'est la raison pour laquelle des analogues (GnRHa) résistants à un clivage et donc à une inactivation trop rapide ont été produits. Ces molécules sont 30 à 100 fois plus actives que la GnRH native (Weil et al 1992). Cette efficacité et leur facilité d'emploi font qu'actuellement les GnRHa tendent à remplacer toute autre forme de traitement hormonal en matière de reproduction chez le poisson (Weil et Crim 1983, Breton et al 1990, Alok et al 1994). Les formes $\left[\mathrm{D}-\mathrm{Arg}^{6}, \mathrm{Pro}^{9}, \mathrm{~N}\right.$-Ethylamide]-salmon GnRH (analogue de la GnRH de saumon) et [D-Ala ${ }^{6}$, Pro $^{9}$,N-Ethylamide]mammalian GnRH (analogue de la GnRH mammalienne) sont couramment utilisées (Zohar et Mylonas 2001). Bien que plusieurs expérimentateurs aient testé les traitements par voie orale (Breton et al 1998, Roelants et al 2000, Mikolajczyk et al 2002), c'est aujourd'hui par injection intrapéritonéale que ces peptides sont administrés. Ce peut être en association à un inhibiteur de la dopamine tel que la dompéridone, le pimozide, la réserpine ou la métoclopramide (Billard et al 1987, Peter et al 1988, Drori et al 1994, Gillet et al 1996, Szabo 2003), la dopamine produite par l'hypothalamus bloquant la sécrétion d'hormone gonadotrope chez certaines espèces - cyprinidés en particulier - et atténuant l'action de la GnRH (Peter 1997). Pour avoir une efficacité maximale des GnRHa, il peut être utile d'induire des taux circulants maintenus constants à un faible niveau sur une longue période (Breton et al 1990). C'est la raison pour laquelle des implants capables de délivrer des GnRHa sur des périodes de plusieurs semaines ont été développés (Mylonas et al 1995, 1998, Mugnier et al 2000, Mylonas et Zohar 2000, 2001). Par ailleurs, la découverte de plusieurs formes de GnRH chez le poisson (Lethimonier et al 2004) devrait conduire au développement de nouvelles stratégies de traitement en fonction des espèces ou du résultat attendu (Forniés et al 2003). D'un point de vue pratique, on peut noter que des préparations pharmaceutiques vétérinaires associant $\mathrm{GnRH}$ et anti-dopamine sont disponibles et couramment utilisées (Pandey et Singh 1997). Par ailleurs, un analogue de la gonadolibérine, le Gonazon $^{\circledR}$, vient d'être mis sur le marché européen avec, à notre connaissance, la seule autorisation officielle disponible pour l'utilisation de ce type de produit chez les poissons. Enfin, il faut rappeler que le succès des méthodes d'induction de ponte dépend aussi de la capacité à évaluer l'état de la gamétogenèse des géniteurs et la réceptivité des gonades à une stimulation hormonale, une induction trop précoce ou effectuée dans des conditions d'environnement trop défavorables étant inefficace (Breton et al 1980, Jalabert et Fostier 1984, Billard et al 1984, King et Pankhurst 2004). La recherche récente d'expressions de gènes liées à l'acquisition de compétence des ovocytes pour leur aptitude à un bon développement vise à une telle évaluation. 


\section{- Sexage}

Hormis l'utilisation d'hormones naturelles ou de synthèse pour contrôler la reproduction des espèces d'intérêt économique, il existe d'autres applications des traitements hormonaux en pisciculture. Certains éleveurs peuvent avoir intérêt à n'utiliser que des populations monosexes (Guiguen et al 1996). Par exemple, pour les tilapias, poissons africains élevés en étangs, il est préférable de ne produire que des mâles afin d'éviter la prolifération d'alevins qui nuisent à la croissance générale et, ainsi, de bénéficier d'un dimorphisme de croissance favorable au mâle (Jalabert et Baroiller 1989). En revanche, pour d'autres espèces comme le bar ou le turbot, le dimorphisme de croissance sera favorable à la femelle (Saillant et al 2001). Pour les salmonidés, on recherchera aussi des populations monosexes femelles car les femelles atteignent la puberté un an en moyenne après les mâles et subissent donc plus tard que ces derniers les conséquences négatives de cette maturation physiologique sur la croissance. On peut aussi éviter cette maturation par l'obtention d'animaux triploïdes stériles, mais seules les femelles n'ont pas de développement des gonades (Chevassus et al 1979). Une méthode directe de contrôle du sexe consiste à exposer les alevins à des stéroïdes sexuels, œstrogènes ou androgènes (Yamamoto 1969, Hunter et Donaldson 1983, Pandian et Sheela 1995). Ces effets reposent sur un rôle physiologique des stéroïdes dans la différenciation du sexe chez les poissons (Baroiller et al 1999, Guiguen 2000, Devlin et Nagahama 2002). Les stéroïdes sont généralement administrés mélangés à de l'aliment artificiel. Des traitements par balnéation peuvent aussi être efficaces (Piferrer 2001). Une méthode indirecte repose sur un monosexage génétique. Ainsi, dans le cas d'espèces à déterminisme $\mathrm{XX} / \mathrm{XY}$ comme les salmonidés, une inversion sexuelle hormonale des femelles en mâles est nécessaire. Ces néomâles, qui sont des femelles génétiques (XX) transformées en mâles, sont utilisables directement par les pisciculteurs pour féconder leur femelles et obtenir ainsi une descendance monosexe composée uniquement de femelles (Chourrout et al 1986). Ce procédé, bien que plus lourd que la méthode directe, donne de meilleurs résultats et permet d'éviter que les poissons destinés à la consommation puissent avoir été exposés à des traitements hormonaux. Chez les salmonidés, la phase d'inversion sexuelle des jeunes femelles en mâles peut être obtenue par distribution, dès les premiers jours de nourrissage des juvéniles et pendant 3 mois, d'un aliment contenant 2 à $5 \mathrm{mg} / \mathrm{kg}$ de $17 \alpha$-méthyltestostérone (Johnston et al 1978, Dunham 1990, Olito et Brock 1991, Chevassus et Krieg 1992). Ces mêmes traitements hormonaux administrés à des doses plus élevées peuvent être utilisés pour produire des animaux stériles qui peuvent également avoir un intérêt zootechnique. La $17 \alpha$-méthyltestostérone (figure 4) est autorisée en Europe, dans des conditions strictes d'utilisation pour la production de néomâles destinés à la production de populations monosexes. Les recherches actuelles visent cependant à réduire l'importance de ces traitements hormonaux d'inversion sexuelle en limitant la période de traitement, en utilisant des balnéations courtes plutôt que l'administration à long terme d'aliment contenant des stéroïdes (Gale et al 1999), ou même à les substituer en maîtrisant des facteurs environnementaux comme la température (Baroiller et al 1995, Saillant et al 2002, Azuma et al 2004).

\subsection{2 / La stimulation de la croissance}

Comme pour toute espèce d'élevage, l'administration d'androgènes, d'hormones thyroïdiennes ou d'hormone de croissance, seuls ou en combinaison, peut induire des effets anabolisants chez les poissons. De nombreux travaux ont montré que les androgènes, en particulier la $17 \alpha$-méthyltestostérone, sont des anabolisants plus actifs chez le poisson qu'ils ne le sont chez les mammifères (Higgs et al 1982, Matty 1986). Ils agissent sur la croissance et l'indice de consommation. Toutefois, d'importantes différences apparaissent selon les espèces considérées et les doses administrées. D'autres études ont démontré l'efficacité de la GH mammalienne ou de poisson comme facteur de croissance, qu'il s'agisse d'hormones naturelles ou recombinantes (Le Bail et al 1993, McLean et Devlin 2000, Peterson et al 2004). Les effets sont particulièrement nets chez les téléostéens comme les salmonidés et les cyprinidés. Comme pour les androgènes, la GH agit sur le gain de poids et l'indice de consommation. Ces effets sont observés à des doses inférieures à $5 \mu \mathrm{g}$ d'hormone injectée par gramme de poids corporel ou lors de la mise en place d'implants contenant la GH. Bien qu'il s'agisse là des deux voies majoritairement utilisées pour les traitements expérimentaux, l'absorption intestinale de la GH pourrait être suffisante chez le poisson pour envisager une administration par voie orale (Sire et Vernier 1992, Breton et al
1998). La GH peut aussi avoir un effet favorable sur la smoltification, phénomène spécifique aux salmonidés migrateurs lors du passage des juvéniles de l'eau douce à l'eau de mer (Bœuf et al 1990). Cependant, les conséquences économiques pour la filière piscicole de l'utilisation de la GH mérite une analyse attentive (Maisse et al 1993). Quoi qu'il en soit, le recours à ces anabolisants en élevage reste interdit dans les pays de l'UE.

\subsection{3 / Conclusion}

L'utilisation des hormones en pisciculture vise, aujourd'hui, essentiellement le contrôle de la ponte et la maîtrise du sexe. Dans le premier cas, les pratiques devraient majoritairement évoluer vers l'usage d'une gonadolibérine de synthèse disponible sur le marché. Des progrès sont surtout à attendre dans une meilleure estimation de l'état de réceptivité des géniteurs et du potentiel de développement des oeufs (prévision de la qualité des gamètes), ainsi que dans l'évolution des modes d'administration. Dans le second cas, l'utilisation de stéroïdes destinés à la production de géniteurs particuliers se fait dans un cadre bien délimité. Des progrès sont aussi à attendre d'une amélioration des procédures permettant de réduire les quantités administrées, et, à plus long terme, de les remplacer par des techniques reposant sur l'utilisation de facteurs environnementaux.

\section{4 / Les aspects toxicolo- giques}

L'évaluation toxicologique des molécules destinées à la maîtrise de la reproduction, au contrôle de la croissance ou à l'accroissement de la production laitière est primordiale pour obtenir une autorisation de mise sur le marché (AMM). L'évaluation sera conduite différemment selon que ces molécules sont de faible poids moléculaire ou non. Dans le cas des hormones stéroïdiennes, des $\beta_{2}$-agonistes ou des produits thyréostatiques, l'évaluation prend d'abord en compte les capacités métaboliques de l'animal cible pour dégrader et éliminer le xénobiotique et ses métabolites, puis la concentration résiduelle tissulaire du composé parent et ses métabolites pour déterminer le risque toxique pour le consommateur. Ce risque est le le plus souvent entendu d'un point de vue strictement hormonal ou apparenté à un effet hormonal. On considérera que cette évaluation prend directement en compte le xénobiotique. 
Cette connaissance permet en outre de mettre en place des stratégies de contrôle de l'utilisation des substances soumises à autorisation ou des substances interdites. Ce mode d'évaluation sera présenté dans la première partie. $\mathrm{Au}$ contraire, les hormones peptidiques présentes en tant que résidus tissulaires dans les produits carnés ou laitiers consommés sont dégradées durant la digestion. Aucune évaluation directe de ces résidus n'a jamais été entreprise, simplement leur détection dans les matrices biologiques. En revanche, une évaluation indirecte consistant à détecter des modifications du statut métabolique ou du statut endocrinien représente une des voies d'approche intéressantes pour contrôler l'utilisation de certaines de ces hormones. Cette approche sera présentée dans un deuxième temps.

\section{1 / L'évaluation toxicologique des petites molécules}

Pour conduire une évaluation du risque toxique que peuvent présenter les teneurs résiduelles des différentes substances (stéroïdes, $\beta$-agonistes ou prostaglandines) utilisées pour une maîtrise des différentes fonctions physiologiques dans un cadre zootechnique donné, ou leurs métabolites majeurs, il est nécessaire de connaître la relation dose-réponse des effets adverses critiques, l'identification de l'espèce animale la plus sensible pour un effet donné, et les conditions d'extrapolation des résultats d'études toxicologiques de l'animal à l'homme (Arnold 2004). Cette évaluation se fait en considérant l'hypothèse forte suivante : les effets physiologiques n'apparaissent qu'au-delà d'un certain seuil. Cet effet de seuil ne s'applique pas aux substances démontrant des effets cancérigènes et/ou génotoxiques ; leur emploi est donc interdit. Pour les autres substances, la dose la plus forte ne donnant aucun effet physiologique dans l'espèce animale la plus sensible sera déclarée dose sans effet observé (en anglais No Observable Effect Level, NOEL). Cette valeur est prise en compte pour définir, moyennant des facteurs de sécurité, la dose journalière admissible (DJA, ou en anglais Acceptable Daily Intake, $A D I$ ) pour le consommateur standard de $60 \mathrm{~kg}$ consommant tous les jours une ration standard (muscle : $300 \mathrm{~g}$, foie : $100 \mathrm{~g}$, rein : $50 \mathrm{~g}$, gras : $50 \mathrm{~g})$ et le cas échéant des œufs $(100 \mathrm{~g})$ et du lait (1,5 L) (Arnold 2004). Les facteurs de sécurité (en général 100 ou 1000) qui permettent de diviser la valeur de NOEL sont justifiés par la faible taille de l'échantillon test définissant la valeur de NOEL, par la variabilité inter-individuelle, en particulier si on considère la fraction de la population pouvant être la plus sensible, et par la variabilité inter-espèce. Ces valeurs de DJA permettent ensuite de définir des limites maximales en résidus (LMR) présents dans les tissus animaux cibles (le tissu qui accumule le plus de résidus après administration, en général le foie), et, par voie de conséquence quand on intègre les données de déplétion tissulaire en résidus, les délais d'attente (ou temps de retrait) à respecter avant de commercialiser les produits animaux. C'est l'ensemble de ces données qui permet actuellement de conduire une expertise la plus pertinente possible de l'innocuité des produits xénobiotiques utilisés en élevage.

L'ensemble de ces procédures d'évaluation des effets hormonaux associés aux teneurs résiduelles en hormones dans les tissus consommés est actuellement remis en question par des travaux qui s'appuient sur l'hypothèse alternative de défaut de seuil de stimulation hormonale (Blair et al 2001). Cette hypothèse est fortement consolidée par l'utilisation de modèles mathématiques tirés du formalisme michaélien qui sont appliqués à d'innombrables données publiées (Sheehan 2006).

\subsection{1 / Métabolisme et détoxication}

- Stéroïdes

a) Androgènes

\section{- Testostérone}

Métabolites majeurs. Les rares études de métabolisme de la testostérone marquée au ${ }^{14} \mathrm{C}$ dans l'espèce bovine remontent à près de quarante ans. Martin (1966) a identifié les principaux métabolites excrétés dans les fèces. Ce sont l'épitestostérone ( $37 \%$ ) et la $17 \alpha$ hydroxy-5 $\beta$-androstane-3-one $(17 \%)$. La $5 \beta$-androstane-3,17-dione aurait aussi été repérée (figure 13). La biosynthèse de l'épitestostérone se fait comme pour l'œstradiol-17 $\alpha$ par l'intermédiaire d'une oxydation de l'hydroxyle en position $17 \beta$ pour donner l'androstènedione, la cétone en 17 étant réduite secondairement en alcool en position $17 \alpha$ par les érythrocytes.

Autres métabolites. Aucune information relative aux différents métabolites tissulaires de la testostérone n'a réellement été établie. Ainsi, les différents produits de réduction du cycle $\mathrm{A}$, de même que les produits d'hydroxylation de la testostérone, de l'androstènedione, de l'épitestostérone ou de leurs produits de réduction restent totalement inconnus en tant que résidus tissulaires. Les conjugaisons, elles aussi, restent complètement ignorées même si la coexistence de dérivés glucuronide et glycoside peut être avancée par analogie avec ce qui a été établi pour des métabolites de l'œstradiol ou de la progestérone.

\section{- Androgènes de synthèse}

Les stéroïdes androgéniques, selon leurs caractéristiques structurales, sont essentiellement administrés chez les animaux de rente par voie intramusculaire ou par voie orale. La pose d'implants dans le tissu conjonctif et, dans une moindre mesure, le mode d'administration «pour-on» sont également

Figure 13. Principales étapes connues de métabolisation sur le cycle $A$ et en position 17 de la testostérone chez les bovins (Martin 1966). Les étapes de conjugaison ne sont pas indiquées.

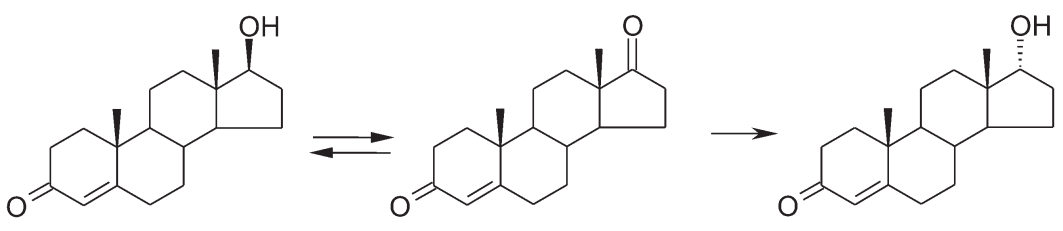

Testostérone

Androstènedione

Testostérone-17 $\alpha$<smiles>CC12CCCC(C)(C(=O)CC1)C1CCC3CC(=O)CCC3C12</smiles><smiles>C[C@]12CC[C@H]3C(CC[C@@H]4CC(=O)CC[C@H]43)[C@@H]1CC[C@@H]2O</smiles>

$5 \beta$-Androstane-3,17-dione 
des pratiques utilisées. Les androgènes $17 \alpha$-alkylés tels que la $17 \alpha$-méthyltestostérone, la noréthandrolone, le stanozolol, la noréthandrone ou encore le dianabol (figure 4), peuvent être utilisés par voie orale étant donnée l'absence d'oxydation en position 17 réalisée par les 17 $\beta$-hydroxystéroïde déshydrogénases (17 $\beta$-HSD). Les androgènes pour lesquels un alcool secondaire est présent en position 3 et/ou 17 sont très souvent utilisés sous forme estérifiée. Il s'agit notamment d'esters de type acétate, propionate, décanoate ou encore undécénoate de stéroïdes comme la testostérone, la nandrolone, la trenbolone ou la boldénone (figure 4). Ces formes estérifiées, préalablement mélangées à un excipient huileux, sont très communément injectées par voie intramusculaire à l'animal. Il faut noter cependant que la testostérone associée au benzoate d'œstradiol ou l'association acétate de trenbolone-œstradiol peuvent être conditionnés sous forme d'implants qui sont commercialisés légalement en dehors de l'UE, notamment sur le marché américain. Le passage dans la circulation est d'autant plus lent que la chaîne d'acide gras est longue. Les estérases plasmatiques hydrolysent ensuite la liaison ester. Le stéroïde actif est transporté dans le sang, la plus grande partie étant le plus souvent liée aux protéines plasmatiques, soit de manière non spécifique à l'albumine, soit de manière spécifique à la SHBG (Sex Hormone Binding Globulin), puis diffuse dans les organes et les tissus.

Les biotransformations sont observées principalement dans le foie et les reins et n'affectent que les androgènes libres (non liés à des protéines). La phase I de métabolisation est assurée par des enzymes dont le rôle est d'oxyder en position 17 la fonction alcool (17ß-HSD), de réaliser des hydroxylations en position $2,6,11,15$ ou 16 (cytochromes $\mathrm{P} 450$ ), de réduire la fonction cétone en position $3(3 \alpha-$ ou $3 \beta$ HSD) ou la double liaison $\triangle_{4}(5 \alpha-$ ou $5 \beta$-réductase). Globalement chez les ruminants, l'épimérisation $(17 \beta \rightarrow 17 \alpha)$ est la réaction principale pour les androgènes de type alcool secondaire en 17 , alors que les $17 \alpha$-alkylstéroïdes sont réduits au niveau du cycle $\mathrm{A}$, conduisant aux 4 isomères possibles $17 \alpha$-alkyl-5 $\alpha / \beta$-androstane- $3 \alpha / \beta, 17 \beta$ diols. Le stanozolol, androgène pyrazolique, se distingue au plan métabolique des autres androgènes chez les bovins puisque son métabolite principal est le $16 \beta$-hydroxystanozolol. Les multiples isomères du stéroïde originel peuvent alors être soumis à une étape de conjugaison. Chez les bovins, ovins et caprins, les androgènes sont plutôt conjugués à l'acide glucuronique, la sulfoconjugaison prenant en charge plutôt des précurseurs androgéniques endogènes (déhydroépiandrostérone ou DHEA, 5-androstènediols). Chez le cheval, la sulfoconjugaison est la voie de conjugaison privilégiée. Les conjugués d'androgènes sont excrétés principalement dans l'urine, de manière non négligeable dans les fèces, notamment les $17 \alpha$-alkylstéroïdes, et, de manière plus anecdotique mais non sans conséquence pour le contrôle de leur usage, par le sébum qui rend possible l'utilisation du poil comme matrice de surveillance.

L'acétate de trenbolone (figure 4) utilisé comme androgène de synthèse de façon réglementaire dans certains pays en dehors de l'UE se caractérise chez les bovins par la formation en quantités importantes de métabolites liés aux macromolécules (Ryan et Hoffmann 1978). Ces métabolites impliqueraient comme forme aglycone la trenbolone, la trenbolone- $17 \alpha$, la triendione ou des dérivés hydroxylés dont la structure chimique reste à établir pour nombre d'entre eux (Pottier et al 1981, Evrard et Maghuin-Rogister 1987, FernandezSuarez 1991, Metzler et Pfeiffer 2001). Chez le rat et le porc, une part importante de métabolites liés est aussi retrouvée (Fernandez-Suarez 1991). Par ailleurs, chez le porc, au contraire du rat, une proportion importante de métabolites extractibles par les solvants organiques présente la particularité d'être réduits sur le cycle A bien que la comparaison chez ces deux espèces des activités $5 \alpha$ - et $5 \beta$-réductases ne laissaient pas prévoir ce résultat (Fernandez-Suarez 1991).

Figure 14. Principales étapes de métabolisation de l'œstradiol-17 $\beta$ dans l'espèce bovine.

17-Esters à longue chaîne (C16:0 à C20:4)

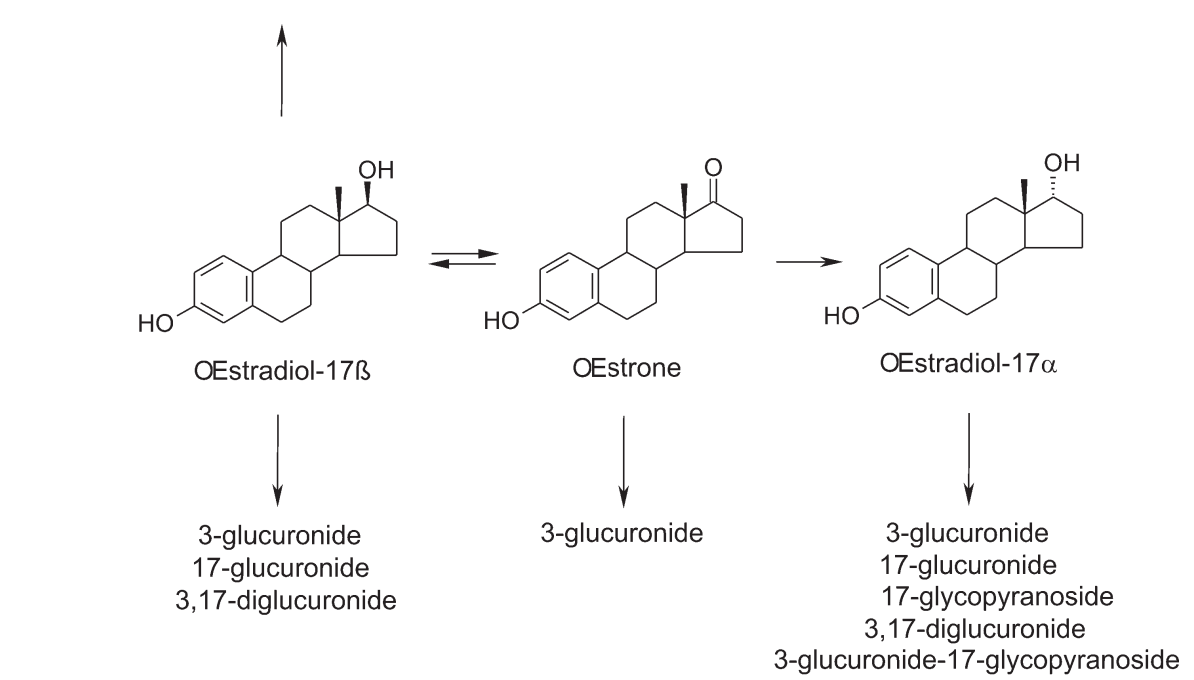

\section{b) Estrogènes}

\section{- Estradiol-17 $\beta$}

Métabolites majeurs. L'œstradiol$17 \alpha$ est, chez l'espèce bovine, le métabolite majeur de l'œstradiol. Il s'obtient par une $\alpha$-réduction de l'œstrone produite par les érythrocytes (Axelrod et Werthessen 1960, Lunaas et Velle 1960). L'interconversion œstrone/ œstradiol réalisée par les $17 \beta-H S D$ a été mise en évidence dans différents tissus (rein (Velle et Erichsen 1960), endomètre utérin (Erichsen et Velle 1960, Szego et Samuels 1943), foie (Erichsen et Velle 1960), testicule (Erichsen et Velle 1960). La voie fécale est la voie majeure d'élimination des œstrogènes sous forme déconjuguée, l'élimination urinaire des mêmes dérivés glucuronoconjugués ne représentant qu'un quart à un tiers de la radioactivité administrée à des bouvillons (Mellin et Erb 1965). En revanche, chez des veaux de boucherie recevant une alimentation exclusivement lactée, l'élimination des œstrogènes se fait principalement par voie urinaire (Paris 1987).

Dunn et al (1977) et Rao et al (1979) ont mis en évidence dans le foie de génisses ou de bouvillons traités par l'œstradiol marqué au ${ }^{14} \mathrm{C}$ l'existence d'un conjugué glycoside (le $\beta$-D-glucopyranoside ou glucose) en position 17 de l'œstradiol-17 $\alpha$ qui représente près de $40 \%$ des œstrogènes tissulaires (figure 14). Ce métabolite majeur, bien qu'appartenant à la classe des métabolites conjugués, possède les caractéristiques analytiques des métabolites «libres», c'est-à-dire qu'il est extractible par les solvants organiques. En 
revanche, chez le veau de boucherie, ce métabolite ne représente que 1 à $2 \%$ des métabolites hépatiques (Paris et al 1993). Ce métabolite glycosylé en position 17 peut être conjugué à l'acide glucuronique en position 3 , ce diconjugué représentant chez des bouvillons traités près de $10 \%$ de la radioactivité extractible (Dunn et al 1977).

Dans le muscle et dans le tissu adipeux périrénal, l'œstradiol non conjugué est l'œstrogène majeur, avec des valeurs oscillant entre 20 et $30 \%$ des œstrogènes tissulaires totaux chez le veau de boucherie (Paris et al 1993, 1994) ou des valeurs variant de 40 à $60 \%$ des œstrogènes tissulaires totaux chez des génisses et des bouvillons (Dunn et al 1977). Cependant, la présence d'œstradiol-3-glucuronide a aussi été démontrée dans ces deux tissus et représente entre 10 et $15 \%$ des œstrogènes tissulaires mesurés chez le veau (Paris et al 1993, 1994). Les quantités trouvées dans ces tissus chez des animaux plus âgés sont comparables : de 2 à $10 \%$ (Dunn et al 1977).

Autres métabolites tissulaires. Des métabolites hydroxylés en position $16 \alpha, 6 \alpha, 11 \beta, 7 \beta$ et $15 \alpha$ ont été isolés à partir d'incubation de broyats de surrénales de bœufs en présence d'œstrone (Knuppen et Breuer 1962, 1964, Knuppen et al 1964a, 1964b). Cependant, aucun de ces métabolites n'a pu être isolé en quantité réellement significative chez des veaux ayant reçu des implants de Revalor ${ }^{\circledR}$ contenant l'association acétate de trenbolone /œstradiol (Paris 1987), ni chez des bouvillons ou des génisses traités par l'œstradiol-14C (Paris et al 2000). De même, la recherche dans les urines de ces animaux de dérivés $O$-méthylés pouvant attester l'existence d'une biosynthèse préalable de catéchols œstrogènes (hydroxylation en position 2 ou 4) est restée vaine, le seul composé déterminé d'après ses caractéristiques chromatographiques, le 2-méthoxyœstrone, représentant moins de $0,5 \%$ des œstrogènes présents dans l'urine (Paris 1987). Dunn et al (1977) signalent chez des animaux plus âgés la présence d'œstriol à des concentrations relatives comprises entre 5 et $10 \%$ du total des œstrogènes tissulaires, aussi bien dans le muscle, le rein, le tissu adipeux que dans le foie, mais sans avoir toutefois caractérisé formellement ce métabolite polaire. Chez ces animaux, aucune mention de la présence dans le foie de catéchols œstrogènes sous forme libre ou conjuguée à l'acide glucuronique ou au glutathion, ni de méthoxyœstrogènes ne peut être relevée (Dunn et al 1977, Rao et al 1979, Paris et al 2000).

Figure 15. Métabolisme du zéranol chez les mammifères (Bories et al 1992, Metzler et Pfeiffer 2001).
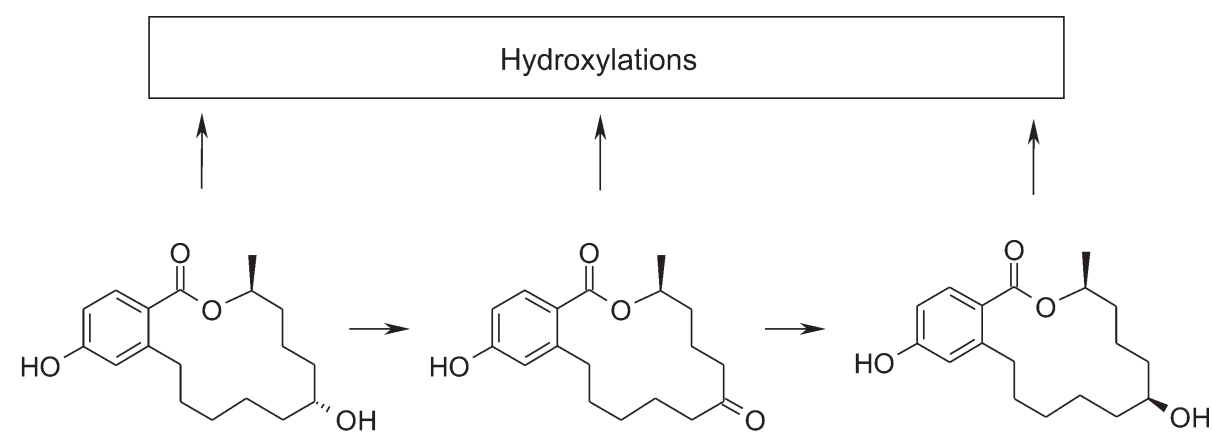

Zéranol ( $\alpha$-Zéaralanol)

Zéralanone

Taléranol ( $\beta$-Zéaralanol)

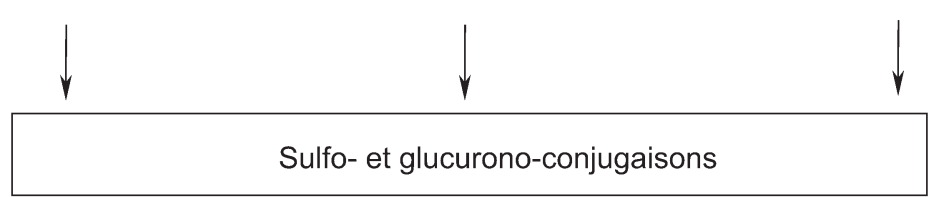

La biosynthèse d'esters d'acides gras à longue chaîne de l'œstradiol acylés en position 17 a été démontrée par MellonNussbaum et al (1982) à partir d'incubation de fragments d'utérus de vache (figure 14). Ces esters forment une classe de pro-œstrogènes particulière, l'œstradiol étant sous cette forme protégé du métabolisme oxydatif ou de conjugaison. L'activité acyl-coenzyme A : œstradiol-acyltransferase a été mise en évidence sur des fractions microsomales préparées à partir de foie de génisses (Paris et Rao 1989). Chez le veau traité par l'œstradiol tritié, une fraction significative de la radioactivité a été retrouvée dans les fractions dites de délipidation contenant cette classe d'esters de l'œstradiol tant dans le foie (4\%), le muscle $(7 \%)$, le rein $(5 \%)$ (Paris et al 1993) que dans le tissu adipeux périrénal (25\%) (Paris et al 1994). Parmi les différents esters isolés dans ce dernier tissu, l'œstradiol-17-oléate est le métabolite le plus abondant $(25 \%$ de l'ensemble des esters de l'œstradiol), les esters d'acides gras saturés (palmitate, stéarate) de l'œstradiol représentant près de $27 \%$ de cette classe (Paris non publié).

\section{- Zéranol}

Le zéranol ( $7 \alpha$-zéralanol) (figure 15) est un œstrogène dérivé de la zéaralénone, un myco-œstrogène produit par les Fusarium, qui est classé dans la famille des acides résorcyliques-lactones. Il est utilisé comme anabolisant, seul ou en association avec un androgène (tableau 1). Le métabolisme du zéranol a été étudié chez le rat, le lapin, le chien, le singe, l'homme (Migdalof et al 1983), le porc (Bories et al 1992) et, in vitro, à partir de microsomes de foie de mouton (Pompa et al 1988) ou de rat ou de bovins (Metzler et Pfeiffer 2001).
Différents conjugués de type glucuronide ou sulfate du zéranol, du taléranol (7ß-zéaralanol) et de la zéaralanone ont été isolés dans l'urine de porcs traités par le zéranol tritié et représentent la majeure partie des résidus hépatiques (Bories et al 1992). Des produits d'oxydation impliquant une activité cytochrome P450 dépendante ont été repérés parmi les métabolites isolés par Metzler et Pfeiffer (2001) mais n'ont pu être formellement identifiés.

\section{- DES, hexostrol}

Le DES comme l'hexœstrol appartiennent à la famille des stilbènes et possèdent des propriétés œstrogéniques puissantes. Ces susbtances ont été utilisées comme anabolisants en élevage bovin jusque dans les années 70 (Lone 1997). Elles ont aussi été utilisées pour le traitement des femmes en début de grossesse pour éviter, à tort, des risques de fausses-couches. Depuis qu'un lien a été établi entre l'utilisation du DES chez ces femmes et la survenue chez leurs filles de malformations des voies génitales, de cas de stérilité plus fréquents et d'un risque accru de cancer de l'utérus, ces substances ont été interdites. Le caractère cancérogène de ces molécules (IARC 1979) s'expliquent pour partie par leurs propriétés métaboliques. En effet, elles subissent une étape d'hydroxylation d'un noyau aromatique produisant un catéchol qui évolue vers la formation de semi-quinones et de quinones (Metzler 1989). Outre leur prise en charge métabolique par des systèmes adaptés (glutathion Stransférases), le caractère électrophile de ces métabolites favorise la formation d'adduits aux macromolécules, en particulier l'ADN, en même temps que la production de lipoperoxydes. 


\section{c) Progestagènes}

\section{- Progestérone}

Métabolites majeurs. De par ses propriétés lipophiles importantes, la progestérone marquée au ${ }^{14} \mathrm{C}$ se retrouve, quand elle est administrée par voie souscutanée, principalement dans le tissu adipeux avec 55 à $62 \%$ de la radioactivité totale estimée chez l'animal au moment de l'abattage. Dans ce tissu, elle représente la quasi-totalité des métabolites (Estergreen et al 1977, Clemens et Estergreen 1982). La quantité de radioactivité retrouvée dans les muscles varie entre 15 et $30 \%$ de la radioactivité totale estimée chez la vache ou le bouvillon au moment de l'abattage (Estergreen et al 1977). Cependant, ces dernières valeurs rapportées au poids de carcasse représentent alors entre 60 et $70 \%$ de la radioactivité retrouvée, celles estimées dans le tissu adipeux n'en valant plus que la moitié. La progestérone correspond au stéroïde le plus abondant retrouvé dans le muscle où elle représente près de $60 \%$ des métabolites (Estergreen et al 1977).

En revanche dans le foie, la progestérone est fortement métabolisée et ne représente que $2 \%$ de la radioactivité analysée après avoir été incubée sur des préparations tissulaires (Clemens et Estergreen 1982). Les principaux métabolites identifiés attestent de la présence d'activités très significatives de réduction en positions $3 \alpha$ et $5 \beta(83 \%$ des métabolites identifiés), la cétone en position 20 étant réduite dans le même temps plutôt en $\alpha$ qu'en $\beta$ (figure 16). Un métabolite plus polaire que les dérivés $5 \beta$-pregnane-diols qui représente $12 \%$ de la radioactivité extraite dans le foie après déconjugaison suggère la présence d'une voie majeure, non identifiée, d'hydroxylation de la progestérone. La nature de la conjugaison des métabolites hépatiques de la progestérone n'a jusqu'à présent pas été établie de manière formelle ; il semble seulement que les métabolites majeurs, la $3 \alpha$-hydroxy-5 $\beta$-pregnane-20-one et le $5 \beta$-pregnane-3 $\alpha, 20$-diol (figure 16), puissent être conjugués aussi bien à l'acide glucuronique qu'à des glycosides, la conjugaison au glucose étant la plus probable dans cette espèce (Purdy et al 1980).

Les métabolites retrouvés dans le rein ont des structures différentes de celles des métabolites hépatiques. La réduction sur le cycle A de la progestérone se fait principalement en $5 \alpha$ et en $3 \alpha$ ou $3 \beta$ (figure 16). Une réduction de la cétone en $20 \beta$ produit aussi un métabolite majeur (Purdy et al 1980). Ainsi, progestérone, 20 $\beta$-hydroxy-pregn-4ène-3-one, $3 \alpha$-hydroxy-5 $\alpha$-pregnane20 -one et $3 \beta$-hydroxy- $5 \alpha$-pregnane- 20 one sont distribués en quantités comparables dans les extraits de rein correspondant à la classe des métabolites non conjugués.

Autres métabolites. Dans le foie, la présence de métabolites réduits en

Figure 16. Principales étapes connues de métabolisation sur le cycle $A$ et en position 20 de la progestérone chez les bovins (Clemens et Estergreen 1982). Les étapes de conjugaison ne sont pas indiquées.

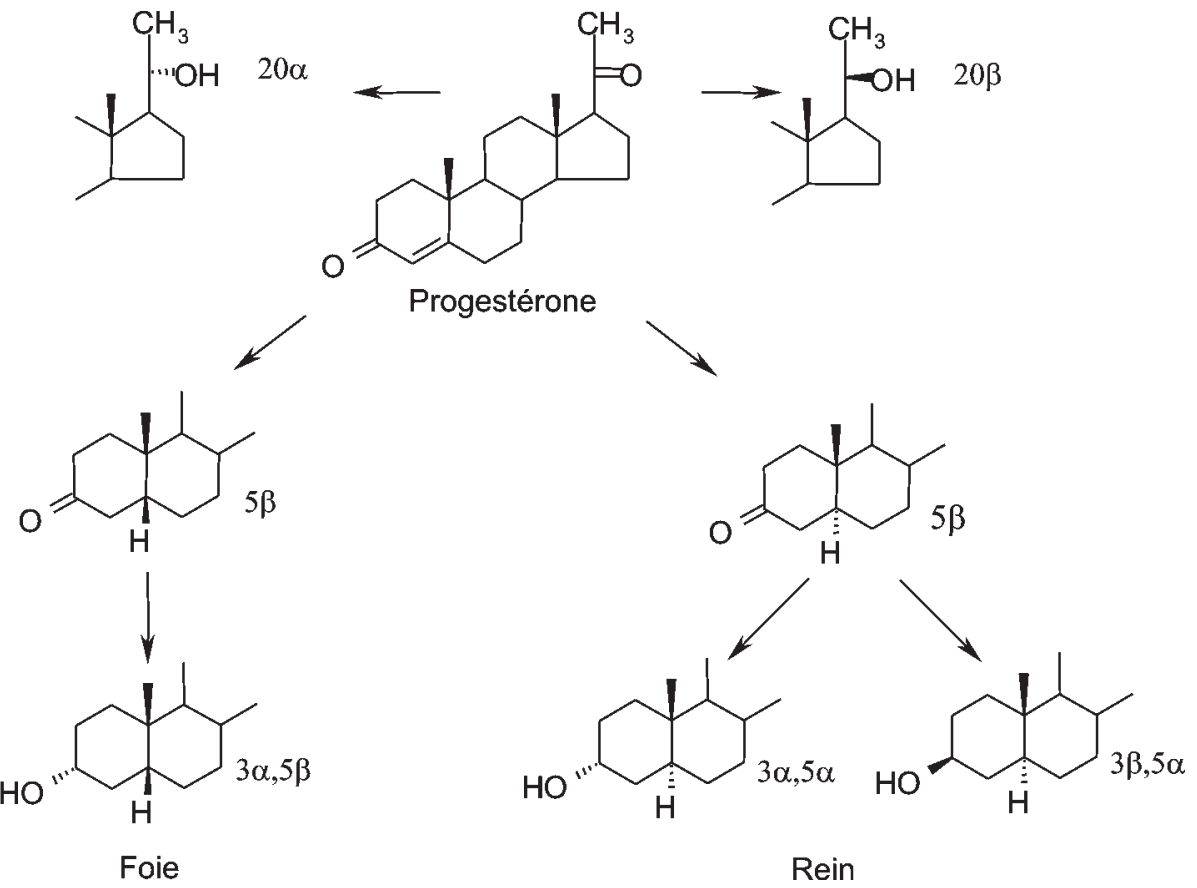

position $3 \beta$ est mineure (Purdy et al 1980, Clemens et Estergreen 1982). De la même manière, dans le tissu adipeux, les métabolites de la progestérone réduits sur le cycle $\mathrm{A}$ en positions $3 \alpha$ et $5 \beta$ ne représentent qu'une fraction négligeable, de l'ordre de $5 \%$, des pregnanes isolés. Les réductions en positions $20 \alpha$ et $20 \beta$ ont été évaluées respectivement à 4 et $1 \%$ de la radioactivité extraite du tissu adipeux (Clemens et Estergreen 1982).

Dans le muscle, des métabolites obtenus par une réduction du cycle A de la progestérone en $5 \alpha$ ou en $5 \beta$ doublée ou non d'une réduction en $3 \alpha$ ou en $20 \beta$ ont été retrouvés en tant que métabolites mineurs (Estergreen et al 1977 , Lin et al 1978).

Dans les surrénales, d'anciens travaux signalent la présence de la $5 \alpha$ pregnane-3,20-dione, la 3ß,21-dihydroxy-5 $\alpha$-pregnane-20-one et la $17 \alpha-$ hydroxy-5 $\alpha$-pregnane-3,20-dione (Pincus, 1954).

\section{- Acétate de mélengestrol}

L'acétate de mélengestrol (MGA, $17 \alpha$-acétoxy-6-méthylène-pregn-4,6diène-3,20-dione) (figure 9) peut être utilisé chez les femelles pour ses propriétés progestatives (Zimbelman et Smith 1966a, 1966b) ou anabolisantes (Bloss et al 1966, Fed. Regist.1968, 1969). La structure du MGA est voisine de celle de l'acétate de mégestrol $(17 \alpha-$ acétoxy-6-méthyl-pregn-4,6-diène3,20-dione), de celle de l'acétate de médroxyprogestérone (MPA, 17 $\alpha$-acétoxy-6 $\alpha$-méthyl-pregn-4-ène-3,20dione) ou de celle de la progestérone. Chez la génisse, le MGA est utilisé comme anabolisant à la dose de 0,25$0,50 \mathrm{mg} / \mathrm{animal} / \mathrm{j}$ avec un temps de retrait de 48 heures avant abattage (Metzler et Pfeiffer 2001). La dose quotidienne de $0,50 \mathrm{mg}$ par tête pendant 20 jours est nécessaire pour obtenir un effet progestagène (Anderson et Day 1998).

Le métabolisme du MGA a été étudié chez l'espèce bovine au moyen de molécules marquées au ${ }^{3} \mathrm{H}$ ou au ${ }^{14} \mathrm{C}$ (Krzeminsky et al 1981). Le tissu cible en terme d'accumulation de radioactivité est le tissu adipeux qui contient essentiellement le MGA. De nombreux métabolites ont été isolés dans le foie mais peu d'entre eux ont été identifiés. Plus récemment, Metzler et Pfeiffer (2001) ont isolé plus d'une dizaine de métabolites mono- et dihydroxylés à partir de microsomes de rats ou de bovins mais leur structure n'a pu être établie complètement. 


\section{- Acétate de fluorogestone}

L'acétate de fluorogestone (FGA) (figure 9) est un progestagène utilisé en élevage ovin et caprin dans l'UE. Il est employé à la dose de 30 à $40 \mathrm{mg}$ par éponge vaginale chez la brebis et à la dose de $45 \mathrm{mg}$ par éponge chez la chèvre. Les éponges vaginales sont retirées après 12 à 14 jours d'action progestative chez la brebis et 11 jours chez la chèvre.

Le FGA est métabolisé principalement en dérivés hydroxylés (EMEA /MRL/780/01-Final 2001). In vitro, le FGA est métabolisé par des hépatocytes de moutons en dérivés hydroxylés mais aucune analyse structurale ne semble avoir été publiée. Aucune étude radiométrique des résidus tissulaires n'a été conduite chez l'animal cible et, de ce fait, aucun résidu marqueur de l'ensemble des résidus tissulaires n'a pu être déterminé. La disparition des résidus de FGA dans le lait est quasi totale après 2 jours de retrait de l'éponge (EMEA /MRL/780/01-Final 2001).

\section{- Norgestomet}

Le norgestomet ( $17 \alpha$-acétoxy-11 $\beta$ méthyl-19-norpregn-4-ène-3,20-dione) (figure 9) est utilisé comme progestagène dans l'espèce bovine. Il est administré sous forme d'implant souscutané (3 mg) placé à la base de 1'oreille pendant 9 à 10 jours. Ce traitement est complété par une administration par injection en $i . m$. de $3 \mathrm{mg}$ de norgestomet et de $5 \mathrm{mg}$ de valérate d'œstradiol.

L'utilisation de norgestomet tritié a permis de déterminer les voies et les cinétiques d'élimination de la molécule administrée par voie intraveineuse ou au moyen d'un implant. Les temps de demi-élimination de la molécule administrée par voie intraveineuse varient de 2,5 à 5,5 jours et de 4,3 à 9,5 jours après retrait de l'implant, l'essentiel de la radioactivité étant éliminé par voie fécale (EMEA/MRL/468/98-Final 1999). Le norgestomet est métabolisé en dérivés polaires dont la plupart n'a pu être identifiée. Seuls trois métabolites du norgestomet résultant d'une modification de la chaîne en $17 \beta$, d'une élimination du groupement acétyl en $17 \alpha$ ou d'une réduction de la cétone en position 20 ont pu être identifiés dans les excreta et le plasma. D'après l'étude radiométrique des résidus tissulaires réalisée au moyen de norgestomet tritié, le foie est l'organe cible du point de vue du métabolisme. Cependant, aucun métabolite tissulaire n'a été isolé (EMEA/MRL/468/98-Final 1999).

\section{- Altrenogest}

L'altrenogest (allyltrenbolone ou $17 \alpha-$ allyl-4,9,11-estratriène-3-one-17 $\beta$-ol ou Regumate $^{\circledR}$ ) (figure 9) est utilisé comme progestagène oral chez la truie (Martinat-Botté et al 1985) ou la jument (Colbern et al 1987, Sigler et al 1989). Une dose quotidienne de $20 \mathrm{mg}$ par truie pendant 18 jours et de $0,044 \mathrm{mg}$ par $\mathrm{kg}$ de poids vif chez la jument pendant 10 jours est recommandée.

Les études de métabolisme de l'altrenogest radiomarqué conduites chez ces deux espèces montrent que la radioactivité plasmatique disparaît de manière biphasique après la dernière administration de la molécule (EMEA/MRL/ 904/04 2004). La radioactivité tissulaire est principalement distribuée dans le foie, et à un moindre degré dans le rein, le muscle et le tissu adipeux. L'altrenogest est métabolisé par des étapes d'oxydation et de conjugaison à l'acide glucuronique, au groupement sulfate ou au glutathion, les métabolites polaires isolés du foie étant partiellement identifiés par spectrométrie de masse. Une large part des métabolites n'est pas extractible 7 et 15 jours après arrêt de l'administration de l'altrenogest. Ces métabolites sont liés par liaison covalente aux macromolécules, notamment sur des sites nucléophiles, ce qui laisse supposer que l'altrenogest subit une étape de métabolisation la rendant électrophile (possibilité théorique de formation d'un époxyde sur la chaîne allylique) ou qu'un carbone électrophile de la molécule, en particulier celui en position 12 , forme par voie chimique un thioéther avec des résidus cystéine. Ces métabolites liés ont perdu leurs propriétés hormonales. Une fraction mineure de métabolites non-polaires n'a pu être caractérisée au plan structural. Aucune preuve de la perte du groupement allylique en $17 \alpha$ permettant d'obtenir la trenbolone n'a été apportée (EMEA/MRL/904/04 2004).

\section{- Acétate de médroxyprogestérone}

L'acétate de médroxyprogestérone (17 $\alpha$-acétoxy-6 $\alpha$-méthyl-pregn-4-ène3,20-dione) (figure 9) est utilisée comme progestagène en élevage ovin. L'administration est réalisée par voie vaginale à la dose de $60 \mathrm{mg}$ par éponge. L'élimination par voie fécale de la médroxyprogestérone et de ses métabolites est prépondérante. Une élimination dans le lait a aussi été montrée. Les données en matière d'étude du métabolisme de la médroxyprogestérone restent très fragmentaires (EMEA/MRL/ 0129/96-Final 1996).

\section{d) Corticostéroïdes}

Certains corticostéroïdes sont utilisés en thérapeutique vétérinaire pour leurs propriétés anti-inflammatoires, mais également frauduleusement comme possibles facteurs de croissance. Le catabolisme des glucocorticostéroïdes est essentiellement hépatique bien qu'un certain nombre de biotransformations se produisent aussi dans d'autres tissus tels que le placenta, les reins ou l'appareil gastro-intestinal (Holland 1982).

Concernant les étapes de métabolisation entraînant l'inactivation de la molécule (figure 17), les corticostéroïdes naturels chez les mammifères sont soumis à des réactions d'oxydoréduction, le plus fréquemment en position 11 ; les $11 \beta$-hydroxystéroïde-déshydrogénases de type I et II (11 $\beta$-HSD) sont impliquées dans l'interconversion cortisol-cortisone. On peut également citer la réduction de la double liaison $\triangle_{4}$ (Damkjoer et al 1969), la réduction des cétones en positions 3 et 20 , ou encore 1'hydroxylation en position 6 (Passingham et Barton 1987, Egford 1995, Kasuya et al 1998) (figure 17). Les isoméries en $5 \beta, 11 \beta-\mathrm{OH}$ et $6 \beta-\mathrm{OH}$ semblent généralement prédominantes chez l'homme, le bovin ou le cheval. On peut noter cependant des différences sensibles de métabolisation entre les corticostéroïdes endogènes et ceux de synthèse. Ainsi, les réactions de réduction des doubles liaisons semblent être les plus fréquentes pour les molécules naturelles pour donner le tétrahydrocortisol ou la tétrahydrocortisone, alors que l'hydroxylation semble être la voie prépondérante d'inactivation des corticostéroïdes xénobiotiques (Anderson et al 1982, Rodchenkov et al 1988, Addison et al 1991, Tomlinson et al 1997, Vree et al 1999). Ces études pour la plupart concernent l'homme, rarement l'animal. Quelques études menées chez le cheval traité par la dexaméthasone ont toutefois montré dans l'urine une large proportion de la forme native non conjuguée et la présence minoritaire de métabolites oxydés (17-céto, 11-déshydro, 6-hydroxy et 6-hydroxy-17-céto) (Skrabalak et Maylin 1982, Dumasia et al 1986). Une étude conduite dans l'espèce bovine a confirmé la faible proportion de métabolites réduits et/ou hydroxylés de la dexaméthasone (Antignac et al 2004).

Concernant les étapes de conjugaison présentes chez les animaux de rente, très peu d'études ont été consacrées à la détermination des proportions des formes conjuguées des corticostéroïdes 
Figure 17. Principales étapes de métabolisation du cortisol connues chez les mammifères (Holland 1982). Les étapes de conjugaison ne sont pas indiquées.
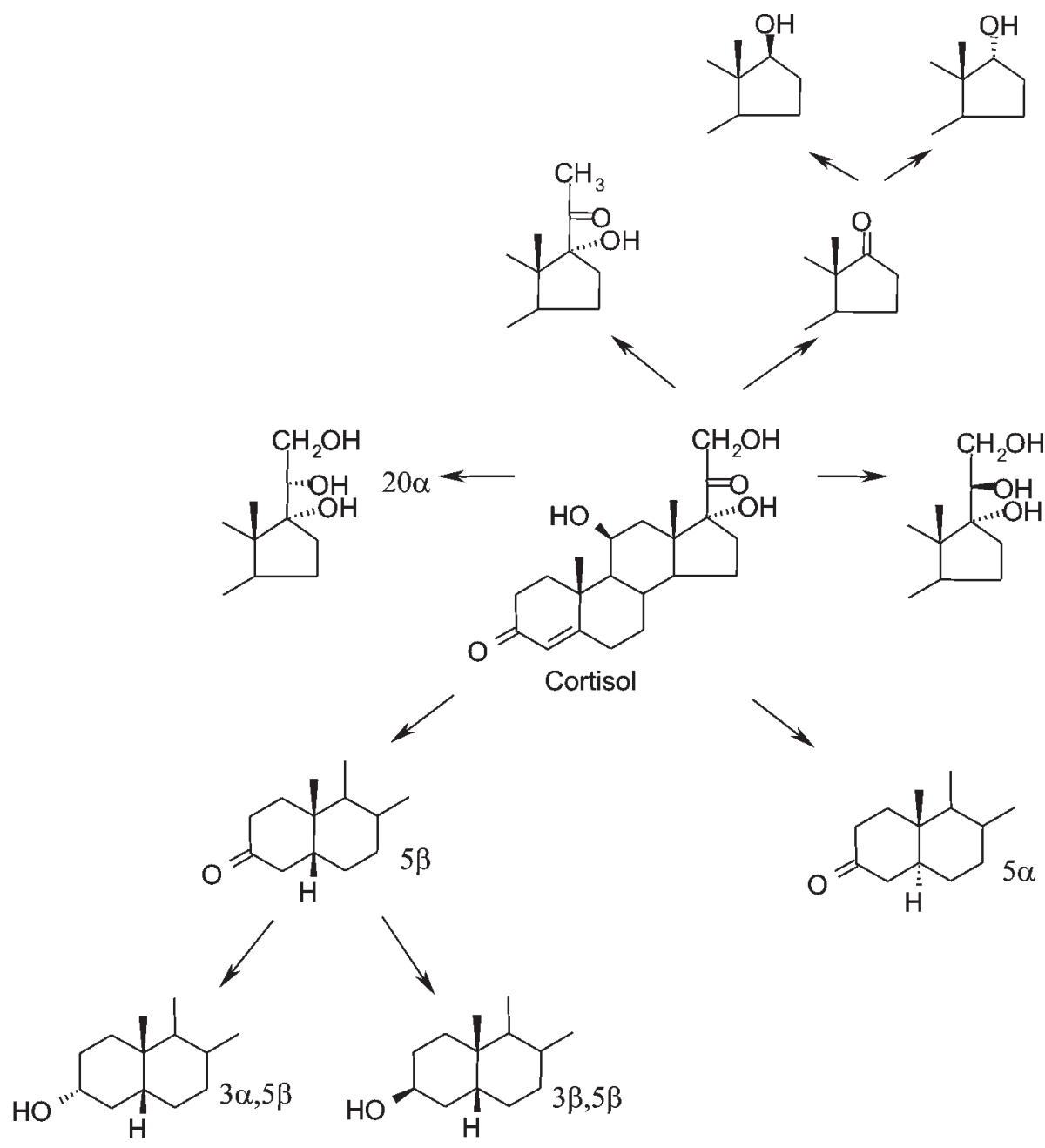

éliminées dans l'urine et les fèces. Pour les corticostéroïdes naturels, l'existence d'une large proportion de glucuronides est généralement admise chez les bovins. Ceci a été rapporté en particulier pour le tétrahydrocortisol (Antignac et al 2002). Pour les corticostéroïdes artificiels, l'introduction d'un halogène en position 6 et/ou 9 diminue cette proportion en faveur des formes libres biologiquement actives. Des études menées chez le bovin rapportent pour la dexaméthasone plus de $70 \%$ de formes libres (Courtheyn et al 1994, Antignac et al 2002). Si la conjugaison en position 21 semble être la moins défavorable du point de vue de l'encombrement stérique, aucune information n'est disponible sur la position de la conjugaison (position 3, 11 ou 17) et sur la possibilité de formation de multi-conjugués.

\section{- Agonistes $\beta$-adrénergiques}

L'adrénaline et la noradrénaline sont des molécules manifestant des effets biologiques de relativement courtes durées. Leur métabolisation par $O$-méthylation du noyau catéchol via la catéchol-O-méthyltransférase (COMT) et par clivage entre le groupement amine et le carbone adjacent par l'activité monoamine-oxydase (MAO) est rapide. Ces biotransformations sont impossibles pour les $\beta$-agonistes de synthèse susceptibles d'être utilisés en élevage car ce ne sont pas des catéchols et la fonction amine de la chaîne latérale est substituée par un groupement chimique de nature variable (isopropyl, tertio-butyl ou autre) (figure 6), la MAO ne pouvant oxyder que les amines primaires. De fait, la biotransformation in vivo des $\beta$-agonistes est le plus souvent réalisée par conjugaison des groupements hydroxy du noyau aromatique. C'est le cas pour le fénotérol, la terbutaline et le salbutamol, majoritairement éliminés par voie urinaire sous forme sulfo-conjuguée (Hochhaus et Mollmann 1992). Pour la ractopamine, l'obtention de conjugués à l'acide glucuronique prédomine
(Smith 1998). Comme pour les sulfoconjugués, il s'agit de métabolites plus solubles dans l'eau que les composés de départ, permettant une élimination facile par les voies biliaire et urinaire. Aucune donnée concernant le métabolisme du zilpatérol n'a été publiée à ce jour. En dehors de la ractopamine et du zilpatérol pour lesquels des études ont été réalisées pour la constitution des dossiers de demande d'AMM, c'est pour le clenbutérol, chef de file structural des $\beta$-agonistes utilisés illégalement, que nous disposons des résultats les plus détaillés. Des expérimentations ont été menées chez le rat (Zalko et al 1997,1998 b) ainsi que chez le veau à la dose «zootechnique» de $5 \mu \mathrm{g} / \mathrm{kg}$ de poids vif (Zalko et al 1998a). Les résultats indiquent que la voie de glucuronoconjugaison a une importance très réduite pour les $\beta$-agonistes de type arylamine (figure 18). Les voies de biotransformation principales du clenbutérol chez ces espèces sont : 1) l'oxydation de l'amine primaire en hydroxylamine, métabolite principal du clenbutérol in vivo et dont l'instabilité chimique fait qu'il est en équilibre avec de petites quantités de nitroso- et de nitroclenbutérol (figure 18, étape I), 2) la formation d'un N-sulfate essentiellement éliminé par voie fécale (figure 18, étape II) et 3) l'oxydation de la chaîne latérale qui, par cassure, aboutit à la formation de métabolites de faible poids moléculaire pouvant être, en dernière étape, conjugués à la glycine (figure 18, étape III). L'oxydation de la chaîne latérale est une voie métabolique qui a également été démontrée pour le salmétérol et le mabutérol (Horiba et al 1984, Manchee et al 1993). Dans le cas du salmétérol, cette voie est probablement favorisée par le caractère relativement lipophile de la molécule (Boulton et Fawcett 1996). Le raccourcissement de la chaîne latérale produit des métabolites ne possédant que peu ou pas d'activité biologique (Horiba et al 1984, Zalko non publié) et peut être considéré comme une voie de détoxication. Ce n'est absolument pas le cas pour la voie d'oxydation de l'amine primaire. En effet, les hydroxylamines, produits d'oxydation des arylamines, sont le plus souvent des composés réactifs du point de vue chimique, susceptibles de former des adduits avec des macromolécules endogènes (ADN, protéines). Les études de toxicité du clenbutérol font état de problèmes limités en dessous d'une dose de $1 \mathrm{mg} / \mathrm{kg}$ : hypersécrétions vaginale et utérine, dilatation trachéale chez l'espèce bovine (Biolatti et al 1994), problèmes de l'appareil 
Figure 18. Principales voies de métabolisation du clenbutérol chez le rat et le veau. Les étapes I, II et III désignent respectivement l'oxydation de l'amine primaire liée au cycle aromatique, la formation d'un N-sulfate et, enfin, l'oxydation de la chaîne latérale.

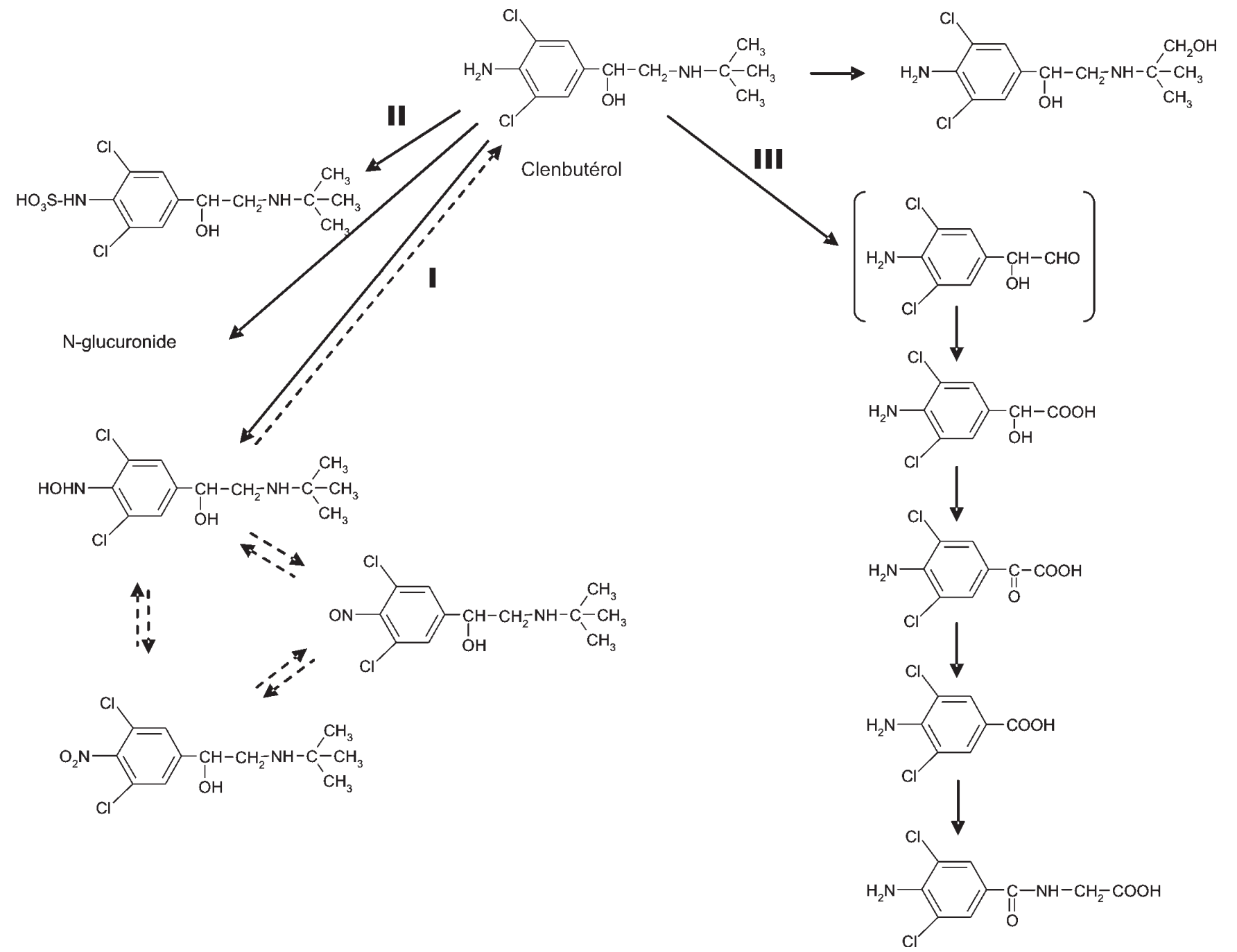

reproducteur chez la ratte $(\mathrm{Re}$ et al 1993). Cependant, la mise en évidence d'une hydroxylamine comme métabolite majeur chez le rat et le veau incite à la prudence, d'autant plus que ce métabolite conserve une activité $\beta$-agoniste au moins équivalente à celle du clenbutérol (Zalko non publié).

\section{- Thyréostatiques}

Les études pharmacocinétiques des ATS ont fait l'objet d'une littérature abondante focalisée essentiellement chez l'homme et le rat, parfois le porc, rarement le bovin (Sitar et Hunninghake 1975, Kampmann et Hansen 1981, Johansen et al 1982, Jansson et al 1983). Globalement, leur absorption est rapide (de 0,5 à $1 \mathrm{~h}$ ) et leur biodisponibilité élevée ( $>80 \%)$. Le transport plasmatique des dérivés du thiouracile s'effectue par liaison à des protéines plasmatiques, ce transport n'étant pas élucidé pour les dérivés du tapazole. Aucun transfert placentaire n'a été mis en évidence. Leur métabo- lisme est peu décrit dans la littérature (Marchant et Alexander 1971, Sitar et Thornhill 1973, Skellern et al 1973). L'élimination chez la vache est rapide (quelques heures), essentiellement par voie urinaire, et se fait en deux temps : une élimination des molécules non stockées, véhiculées par le sang et éliminées par le rein est d'abord observée, puis un relargage progressif des molécules stockées de manière non spécifique. Le tapazole est ainsi complètement éliminé en moins de $48 \mathrm{~h}$ chez la vache traitée (De Brabander et Verbecke 1975, 1984).

Les ATS s'accumulent dans la glande thyroïde pendant une période assez longue où ils ne sont pas métabolisés. Bien que de nombreux travaux aient été réalisés, principalement sur le tapazole et le propylthiouracile (Marchant et Alexander 1971, Sitar et Thornhill 1973, Skellern et al 1973), les métabolites des ATS restent assez mal connus. Dans le cas du tapazole, une quantité importante non métabolisée est retrou- vée dans l'urine sous forme libre; des métabolites conjugués ont été décrits dans la bile et l'urine. La liaison à l'acide glucuronique semble être l'étape de conjugaison privilégiée. Concernant le propylthiouracile, de nombreux métabolites glucuronoconjugués ont également été identifiés, le site principal des modifications étant le soufre.

\section{- Prostaglandines}

Outre $\mathrm{PgF}_{2 \alpha}$, prostaglandine naturelle qui prend aussi les noms de dinoprost ou de dinoprost trométhamine suivant la forme administrée aux animaux, des analogues peuvent être utilisés dans un cadre réglementaire. $\mathrm{Ce}$ sont le cloprosténol, l'alfaprostol, le tiaprost, le 17-phényl trinor $\mathrm{PgE}_{2}$, le misoprostol, le luprostiol, le fluprosténol, et le fenprostalène (figure 19 et tableau 6). La demi-vie de $\mathrm{PgF}_{2 \alpha}$ est faible. Elle est métabolisée en 13, 14-dihydro-15-céto- $\mathrm{PgF}_{2 \alpha}$, métabolite plus facile à doser que $\mathrm{PgF}_{2 \alpha}$ et qui est utilisé pour étudier la variation de bio- 
Figure 19. Principales prostaglandines utilisées en élevage.
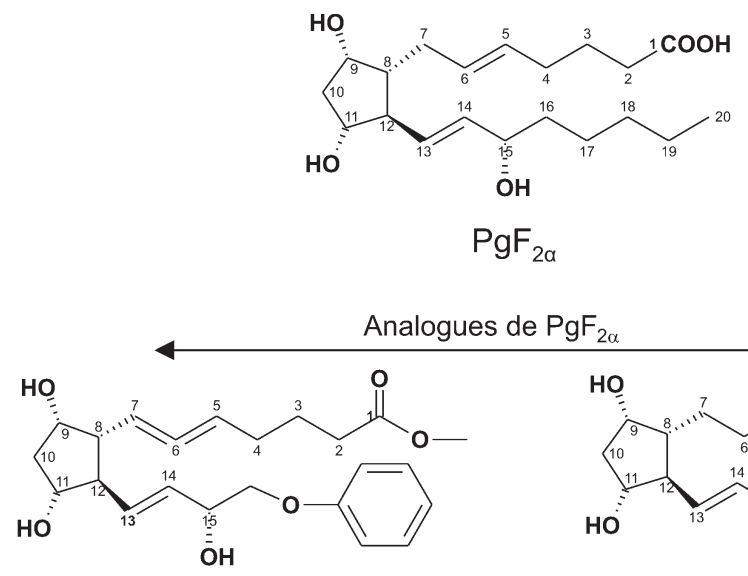

Fenprostalène<smiles>O=C(O)CCCC=C1C[C@@H]2[C@H](C=C1C1(COc3ccccc3)OCCO1)[C@H](O)C[C@H]2O</smiles>

Etiproston

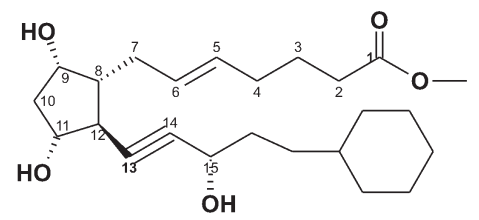

Alfaprosténol<smiles>O=C(O)CCCC=C1C[C@@H]2[C@H](C=C1[C@H](O)COc1cccc(Cl)c1)[C@H](O)C[C@H]2O</smiles>

Cloprosténol<smiles>O=C(O)CCC/C=C/C[C@@H]1[C@H](/C=C/[C@H](O)COc2cccc(C(F)(F)F)c2)[C@@H](O)C[C@H]1O</smiles>

Fluprosténol

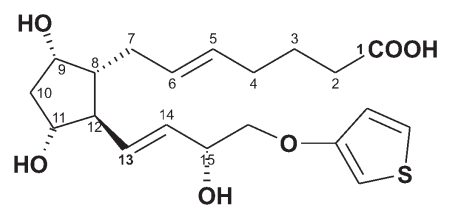

Tiaprost

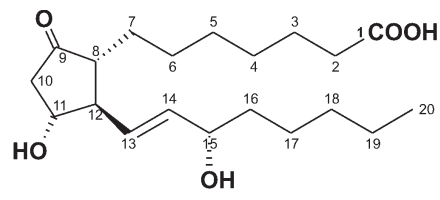

$\mathrm{PgE}_{1}$

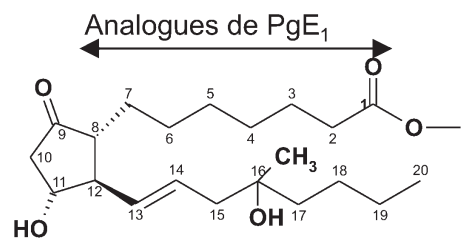

Misoprotol<smiles>O=C(O)CCCC=CC1=C[C@H](O)C=N[C@H]2C(=O)C[C@@H](O)[C@@H]12</smiles>

17-Phényl-trinorPgE 2

Tableau 6. Principaux analogues de $P g F_{2 \alpha}$ utilisés pour la maîtrise de la reproduction en élevage.

\begin{tabular}{|c|c|c|c|c|}
\hline Composés & Noms commerciaux & Firmes & $\begin{array}{c}\text { Mode } \\
\text { d'administration }\end{array}$ & Dose (mg) \\
\hline Alfaprostol & $\begin{array}{c}\text { Gabbrostim, Alphacept, } \\
\text { Alphabedyl }\end{array}$ & Intervet & IM & $\begin{array}{l}\text { Vache : } 8 \\
\text { Truie : } 2 \\
\text { Jument : } 3\end{array}$ \\
\hline Cloprosténol & $\begin{array}{l}\text { Planate, Estrumate, } \\
\text { Uniandine, Estroplan }\end{array}$ & $\begin{array}{c}\text { Schering-Plough } \\
\text { Animal Health Corp., } \\
\text { Pfizer Animal Health }\end{array}$ & IM & $\begin{array}{c}\text { Vache }: 0,5 \\
\text { Truie : } 0,175 \\
\text { Jument : } 0,125-0,5\end{array}$ \\
\hline $\begin{array}{l}\text { Dinoprost } \\
\text { trométhamine }\end{array}$ & Dinolytic, HormoP2alpha & $\begin{array}{c}\text { Pharmacia \& } \\
\text { Upjohn Co. }\end{array}$ & IM & $\begin{array}{l}\text { Vache : } 25 \\
\text { Truie : } 10 \\
\text { Jument }: 5\end{array}$ \\
\hline Dinoprost $\left(\mathrm{PgF}_{2 \alpha}\right)$ & Enzaprost & Sanofi & IM & $\begin{array}{l}\text { Vache : } 25 \\
\text { Truie : } 10\end{array}$ \\
\hline Luprostiol & Prosolvin, Prostpar, Reprodin & Intervet & IM & $7,5-15$ \\
\hline Tiaprost & Iliren & Intervet & IM & $\begin{array}{c}\text { Vache : } 0,75 \\
\text { Jument : } 0,45 \\
\text { Brebis : } 0,2 \\
\text { Truie : } 0,3-0,6\end{array}$ \\
\hline Etiproston & Prostavet, Vetiprost, Suiprost & Virbac & IM & $\begin{array}{l}\text { Vache }: 10 \\
\text { Truie : } 1,3\end{array}$ \\
\hline Fenprostalène & $\begin{array}{l}\text { Synchrosept-B, Bovilène, } \\
\text { Porcilene }\end{array}$ & $\begin{array}{l}\text { Fort-Dodge Animal Health, } \\
\text { Syntex Animal Health }\end{array}$ & SC & $\begin{array}{c}\text { Vache : } 1 \\
\text { Jument : } 0,1-0,25\end{array}$ \\
\hline Fluprosténol & Equimate & $\begin{array}{l}\text { Schering-Plough Animal } \\
\text { Health Corp. }\end{array}$ & IM & Jument : 0,25 \\
\hline
\end{tabular}

synthèse de $\mathrm{PgF}_{2 \alpha}$ durant la lutéolyse. Les analogues de $\mathrm{PgF}_{2 \alpha}$ ou de $\mathrm{PgE}_{1}$ possèdent tous une modification en position 16 (groupement méthyl) ou en position 17 (groupement éther lié à un cycle saturé, à un cycle aromatique avec éventuellement une substitution par des halogènes ou à un hétérocy- cle). Ces substitutions diminuent la vitesse d'élimination de ces substances. 
Les métabolites majeurs des analogues de $\mathrm{PgF}_{2 \alpha}$ ou $\mathrm{PgE}_{1}$ retrouvés dans l'urine correspondent à des dérivés ayant perdu la substitution en position 17 et/ou ayant subi une $\beta$-oxydation à partir de la position 1 (tableau 7). Les prostaglandines et leurs métabolites sont éliminés très rapidement dans les urines et les fèces après l'administration par injection sous-cutanée ou intra musculaire. L'élimination dans le lait est négligeable.

\subsection{2 / Analyse des résidus, biodisponi- bilité et caractérisation toxicologique}

\section{- Stéroïdes}

a) Généralités

Le contrôle de l'utilisation des stéroïdes anabolisants en production animale représente un véritable challenge analytique. En effet, la mise en évidence de pratiques illégales oblige les laboratoires à maîtriser l'analyse de traces, voire d'ultra-traces, dans des matrices biolo- giques variables et plus ou moins complexes. Il s'agit en élevage de prélèvements d'urine, matrice la plus utilisée dans les plans de contrôle des différents Etats membres de l'UE, de matières fécales utilisées en particulier pour le contrôle ciblé des progestagènes, de phanères utilisés pour la mise en évidence à long terme de certains stéroïdes, par exemple le stanozolol, ou encore d'aliments ou de produits suspects découverts dans l'exploitation. A l'abattoir ou à l'étal, mais aussi aux

Tableau 7. Les propriétés métaboliques et les concentrations tissulaires résiduelles de $\mathrm{PgF}_{2 \alpha}$ et de ses analogues.

\begin{tabular}{|c|c|c|c|c|}
\hline Composés & $\begin{array}{l}\text { Principales voies } \\
\text { métaboliques }\end{array}$ & Excrétion & Résidus tissulaires & $\begin{array}{l}\text { Consommation de } \\
\text { résidus maximale } \\
\text { théorique } \\
\text { (en \% de la DJA) }\end{array}$ \\
\hline Alfaprostol & $\begin{array}{l}\text { Voies majeures: } \\
\text { - hydrolyse de l'ester } \\
\text { méthylique } \\
\text { - } \beta \text {-oxydation }\end{array}$ & Urinaire et fécale & $\begin{array}{c}\text { Muscle : 0,05-0,06 } \mathrm{ppb}^{1} \\
\text { Foie : } 2-2,8 \mathrm{ppb} \\
\text { Rein : } 2-3,4 \mathrm{ppb} \\
\text { Graisse : 0,14-0,32 ppb } \\
\text { Lait : } 0,35 \mathrm{ppb}\end{array}$ & $\begin{array}{c}\text { Vache : } 2 \% \\
\text { Truie, jument : }<2 \%\end{array}$ \\
\hline Cloprosténol & $\begin{array}{l}\text { Voies majeures: } \\
\text { - hydrolyse de l'éther chloro- } \\
\text { benzylique (porc, vache) } \\
\text { - conjugaison (porc, vache) } \\
\text { - } \beta \text {-oxydation (vache) } \\
\text { Forme inchangée présente } \\
\text { dans l'urine à } 24 \mathrm{~h}: \\
\text { - porc: } 10-14 \% \\
\text { - vache : } 18 \%\end{array}$ & $\begin{array}{l}\text { Porc : } 50 \% \text { éliminé } \\
\text { dans les urines et fèces } \\
\text { après } 24 \mathrm{~h} \\
\text { Vache : } 52,5 \% \text { élimés } \\
\text { dans l'urine après } 16 \mathrm{~h}\end{array}$ & $\begin{array}{c}\text { Muscle : }<0,04 \mathrm{ppb}^{2} \\
\text { Foie : } 0,05-0,1 \mathrm{ppb} \\
\text { Rein : } 0,1-0,12 \mathrm{ppb} \\
\text { Graisse : }<0,04 \mathrm{ppb} \\
\text { Lait : } 0,012 \mathrm{ppb}\end{array}$ & $\begin{array}{l}\text { Vache : } 4,8 \% \\
\text { Truie : } 6,7 \% \\
\text { Chèvre : } 7 \%\end{array}$ \\
\hline $\begin{array}{l}\text { Dinoprost } \\
\text { trométhamine } \\
\left(\# \mathrm{PgF}_{2 \alpha}\right)\end{array}$ & $\begin{array}{l}\text { Voies majeures: } \\
-\Delta_{13} \text {-réduction et } 15 \text {-oxydation } \\
-\beta \text {-oxydation } \\
\text { Métabolisme très rapide }\end{array}$ & $N^{2}$ & ND & ND \\
\hline Luprostiol & $\begin{array}{l}\text { Voies majeures: } \\
-\beta \text {-oxydation sans identification } \\
\text { formelle }\end{array}$ & $\begin{array}{l}\text { - } 80-100 \% \text { en } 24 \mathrm{~h} \\
\text { dans les urines et fèces } \\
\text { - négligeable dans le } \\
\text { lait }\end{array}$ & $\begin{array}{c}\text { Muscle : non détectable } \\
\text { Foie : } 0,92 \mathrm{ppb}^{3} \\
\text { Rein : } 0,85 \mathrm{ppb}^{3} \\
\text { Graisse : non détectable } \\
\text { Lait : } 0,04 \mathrm{ppb}^{4}\end{array}$ & Vache : $1,2 \%$ \\
\hline Tiaprost & $\begin{array}{l}\text { Voies majeures : } \\
\text { - hydrolyse de groupement } \\
\text { O-thiényl (truie, vache, jument) } \\
\text { - conjugaison à un groupement } \\
\text { sulfate (jument) } \\
\text { Forme inchangée présente } \\
\text { dans l'urine à } 24 \mathrm{~h} \text { : } \\
\text { - porc: } 10-14 \% \\
\text { - vache : } 18 \%\end{array}$ & $\begin{array}{l}\text { - Vache : excrétion } \\
\text { complète en } 24 \mathrm{~h} \\
\text { (urine : } 83 \% \text {, fèces : } \\
16 \% \text {, lait : <0,05\%) } \\
\text { - Truie : } \\
\text { excrétion complète en } \\
72 \mathrm{~h} \text { (urine : } 85 \% \text {, } \\
\text { fèces : } 15 \% \text { ) } \\
\text { - Jument : } \\
91 \% \text { excrétés en } 72 \mathrm{~h} \\
\text { (urine : } 67 \% \text { ) }\end{array}$ & $\begin{array}{c}\text { Muscle : }<0,15 \mathrm{ppb} \\
\text { Foie : } 0,26 \mathrm{ppb} \\
\text { Rein : } 1,44 \mathrm{ppb} \\
\text { Graisse : }<0,15 \mathrm{ppb} \\
\text { Lait : } 0,05 \mathrm{ppb}\end{array}$ & Vache, truie : $3,75 \%$ \\
\hline $\begin{array}{l}\text { Etiproston } \\
\text { méthamine }\end{array}$ & $\begin{array}{l}\text { Voies majeures : } \\
\text { - } \beta \text {-oxydation (truie, vache) } \\
\text { Forme inchangée présente } \\
\text { dans l'urine à } 24 \mathrm{~h}: \\
\text { - truie, vache }:<20 \%\end{array}$ & $\begin{array}{l}\text { Excrétion urinaire } \\
\text { majoritaire. } \\
\text { Excrétion dans le lait en } \\
\text { dessous de la limite de } \\
\text { détection }\end{array}$ & $\begin{array}{c}<\text { à la limite de détection } \\
36 \text { h après injection }\end{array}$ & ND \\
\hline
\end{tabular}

\footnotetext{
* Dose Journalière Admissible.
}

1 Résidus d'alfaprostol à 24 h après administration de 1,5, 3 et 3 mg à des vaches, des juments ou des truies, respectivement. Les données dans le lait proviennent uniquement de vaches traitées.

2 Non déclaré dans le résumé de dossier évalué par l'EMEA.

3 Résidus estimés en équivalents de luprostiol-35S déterminés à 3 jours.

4 Résidus estimés en équivalents de luprostiol-35S déterminés à 2 jours. 
frontières, les matrices privilégiées sont le muscle, le gras de couverture et périrénal, le foie ou le rein. Selon la matrice concernée, l'analyste doit prendre en compte le métabolisme des molécules recherchées pour être capable de démontrer un écart vis-à-vis de la législation en vigueur. L'échantillon quel qu'il soit doit subir plusieurs étapes d'extraction et de purification avant toute détermination de la présence de composés, éventuellement de leur quantification. La mesure proprement dite nécessite à la fois une sensibilité adaptée pour éviter tout risque de fauxnégatif et une spécificité forte pour interdire tout risque de faux-positif. Enfin, l'ensemble de la méthode doit prouver son efficacité pour chaque cou- ple analyte-matrice en mettant en œuvre un processus de validation tel que décrit dans la décision analytique 2002/657/EC. L'ensemble du processus analytique appliqué à un échantillon doit être conduit dans un référentiel qualité adapté (accréditation du laboratoire selon la norme ISO 17025 par exemple).

b) Androgènes naturels ou à utilisation réglementée

\section{- Testostérone}

Les valeurs résiduelles de testostérone trouvées dans le muscle et le foie des animaux implantés sont comprises entre 15 et $350 \mathrm{pg} / \mathrm{g}$ de tissu (tableau 8). Ces variations dans les teneurs mesurées peuvent s'expliquer par des facteurs zootechniques, physiologiques et pharmacologiques (implant utilisé, dose administrée). Ces concentrations en testostérone sont toujours supérieures à celles mesurées parallèlement chez des animaux témoins. Les concentrations retrouvées dans les reins et le tissu adipeux des animaux traités varient entre 0,1 et $1 \mathrm{ng} / \mathrm{g}$ de tissu. A titre de comparaison, les concentrations en testostérone retrouvées dans le tissu adipeux et les reins qui concentrent le plus de résidus s'établissent respectivement à près de 2,8 et $10,9 \mathrm{ng} / \mathrm{g}$ chez le taureau, les teneurs mesurées dans le muscle et le foie variant en moyenne entre 0,5 et $0,7 \mathrm{ng} / \mathrm{g}$ (tableau 8 ).

Tableau 8. Compilation des différentes quantifications de la testostérone présente dans différents tissus animaux en fonction des traitements anabolisants pratiqués ou des situations physiologiques observées.

\begin{tabular}{|c|c|c|c|c|c|c|c|}
\hline \multirow{2}{*}{$\begin{array}{c}\text { Type } \\
\text { zootechnique }\end{array}$} & \multirow{2}{*}{$\begin{array}{l}\text { Traitements ou } \\
\text { situations } \\
\text { physiologiques }\end{array}$} & \multicolumn{4}{|c|}{$\begin{array}{c}\text { Résidus tissulaires en testostérone } \\
\text { (moyenne } \pm \text { écart-type en } \mathrm{pg} / \mathrm{g} \text { ) }\end{array}$} & \multirow{2}{*}{ Méthode } & \multirow{2}{*}{ Références } \\
\hline & & Muscle & Foie & Reins & $\begin{array}{c}\text { Tissu } \\
\text { adipeux }\end{array}$ & & \\
\hline \multirow{5}{*}{ Génisse } & Témoins & $19,6 \pm 7,1$ & $12,9 \pm 2,0$ & $189 \pm 91,6$ & $25,5 \pm 6,9$ & \multirow{15}{*}{ RIA } & \multirow{5}{*}{$\begin{array}{c}\text { Monography on } \\
\text { Residues of } \\
\text { some } \\
\text { Veterinary } \\
\text { Drugs in } \\
\text { Animals and } \\
\text { Foods (FAO/ } \\
\text { OMS, Rome, } \\
\text { 15-23 juin } \\
\text { 1987). } \\
\text { Repris dans } \\
\text { NADA 11-427 } \\
\text { (Suppl.), 1999 }\end{array}$} \\
\hline & $\begin{array}{c}\text { Synovex }^{(\Theta)}-\mathrm{H} \\
\text { (30 jours après } \\
\text { implantation) }\end{array}$ & $102,0 \pm 48,1$ & $34,1 \pm 10,0$ & $451 \pm 201$ & $339 \pm 228$ & & \\
\hline & $\begin{array}{c}\text { Synovex }^{(\otimes)}-\mathrm{H} \\
\text { (61 jours après } \\
\text { implantation) }\end{array}$ & $46,7 \pm 22,3$ & $15,7 \pm 3,4$ & $228 \pm 143$ & $142 \pm 104$ & & \\
\hline & $\begin{array}{c}\text { Synovex }{ }^{(8)}-\mathrm{H} \\
\text { (90 jours après } \\
\text { implantation) }\end{array}$ & $56,7 \pm 34,2$ & $22,6 \pm 7,9$ & $371 \pm 267$ & $115 \pm 69,8$ & & \\
\hline & $\begin{array}{c}\text { Synovex }^{(\Theta)}-\mathrm{H} \\
\text { (120 jours après } \\
\text { implantation) }\end{array}$ & $31,3 \pm 12,4$ & $16,1 \pm 5,3$ & $307 \pm 89,3$ & $32,1 \pm 12,1$ & & \\
\hline \multirow{4}{*}{ Veau femelle } & Témoins & $\begin{array}{l}6 \pm 0,3 \\
(n=2) \\
\end{array}$ & $\begin{array}{c}108 \pm 18 \\
(n=2)\end{array}$ & $\begin{array}{l}96 \pm 53 \\
(n=2) \\
\end{array}$ & $\begin{array}{l}22 \pm 1 \\
(n=2)\end{array}$ & & \multirow{4}{*}{$\begin{array}{c}\text { Roberts et } \\
\text { Cameron } 1986\end{array}$} \\
\hline & $\begin{array}{c}\text { Implix }{ }^{(B)}-B F \\
\text { (15 jours après } \\
\text { implantation) }\end{array}$ & $\begin{array}{c}360 \pm 58 \\
(n=3)\end{array}$ & $\begin{array}{c}196 \pm 104 \\
(n=3)\end{array}$ & $\begin{array}{c}588 \pm 153 \\
(n=3)\end{array}$ & $\begin{array}{c}1027 \pm 620 \\
(n=3)\end{array}$ & & \\
\hline & $\begin{array}{c}\text { Implix }{ }^{(B)}-B F \\
\text { (30 jours après } \\
\text { implantation) }\end{array}$ & $\begin{array}{c}245 \pm 28 \\
(n=3)\end{array}$ & $\begin{array}{l}66 \pm 7 \\
(n=3)\end{array}$ & $\begin{aligned} 564 & \pm 125 \\
(n & =3)\end{aligned}$ & $\begin{array}{c}1258 \pm 600 \\
(n=3)\end{array}$ & & \\
\hline & $\begin{array}{c}\text { Implix }{ }^{(B)}-\mathrm{BF} \\
\text { (50 jours après } \\
\text { implantation) }\end{array}$ & $\begin{array}{c}225 \pm 87 \\
(n=3)\end{array}$ & $\begin{array}{l}71 \pm 22 \\
(n=3)\end{array}$ & $\begin{array}{c}515 \pm 117 \\
(\mathrm{n}=3)\end{array}$ & $\begin{array}{c}750 \pm 157 \\
(n=3)\end{array}$ & & \\
\hline Taureau & \multirow{3}{*}{ Témoins } & $\begin{array}{l}535 \pm 525 \\
\quad(n=4)\end{array}$ & $\begin{array}{c}749 \pm 405 \\
(n=4)\end{array}$ & $\begin{array}{c}2783 \pm \\
2192 \\
(n=3)\end{array}$ & $\begin{array}{c}10950 \pm \\
8683 \\
(n=5)\end{array}$ & & \multirow{3}{*}{$\begin{array}{c}\text { Hoffmann et } \\
\text { Rattenberger } \\
1977\end{array}$} \\
\hline Génisse & & $\begin{array}{c}92 \pm 29 \\
(n=5)\end{array}$ & $\begin{array}{c}193 \pm 101 \\
(\mathrm{n}=5)\end{array}$ & $\begin{array}{c}595 \pm 650 \\
(\mathrm{n}=5)\end{array}$ & $\begin{array}{c}250 \pm 64 \\
(n=5)\end{array}$ & & \\
\hline Veau femelle & & $\begin{array}{l}16 \pm 13 \\
(n=5)\end{array}$ & $\begin{array}{l}39 \pm 18 \\
(n=5)\end{array}$ & $\begin{array}{c}256 \pm 110 \\
(\mathrm{n}=5)\end{array}$ & $\begin{array}{c}178 \pm 118 \\
(\mathrm{n}=5)\end{array}$ & & \\
\hline \multirow{3}{*}{ Vache } & $\begin{array}{l}\text { Gestation } \\
\text { (120 jours) }\end{array}$ & $\begin{array}{c}267 \pm 101 \\
(n=3)\end{array}$ & $\begin{array}{c}52,8 \pm 10,1 \\
(n=3)\end{array}$ & $\begin{array}{c}1513 \pm 331 \\
(n=3)\end{array}$ & $\begin{array}{c}590 \pm 176 \\
(\mathrm{n}=3)\end{array}$ & & \multirow{3}{*}{ Kushinsky 1983} \\
\hline & $\begin{array}{l}\text { Gestation } \\
\text { (180 jours) }\end{array}$ & $\begin{array}{c}343 \pm 117 \\
(n=3)\end{array}$ & $\begin{array}{c}121 \pm 19,4 \\
(n=3)\end{array}$ & $\begin{array}{c}3505 \pm \\
1537 \\
(n=3) \\
\end{array}$ & $\begin{aligned} & 751 \pm 174 \\
&(n=3)\end{aligned}$ & & \\
\hline & $\begin{array}{l}\text { Gestation } \\
(240 \text { jours })\end{array}$ & $\begin{array}{c}418 \pm 180 \\
(n=3)\end{array}$ & $\begin{array}{c}274 \pm 69,4 \\
(n=3)\end{array}$ & $\begin{array}{c}4014 \pm \\
2269 \\
(n=3)\end{array}$ & $\begin{array}{c}694 \pm 231 \\
(n=3)\end{array}$ & & \\
\hline
\end{tabular}


Les connaissances en matière de métabolisme et donc de quantification des principaux métabolites de la testostérone restent limitées. Certains de ces possibles métabolites pourraient néanmoins présenter des propriétés biologiques significatives. Ainsi, la présence d'esters d'acides gras à longue chaîne de la testostérone dont la synthèse dans le tissu adipeux a été démontrée chez le rat (Borg et al 1995) ou celle de la $5 \alpha$-dihydrotestostérone mériterait d'être recherchée. De la même manière, l'identification des différents conjugués (glucuronides, glycosides) permettrait d'établir des méthodes de dosages pertinentes pour quantifier les concentrations tissulaires des métabolites majeurs. Enfin, dans certains tissus présentant des propriétés significatives d'aromatisation des androgènes, le taux de formation de l'œstradiol ou de l'œstrone à partir de la testostérone apportée dans l'implant reste inconnu.

\section{- Acétate de trenbolone}

L'utilisation de l'acétate de trenbolone est interdite dans l'UE mais est autorisée à l'extérieur de la zone Europe, en particulier aux USA ou en Australie. Il est utilisé seul ou associé à un œstrogène et est administré au moyen d'im- plants qui restent présents jusqu'au moment de l'abattage des animaux (tableau 1).

Les teneurs résiduelles tissulaires ont été mesurées par Henricks et al (2001). Quand l'acétate de trenbolone est administré en association avec l'œstradiol, les valeurs moyennes de trenbolone dans les différents tissus destinés à la consommation sont supérieures respectivement à $145 \mathrm{pg} / \mathrm{g}$ et $125 \mathrm{pg} / \mathrm{g}$ après 15 et 30 jours de relargage de l'implant, le rein présentant les valeurs résiduelles les moins élevées, proches de la limite de détection (tableau 9). Les valeurs moyennes de résidus de trenbolone dans le muscle sont comprises entre 200 et $300 \mathrm{pg} / \mathrm{g}$, celles dans le tissu adipeux étant légèrement supérieures. Quand 1'acétate de trenbolone est administré seul, les teneurs résiduelles en trenbolone sont comparables dans le muscle à celles mesurées dans des conditions d'administration combinant acétate de trenbolone et œstradiol. En revanche dans le foie, le rein et le tissu adipeux, les teneurs résiduelles en trenbolone administrée seule représentent le double de celles mesurées dans des conditions d'administration combinant acétate de trenbolone et œstradiol, que ce soit après 15 ou 30 jours de relargage de l'implant (tableau 9).

Les teneurs résiduelles en trenbolone-17 $\alpha$ libre, métabolite principal de la trenbolone dans l'espèce bovine, sont négligeables dans le muscle et faibles dans le tissu adipeux (tableau 9). Elles représentent des teneurs comparables à celles de la trenbolone dans le rein mais sont 4 à 7 fois plus élevées que celles en trenbolone mesurée dans le foie (tableau 9).

Les résultats obtenus au cours des tests de génotoxicité conduits par Metzler et Pfeiffer (2001) sur la trenbolone sont globalement négatifs, ce qu'avait déjà montré Richold (1988). Seule une tendance à l'augmentation du nombre d'adduits à l'ADN sur hépatocytes de rat exprimant des activités de métabolisation très significatives a pu être observée par ces auteurs (tableau 10).

c) Androgènes de synthèse utilisés illégalement

Différentes molécules à activité androgénique ont été synthétisées par le passé, mais n'ont fait l'objet d'aucune étude toxicologique. Elles sont

Tableau 9. Résidus tissulaires en trenbolone et trenbolone-17 $\alpha$ chez des bouvillons traités par des implants contenant l'acétate de trenbolone.

\begin{tabular}{|c|c|c|c|c|c|c|c|c|}
\hline \multirow{2}{*}{$\begin{array}{l}\text { Type } \\
\text { zootech- } \\
\text { nique }\end{array}$} & \multirow{2}{*}{$\begin{array}{c}\text { Traitements } \\
\text { ou situations } \\
\text { physiologiques }\end{array}$} & \multirow{2}{*}{$\begin{array}{c}\text { Type } \\
\text { ou classe } \\
\text { de } \\
\text { métabolites }\end{array}$} & \multicolumn{4}{|c|}{$\begin{array}{l}\text { Résidus tissulaires en trenbolone ou trenbolone-17 } \alpha \\
\text { (moyenne ou moyenne } \pm \text { écart-type en pg/g) }\end{array}$} & \multirow{2}{*}{ Méthode } & \multirow{2}{*}{ Référence } \\
\hline & & & Muscle & Foie & Reins & Tissu adipeux & & \\
\hline \multirow{10}{*}{ Bouvillons } & Témoins & \multirow{5}{*}{ Trenbolone } & $\begin{array}{c}29 \\
(n=8)\end{array}$ & $\begin{array}{c}124 \\
(n=8)\end{array}$ & $\begin{array}{c}124 \\
(n=8)\end{array}$ & $\begin{array}{c}29 \\
(n=8)\end{array}$ & \multirow{10}{*}{ RIA } & \multirow{10}{*}{$\begin{array}{l}\text { Henricks } \\
\text { et al } 2001\end{array}$} \\
\hline & $\begin{array}{c}\text { Finaplix }^{(B}-200 \\
\text { (15 jours après } \\
\text { implantation) }\end{array}$ & & $\begin{array}{c}211,3 \pm 39,5 \\
(n=4)\end{array}$ & $\begin{array}{c}761,7 \pm 161,2 \\
(n=4)\end{array}$ & $\begin{array}{c}387,4 \pm 35,3 \\
(n=4)\end{array}$ & $\begin{array}{c}846,6 \pm 73,2 \\
(n=4)\end{array}$ & & \\
\hline & $\begin{array}{c}\text { Finaplix }^{8}-200 \\
\text { (30 jours après } \\
\text { implantation) }\end{array}$ & & $\begin{array}{l}178,6 \pm 63,1 \\
(n=4)\end{array}$ & $\begin{array}{c}497,7 \pm 67,8 \\
(n=4)\end{array}$ & $\begin{array}{l}337,1 \pm 66,0 \\
(n=4)\end{array}$ & $\begin{array}{l}660,9 \pm 127,4 \\
(n=4)\end{array}$ & & \\
\hline & $\begin{array}{l}\text { Revalor }^{(B)}-200 \\
\text { (15 jours après } \\
\text { implantation) }\end{array}$ & & $\begin{array}{l}279,4 \pm 32,4 \\
(n=4)\end{array}$ & $\begin{array}{l}241,8 \pm 85,8 \\
(n=4)\end{array}$ & $\begin{array}{l}145,6 \pm 26,2 \\
(n=4)\end{array}$ & $\begin{array}{l}378,3 \pm 47,3 \\
(n=4)\end{array}$ & & \\
\hline & $\begin{array}{l}\text { Revalor }^{\beta}-200 \\
\text { (30 jours après } \\
\text { implantation) }\end{array}$ & & $\begin{array}{c}233,8 \pm 43,0 \\
(n=4)\end{array}$ & $\begin{array}{c}185,9 \pm 48,0 \\
(n=4)\end{array}$ & $\begin{array}{c}125,0 \pm 1,5 \\
(n=4)\end{array}$ & $\begin{array}{c}260,2 \pm 87,0 \\
(n=4)\end{array}$ & & \\
\hline & Témoins & \multirow{5}{*}{$\begin{array}{l}\text { Trenbolone } \\
\qquad-17 \alpha\end{array}$} & $\begin{array}{c}14 \\
(\mathrm{n}=8)\end{array}$ & $\begin{array}{c}124 \\
(n=8)\end{array}$ & $\begin{array}{c}124 \\
(n=8)\end{array}$ & $\begin{array}{c}29 \\
(n=8)\end{array}$ & & \\
\hline & $\begin{array}{c}\text { Finaplix }^{8}-200 \\
\text { (15 jours après } \\
\text { implantation) }\end{array}$ & & $\begin{array}{c}15 \\
(n=4)\end{array}$ & $\begin{array}{c}4023 \pm 2415 \\
(n=4)\end{array}$ & $\begin{array}{c}182,3 \pm 282,3 \\
(n=4)\end{array}$ & $\begin{array}{c}194,2 \pm 110,0 \\
(n=4)\end{array}$ & & \\
\hline & $\begin{array}{l}\text { Finaplix }^{8}-200 \\
\text { (30 jours après } \\
\text { implantation) }\end{array}$ & & $\begin{array}{c}14 \\
(n=4)\end{array}$ & $\begin{array}{l}1774 \pm 470 \\
\quad(n=4)\end{array}$ & $\begin{array}{c}124 \\
(n=4)\end{array}$ & $\begin{array}{l}59,5 \pm 14,2 \\
(n=4)\end{array}$ & & \\
\hline & $\begin{array}{l}\text { Revalor }^{8}-200 \\
\text { (15 jours après } \\
\text { implantation) }\end{array}$ & & $\begin{array}{c}16,6 \pm 3,3 \\
(n=4)\end{array}$ & $\begin{array}{c}1550 \pm 992 \\
(n=4)\end{array}$ & $\begin{array}{c}164,5 \pm 47,2 \\
(n=4)\end{array}$ & $\begin{array}{c}52,4 \pm 17,5 \\
(n=4)\end{array}$ & & \\
\hline & $\begin{array}{c}\text { Revalor }^{8}-200 \\
\text { (30 jours après } \\
\text { implantation) }\end{array}$ & & $\begin{array}{c}14 \\
(n=4)\end{array}$ & $\begin{array}{c}802,2 \pm 249,0 \\
(n=4)\end{array}$ & $\begin{array}{c}145,6 \pm 25,1 \\
(n=4)\end{array}$ & $\begin{array}{l}33,8 \pm 7,3 \\
(n=4)\end{array}$ & & \\
\hline
\end{tabular}


Tableau 10. Résumé des observations obtenues lors de l'évaluation génotoxique du zéranol, de l'acétate de mélengestrol et de la trenbolone (d'après Metzler et Pfeiffer 2001).

\begin{tabular}{|c|c|c|c|c|c|}
\hline \multicolumn{2}{|c|}{} & \multicolumn{4}{|c|}{$\begin{array}{c}\text { Tests } \\
\text { Moénotoxiques }\end{array}$} \\
\cline { 3 - 6 } & \multirow{2}{*}{ Molécules } & $\begin{array}{c}\text { Mutations du } \\
\text { gène HPRT } \\
\text { sur cellules } \\
\text { V79 }\end{array}$ & $\begin{array}{c}\text { Mutations } \\
\text { du gène } \\
\text { Lac I sur } \\
\text { E. coli }\end{array}$ & $\begin{array}{c}\text { Micronoyaux } \\
\text { sur cellules } \\
\text { V79 }\end{array}$ & $\begin{array}{c}\text { Adduits à } \\
\text { l'ADN sur } \\
\text { hépatocytes } \\
\text { de rat }\end{array}$ \\
\hline \multirow{2}{*}{ Trenbolone } & Concentrations $(\mu \mathrm{M})$ & $50-125(7)^{1}$ & $1500(5)$ & $50-125(5)$ & $3-30(2)$ \\
\cline { 2 - 6 } & Résultats & - & - & $-(+)^{2}$ & $-(+)^{3}$ \\
\hline \multirow{2}{*}{ Zéranol } & Concentrations $(\mu \mathrm{M})$ & $50-150(4)$ & $400(5)$ & $50-150(3)$ & $3-30(2)$ \\
\cline { 2 - 6 } & Résultats & - & - & $-(+)^{4}$ & - \\
\hline $\begin{array}{c}\text { Acétate de } \\
\text { mélengestrol }\end{array}$ & Concentrations $(\mu \mathrm{M})$ & $50-125(5)$ & $400(5)$ & $20-100(5)$ & \\
\cline { 2 - 6 } & Résultats & - & - & - & \\
\hline
\end{tabular}

1 Nombre d'expériences conduites.

2 Augmentation jusqu'à 3 fois du nombre de micro-noyaux à $125 \mu \mathrm{M}$.

$375 \pm 5$ adduits par 109 nucléotides à $30 \mu \mathrm{M}$ comparés au niveau de base de 0,5 adduit par 109 nucléotides sur hépatocytes non traités.

${ }^{4}$ Augmentation d'environ deux fois du nombre de micro-noyaux à $150 \mu \mathrm{M}$ par rapport au témoin. Observation comparable obtenue avec la zéaralanone et le taléranol ( $\beta$-zéaralanol) à $150 \mu \mathrm{M}$.

néanmoins susceptibles d'être utilisées frauduleusement (figure 4). Les stratégies analytiques de contrôle consistent alors à attester la présence de ces susbtances ou de leurs métabolites. La sensibilité des méthodes s'améliorant progressivement, la traque des fraudes éventuelles peut alors remonter plus loin dans le temps, contrecarrant sérieusement au niveau économique tout tentative de fraude, les délais d'attente à observer avant commercialisation du bétail traité frauduleusement devenant redhibitoires. Les quelques grands principes analytiques utilisés dans les laboratoires de contrôle sont décrits ci-après.

\section{- Préparation de l'échantillon}

La première étape consiste le plus souvent à réaliser une extraction liquide-liquide ou solide-liquide de l'échantillon selon son état physique. Dans le cas des tissus (muscle, foie, rein, etc.), beaucoup de laboratoires préfèrent procéder à une étape préalable de lyophilisation puis de broyage pour une meilleure efficacité et répétabilité du dosage ou de la détection. Ensuite, pour les matrices biologiques (excepté le poil et le plus souvent les fèces), une étape d'hydrolyse chimique ou enzymatique des formes conjuguées est appliquée. Dans le premier cas, la solvolyse ou la méthanolyse sont préférées. Dans le second, des préparations de type arylsulphatase et/ou $\beta$-glucuronidase (suc d'Helix pomatia, Escherichia coli, etc.) sont utilisées. La recherche est alors simplifiée par restriction du suivi aux seuls métabolites de phase I. Des étapes de purification impliquant une extraction en phase solide sur cartouche (SPE) sont alors appliquées. Les stratégies de purification utilisent habituellement une phase inverse sur silice greffée avec des groupements en $\mathrm{C} 8$ ou $\mathrm{C} 18$ ou sur une phase polymérique (polystyrène - divinylbenzène), puis des phases normales de type $\mathrm{NH}_{2}, \mathrm{CN}$ ou encore $\mathrm{SiOH}$. Les phénolstéroïdes (stilbènes, lactones d'acides résorcycliques et œstrogènes) peuvent aussi être efficacement isolés au cours de cette procédure analytique sur des phases échangeuses d'anions, alors que le stanozolol, de par son groupe pyrazolique, peut être purifié sur des échangeurs de cations. Enfin, la CLHP semi-préparative en phase inverse ou normale est parfois utilisée pour conduire des analyses de confirmation.

\section{- Techniques de détection et de me- sure}

Le choix de la technique est conditionné par la complexité de la matrice étudiée, par les teneurs résiduelles, et par l'objectif du contrôle proprement dit : mesure, dépistage ou confirmation. En dépistage, les techniques immunologiques telles que le radioimmunodosage (RIA), l'immunoenzymodosage (ELISA) ou certains dosages par radiorécepteurs (RRA), sont préférées par certaines équipes. Elles ont l'avantage de procurer à la méthode une sensibilité poussée (de l'ordre du picogramme), d'assurer une bonne productivité (gestion possible de larges séries d'échantillons), mais sont limitées en spécificité, entraînant ainsi des risques de faux-positifs importants. Elles nécessitent en outre l'utilisation de plusieurs kits pour couvrir l'ensemble des analytes visés, ce qui peut rendre le coût non négligeable.
D'autres pays, dont la France, utilisent en dépistage comme en confirmation la spectrométrie de masse. Les filtres de masse utilisés dans les laboratoires depuis le début des années 1990 ont été principalement le quadripôle et la trappe ionique en spectrométrie de masse mono-dimensionnelle; depuis quelques années, la mise en place de systèmes triple quadripolaires et l'amélioration des trappes ioniques a permis de faire évoluer presque systématiquement la technique vers la spectrométrie de masse multidimensionnelle $\left(\mathrm{MS}^{\mathrm{n}}\right)$. Jadis limitée à des concentrations qui étaient au mieux de l'ordre du $\mathrm{ng} / \mathrm{g}$ ou $\mathrm{ng} / \mathrm{ml}$ (ppb), la technique autorise aujourd'hui la détection des stéroïdes à des concentrations de l'ordre de la dizaine de pg/g ou $\mathrm{pg} / \mathrm{ml}(\mathrm{ppt})$ et leur identification et leur quantification à des valeurs de l'ordre de la centaine de ppt. La spectrométrie de masse est systématiquement utilisée en couplage avec, le plus souvent, la chromatographie en phase gazeuse sur colonne capillaire (GC-MS) pour obtenir une meilleure séparation des différents métabolites isomères, mais aussi en couplage avec la chromatographie liquide haute performance (LC-MS) pour des séparations de stéroïdes particuliers tels que les esters de progestagènes, le stanozolol, les trenbolone-like ou encore l'analyse directe des conjugués de stéroïdes.

Les hormones stéroïdes naturelles font l'objet d'une approche à part s'appuyant sur le couplage GC-C-IRMS, technique émergente permettant de mesurer finement la composition isotopique en ${ }^{13} \mathrm{C}$ et ${ }^{12} \mathrm{C}$ des stéroïdes et, finalement, de repérer une origine exogène révélée par une composition relativement appauvrie en ${ }^{13} \mathrm{C}$. 


\section{- Précautions analytiques}

Les dosages sont invariablement entourés de précautions analytiques. Il s'agit tout d'abord de l'utilisation systématique d'étalons internes et externes pour garantir a posteriori le bon déroulement des étapes de préparation et de mesure. Ces molécules de référence sont des analogues structuraux des analytes visés ou de préférence les molécules cibles elles-mêmes, marquées au ${ }^{2} \mathrm{H}$ ou au ${ }^{13} \mathrm{C}$. Dans chaque série d'analyses, des échantillons témoins et surchargés sont introduits pour vérifier l'absence de contamination, calculer le taux de récupération et établir une courbe de dosage. Lorsque la présence d'un analyte est suspectée, l'échantillon est généralement réextrait ; l'identité structurale doit être prouvée par un critère chromatographique (temps de rétention comparé à celui de l'étalon) et spectrométrique (intensités relatives des ions ou des transitions). En Europe, la décision analytique 2002/657/EC décrit parfaitement ces critères et les tolérances associées pour pouvoir déclarer un échantillon conforme («compliant») ou non conforme («non compliant»). Les stéroïdes, étant donnée leur appartenance au groupe A de la Directive 96/23/EC, nécessitent au moins 4 points d'identification, c'est-àdire la présence d'au moins quatre ions en spectrométrie de masse basse résolution, deux ions en haute résolution, ou encore deux transitions en spectrométrie de masse multidimensionnelle, répondant à des critères d'intensité absolue (rapport signal sur bruit supérieur à 3 ) et d'intensité relative (superposition des rapports d'intensité des signaux de l'analyte suspecté dans l'échantillon avec ceux de l'analyte de référence).

\section{d) Estrogènes}

\section{- Estrogènes naturels}

Alors que l'établissement de données originales dans le domaine de l'étude du métabolisme de l'œstradiol a été réalisé à la toute fin des années 70 (Dunn et al 1977, Rao et al 1979), ce n'est que récemment que des études importantes menées dans le domaine de l'analyse des résidus d'œstrogènes tissulaires ont été entreprises pour quantifier les métabolites majeurs de l'œstradiol, notamment l'œstradiol-17 $\alpha$ libre ou conjugué sous forme de glucopyranoside ou de glucuronide ainsi que les esters d'acide gras de l'œstradiol (Maume et al 2001, 2003). Jusqu'alors, seuls l'œstradiol (le composé administré), l'œstradiol-17 $\alpha$ et l'œstrone présents sous forme libre ou conjuguée à l'acide glucuronique avaient le plus souvent été pris en compte. De plus, ces analyses de résidus avaient été réalisées par RIA, aucune validation n'ayant été effectuée par des méthodes spectroscopiques telles que la spectrométrie de masse (GC-MS, LC-MS). Vraisemblablement, des problèmes liés au traitement analytique de ces matrices biologiques permettent d'expliquer de très grandes variations dans les résultats obtenus, notamment dans le muscle. En effet, les résultats produits avec les premiers RIA (Hoffmann et al 1975) sont nettement plus variables que ceux obtenus plus récemment (Scippo et al 1993, Henricks et al 2001). Cette difficulté limite la portée des étapes de validation interne de la méthode princeps de dosage par RIA (Henricks et Torrence 1978) qui a été largement utilisée dans l'établissement des valeurs de résidus de l'œstradiol dans des extraits tissulaires figurant dans les dossiers réglementaires de la FDA [(NADA 001-427 Suppl. (1999), 140-992 (1994) et 140-897 Suppl. (1996)]. Si l'on s'appuie sur les dernières données produites en matière d'analyse de résidus en œstradiol administré comme stéroïde anabolisant sous forme d'implant (tableau 1), on peut les résumer comme suit.

Dans les études présentées par Scippo et al (1993) (tableau 11), les

Tableau 11. Compilation des différentes quantifications de l'œstradiol présent dans différents tissus animaux sous forme libre, conjuguée à l'acide glucuronique, à des glycosides ou sous forme d'esters d'acides gras à longue chaîne en fonction des traitements anabolisants pratiqués ou des situations physiologiques observées.

\begin{tabular}{|c|c|c|c|c|c|c|c|c|}
\hline \multirow{2}{*}{$\begin{array}{c}\text { Type } \\
\text { Zootechnique }\end{array}$} & \multirow{2}{*}{$\begin{array}{l}\text { Traitements ou } \\
\text { situations } \\
\text { physiologiques }\end{array}$} & \multirow{2}{*}{$\begin{array}{c}\text { Type ou } \\
\text { classe de } \\
\text { métabolites }\end{array}$} & \multicolumn{4}{|c|}{ Résidus tissulaires en œstradiol (pg/g) } & \multirow[b]{2}{*}{ Méthodes } & \multirow[b]{2}{*}{ Références } \\
\hline & & & Muscle & Foie & Reins & $\begin{array}{c}\text { Tissu } \\
\text { adipeux }\end{array}$ & & \\
\hline \multirow[b]{2}{*}{ Veau } & Témoins & \multirow{2}{*}{$\begin{array}{c}\text { Libres } \\
\text { (moyenne } \pm \\
\text { écart-type) }\end{array}$} & $\begin{array}{c}113 \pm 143 \\
(n=5)\end{array}$ & $\begin{array}{c}73 \pm 136 \\
(n=5)\end{array}$ & $\begin{array}{l}11 \pm 10 \\
(n=5)\end{array}$ & $\begin{array}{c}129 \pm 57 \\
(n=5)\end{array}$ & \multirow[b]{2}{*}{ RIA } & \multirow[b]{2}{*}{$\begin{array}{l}\text { Hoffmann } \\
\text { et al } 1975\end{array}$} \\
\hline & $\begin{array}{c}\mathrm{E}_{2}(20 \mathrm{mg})+\mathrm{P}_{4} \\
(200 \mathrm{mg})(70 \\
\text { jours après } \\
\text { implantation) }\end{array}$ & & $\begin{array}{c}177 \pm 149 \\
(n=6)\end{array}$ & $\begin{array}{c}108 \pm 71 \\
(n=6)\end{array}$ & $\begin{array}{c}29 \pm 28 \\
(n=6)\end{array}$ & $\begin{array}{c}104 \pm 87 \\
(n=6)\end{array}$ & & \\
\hline \multirow[b]{2}{*}{ Bouvillon } & Témoins & \multirow{4}{*}{$\begin{array}{l}\text { Libres } \\
\text { (moyenne) }\end{array}$} & $\begin{array}{c}14 \\
(n=6)\end{array}$ & $\begin{array}{c}14 \\
(n=6)\end{array}$ & - & $\begin{array}{c}10 \\
(n=6)\end{array}$ & \multirow[b]{2}{*}{$\mathrm{RIA}$} & \multirow{2}{*}{$\begin{array}{l}\text { Henricks } \\
\text { et al } 1983\end{array}$} \\
\hline & $\begin{array}{l}\text { Compudose }^{(B)} \\
\text { (90 jours après } \\
\text { implantation) }\end{array}$ & & $\begin{array}{c}17 \\
(n=6)\end{array}$ & $\begin{array}{c}79 \\
(n=6)\end{array}$ & - & $\begin{array}{c}54 \\
(n=6)\end{array}$ & & \\
\hline \multirow[b]{2}{*}{ Génisse } & Témoins & & $\begin{array}{c}5,5 \\
(n=15)\end{array}$ & $\begin{array}{c}1,5 \\
(n=10)\end{array}$ & $\begin{array}{c}2,9 \\
(n=15)\end{array}$ & $\begin{array}{c}13,4 \\
(n=35)\end{array}$ & \multirow[b]{2}{*}{ RIA } & \multirow{2}{*}{$\begin{array}{c}\text { NADA } \\
011-427 \\
\text { (Suppl.), } \\
1999\end{array}$} \\
\hline & $\begin{array}{c}\text { Synovex }^{\circledR}-\mathrm{H} \\
\text { (30 jours après } \\
\text { implantation) }\end{array}$ & & $\begin{array}{c}33,2 \\
(n=20)\end{array}$ & $\begin{array}{c}23,1 \\
(n=10)\end{array}$ & $\begin{array}{c}23,5 \\
(n=10)\end{array}$ & $\begin{array}{c}86,7 \\
(n=20)\end{array}$ & & \\
\hline \multirow[b]{2}{*}{ Génisse } & Témoins & \multirow{2}{*}{$\begin{array}{c}\text { Libres } \\
\text { (moyenne } \pm \\
\text { écart-type) }\end{array}$} & $\begin{array}{l}<6,0 \\
(n=4)\end{array}$ & $\begin{array}{l}<25 \\
(n=4)\end{array}$ & $\begin{array}{c}<25 \\
(n=4)\end{array}$ & $\begin{array}{l}<6,0 \\
(n=4)\end{array}$ & \multirow[b]{2}{*}{ RIA } & \multirow{2}{*}{$\begin{array}{c}\text { NADA } \\
140-992 \\
\text { (Original), } \\
1994\end{array}$} \\
\hline & $\begin{array}{c}\text { Revalor }{ }^{\Theta}-\mathrm{H} \\
\text { (30 jours après } \\
\text { implantation) }\end{array}$ & & $\begin{array}{c}6,7 \pm 1,0 \\
(n=4)\end{array}$ & $\begin{array}{l}<25 \\
(n=4)\end{array}$ & $\begin{array}{c}46,1 \pm 3,7 \\
(n=4)\end{array}$ & $\begin{array}{c}28,5 \pm 1,6 \\
(n=4)\end{array}$ & & \\
\hline \multirow[b]{2}{*}{ Bouvillon } & Témoins & \multirow{2}{*}{$\begin{array}{c}\text { Libres } \\
\text { (moyenne } \pm \\
\text { écart-type) }\end{array}$} & $\begin{array}{l}<6,0 \\
(n=4)\end{array}$ & $\begin{array}{l}<25 \\
(n=4)\end{array}$ & $\begin{array}{c}<25 \\
(n=4)\end{array}$ & $\begin{array}{c}6,1 \pm 1,7 \\
(n=4)\end{array}$ & \multirow[b]{2}{*}{ RIA } & \multirow{2}{*}{$\begin{array}{c}\text { NADA } \\
140-897 \\
\text { (Suppl.), } \\
1996\end{array}$} \\
\hline & $\begin{array}{c}\text { Revalor }^{\Theta}-S \\
\text { (30 jours après } \\
\text { implantation) }\end{array}$ & & $\begin{array}{l}<6,0 \\
(n=4)\end{array}$ & $\begin{array}{l}<25 \\
(n=4)\end{array}$ & $\begin{array}{l}<25 \\
(n=4)\end{array}$ & $\begin{array}{c}16,1 \pm 2,6 \\
(n=4)\end{array}$ & & \\
\hline
\end{tabular}




\begin{tabular}{|c|c|c|c|c|c|c|c|c|c|c|c|}
\hline \multirow{2}{*}{$\begin{array}{c}\text { Type } \\
\text { Zootechnique }\end{array}$} & \multirow{2}{*}{$\begin{array}{l}\text { Traitements ou } \\
\text { situations } \\
\text { physiologiques }\end{array}$} & \multirow{2}{*}{$\begin{array}{c}\text { Type ou } \\
\text { classe de } \\
\text { métabolites }\end{array}$} & \multicolumn{7}{|c|}{ Résidus tissulaires en œstradiol (pg/g) } & \multirow[b]{2}{*}{ Méthodes } & \multirow[b]{2}{*}{ Références } \\
\hline & & & \multicolumn{2}{|c|}{ Muscle } & \multicolumn{2}{|c|}{ Foie } & Reins & \multicolumn{2}{|c|}{$\begin{array}{c}\text { Tissu } \\
\text { adipeux }\end{array}$} & & \\
\hline \multirow{3}{*}{ Bouvillon } & $\begin{array}{c}\text { Témoins } \\
\text { (15 jours / } \\
30 \text { jours) } \\
\end{array}$ & \multirow{3}{*}{$\begin{array}{c}\text { Libres } \\
\text { (moyenne } \pm \\
\text { écart-type) }\end{array}$} & \multicolumn{2}{|c|}{$\begin{array}{c}<5,0 \\
(n=2 / 2)\end{array}$} & \multicolumn{2}{|c|}{$\begin{array}{l}<24,0 \\
(n=2 / 2)\end{array}$} & $\begin{array}{c}61,2 / 98,6 \\
(n=2 / 2) \\
\end{array}$ & \multicolumn{2}{|c|}{$\begin{array}{c}<5,0 \\
(n=2 / 2)\end{array}$} & \multirow{3}{*}{ RIA } & \multirow{3}{*}{$\begin{array}{c}\text { NADA } \\
140-992 \\
(1999)\end{array}$} \\
\hline & $\begin{array}{l}\text { Revalor }{ }^{8}-200 \\
(15 \text { jours après } \\
\text { implantation) }\end{array}$ & & \multicolumn{2}{|c|}{$\begin{array}{c}13,4 \pm 2,4 \\
(n=4)\end{array}$} & \multicolumn{2}{|c|}{$\begin{array}{c}84,8 \pm 23,9 \\
(n=4)\end{array}$} & $\begin{array}{c}60,4 \pm 20,7 \\
(n=4)\end{array}$ & \multicolumn{2}{|c|}{$\begin{array}{c}67,1 \pm 16,9 \\
(n=4)\end{array}$} & & \\
\hline & $\begin{array}{l}\text { Revalor }^{\mathbb{B}}-200 \\
\text { (30 jours après } \\
\text { implantation) }\end{array}$ & & \multicolumn{2}{|c|}{$\begin{array}{c}13,6 \pm 3,7 \\
(n=4)\end{array}$} & \multicolumn{2}{|c|}{28,6} & $\begin{array}{c}64,9 \pm 22,2 \\
(n=4)\end{array}$ & \multicolumn{2}{|c|}{$\begin{array}{c}59,4 \pm 20,5 \\
(n=4)\end{array}$} & & \\
\hline \multirow[b]{2}{*}{ Bouvillons } & Témoins & \multirow[b]{2}{*}{$\begin{array}{c}\text { Libres } \\
\text { (moyenne } \pm \\
\text { écart-type) }\end{array}$} & \multicolumn{2}{|c|}{$\begin{array}{c}14 \pm 1,2 \\
(n=6)\end{array}$} & \multicolumn{2}{|c|}{$\begin{array}{c}14 \pm 0,9 \\
(n=6)\end{array}$} & - & \multicolumn{2}{|c|}{$\begin{array}{c}10 \pm 1,0 \\
(n=6)\end{array}$} & \multirow[b]{2}{*}{ RIA } & \multirow[b]{2}{*}{$\begin{array}{l}\text { Henricks } \\
\text { et al } 2001\end{array}$} \\
\hline & $\begin{array}{c}\text { Implant }\left(\mathrm{E}_{2}: 20 \%\right. \\
\text { du poids de } \\
\text { l'implant silastic) } \\
\text { (90 jours après } \\
\text { implantation) }\end{array}$ & & $\begin{array}{c}0 \mathrm{~h}^{*} \\
17 \pm \\
1,6 \\
(\mathrm{n}=9) \\
\end{array}$ & $\begin{array}{c}07 \\
-24 h \\
13 \pm \\
1,0 \\
(n=9)\end{array}$ & $\begin{array}{c}0 \mathrm{~h} \\
79 \pm \\
3,6 \\
(\mathrm{n}=9) \\
\end{array}$ & $\begin{array}{c}-24 h \\
42 \pm \\
2,1 \\
(n=9) \\
\end{array}$ & - & $\begin{array}{c}0 \mathrm{~h} \\
\\
54 \pm \\
2,7 \\
(\mathrm{n}=9)\end{array}$ & $\begin{array}{c}-24 h \\
29 \pm \\
1,9 \\
(n=9)\end{array}$ & & \\
\hline Génisses & \multirow{2}{*}{ Témoins } & \multirow{2}{*}{$\begin{array}{c}\text { Libres } \\
\text { (moyenne } \pm \\
\text { écart-type) }\end{array}$} & $\begin{array}{r}12= \\
2 \mathrm{n}=\end{array}$ & & $\begin{array}{r}38,3 \\
\quad n=\end{array}$ & $\begin{array}{l} \pm 1,9 \\
18) \\
\end{array}$ & $\begin{array}{c}39,8 \pm 3,7 \\
(n=18)\end{array}$ & & 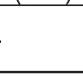 & & Henricks \\
\hline Bouvillons & & & $\begin{array}{r}14,4 \\
(n=\end{array}$ & $\begin{array}{l} \pm 1,4 \\
14)\end{array}$ & $\begin{array}{r}12 \pm \\
(n=\end{array}$ & $\begin{array}{l}0,6 \\
14)\end{array}$ & $\begin{array}{c}12,6 \pm 0,9 \\
(n=14)\end{array}$ & & . & RIA & et al 2001 \\
\hline & Témoins & Libres + & $\begin{array}{l}3,5 \\
(\mathrm{n}=\end{array}$ & $\begin{array}{l}33,2 \\
34)\end{array}$ & $\begin{array}{l}5,3 \\
(\mathrm{n}=\end{array}$ & $\begin{array}{l}-53 \\
24)\end{array}$ & $\begin{array}{c}7,9-69 \\
(n=23)\end{array}$ & & & & \\
\hline $\begin{array}{l}\text { veaux (males } \\
\text { et femelles) }\end{array}$ & $\begin{array}{c}\text { Revalor }^{(\otimes)} \text { ou } \\
\text { Implix }^{(B} \text { BM ou } \\
\text { Crestar }^{(B)} \text { F ou M }\end{array}$ & $\begin{array}{l}\text { conjugués } \\
\text { (min-max) }\end{array}$ & $\begin{array}{l}11- \\
(n=\end{array}$ & 80 & $\begin{array}{r}5-1 \\
(n=\end{array}$ & $\begin{array}{l}650 \\
111) \\
\end{array}$ & $\begin{array}{c}6,4-589 \\
(n=100)\end{array}$ & 9,3 & $\begin{array}{l}358 \\
103)\end{array}$ & RIA & $\begin{array}{l}\text { Sclppo } \\
\text { et al } 1993\end{array}$ \\
\hline & & $\begin{array}{c}\text { Libres } \\
\text { (moyenne } \pm \\
\text { écart-type) }\end{array}$ & $\begin{array}{r}20,1 \\
(n\end{array}$ & $\begin{array}{l} \pm 3,5 \\
2)\end{array}$ & $\begin{array}{r}13,2 \\
(n=\end{array}$ & $\begin{array}{l} \pm 6,9 \\
2)\end{array}$ & $\begin{array}{c}28,0 \pm 9,3 \\
(n=2)\end{array}$ & & . & & \\
\hline Veau & $\begin{array}{l}{\left[{ }^{3} \mathrm{H}\right]-\text { Revalor }^{(1)}} \\
\text { (33 jours après } \\
\text { implantation) }\end{array}$ & $\begin{array}{c}\text { Conjugués } \\
\text { (moyenne } \pm \\
\text { écart-type) }\end{array}$ & $\begin{array}{r}0,33 \\
(\mathrm{n}\end{array}$ & $\begin{array}{l}0,16 \\
2)\end{array}$ & & & $\begin{array}{c}69,9 \pm 54,4 \\
(n=2)\end{array}$ & & . & $\begin{array}{l}\text { Radio- } \\
\text { métrie }\end{array}$ & $\begin{array}{l}\text { D'après } \\
\text { Paris } \\
\text { et al } 1993\end{array}$ \\
\hline & & $\begin{array}{c}\text { Esters } \\
\text { (moyenne } \pm \\
\text { écart-type) }\end{array}$ & $\begin{array}{r}5,8 \\
(n\end{array}$ & 2,5 & & & - & & . & & \\
\hline Voch & Phase folliculaire & Libres & & & & & - & & & RIA & Henricks \\
\hline vacne & Phase lutéale & (moyenne) & & & & & - & & & RIA & et al 1983 \\
\hline & 120 jours & & 13,3 & $\pm 5,2$ & 82,5 & 75,9 & $118,0 \pm 58,6$ & 48,1 & $=19,8$ & & Kushinsky, \\
\hline Vache en & 180 jours & & 27,3 & 14,3 & 380 & 280 & $230,0 \pm 99,9$ & 71,5 & $=37,2$ & & $\begin{array}{l}1983 \text { (cile } \\
\text { par }\end{array}$ \\
\hline gestation & 240 jours & $\begin{array}{l}\text { (moyenne } \pm \\
\text { écart-type) }\end{array}$ & 32,7 & 16,1 & 1027 & \pm 365 & $274 \pm 84,8$ & 67,5 & $=34,6$ & RIA & $\begin{array}{l}\text { Hoffmann et } \\
\text { Evers, } \\
1986)\end{array}$ \\
\hline & & $\begin{array}{c}\text { Libres } \\
\text { (moyenne } \pm \\
\text { écart-type) }\end{array}$ & 5,0 & 2,4 & $\begin{array}{r}1,4 \\
(n\end{array}$ & $\begin{array}{l}0,6 \\
5)\end{array}$ & $\begin{array}{c}2,4 \pm 1,1 \\
(n=5)\end{array}$ & & & & \\
\hline & $\begin{array}{l}\text { Témoins } \\
(n=5)\end{array}$ & $\begin{array}{l}\text { Conjugués } \\
\text { (moyenne } \pm \\
\text { écart-type) }\end{array}$ & & & $\begin{array}{r}9,2 \\
(\mathrm{n}\end{array}$ & $\begin{array}{l}5,8 \\
5)\end{array}$ & $\left(\begin{array}{c}0 \\
(n=5)\end{array}\right.$ & & & & \\
\hline Bouv & & $\begin{array}{c}\text { Esters } \\
\text { (moyenne } \pm \\
\text { écart-type) }\end{array}$ & & & $\begin{array}{c}13,0 \\
(n\end{array}$ & $\begin{array}{l} \pm 1,4 \\
5)\end{array}$ & $\begin{array}{c}4,6 \pm 5,9 \\
(n=5)\end{array}$ & & & MS & Maume et al \\
\hline Bouvillons & & $\begin{array}{c}\text { Libres } \\
\text { (moyenne } \pm \\
\text { écart-type) }\end{array}$ & $\begin{array}{c}22,5 \\
(n\end{array}$ & $\begin{array}{l} \pm 6,6 \\
4)\end{array}$ & $\begin{array}{r}35,0 \\
(n\end{array}$ & $\begin{array}{l}45,7 \\
4)\end{array}$ & $\begin{array}{c}32,5 \pm 16,6 \\
(n=4)\end{array}$ & $\begin{array}{r}41,3 \\
(n\end{array}$ & $\begin{array}{l}=19,2 \\
=4)\end{array}$ & GC-HRIVIS & 2003 \\
\hline & $\begin{array}{l}\text { Revalor }^{\circledR} \\
\text { (90 jours après } \\
\text { implantation) }\end{array}$ & $\begin{array}{l}\text { Conjugués } \\
\text { (moyenne } \pm \\
\text { écart-type) }\end{array}$ & & & $\begin{array}{c}14,5 \\
(n\end{array}$ & $\begin{array}{l} \pm 6,5 \\
4)\end{array}$ & $\begin{array}{c}15 \pm 11,6 \\
(n=4)\end{array}$ & & & & \\
\hline & & $\begin{array}{c}\text { Esters } \\
\text { (moyenne } \pm \\
\text { écart-type) }\end{array}$ & & & $\begin{array}{r}21,8 \\
(n\end{array}$ & :12,1 & $\begin{array}{c}2,8 \pm 1,9 \\
(n=4)\end{array}$ & $\begin{array}{r}33,5 \\
(\mathrm{n}\end{array}$ & $\begin{array}{l}=11,1 \\
=4)\end{array}$ & & \\
\hline
\end{tabular}

* Moment de retrait de l'implant par rapport à la date d'abattage de l'animal.

teneurs en œstradiol libre et conjugué dans le muscle sont toutes inférieures à $280 \mathrm{pg} / \mathrm{g}$, les valeurs moyennes mesurées chez des animaux traités par différents implants contenant de l'œstradiol étant inférieures à $33 \mathrm{pg} / \mathrm{g}$, les valeurs moyennes trouvées chez des animaux non traités étant comprises entre 5 et $20 \mathrm{pg} / \mathrm{g}$. Ces valeurs ont été confirmées par Maume et al (2003) qui ont de plus noté une augmentation des valeurs moyennes avec le nombre d'implants utilisés. A titre de comparaison, celles mesurées chez la vache en fin de gestation sont en moyenne de $32,7 \mathrm{pg} / \mathrm{g}$. Les valeurs mesurées grâce à une méthode radiométrique qui utilise des implants contenant de l'œstradiol tritié sont du 
même ordre de grandeur, mais permettent en plus de mesurer des quantités d'esters d'acides gras à longue chaîne de l'œstradiol de l'ordre de 5 pg/g (Paris et al 1993). La présence de ces esters semble cependant très variable dans le muscle d'animaux traités par un seul implant alors que les teneurs résiduelles de ces esters sont beaucoup moins variables chez les animaux traités par deux ou quatre implants, les valeurs étant néanmoins toujours inférieures à 10 pg/g (Maume et al 2003).

Tout en avoisinant le double de concentration, les teneurs en œstradiol libre dans le tissu adipeux varient parallèlement à celles trouvées dans le muscle. De plus, Maume et al (2003) ont montré que les teneurs en ostradiol et celles en œstradiol estérifié à des acides gras à longue chaîne augmentaient proportionnellement au nombre d'implants utilisés.

Les teneurs en œstradiol libre dans le foie et le rein ne sont guère différentes de celles retrouvées dans le muscle même si, pour certains résultats de dosage présentés dans le tableau 11, la sensibilité de détection dans ces tissus n'est pas satisfaisante [NADA 140-992 $(1994,1999)$ et NADA-140-897 (1996)]. Les teneurs en astradiol conjugué à l'acide glucuronique dans le foie et le rein d'animaux implantés sont deux fois moindres que celles en œstradiol libre (Maume et al 2003). Elles sont nettement inférieures à celles mesurées dans les mêmes organes chez la vache en fin de gestation.
Les quantifications systématiques de résidus de l'ensemble des œstrogènes (œstradiol, œstrone et œstradiol-17 $\alpha$ ) ont fait l'objet d'assez peu d'études, soit par RIA (Scippo et al 1993), soit par radiométrie (Paris et al 1993), soit par spectrométrie de masse (Maume et al 2001, 2003) (tableau 12). Les concentrations en œstrone mesurées par RIA chez des animaux ayant reçu un traitement anabolisant sont du même ordre de grandeur que celles en œstradiol. Une quantification plus précise par radiométrie des métabolites libres et conjugués a permis cependant d'établir que dans le muscle, le foie et le rein, les concentrations en œstrone libre sont entre 3 et 5 fois plus faibles que celles en œstradiol, alors que celles en œstrone conjuguée sont comparables à celles en œstradiol (tableaux 11 et 13). Chez ce type d'animal traité, cette même méthode donne aussi les concentrations en œstradiol-17 $\alpha$ libre et conjugué dans le muscle, le foie et le rein. Scippo et al (1993) ont mesuré par RIA sur des extraits hépatiques la quantité totale d'œstradiol-17 $\alpha$ (libre et conjugué) chez des veaux implantés : les valeurs sont comprises entre 0,3 et 4,2 ng/g de tissu (tableau 14). Celles-ci sont largement supérieures aux valeurs maximales trouvées chez des animaux non implantés $(<0,8 \mathrm{ng} / \mathrm{g})$ et déterminent en fait la quasi-totalité des résidus tissulaires d'œstrogènes. Maume et al (2003) ont montré que les teneurs en œstradiol-17 $\alpha$ libre qui étaient retrouvées dans le foie et le rein de bouvillons implantés représentaient la part la plus importante des résidus d'œstrogènes (tableau 14). La méthode radiométrique a permis de préciser dans le foie de deux veaux implantés la valeur moyenne en l'œstradiol-17 $\alpha$ libre : $0,03 \mathrm{ng} / \mathrm{g}$ de tissu, ainsi que celle en œstradiol$17 \alpha$ conjugué à l'acide glucuronique ou au glucose : 1,75 ng/g (Paris et al 1993). Cette dernière valeur est près de 4 fois supérieure à celle mesurée dans le rein de ces animaux. Les concentrations en l'œstradiol-17 $\alpha$ libre et conjugué dans le muscle sont négligeables (0,9 - 2,5 pg/g) (Paris et al 1993), ce que retrouvent aussi Maume et al (2003). La méthode radiométrique présente de plus un intérêt évident dans la quantification des différents conjugués de l'œstradiol-17 $\alpha$. Contrairement à ce qui est observé chez des animaux plus âgés pour lesquels la rumination est pleinement fonctionnelle (Dunn et al 1977, Rao et al 1979) et chez lesquels le dérivé œstradiol-17 $\alpha$-17-glucopyranoside représente près de $40 \%$ des métabolites hépatiques de l'œstradiol, ce même métabolite chez des veaux de boucherie recevant une alimentation exclusivement lactée représente moins de $2 \%$ des astrogènes dans le foie (Paris et al 1993). Chez des bouvillons implantés, les teneurs hépatiques en conjugués glycosides sont du même ordre de grandeur que celle en glucuronides, le total en conjugués polaires représentant moins de la moitié de la fraction en œstradiol-17 $\alpha$ libre (Maume et al 2003). Ainsi dans l'espèce bovine, l'âge, la race, le sexe et le régime alimentaire peuvent apparaître comme des facteurs de variation non négligeables dans l'orientation des voies de conjugaison.

Tableau 12. Compilation des différentes quantifications des œstrogènes totaux présents dans différents tissus animaux sous forme libre, conjuguée à l'acide glucuronique, à des glycosides ou sous forme d'esters d'acides gras à longue chaîne ou enfin liés aux macromolécules en fonction des traitements anabolisants pratiqués ou des situations physiologiques observées.

\begin{tabular}{|c|c|c|c|c|c|c|c|c|}
\hline \multirow{2}{*}{$\begin{array}{c}\text { Types } \\
\text { Zootechniques }\end{array}$} & \multirow{2}{*}{$\begin{array}{l}\text { Traitements ou } \\
\text { Situations } \\
\text { Physiologiques }\end{array}$} & \multirow{2}{*}{$\begin{array}{c}\text { Type ou } \\
\text { Classes de } \\
\text { Métabolites }\end{array}$} & \multicolumn{4}{|c|}{$\begin{array}{c}\text { QEstrogènes totaux } \\
\text { (moyenne } \pm \text { écart-type en pg/g) }\end{array}$} & \multirow{2}{*}{ Méthodes } & \multirow{2}{*}{ Références } \\
\hline & & & Muscle & Foie & Reins & $\begin{array}{c}\text { Tissu } \\
\text { Adipeux }\end{array}$ & & \\
\hline Génisse & \multirow{2}{*}{ Témoins } & \multirow{2}{*}{ Libres } & $\begin{array}{c}13,0 \pm 1,1 \\
(n=18)\end{array}$ & $\begin{array}{c}71,0 \pm 3,7 \\
(n=18)\end{array}$ & $\begin{array}{c}70,8 \pm 3,7 \\
(\mathrm{n}=18) \\
\end{array}$ & - & \multirow{2}{*}{ RIA } & \multirow{2}{*}{$\begin{array}{l}\text { Henricks } \\
\text { et al } 1983\end{array}$} \\
\hline Bouvillon & & & $\begin{array}{l}12,5 \pm 0,7 \\
(n=14)\end{array}$ & $\begin{array}{c}27,6 \pm 3,3 \\
(n=14)\end{array}$ & $\begin{array}{l}26,0 \pm 2,9 \\
(n=14)\end{array}$ & - & & \\
\hline \multirow[b]{2}{*}{ Veaux femelles } & Témoins & \multirow[b]{2}{*}{$\begin{array}{l}\text { Libres + } \\
\text { conjugués }\end{array}$} & $2 \pm 1,5$ & $600 \pm 339$ & $270 \pm 227$ & - & \multirow[b]{2}{*}{ RIA } & \multirow[b]{2}{*}{$\begin{array}{c}\text { Meyer } \\
\text { et al } 1984\end{array}$} \\
\hline & $\begin{array}{c}\mathrm{E}_{2} \text {-benzoate } \\
(20 \mathrm{mg})+\mathrm{T}- \\
\text { propionate } \\
(200 \mathrm{mg}) \\
\text { (75 jours après } \\
\text { implantation) }\end{array}$ & & $16 \pm 7,5$ & $854 \pm 417$ & $780 \pm 435$ & - & & \\
\hline Veau & $\begin{array}{c}\left.{ }^{3} \mathrm{H}\right]- \text { Revalor } \\
\text { (33 jours après } \\
\text { implantation) }\end{array}$ & $\begin{array}{l}\text { Libres + liés } \\
+ \text { conjugués }\end{array}$ & $\begin{array}{c}75,5 \pm 6,4 \\
(n=2)\end{array}$ & $\begin{array}{c}3096 \pm 974 \\
(n=2)\end{array}$ & $\begin{array}{c}1673 \pm 635 \\
(\mathbf{n}=2)\end{array}$ & $\begin{array}{c}302 \pm 1 \\
(n=2)\end{array}$ & Radiométrie & $\begin{array}{c}\text { D'après } \\
\text { Paris et al } \\
1993 \\
\end{array}$ \\
\hline
\end{tabular}


Tableau 13. Compilation des différentes quantifications de l'œstrone présent dans différents tissus animaux sous forme libre, conjuguée à l'acide glucuronique en fonction des traitements anabolisants pratiqués ou des situations physiologiques observées.

\begin{tabular}{|c|c|c|c|c|c|c|c|c|}
\hline \multirow{2}{*}{$\begin{array}{c}\text { Type } \\
\text { zootechnique }\end{array}$} & \multirow{2}{*}{$\begin{array}{l}\text { Traitements ou } \\
\text { situations } \\
\text { physiologiques }\end{array}$} & \multirow{2}{*}{$\begin{array}{l}\text { Types ou } \\
\text { classes de } \\
\text { métabolites }\end{array}$} & \multicolumn{4}{|c|}{$\begin{array}{l}\text { Résidus tissulaires en œstrone } \\
(\mathrm{pg} / \mathrm{g})\end{array}$} & \multirow{2}{*}{ Méthodes } & \multirow{2}{*}{ Références } \\
\hline & & & Muscle & Foie & Reins & Tissu adipeux & & \\
\hline \multirow[b]{2}{*}{ Veaux } & Témoins & \multirow{2}{*}{$\begin{array}{c}\text { Libres } \\
\text { (moyenne } \pm \\
\text { écart-type) }\end{array}$} & $\begin{array}{l}75 \pm 38 \\
(n=5)\end{array}$ & $\begin{array}{c}204 \pm 88 \\
(n=5)\end{array}$ & $\begin{array}{l}47 \pm 38 \\
(n=5)\end{array}$ & $\begin{array}{c}275 \pm 84 \\
(n=5)\end{array}$ & \multirow[b]{2}{*}{ RIA } & \multirow{2}{*}{$\begin{array}{l}\text { Hoffmann } \\
\text { et al } 1975\end{array}$} \\
\hline & $\begin{array}{c}E_{2}(20 \mathrm{mg})+P_{4} \\
(200 \mathrm{mg})(70 \text { jours } \\
\text { après implantation) }\end{array}$ & & $\begin{array}{l}84 \pm 65 \\
(n=6)\end{array}$ & $\begin{array}{c}271 \pm 144 \\
(n=6)\end{array}$ & $\begin{array}{l}81 \pm 76 \\
(n=6)\end{array}$ & $\begin{array}{c}252 \pm 183 \\
(n=6)\end{array}$ & & \\
\hline \multirow[b]{2}{*}{ Bouvillon } & Témoins & \multirow{2}{*}{$\begin{array}{c}\text { Libres } \\
\text { (moyenne) }\end{array}$} & $\begin{array}{c}6 \\
(n=6)\end{array}$ & $\begin{array}{c}20 \\
(n=6)\end{array}$ & & $\begin{array}{c}23 \\
(n=6)\end{array}$ & \multirow[b]{2}{*}{ RIA } & \multirow{2}{*}{$\begin{array}{l}\text { Henricks } \\
\text { et al } 1983\end{array}$} \\
\hline & $\begin{array}{c}\text { Compudose }^{(8)}(90 \\
\text { jours après } \\
\text { implantation) }\end{array}$ & & $\begin{array}{c}8 \\
(n=6)\end{array}$ & $\begin{array}{c}57 \\
(n=6)\end{array}$ & & $\begin{array}{c}55 \\
(n=6)\end{array}$ & & \\
\hline \multirow{2}{*}{$\begin{array}{l}\text { Veaux } \\
\text { (mâles et } \\
\text { femelles) }\end{array}$} & Témoins & \multirow{2}{*}{$\begin{array}{l}\text { Libres + } \\
\text { Conjugués } \\
\text { (min-max) }\end{array}$} & $\begin{array}{c}15-78 \\
(n=3)\end{array}$ & $\begin{array}{c}170-198 \\
(n=3)\end{array}$ & $\begin{array}{l}23-166 \\
(\mathrm{n}=3)\end{array}$ & $\begin{array}{l}80-94 \\
(n=3)\end{array}$ & \multirow[b]{2}{*}{ RIA } & \multirow[b]{2}{*}{$\begin{array}{l}\text { Scippo } \\
\text { et al } 1993\end{array}$} \\
\hline & $\begin{array}{c}\text { Revalor }^{(B)} \text { ou Implix } \\
\text { BM ou Crestar } \\
\text { ou M } \\
\end{array}$ & & $\begin{array}{c}3-72 \\
(n=18)\end{array}$ & $\begin{array}{l}73-284 \\
(n=18)\end{array}$ & $\begin{array}{c}34-144 \\
(n=18)\end{array}$ & $\begin{array}{c}29-149 \\
(n=18)\end{array}$ & & \\
\hline \multirow{2}{*}{ Veau } & \multirow{2}{*}{$\begin{array}{c}{\left[{ }^{3} \mathrm{H}\right]-\text { Revalor }^{\circledR}(33} \\
\text { jours après } \\
\text { implantation) }\end{array}$} & $\begin{array}{c}\text { Libres } \\
\text { (moyenne } \pm \\
\text { écart-type) } \\
\end{array}$ & $\begin{array}{c}3,0 \pm 0,1 \\
(n=2)\end{array}$ & $\begin{array}{c}2,5 \pm 0,3 \\
(n=2)\end{array}$ & $\begin{array}{c}11,3 \pm 3,4 \\
(n=2)\end{array}$ & & \multirow{2}{*}{$\begin{array}{l}\text { Radio- } \\
\text { métrie }\end{array}$} & \multirow{2}{*}{$\begin{array}{c}\text { D'après } \\
\text { Paris et al } \\
1993\end{array}$} \\
\hline & & $\begin{array}{c}\text { Conjugués } \\
\text { (moyenne } \pm \\
\text { écart-type) }\end{array}$ & $\begin{array}{l}<1,0 \\
(n=2)\end{array}$ & $\begin{array}{c}60,8 \pm 35,3 \\
(n=2)\end{array}$ & $\begin{array}{c}43,7 \pm 29,8 \\
(n=2)\end{array}$ & & & \\
\hline \multirow{5}{*}{ Vache } & Phase folliculaire & \multirow{9}{*}{$\begin{array}{c}\text { Libres } \\
\text { (moyenne } \pm \\
\text { écart-type) }\end{array}$} & $\begin{array}{c}30,8 \pm 3,9 \\
(n=8)\end{array}$ & $\begin{array}{l}23,0 \pm 2,8 \\
(\mathrm{n}=8)\end{array}$ & $\begin{array}{l}13,5 \pm 1,6 \\
(n=8)\end{array}$ & $\begin{array}{c}28,4 \pm 3,3 \\
(\mathrm{n}=8)\end{array}$ & \multirow{5}{*}{ RIA } & \multirow{5}{*}{$\begin{array}{l}\text { Henricks } \\
\text { et al } 1983\end{array}$} \\
\hline & Phase lutéale & & $\begin{array}{c}18,9 \pm 1,6 \\
(n=8)\end{array}$ & $\begin{array}{l}14,3 \pm 1,6 \\
(n=8)\end{array}$ & $\begin{array}{c}15,1 \pm 4,6 \\
(n=8)\end{array}$ & $\begin{array}{c}25,9 \pm 4,1 \\
(n=8)\end{array}$ & & \\
\hline & $\begin{array}{c}\text { Gestation } 1^{\mathrm{er}} \\
\text { trimestre }\end{array}$ & & $\begin{array}{c}13,2 \pm 2,9 \\
(n=5)\end{array}$ & $\begin{array}{l}24,5 \pm 7,9 \\
(n=5)\end{array}$ & $\begin{array}{c}10,0 \pm 4,0 \\
(n=5)\end{array}$ & $\begin{array}{c}18,0 \pm 2,8 \\
(n=5)\end{array}$ & & \\
\hline & $\begin{array}{c}\text { Gestation } 2^{e} \\
\text { trimestre }\end{array}$ & & $\begin{array}{c}136,0 \pm \\
13,0 \\
(n=9)\end{array}$ & $\begin{array}{c}125,0 \pm \\
26,0 \\
(n=9)\end{array}$ & $\begin{array}{c}262,0 \pm \\
67,0 \\
(n=9) \\
\end{array}$ & $\begin{array}{c}462,0 \pm 55,0 \\
(n=9)\end{array}$ & & \\
\hline & $\begin{array}{c}\text { Gestation } 3^{\mathrm{e}} \\
\text { trimestre }\end{array}$ & & $\begin{array}{c}208,0 \pm \\
43,0 \\
(n=9)\end{array}$ & $\begin{array}{c}252,0 \pm \\
53,0 \\
(n=9) \\
\end{array}$ & $\begin{array}{c}550,0 \pm \\
72,0 \\
(n=9)\end{array}$ & $\begin{array}{c}3687 \pm 549 \\
(n=9)\end{array}$ & & \\
\hline \multirow{3}{*}{ Vache } & $\begin{array}{c}120 \text { jours de } \\
\text { gestation }\end{array}$ & & $\begin{array}{l}156,0 \pm \\
79,3\end{array}$ & $18,2 \pm 15,1$ & $85,3 \pm 69,4$ & $1283 \pm 885$ & \multirow{3}{*}{ RIA } & \multirow{3}{*}{$\begin{array}{c}\text { Kushinsky, } \\
1983 \text { (cité } \\
\text { par } \\
\text { Hoffmann } \\
\text { et Evers } \\
1986 \text { ) }\end{array}$} \\
\hline & $\begin{array}{l}180 \text { jours de } \\
\text { gestation }\end{array}$ & & $482 \pm 301$ & $\begin{array}{c}115,0 \pm \\
82,6\end{array}$ & $166 \pm 94$ & $2717 \pm 1259$ & & \\
\hline & $\begin{array}{c}240 \text { jours de } \\
\text { gestation }\end{array}$ & & $523 \pm 240$ & $\begin{array}{c}145,0 \pm \\
55,4 \\
\end{array}$ & $\begin{array}{c}142,0 \pm \\
41,2 \\
\end{array}$ & $2786 \pm 1497$ & & \\
\hline Taureau & Adulte & & $\begin{array}{c}14,8 \pm 1,7 \\
(n=7)\end{array}$ & $\begin{array}{c}13,4 \pm 1,0 \\
(n=7)\end{array}$ & $\begin{array}{c}2,7 \pm 0,4 \\
(n=7)\end{array}$ & $\begin{array}{c}35,6 \pm 5,0 \\
(n=7)\end{array}$ & RIA & $\begin{array}{l}\text { Henricks } \\
\text { et al } 1983\end{array}$ \\
\hline
\end{tabular}

Les concentrations en œstradiol libre et conjugué retrouvées dans le lait de vache sont inférieures à $25 \mathrm{pg} / \mathrm{ml}$ durant tout le cycle ovarien (Daxenberger et al 2001). En début de lactation, les valeurs en œstradiol sont du même ordre et celles en œstrone et en œstradiol-17 $\alpha$ sont respectivement 3 et 10 fois plus fortes. Au cours de la gestation, les valeurs en œstrone sulfate progressent de $150 \mathrm{pg} / \mathrm{mL}$ entre le $1^{\mathrm{er}}$ et le $2^{\mathrm{e}}$ mois à plus de $1000 \mathrm{pg} / \mathrm{ml}$ au $8^{\mathrm{e}}$ mois. Parmi les produits de transformation du lait, le beurre concentre le plus les œstrogènes libres; les valeurs mesurées en œstradiol sont de l'ordre de $80 \mathrm{pg} / \mathrm{g}$ et celles en œstrone et œstradiol-17 $\alpha$ sont respectivement 7 et 12 fois plus élevées (Daxenberger et al 2001).
Les activités d'hydroxylation des œstrogènes, en particulier celles à l'origine de la formation des catéchols œstrogènes, sont extrêmement réduites, voire inexistantes, chez les bovins à l'engrais, qu'ils soient traités ou non par des implants contenant l'association œstradiol/acétate de trenbolone (Paris et al 2000). En revanche, la présence en quantités non négligeables d'œstrogènes libres ou conjugués à l'acide glucuronide ou à des glycosides, en particulier l'œstradiol-17 $\alpha$, doit être considérée comme un paramètre à prendre en compte dans l'évaluation du risque que présentent ces résidus pour le consommateur, ceci indépendamment de leur potentiel œstrogénique. En effet, l'œstradiol-17 $\alpha$ peut subir une hydroxylation sur le noyau aromatique de la même manière que l'œstradiol ou l'œstrone chez l'homme (Rizzati et al 2005). Les catéchol œstrogènes ainsi formés peuvent alors former des adduits stables ou instables sur l'ADN (Jouanin et al 2002). Un bilan résiduel complet des œstrogènes présents dans les tissus animaux destinés à la consommation permet ainsi de mieux en évaluer le risque pour le consommateur, que ce risque soit de nature exclusivement hormonale ou qu'il soit lié à la réactivité chimique des catéchols œstrogènes produits secondairement chez l'homme à partir de l'œstradiol, l'œstrone ou l'œstradiol-17 $\alpha$.

De la même manière, la prise en compte des esters de l'œstradiol présents en quantité significative dans le 
Tableau 14. Compilation des différentes quantifications de l'œstradiol-17 $\alpha$ présent dans différents tissus animaux sous forme libre, conjuguée à l'acide glucuronique ou à des glycosides ou sous forme d'esters d'acides gras à longue chaîne en fonction des traitements anabolisants pratiqués ou des situations physiologiques observées.

\begin{tabular}{|c|c|c|c|c|c|c|c|c|c|c|c|}
\hline \multirow{2}{*}{$\begin{array}{c}\text { Type } \\
\text { zootechnique }\end{array}$} & \multirow{2}{*}{$\begin{array}{l}\text { Traitements ou } \\
\text { situations } \\
\text { physiologiques }\end{array}$} & \multirow{2}{*}{$\begin{array}{l}\text { Types ou } \\
\text { classes de } \\
\text { métabolites }\end{array}$} & \multicolumn{7}{|c|}{ Résidus tissulaires en œstradiol-17 $\alpha$ (pg/g) } & \multirow[b]{2}{*}{ Méthodes } & \multirow[b]{2}{*}{ Références } \\
\hline & & & Muscle & \multicolumn{2}{|c|}{ Foie } & \multicolumn{2}{|c|}{ Reins } & \multicolumn{2}{|c|}{$\begin{array}{c}\text { Tissu } \\
\text { adipeux }\end{array}$} & & \\
\hline \multirow[b]{2}{*}{ Bouvillon } & Témoins & \multirow{2}{*}{$\begin{array}{c}\text { Libres } \\
\text { (moyenne } \pm \\
\text { écart-type) }\end{array}$} & & \multicolumn{2}{|c|}{$\begin{array}{c}<10 \\
(n=6)\end{array}$} & \multicolumn{2}{|c|}{$\begin{array}{c}11,2 \pm 3,5 \\
(n=6)\end{array}$} & \multicolumn{2}{|c|}{$\begin{array}{c}12,6 \pm 1,2 \\
(n=6)\end{array}$} & \multirow[b]{2}{*}{ RIA } & \multirow[b]{2}{*}{$\begin{array}{l}\text { Henricks } \\
\text { et al } 1983\end{array}$} \\
\hline & $\begin{array}{l}\text { Compudose }^{\otimes} \\
\text { (90 jours après } \\
\text { implantation) }\end{array}$ & & & \multicolumn{2}{|c|}{$\begin{array}{l}53,2 \pm 17,0 \\
\quad(n=6)\end{array}$} & \multicolumn{2}{|c|}{$\begin{array}{l}55,5 \pm 10,6 \\
\quad(n=6)\end{array}$} & \multicolumn{2}{|c|}{$\begin{array}{c}20,7 \pm 5,2 \\
(n=6)\end{array}$} & & \\
\hline \multirow{2}{*}{$\begin{array}{l}\text { Veaux } \\
\text { (mâles et } \\
\text { femelles) }\end{array}$} & Témoins & \multirow{2}{*}{$\begin{array}{l}\text { Libres + } \\
\text { Conjugués } \\
\text { (min-max) }\end{array}$} & & \multicolumn{2}{|c|}{$\begin{array}{l}560-761 \\
(n=13) \\
\end{array}$} & & & & & \multirow[b]{2}{*}{ RIA } & \multirow[b]{2}{*}{$\begin{array}{l}\text { Scippo } \\
\text { et a/ } 1993\end{array}$} \\
\hline & $\begin{array}{c}\text { Revalor }^{(\otimes)} \text { ou } \\
\text { Implix } \\
\text { Crestar }^{(B)} \text { F ou ou } \\
\end{array}$ & & & \multicolumn{2}{|c|}{$\begin{array}{c}294-4158 \\
(n=56)\end{array}$} & & & & & & \\
\hline \multirow[b]{2}{*}{ Veau } & \multirow[b]{2}{*}{$\begin{array}{c}\left.{ }^{3} \mathrm{H}\right]- \text { Revalor }^{\circledR} \\
\text { (33 jours après } \\
\text { implantation) }\end{array}$} & $\begin{array}{c}\text { Libres } \\
\text { (moyenne } \pm \\
\text { écart-type) }\end{array}$ & $\begin{array}{c}0,9 \pm 0,5 \\
(n=2)\end{array}$ & \multicolumn{2}{|c|}{$\begin{array}{c}29,5 \pm 3,3 \\
(n=2)\end{array}$} & \multicolumn{2}{|c|}{$\begin{array}{c}78,5 \pm 24,1 \\
(n=2)\end{array}$} & & & \multirow[b]{2}{*}{$\begin{array}{l}\text { Radio- } \\
\text { métrie }\end{array}$} & \multirow[b]{2}{*}{$\begin{array}{l}\text { D'après } \\
\text { Paris et al } \\
1993\end{array}$} \\
\hline & & $\begin{array}{c}\text { Conjugués } \\
\text { (glucuronides } \\
+ \text { gluco- } \\
\text { pyranosides) } \\
\text { (moyenne } \pm \\
\text { écart-type) }\end{array}$ & $\begin{array}{c}2,5 \pm 0,6 \\
(n=2)\end{array}$ & \multicolumn{2}{|c|}{$\begin{array}{c}1742 \pm 707 \\
(n=2)\end{array}$} & \multicolumn{2}{|c|}{$\begin{array}{c}436 \pm 249 \\
(n=2)\end{array}$} & & & & \\
\hline \multirow[b]{2}{*}{ Bouvillons } & Témoins & \multirow[b]{2}{*}{$\begin{array}{c}\text { Libres } \\
\text { (moyenne } \pm \\
\text { écart-type) }\end{array}$} & & & & $\begin{array}{r}11,2 \\
(\mathrm{n}=\end{array}$ & $\begin{array}{l}=3,5 \\
6)\end{array}$ & $\begin{array}{r}12,6 \\
(\mathrm{n}\end{array}$ & $\begin{array}{l} \pm 1,2 \\
6)\end{array}$ & & \\
\hline & $\begin{array}{c}\text { Implant }\left(\mathrm{E}_{2}:\right. \\
20 \% \text { du poids } \\
\text { de l'implant } \\
\text { silastic) } \\
\text { (90 jours après } \\
\text { implantation) }\end{array}$ & & & $\begin{array}{c}0 \mathrm{~h} \\
\\
53,2 \pm \\
17,0 \\
(\mathrm{n}=6)\end{array}$ & $\begin{array}{l}-12 h^{*} \\
<10,0 \\
(n=6)\end{array}$ & $\begin{array}{c}0 \mathrm{~h} \\
\\
55,5 \pm \\
10,6 \\
(\mathrm{n}=6)\end{array}$ & $\begin{array}{l}-12 h \\
20,5 \\
\pm 4,2 \\
(n=6)\end{array}$ & $\begin{array}{c}0 h \\
\\
20,7 \\
\pm 5,2 \\
(n=6)\end{array}$ & $\begin{array}{c}-12 h \\
< \\
10,0 \\
(n=6)\end{array}$ & RIA & $\begin{array}{l}\text { Henricks } \\
\text { et al } 2001\end{array}$ \\
\hline & & $\begin{array}{c}\text { Libres } \\
\text { (moyenne } \pm \\
\text { écart-type) }\end{array}$ & $\left(\begin{array}{c}0 \\
(n=5)\end{array}\right.$ & $\begin{array}{r}1,4 \\
(n\end{array}$ & $\begin{array}{l}0,9 \\
5)\end{array}$ & $\begin{array}{r}1,2 \pm \\
(\mathrm{n}=\end{array}$ & $\begin{array}{l}0,8 \\
5)\end{array}$ & & & & \\
\hline & Témoins & $\begin{array}{l}\text { Conjugués } \\
\text { (moyenne } \pm \\
\text { écart-type) }\end{array}$ & $\begin{array}{c}0 \\
(n=5)\end{array}$ & & & $\begin{array}{r}2,2 \pm \\
(\mathrm{n}=\end{array}$ & $\begin{array}{l}1,5 \\
5)\end{array}$ & & $5)$ & & \\
\hline & & $\begin{array}{c}\text { Esters } \\
\text { (moyenne } \pm \\
\text { écart-type) }\end{array}$ & $\left(\begin{array}{c}0 \\
(n=4)\end{array}\right.$ & & & $(n=$ & & & $5)$ & GC- & Maume \\
\hline Bouvillons & & $\begin{array}{c}\text { Libres } \\
\text { (moyenne } \pm \\
\text { écart-type) }\end{array}$ & $\begin{array}{c}0 \\
(n=5)\end{array}$ & $\begin{array}{c}190,3 \\
\text { (n }\end{array}$ & $\begin{array}{l}240,1 \\
4)\end{array}$ & $\begin{array}{r}73,8 \pm \\
\quad(n=\end{array}$ & $\begin{array}{l}53,7 \\
4)\end{array}$ & $\begin{array}{r}1,4 \\
(n\end{array}$ & $\begin{array}{l}1,3 \\
5)\end{array}$ & HRMS & et a/ 2003 \\
\hline & $\begin{array}{c}\text { Revalor }^{\circledR} \\
(90 \text { jours après } \\
\text { implantation) }\end{array}$ & $\begin{array}{c}\text { Conjugués } \\
\text { (moyenne } \pm \\
\text { écart-type) }\end{array}$ & $\begin{array}{c}0 \\
(n=5)\end{array}$ & $\begin{array}{c}27,8 \\
(n\end{array}$ & $\begin{array}{l}7,3 \\
4)\end{array}$ & $\begin{array}{r}59,5 \pm \\
\quad(n=\end{array}$ & $\begin{array}{l}37,7 \\
4)\end{array}$ & & $5)$ & & \\
\hline & & $\begin{array}{c}\text { Esters } \\
\text { (moyenne } \pm \\
\text { écart-type) }\end{array}$ & $\begin{array}{c}0 \\
(n=5)\end{array}$ & $\begin{array}{r}9,5 \pm \\
(n\end{array}$ & $\begin{array}{l}12,6 \\
4)\end{array}$ & $\begin{aligned} 2,0 \pm \\
(\mathrm{n}=\end{aligned}$ & $\begin{array}{l}1,6 \\
4)\end{array}$ & & & & \\
\hline
\end{tabular}

* Moment de retrait de l'implant par rapport à la date d'abattage de l'animal.

tissu adipeux et, à des degrés divers dans le foie et le rein (Maume et al 2003) permet de mieux évaluer l'activité œstrogénique résiduelle, aussi bien sur le plan quantitatif que celui de la biodisponibilité après ingestion chez l'homme. A ce propos, une étude conduite sur des rattes impubères a permis de montrer que le potentiel œstrogénique d'un ester à longue chaîne de l'œstradiol administré par voie orale était près de 10 fois plus important que celui obtenu par l'œstradiol administré dans les mêmes conditions (Paris et al
2001). Une circulation lymphatique des esters ingérés est possible si l'on en croit les résultats pharmacocinétiques obtenus sur porcelet dont le tronc lymphatique avait été canulé (Paris et al 2000). Ceci souligne l'intérêt d'une évaluation la plus complète possible du spectre de résidus retrouvés chez l'animal traité.

- Estrogènes de synthèse utilisés de façon réglementée

Aux USA et au Canada, le zéranol est le seul œstrogène de synthèse utilisa- ble, sous forme d'implant sous cutané, seul ou en association avec un androgène naturel ou de synthèse pour provoquer un effet anabolisant (tableau 1). Le diéthylstilbœstrol (DES) et les autres stilbènes (figure 4) utilisés il y a plusieurs décennies sont interdits depuis de très nombreuses années dans tous les pays occidentaux. Les teneurs résiduelles en zéranol sont les plus élevées dans le foie des animaux traités avec des valeurs comprises entre 0,3 et $0,8 \mathrm{ng} / \mathrm{g}$ de tissu (tableau 15). Celles dans le muscle varient entre 0,1 et 
Tableau 15. Résidus tissulaires en zéranol chez des veaux, des bouvillons ou des vaches traités par des implants de zéranol.

\begin{tabular}{|c|c|c|c|c|c|c|c|c|}
\hline \multirow{2}{*}{$\begin{array}{c}\text { Type } \\
\text { zootechnique }\end{array}$} & \multirow{2}{*}{$\begin{array}{l}\text { Traitements ou } \\
\text { situations } \\
\text { physiologiques }\end{array}$} & \multirow{2}{*}{$\begin{array}{c}\text { Types ou } \\
\text { classes de } \\
\text { métabolites }\end{array}$} & \multicolumn{4}{|c|}{ Résidus tissulaires en zéranol (ng/g) } & \multirow[b]{2}{*}{ Méthode } & \multirow[b]{2}{*}{ Références } \\
\hline & & & Muscle & Foie & Reins & $\begin{array}{c}\text { Tissu } \\
\text { adipeux }\end{array}$ & & \\
\hline \multirow{3}{*}{ Veaux mâles } & Témoins & \multirow{3}{*}{$\begin{array}{c}\text { Composé } \\
\text { parental } \\
\text { (moyenne } \pm \\
\text { écart-type) }\end{array}$} & $\begin{array}{c}0,105 \pm \\
0,079 \\
(\mathrm{n}=3)\end{array}$ & $\begin{array}{c}0,102 \pm \\
0,040 \\
(\mathrm{n}=3)\end{array}$ & $\begin{array}{c}0,014 \pm \\
0,016 \\
(\mathrm{n}=4)\end{array}$ & $\begin{array}{l}0,010 \pm \\
0,004 \\
(\mathrm{n}=3)\end{array}$ & \multirow{11}{*}{ RIA } & \multirow{3}{*}{$\begin{array}{c}\text { Jansky, } \\
1983\end{array}$} \\
\hline & $\begin{array}{c}1 \text { à } 3 \text { implants } \\
\text { de Ralgro } \\
\text { (1 à } 3 \times 65 \text { jours) }\end{array}$ & & $\begin{array}{c}0,040 \pm \\
0,041 \\
(\mathrm{n}=8)\end{array}$ & $\begin{array}{c}0,315 \pm \\
0,240 \\
(n=8)\end{array}$ & $\begin{array}{c}0,104 \pm \\
0,074 \\
(n=9)\end{array}$ & $\begin{array}{c}0,039 \pm \\
0,024 \\
(\mathrm{n}=8)\end{array}$ & & \\
\hline & $\begin{array}{c}6 \text { implants de } \\
\text { Ralgro } \\
(6 \times 65 \text { jours }) \\
\end{array}$ & & $\begin{array}{c}0,115 \pm \\
0,051 \\
(\mathrm{n}=3) \\
\end{array}$ & $\begin{array}{c}1,209 \pm \\
0,326 \\
(n=3) \\
\end{array}$ & $\begin{array}{c}0,219 \pm \\
0,181 \\
(n=3)\end{array}$ & $\begin{array}{c}0,218 \pm \\
0,260 \\
(\mathrm{n}=3) \\
\end{array}$ & & \\
\hline \multirow{2}{*}{ Bouvillons } & Témoins & \multirow{2}{*}{$\begin{array}{c}\text { Composé } \\
\text { parental } \\
\text { (moyenne) }\end{array}$} & $\begin{array}{c}0,001 \\
(n=11)\end{array}$ & $\begin{array}{c}0,140 \\
(n=11)\end{array}$ & $\begin{array}{c}0,028 \\
(n=11)\end{array}$ & $\begin{array}{c}0,064 \\
(n=11)\end{array}$ & & \multirow{2}{*}{$\begin{array}{c}\text { O'Keeffe, } \\
1984\end{array}$} \\
\hline & Ralgro ${ }^{\circledast}$ & & $\begin{array}{c}0,014 \\
(n=11)\end{array}$ & $\begin{array}{c}0,350 \\
(n=11)\end{array}$ & $\begin{array}{c}0,076 \\
(n=11)\end{array}$ & $\begin{array}{c}0,060 \\
(n=11)\end{array}$ & & \\
\hline Vaches & $\begin{array}{c}\text { Ralgro }^{\circledR} \\
\text { (70 jours après } \\
\text { implantation) }\end{array}$ & $\begin{array}{c}\text { Composé } \\
\text { parental } \\
\text { (moyenne) }\end{array}$ & $\begin{array}{c}0,130 \\
(n=4)\end{array}$ & $\begin{array}{l}0,300 \\
(n=4)\end{array}$ & $\begin{array}{c}0,160 \\
(n=4)\end{array}$ & $\begin{array}{c}0,180 \\
(n=4)\end{array}$ & & $\begin{array}{c}\text { Dixon et } \\
\text { Russel, } \\
1986 \\
\end{array}$ \\
\hline \multirow{5}{*}{ Bouvillons } & Témoins & \multirow{5}{*}{$\begin{array}{c}\text { Composé } \\
\text { parental } \\
\text { (moyenne) }\end{array}$} & $\begin{array}{c}0,280 \\
(\mathrm{n}=6)\end{array}$ & $\begin{array}{c}0,100 \\
(n=6)\end{array}$ & $\begin{array}{c}0,100 \\
(n=6)\end{array}$ & $\begin{array}{c}0,075 \\
(n=6)\end{array}$ & & \multirow{5}{*}{$\begin{array}{c}\text { Dixon et al., } \\
\quad 1986\end{array}$} \\
\hline & $\begin{array}{c}\text { Ralgro }^{\circledR} \\
\text { (7 jours après } \\
\text { implantation) }\end{array}$ & & $\begin{array}{c}0,290 \\
(n=27)\end{array}$ & $\begin{array}{c}0,470 \\
(n=27)\end{array}$ & & $\begin{array}{c}0,077 \\
(n=27)\end{array}$ & & \\
\hline & $\begin{array}{c}\text { Ralgro }^{\circledR} \\
\text { (30 jours après } \\
\text { implantation) }\end{array}$ & & $\begin{array}{c}0,280 \\
(n=27)\end{array}$ & $\begin{array}{c}0,810 \\
(n=27)\end{array}$ & & $\begin{array}{c}0,110 \\
(n=27)\end{array}$ & & \\
\hline & $\begin{array}{c}\text { Ralgro }^{\circledR} \\
\text { (70 jours après } \\
\text { implantation) }\end{array}$ & & $\begin{array}{c}0,730 \\
(n=27)\end{array}$ & $\begin{array}{c}0,200 \\
(n=27)\end{array}$ & $\begin{array}{c}0,130 \\
(n=27)\end{array}$ & $\begin{array}{c}0,073 \\
(n=27)\end{array}$ & & \\
\hline & $\begin{array}{c}\text { Ralgro }^{\Theta} \\
\text { (120 jours après } \\
\text { implantation) }\end{array}$ & & $\begin{array}{c}0,280 \\
(n=27)\end{array}$ & $\begin{array}{c}0,100 \\
(n=27)\end{array}$ & $\begin{array}{c}0,084 \\
(n=27)\end{array}$ & $\begin{array}{c}0,066 \\
(n=27)\end{array}$ & & \\
\hline
\end{tabular}

$0,3 \mathrm{ng} / \mathrm{g}$. Même si des éléments sérieux de validation interne du dosage radioimmunologique utilisé ont été produits au début des années 80 (Janski 1983), les résultats publiés laissent penser que des biais non spécifiques peuvent exister dans les matrices tissulaires, notamment dans le muscle et le foie, ce qu'un dosage par spectrométrie de masse permettrait de résoudre en même temps qu'il donnerait accès aux concentrations en taléranol et zéaralanone, les métabolites majeurs du zéranol. Aucune donnée de concentrations résiduelles des conjugués du zéranol n'a été publiée.

Des données relatives à la génotoxicité du zéranol ont été produites par Metzler et Pfeiffer (2001). Les tests utilisés se sont tous révélés négatifs, exceptée une faible augmentation du nombre de micro-noyaux sur cellules V79 de hamster induite par le zéranol et ses métabolites, le taléranol et la zéaralanone (tableau 10).

Leffers et al (2001) ont montré sur cellules MCF7 que le zéranol induisait 1'expression des gènes $P S 2$ et $T G F-\beta 3$ avec la même efficacité que l'œstradiol, tandis qu'une inhibition du gène $M R G 1 / p 35 s r j$ était obtenue avec le zéranol à des concentrations de l'ordre du $\mathrm{fM}$, la même réponse à l'œstradiol étant de plusieurs ordres de grandeur moins sensible. Ceci montre bien la difficulté de préciser à l'échelle moléculaire ce que représentent les réponses hormonales des analogues de l'œstradiol quand une approche multidimensionnelle est mise en œuvre. Ainsi considérée, la qualification d'une situation œstrogénique résiduelle ne peut, pour le zéranol, s'apprécier de façon strictement homothétique à celle établie pour l'œstradiol.

e) Progestagènes utilisés de façon réglementée

\section{- Progestérone}

Seuls, les résidus tissulaires en progestérone ont été mesurés par dosage radioimmunologique dans les différents tissus destinés à la consommation qui proviennent d'animaux traités. Les valeurs les plus importantes sont retrou- vées dans le tissu adipeux à des concentrations qui varient entre 1,5 et 12,5 $\mathrm{ng} / \mathrm{g}$ de tissu. Les concentrations mesurées dans le muscle, le foie et le rein sont près de 10 fois moins importantes que celles mesurées dans le tissu adipeux (tableau 16). Chez des veaux traités par des implants contenant l'association œstradiol (20 mg) - progestérone $(200 \mathrm{mg})$, l'augmentation des niveaux résiduels est sensible (Hoffmann et Evers 1986). En revanche, chez des bouvillons traités de la même manière, cette augmentation dans les teneurs résiduelles n'est pas manifeste, la variabilité de la mesure étant beaucoup plus grande (tableau 16). Ceci pose à nouveau le problème sous-jacent de la validation des méthodes de dosage radioimmunologique qui ne sont pas confortées par des méthodes spectrophysiques qui atteignent aujourd'hui les sensibilités requises. Des valeurs de teneurs en progestérone mesurées dans ces mêmes tissus prélevés chez des génisses gravides se montrent beaucoup plus importantes que celles mesurées chez des animaux implantés ; dans le tissu adipeux, 
Tableau 16. Compilation des différentes quantifications de la progestérone présente dans différents tissus animaux en fonction des traitements anabolisants pratiqués ou des situations physiologiques observées.

\begin{tabular}{|c|c|c|c|c|c|c|c|c|}
\hline \multirow{2}{*}{$\begin{array}{c}\text { Type } \\
\text { zootechnique }\end{array}$} & \multirow{2}{*}{$\begin{array}{l}\text { Traitements ou } \\
\text { situations } \\
\text { physiologiques }\end{array}$} & \multirow{2}{*}{$\begin{array}{l}\text { Types ou } \\
\text { classes de } \\
\text { métabolites }\end{array}$} & \multicolumn{4}{|c|}{ Résidus tissulaires en progestérone (ng/g) } & \multirow[b]{2}{*}{ Méthode } & \multirow[b]{2}{*}{ Références } \\
\hline & & & Muscle & Foie & Reins & $\begin{array}{c}\text { Tissu } \\
\text { adipeux }\end{array}$ & & \\
\hline \multirow{6}{*}{ Bouvillon } & Témoins & \multirow{6}{*}{$\begin{array}{c}\text { Composé } \\
\text { parental } \\
\text { (moyenne } \pm \\
\text { écart-type) }\end{array}$} & $0,27 \pm 0,33$ & $0,26 \pm 0,07$ & $0,17 \pm 0,14$ & $2,48 \pm 1,61$ & \multirow{13}{*}{ RIA } & \multirow{6}{*}{$\begin{array}{c}\text { Monography on } \\
\text { Residues of } \\
\text { some } \\
\text { Veterinary } \\
\text { Drugs in } \\
\text { Animals and } \\
\text { Foods } \\
\text { (FAO/OMS, } \\
\text { Rome, 15-23 } \\
\text { juin 1987) } \\
\text { Repris dans } \\
\text { NADA 009-576 } \\
\text { (Suppl.), 1994 }\end{array}$} \\
\hline & $\begin{array}{c}\text { Synovex }^{\circledR}-S \\
\text { (15 jours après } \\
\text { implantation) }\end{array}$ & & $0,23 \pm 0,12$ & $0,18 \pm 0,03$ & $0,14 \pm 0,05$ & $3,20 \pm 1,17$ & & \\
\hline & $\begin{array}{c}\text { Synovex }{ }^{\circledR}-S \\
\text { (30 jours après } \\
\text { implantation) }\end{array}$ & & $0,23 \pm 0,53$ & $0,16 \pm 0,03$ & $0,11 \pm 0,32$ & $3,48 \pm 1,64$ & & \\
\hline & $\begin{array}{c}\text { Synovex }{ }^{(6)}-S \\
(61 \text { jours après } \\
\text { implantation) }\end{array}$ & & $0,41 \pm 0,48$ & $0,35 \pm 0,07$ & $0,20 \pm 0,33$ & $3,40 \pm 1,32$ & & \\
\hline & $\begin{array}{c}\text { Synovex }{ }^{\circledR}-S \\
\text { (90 jours après } \\
\text { implantation) }\end{array}$ & & $0,44 \pm 0,57$ & $0,24 \pm 0,12$ & $0,32 \pm 0,42$ & $3,67 \pm 2,25$ & & \\
\hline & $\begin{array}{c}\text { Synovex }{ }^{\circledR}-S \\
\text { (120 jours après } \\
\text { implantation) }\end{array}$ & & $0,58 \pm 0,84$ & $0,27 \pm 0,08$ & $0,17 \pm 0,17$ & $2,62 \pm 1,09$ & & \\
\hline \multirow{4}{*}{ Veau mâle } & Témoins & \multirow{4}{*}{$\begin{array}{l}\text { Composé } \\
\text { parental } \\
\text { (moyenne) }\end{array}$} & $\begin{array}{c}0,901 \\
(n=2)\end{array}$ & $\begin{array}{c}0,749 \\
(n=2)\end{array}$ & $\begin{array}{c}4,066 \\
(n=2)\end{array}$ & $\begin{array}{c}1,598 \\
(n=2)\end{array}$ & & \multirow{6}{*}{$\begin{array}{l}\text { Cité par } \\
\text { Hoffmann et } \\
\text { Evers, } 1986\end{array}$} \\
\hline & $\begin{array}{c}\text { Implix }{ }^{\circledR}-\mathrm{BM} \\
\text { (15 jours après } \\
\text { implantation) }\end{array}$ & & $\begin{array}{c}0,606 \\
(n=3)\end{array}$ & $\begin{array}{c}0,599 \\
(n=3)\end{array}$ & $\begin{array}{c}0,994 \\
(n=3)\end{array}$ & $\begin{array}{c}5,407 \\
(n=3)\end{array}$ & & \\
\hline & $\begin{array}{c}\text { Implix }{ }^{\circledR}-B M \\
(30 \text { jours après } \\
\text { implantation) }\end{array}$ & & $\begin{array}{c}0,597 \\
(n=3)\end{array}$ & $\begin{array}{c}0,924 \\
(n=3)\end{array}$ & $\begin{array}{l}2,798 \\
(n=3)\end{array}$ & $\begin{array}{l}6,520 \\
(n=3)\end{array}$ & & \\
\hline & $\begin{array}{c}\text { Implix }{ }^{(B}-B M \\
(50 \text { jours après } \\
\text { implantation })\end{array}$ & & $\begin{array}{c}0,772 \\
(n=3)\end{array}$ & $\begin{array}{c}0,771 \\
(n=3)\end{array}$ & $\begin{array}{c}1,408 \\
(n=3)\end{array}$ & $\begin{array}{c}8,664 \\
(n=3)\end{array}$ & & \\
\hline \multirow{2}{*}{ Veau mâle } & Témoins & \multirow{2}{*}{$\begin{array}{c}\text { Progestérone } \\
\text { (moyenne } \pm \\
\text { écart-type) }\end{array}$} & $0,25 \pm 0,09$ & $0,27 \pm 0,11$ & $0,46 \pm 0,21$ & $5,8 \pm 2,5$ & & \\
\hline & $\begin{array}{c}\text { Implix }{ }^{\circledR}-\mathrm{BM} \\
\text { (70 jours après } \\
\text { implantation) }\end{array}$ & & $0,52 \pm 0,36$ & $0,33 \pm 0,06$ & $0,61 \pm 0,15$ & $12,5 \pm 6,7$ & & \\
\hline Génisse & Gestation & $\begin{array}{c}\text { Progestérone } \\
\text { (moyenne } \pm \\
\text { écart-type) }\end{array}$ & $\begin{array}{c}10,1 \pm 6,65 \\
(n=3)\end{array}$ & $\begin{array}{c}3,42 \pm 1,37 \\
(n=3)\end{array}$ & $\begin{array}{c}6,19 \pm 1,86 \\
(n=3)\end{array}$ & $\begin{array}{c}239 \pm 116 \\
(n=3)\end{array}$ & & $\begin{array}{c}\text { Kushinsky, } \\
1983\end{array}$ \\
\hline
\end{tabular}

celles-ci peuvent atteindre des concentrations de l'ordre de $240 \mathrm{ng} / \mathrm{g}$ de tissu (Kushinsky 1983). Dans le lait de vache, les quantités de progestérone retrouvées sont de l'ordre de la dizaine de ppb. Dans le beurre, elles oscillent entre 140 et $300 \mathrm{ppb}$ (Hartmann et al 1998, Fritsche et Steinhart 1999). Les teneurs en 5 $\alpha$-pregnagne-3,20-dione, un métabolite majeur de la progestérone dans le lait, seraient trois fois moindres que celles en progestérone (Purdy et al 1980).

Les valeurs des teneurs résiduelles tissulaires en progestérone établies par les méthodes RIA ou ELISA suffisent à en apprécier le risque hormonal. L'évaluation doit se faire eu égard aux teneurs mesurées dans le tissu adipeux qui stocke préférentiellement cette hormone. En revanche, malgré les connaissances acquises dans le domaine du métabolisme depuis plus de vingt ans, aucune quantification des métabolites majeurs dans aucun des tissus propres à la consommation n'a été effectuée à ce jour. Enfin, si bon nombre de métabolites obtenus par réduction du cycle A en position 5 ou de la cétone en position 3 ou par réduction de la cétone en position 20 ont pu être identifiés, aucune identification de possibles métabolites hydroxylés de ces composés ou de la progestérone, pas plus que la recherche de composés acylés en position 3 à des acides gras à longue chaîne, n'ont été effectuées.

\section{- Progestagènes de synthèse}

L'altrenogest, le norgestomet, l'acétate de fluorogestone et la médroxyprogestérone sont les progestines de synthèse pour lesquelles une AMM a été accordée dans l'UE. L'acétate de mélengestrol peut aussi être utilisé comme sté- roïde anabolisant chez la génisse. Cette molécule est interdite d'utilisation dans l'UE mais autorisée aux USA. Pour les 3 premières molécules, des Limites Maximales Résiduelles (LMR) ont été définies au-delà desquelles il n'est pas possible de commercialiser les tissus animaux. Ces valeurs varient entre 0,4 et $1 \mathrm{ng} / \mathrm{g}$ (tableau 17). Pour la médroxyprogestérone, aucune nécessité de définir des LMR n'a été retenue (EMEA/MRL/0129/96-Final 1996). Ces valeurs ont été définies après examen des caractéristiques toxicologiques et métaboliques des molécules (tableau 18). Aucune ne revêt de caractère génotoxique ni tératogène. Compte tenu de leurs caractéristiques métaboliques, aucune propriété carcinogène n'a été suspectée ou décelée.

L'acétate de mélengestrol n'a révélé aucune propriété génotoxique sur la 
Tableau 17. LMR des progestines utilisées en élevage dans I'UE.

\begin{tabular}{|c|c|c|c|c|c|c|}
\hline Composés & $\begin{array}{l}\text { Résidu } \\
\text { marqueur }\end{array}$ & $\begin{array}{l}\text { Espèces } \\
\text { cibles }\end{array}$ & $\begin{array}{l}\text { LMRs } \\
\text { (ng/g) }\end{array}$ & Tissu cible & Remarques & Utilisations \\
\hline $\begin{array}{l}\text { Acétate de } \\
\text { flugestone }\end{array}$ & Fluorogestone & Ovins, caprins & $\begin{array}{l}0,5 \\
0,5 \\
0,5 \\
0,5\end{array}$ & $\begin{array}{c}\text { Muscle } \\
\text { Tissu adipeux } \\
\text { Foie } \\
\text { Rein }\end{array}$ & $\begin{array}{c}\text { Classement en } \\
\text { Annexe I }\end{array}$ & $\begin{array}{l}\text { Thérapeutique } \\
\text { et zootechnique }\end{array}$ \\
\hline Norgestomet $^{2}$ & Norgestomet & Bovins & $\begin{array}{c}0,2 \\
0,2 \\
0,2 \\
0,2 \\
0,12\end{array}$ & $\begin{array}{c}\text { Muscle } \\
\text { Tissu adipeux } \\
\text { Foie } \\
\text { Rein } \\
\text { Lait }\end{array}$ & $\begin{array}{c}\text { Classement en } \\
\text { Annexe I }\end{array}$ & $\begin{array}{l}\text { Thérapeutique } \\
\text { et zootechnique }\end{array}$ \\
\hline Altrenogest $^{3}$ & Altrenogest & $\begin{array}{l}\text { Porcins } \\
\text { Equins }\end{array}$ & $\begin{array}{c}1 \\
\\
0,4 \\
1 \\
0,9\end{array}$ & $\begin{array}{c}\text { Peau }+ \text { tissu } \\
\text { adipeux sous-cutané } \\
\text { Foie } \\
\text { Tissu adipeux } \\
\text { Foie }\end{array}$ & $\begin{array}{c}\text { Classement en } \\
\text { Annexe I }\end{array}$ & Zootechnique \\
\hline $\begin{array}{l}\text { Médroxypro- } \\
\text { gestérone }\end{array}$ & - & Ovins & - & - & $\begin{array}{c}\text { Classement en } \\
\text { Annexe II }\end{array}$ & Zootechnique \\
\hline
\end{tabular}

1 Document EC N ${ }^{\circ} 1911 / 2005$ du 23/11/2005.

2 Document EC N ${ }^{\circ} 1299 / 2005$ du 8/08/2005.

3 Document EC N ${ }^{\circ} 2232 / 2004$ du 23/12/2004.

4 Document EC N² 270/97 du 14/02/1997.

Tableau 18. Caractéristiques de toxicité des progestines utilisés en élevage dans I'UE.

\begin{tabular}{|c|c|c|c|c|}
\hline Tests ou propriétés & $\begin{array}{c}\text { Acétate de } \\
\text { fluorogestone }\end{array}$ & Norgestomet $^{2}$ & Altrenogest $^{3}$ & Médroxypro-gestérone ${ }^{4}$ \\
\hline $\begin{array}{c}\text { Toxicité hormonale à } \\
90 \mathrm{j} \text { (NOEL en } \mathrm{mg} / \mathrm{kg} / \mathrm{j} \\
\text { chez le rat) }\end{array}$ & 0,2 & $\begin{array}{c}>0,05 \\
\text { (dose sans effet non } \\
\text { déterminée) }\end{array}$ & $\begin{array}{c}0,04 \\
(0,004 \text { chez la truie })\end{array}$ & 0,03 \\
\hline $\begin{array}{l}\text { Actions hormonales } \\
\text { secondaires }\end{array}$ & Glucocorticoïde faible & Progestagène strict. & $\begin{array}{l}\text { Effets anabolisants, } \\
\text { androgéniques et } \\
\text { œstrogéniques faibles } \\
\text { hypothétiques. Pas } \\
\text { d'effet glucocorticoïde } \\
\text { ou inflammatoire. }\end{array}$ & $\begin{array}{c}\text { Effets de type } \\
\text { glucocorticoïde } \\
\text { et masculinisants }\end{array}$ \\
\hline $\begin{array}{c}\text { Toxicité de la } \\
\text { reproduction (NOEL } \\
\text { en } \mathrm{mg} / \mathrm{kg} / \mathrm{j} \text { chez le } \\
\text { lapin) }\end{array}$ & $\begin{array}{l}\text { Maternelle : } 0,003 \\
\text { Fœtale : } 0,010\end{array}$ & $\begin{array}{c}\text { Maternelle : 0,01 } \\
\text { Fœtale : 0,01 }\end{array}$ & 0,03 & $\begin{array}{l}\text { Maternelle : } 1 \\
\text { Fœtale : } 10\end{array}$ \\
\hline $\begin{array}{c}\text { Tératogénicité (NOEL } \\
\text { en } \mathrm{mg} / \mathrm{kg} / \mathrm{j})\end{array}$ & $\begin{array}{c}\text { Toxicité maternelle } \\
\text { - rat : } 0,1 \\
\text { - lapin : } 0,01 \\
\text { Embryotoxicité : } \\
\text { - rat : ND } \\
\text { - lapin : } 0,04 \\
\text { Non tératogène }\end{array}$ & $\begin{array}{c}\text { Toxicité maternelle } \\
\text { - rat : } 1\end{array}$ & $\begin{array}{l}\text { Non tératogène chez le } \\
\text { rat et le porc }\end{array}$ & $\begin{array}{l}\text { Embryotoxicité : } \\
\text { - chien : } 10 \\
\text { - lapin : > } 1 \\
\text { Non tératogène }\end{array}$ \\
\hline Génotoxicité & Négatif & Négatif & Négatif & Négatif \\
\hline Carcinogénicité & Négatif & Tests non réalisés & Tests non réalisés & $\begin{array}{l}\text { Négatif pour le rat, } \\
\text { la souris et le singe }\end{array}$ \\
\hline$D^{*}{ }^{*}(\mu \mathrm{g} / \mathrm{kg})$ & 0,03 & 0,01 & 0,04 & Pharmacologique : 0,3 \\
\hline $\begin{array}{c}\text { Consommation } \\
\text { maximale de résidus } \\
(\% \text { DJA })\end{array}$ & $35 \%$ & $\begin{array}{c}20 \% \text { après retrait } \\
\text { de l'implant } \\
70 \% \text { dans le lait pendant } \\
\text { l'implantation }\end{array}$ & $\begin{array}{l}<5 \% \text { après un délai } \\
\text { d'attente de } 7 \text { jours }\end{array}$ & Pharmacologique : $60 \%$ \\
\hline
\end{tabular}

1 Document EMEA-V-8486-03 (flugestone acetate).

2 Document EMEA-V-8473-03.

3 Document EMEA/CVMP/572/04.

4 Document EMEA/MRL/0129/96-Final.

Génotoxicité : Mutations génétiques sur bactéries, cellules de lymphome de souris, aberrations chromosomiques sur lymphocytes humains.

*Dose journalière admissible. 
batterie de tests habituellement utilisées (Metzler et Pfeiffer 2001) (tableau 10).

\section{f) Corticostéroïdes}

L'usage thérapeutique des corticostéroïdes pour leurs propriétés anti-inflammatoires en médecine humaine ou vétérinaire, mais également leur utilisation frauduleuse en tant que facteurs de croissance, ont conduit au développement de diverses méthodes de détection de ces molécules. Les couplages HPLCfluorimétrie (Vanoosthuyze et al 1993, Neufeld et al 1998) et HPLC-UV (Cham et al 1980, Shearan et al 1991, Mallinson et al 1995, Cudina et al 2000) ont tout d'abord été utilisés. Différentes méthodes immunochimiques ont ensuite été proposées, certaines faisant encore aujourd'hui l'objet de développements (Stanley et al 1993, Calvarese et al 1994, Pedersen et al 2000, Van den Hauwe et al 2003). Ces techniques ont l'avantage d'être rapides et facilement applicables à un grand nombre d'échantillons, mais leur manque de spécificité peut conduire dans certains cas à un nombre redhibitoire de faux-positifs.

La spectrométrie de masse est la technique de détection et d'identification la plus largement répandue dans le domaine de l'analyse des corticostéroïdes dans les aliments, ses performances en matière de sensibilité et de spécificité la rendant compatible avec les niveaux de concentration de ces molécules présentes à l'état de traces et les contraintes analytiques liées à la complexité des matrices biologiques contrôlées (urine, tissus, organes, phanères, etc.). La GCMS fut la première technique utilisée dans ce sens (Baillie et al 1972, Houghton et al 1982, Her et Watson 1986, Girault et al 1990, Yap et al 1992, Courtheyn et al 1994, Furuta et al 1998). L'oxydation chimique pour cliver la chaîne latérale et aboutir à une cétone en position 17, suivie d'une ionisation chimique en mode négatif (NCI) reste encore aujourd'hui une méthode de détection assez utilisée, en particulier pour la dexaméthasone. Cependant, son application à un plus grand nombre de corticostéroïdes reste délicate. La spectrométrie de masse de rapport isotopique (GC-IRMS) a également été utilisée afin de mettre en évidence une administration exogène de cortisol (Aguilera et al 1997). L'introduction de la LC-MS a nettement contribué à l'amélioration des performances des méthodes analytiques consacrées aux corticostéroïdes. Plusieurs méthodes LC-MS (Cairns et al 1983, Rodchenkov et al 1988, Shibasaki et al 1997, Huetos-Hidalgo et al 2003) et $\mathrm{LC}_{-\mathrm{MS}}^{2}$ avec une interface de type Ionisation Chimique à Pression Atmosphérique (APCI) ou Ionisation par Electronébullisation (Electrospray, ESI) (Rizea Savu et al 1996, Dodds et al 1997, Fiori et al 1998, De Wasch et al 1998a, Antignac et al 2000, Sangiorgi et al 2003) ont été proposées. Aujourd'hui, l'ionisation en mode négatif semble la plus adaptée pour l'analyse multirésidus de corticostéroïdes sous leur forme native, mais également pour l'analyse directe de leurs formes estérifiées et conjuguées (Antignac et al 2004).

La plupart des pays de l'UE sont aujourd'hui en possession de méthodes performantes et validées selon les exigences en vigueur pour l'analyse des corticostéroïdes, permettant ainsi un contrôle efficace de l'utilisation de ces substances. Les meilleurs niveaux de sensibilité atteints sont en effet de l'ordre de quelques dizaines de ppt pour des échantillons d'urine ou de tissus. Une recherche de résidus de corticostéroïdes dans des échantillons de poil est également proposée par de rares laboratoires, cette matrice apparaissant complémentaire aux deux précédentes avec une plus grande pertinence pour des recherches de molécules attestant d'une administration remontant plus loin dans le temps.

\section{- Agonistes $\beta$-adrénergiques}

\section{a) Généralités}

$\mathrm{Au}$ cours des dernières années, plusieurs intoxications de consommateurs dues à la présence de $\beta$-agonistes dans les denrées alimentaires se sont produites (Prezelj et al 2003), avec le plus souvent des symptômes liés aux propriétés pharmacologiques connues des effecteurs des AR : tachycardie, crampes musculaires, tremblements. Dans tous les cas, ces intoxications étaient dues à une administration illégale d'un $\beta$-agoniste, le plus souvent du clenbutérol, suivie d'un abattage très peu de temps après arrêt du traitement. La demi-vie des $\beta$-agonistes chez les animaux traités est relativement courte. Elle est de quelques heures pour des molécules comme le salbutamol (Smith 1998) et a été estimée entre 18 et 36 heures pour le clenbutérol chez le veau (Meyer et Rinke 1991). L'utilisation illégale de molécules telles que le clenbutérol pose un triple problème : l'absence de contrôle des doses administrées, l'absence de période de déplétion des résidus après traitement et l'existence d'une voie de biotransformation produisant des métabolites potentiellement réactifs. b) Résidus tissulaires des $\beta$-agonistes à utilisation contrôlée

Actuellement, seuls deux $\beta$-agonistes, la ractopamine et le zilpatérol, peuvent être utilisés légalement chez l'animal d'élevage, et ce pour un nombre très restreint d'espèces et de pays (ractopamine pour les espèces porcine et bovine aux USA; zilpatérol pour l'espèce bovine au Mexique et en Afrique du Sud). Pour la ractopamine, les niveaux résiduels détectés dans le foie chez le bovin sont de 9,3 et de $2,5 \mathrm{ppb}$, respectivement 0 et 3 jours après arrêt d'un traitement de 8 jours. Les niveaux résiduels détectés dans les reins sont nettement plus élevés à l'arrêt du traitement (97 ppb), mais ne représentent plus que $3,4 \mathrm{ppb}$ après 3 jours (Smith et Shelver 2002). Une semaine après le traitement, ces niveaux sont en dessous de la limite de détection pour les deux tissus. De même, pour le zilpatérol, peu de temps après arrêt d'une administration prolongée, on observe chez les génisses des niveaux résiduels plus élevés dans le rein que dans le foie, ceci du fait de l'élimination majoritairement urinaire des $\beta$-agonistes. Ainsi, après un traitement de 14 jours et un temps de retrait de 24 heures, on détecte respectivement 27,44 et 7 ppb dans le foie, les reins et le muscle des animaux traités. Après un temps de retrait de 10 jours, ces valeurs ne sont plus que de $0,03 \mathrm{ppb}$ dans le foie et les reins et de $0,01 \mathrm{ppb}$ dans le muscle (Stachel et al 2003). Dans les conditions légales d'utilisation, il est peu probable que les quantités de résidus présentes dans les viandes et les abats provenant d'animaux traités suffisent à produire des effets pharmacologiques chez l'homme. Les LMR proposées pour la ractopamine (JECFA 2004) sont de $10 \mathrm{ppb}$ pour le muscle et le tissu adipeux, de $40 \mathrm{ppb}$ pour le foie et de 90 ppb pour le rein, aussi bien pour les bovins que pour les porcins. Pour le zilpatérol, ces LMR ne sont pas disponibles à l'heure actuelle.

c) Contrôle des $\beta$-agonistes utilisés frauduleusement

Le contrôle des $\beta$-agonistes en élevage est bien maîtrisé depuis le début des années 1990 après avoir dû résoudre bon nombre de difficultés. La première était liée à la facilité que possèdaient les fraudeurs à synthétiser ces molécules, à les introduire sur le marché noir, et, par conséquent, pour les laboratoires de contrôle la difficulté à les mettre en évidence. La seconde est liée à leur grande efficacité zootechnique impliquant leur utilisation à de faibles doses, combinée à une élimination rapide de 
ces molécules. De ce fait, les structures analytiques de contrôle ont dû développer des outils de mesure extrêmement sensibles. Les matrices les plus appropriées où sont recherchées prioritairement ces molécules sont l'urine, les phanères et la rétine (détectabilité de l'administration très longue), le poumon et les viscères ou encore les buvées et les aliments collectés en élevage. Les analytes cibles, généralement la molécule mère glucurono- et sulfoconjuguée, sont soumis à plusieurs étapes d'extraction-purification avant toute détermination d'un diagnostic du type présence/absence et, le cas échéant, toute quantification. Les mêmes critères analytiques que ceux utilisés pour les autres facteurs de croissance sont appliqués aux $\beta$-agonistes (groupe A5 de la directive 96/23/EC).

\section{- Préparation de l'échantillon}

Comme pour les stéroïdes anabolisants, la première étape consiste le plus souvent à réaliser une extraction liquide-liquide ou solide-liquide selon le type d'échantillon. L'hydrolyse des conjugués est pratiquée le plus souvent par voie enzymatique. Une à deux étapes de purification sont ensuite appliquées ; elles consistent généralement à profiter du caractère ionisable à $\mathrm{pH}$ acide de ces aryl-éthanolamines (utilisation de cartouches SPE échangeuses de cations) et de leur hydrophobicité (SPE greffées en C18 ou C8). Ces étapes suffisent en principe à éliminer les principales interférences.

\section{- Technique de mesure}

Les méthodes indirectes adaptées à un premier dépistage en routine regroupent les techniques d'analyse ELISA et RIA. Un grand nombre de kits ELISA a été commercialisé, et reste largement utilisé sur le territoire communautaire. Etant donnée la relative variabilité des structures chimiques au sein de cette famille de composés, plusieurs kits doivent être malheureusement utilisés pour couvrir l'ensemble de ces molécules. Depuis quelques années, des approches fondées sur la mesure de la liaison au récepteur AR des résidus de $\beta$-agoniste par dosage RRA, font leur apparition et démontrent leur efficacité à des fins de dépistage. La spectrométrie de masse peut être également employée à des fins de screening comme c'est le cas en France. Elle reste d'ailleurs la technique obligée pour toute analyse de confirmation. Les filtres de masse utilisés sont classiques et ne sont pas différents de ceux utilisés pour l'analyse des stéroïdes. Les simples quadripôles font place aux systèmes triples quadripolaires et aux trappes ioniques de dernières générations, qui autorisent l'acquisition des signaux en MSn . Etant donnée leur composition élémentaire particulière (défaut de masse), la haute résolution $\left(\mathrm{R}>10^{4}\right)$ sur secteur magnétique a démontré sa puissance diagnostique jusqu'à des concentrations de l'ordre de la ppt, repoussant considérablement le délai de détectabilité de ces molécules, en particulier dans les tissus. Les premiers couplages GC-MS ont été utilisés moyennant des réactions de dérivation parfois complexes des molécules extraites. Depuis la fin des années 1990, l'introduction dans les laboratoires de systèmes robustes LC-MSn avec interface électrospray et de détection en mode positif a considérablement simplifié leur analyse et abaissé les limites de détection et d'identification/quantification. Aujourd'hui, ces seuils de performance sont de l'ordre de la dizaine et de la centaine de ppt, respectivement.

\section{- Précautions analytiques}

Comme pour les autres facteurs de croissance, a fortiori dans l'UE où ils sont interdits, les dosages sont invariablement entourés de précautions analytiques : étalons-internes et externes, de préférence identiques aux molécules cibles mais marquées au ${ }^{2} \mathrm{H}$ ou au ${ }^{13} \mathrm{C}$, introduction d'échantillons témoins et surchargés. Lors d'une première analyse, l'échantillon ne peut être déclaré que conforme (résultat négatif) ou suspect ; dans ce cas, il doit être extrait de nouveau pour qu'une conclusion non ambiguë de type «conforme/non conforme» (négatif/positif) soit apportée. Les mêmes critères analytiques, chromatographiques et spectrométriques, doivent être respectés (cf décision analytique 2002/657/EC en Europe).

\section{- Thyréostatiques}

Les ATS sont des molécules appartenant au groupe A2 de la directive 96/23/EC et, par conséquent, interdits en tant que promoteurs de croissance en élevage. Les techniques analytiques utilisées pour leur contrôle doivent être de fait caractérisées par une bonne sensibilité pour diminuer le nombre de faux-négatifs et une spécificité sans faille pour éliminer les faux-positifs.

La mise en évidence d'un usage illégal d'ATS chez les animaux de rente peut dans un premier temps s'appuyer sur des critères morphologiques et histologiques reposant sur l'hypothyroïdie des animaux (Griem 1973, De Brabander et Verbeke 1984). L'étude gravimétrique de thyroïdes est ainsi un test de dépistage simple. Cependant, la confirmation de suspicions éventuelles doit impérativement mettre en évidence la présence de résidus par une méthode directe (spectrométrie de masse par exemple) dans des matrices cibles telles que le plasma, l'urine ou la glande thyroïde, les concentrations les plus élevées étant retrouvées dans cette dernière. La traque de l'utilisation illégale passe également par l'analyse d'aliment, poudres ou fluides prélevés en élevage.

Trois principaux types d'analyses ont été mis au point depuis les années 1940, faisant appel à des méthodes analytiques différentes : colorimétriques, chromatographiques et plus récemment chromatographiques couplées à la spectrométrie de masse. Les méthodes colorimétriques utilisent la réaction des ATS avec le 2,6-dichloroquinonechloroimide dont le produit de réaction est jaune et mesurable par densité optique (McAllister et Howells 1952). Une dérivation avec le NBD-Cl (7chloro-4-nitrobenzo-2-oxal-1,3-diazole) permet la formation d'un composé fluorescent (Birkett et al 1970). Le couplage de la chromatographie sur couche mince à cette détection colorimétrique permet de séparer les différents ATS. Cette méthode de recherche de résidus thyréostatiques dans des tissus et fluides biologiques a été appliquée avec succès dans le cadre du contrôle des animaux de boucherie (De Brabander et Verbecke 1975, 1984). L'addition d'une étape de purification des ATS sur colonne au mercure a considérablement amélioré la technique de détection. De nombreuses méthodes se sont inspirées de cette procédure et ont été appliquées dans des pays de l'UE. Une méthode de détection par HPLC-UV a également été appliquée au contrôle des animaux de boucherie (Wildanger 1975, Hooijerink et De Ruig 1987, Buick et al 1998). Cependant, le manque de spécificité et de sensibilité de ces méthodes a conduit au développement de techniques faisant intervenir la spectrométrie de masse en couplage avec la chromatographie. En effet, les performances de cette technique de mesure en font la méthode de choix pour répondre aux critères d'identification fixés par la décision analytique 2002/657/CE. Des méthodes de type GC-MS ont été appliquées avec succès (Pochard 1988, Batjoens et al 1996, Yu et al 1997, Le Bizec et al 1996, 1997). La limite de détection des ATS par ces méthodes est de 1 'ordre de $50 \mathrm{ppb}$ dans la thyroïde et les urines et de $100 \mathrm{ppb}$ dans les aliments pour le bétail. Plus récemment, 
l'émergence des méthodes LC-MS, avec interface APCI (Blanchflower et al 1997) ou ESI (De Wasch et al 1998b, 2001), a permis d'améliorer les performances des méthodes analytiques dédiées aux ATS. Les meilleures sensibilités atteintes actuellement sont de $20 \mathrm{ppb}$ dans la thyroïde pour les ATS suivants : tapazol, thiouracile, méthylthiouracile, propylthiouracile et mercapto-benzimidazole (De Wasch et al 2001).

\section{- Prostaglandines}

L'élimination des résidus de prostaglandines administrées est rapide compte tenu de leur prise en charge efficace par les voies métaboliques de détoxication. Vingt-quatre heures après administration, les teneurs résiduelles retrouvées dans le muscle et le tissu adipeux sont négligeables et le plus souvent à des niveaux inférieurs aux limites de détection des dosages. Les résidus retrouvés dans le foie et les reins varient entre 0,1 et $2-3$ ppb suivant les substances considérées (tableau 19). Les résidus de ces mêmes substances sont présents en quantités négligeables dans le lait.

Les études de toxicité aiguë signalent des effets létaux à des doses supérieures au $\mathrm{mg} / \mathrm{kg}$, ceci variant en fonction de l'espèce considérée (rat, souris), de la molécule et du mode d'administration. Ces substances ne sont ni génotoxiques, ni tératogènes, ni immunotoxiques et ne présentent pas de risque toxique dans le domaine de la reproduction, hormis leurs propriétés abortives pour lesquelles elles peuvent être justement, pour certaines d'entre elles, préconisées (tableau 19).

Les calculs de simulation de doses de résidus ingérés dans une ration type qui se compose des principaux tissus destinés à la consommation humaine montrent que, pour l'ensemble de ces produits, les valeurs maximales théoriques représenteraient moins de 5-7\% d'une dose journalière admissible (tableau 19). Les résidus de ces produits ne semblent donc pas présenter de risque toxique pour le consommateur.

Tableau 19. Résumé des observations obtenues lors de l'évaluation toxicologique de $P g F_{2 \alpha}$ et ses analogues utilisés en élevage.

\begin{tabular}{|c|c|c|c|c|c|}
\hline \multirow[b]{2}{*}{ Molécules } & \multicolumn{5}{|c|}{ Tests } \\
\hline & $\begin{array}{l}\text { Toxicité aiguë \& } \\
\text { subchronique }\end{array}$ & Génotoxicité & Tératogénicité & Reprotoxicité & $\mathrm{DJA}^{\mathrm{a}}$ \\
\hline Cloprosténol $^{1}$ & $\begin{array}{l}\text { Rat : } \\
- \text { DL }_{50} \text { ip }>5 \mathrm{mg} / \mathrm{kg} \\
\text { - DL } 50 \text { po > } 25 \mathrm{mg} / \mathrm{kg} \\
\text { - Toxicité à } 90 \mathrm{j}: \\
\quad \text { NOEL }^{\mathrm{b}}>50 \mu \mathrm{g} / \mathrm{kg} / \mathrm{j} \\
\text { Souris : } \\
\text { - DL } 50 \mathrm{im}>350 \mathrm{mg} / \mathrm{kg} \\
\text { Singe : } \\
\text {-Toxicité à } 90 \mathrm{j}: \\
\text { NOEL > } 50 \mu \mathrm{g} / \mathrm{kg} / \mathrm{j} \\
\text { Vache : } \\
-200 \times \text { dose : NS } \\
\text { Truie : } \\
-10 \times \text { dose : NS }\end{array}$ & $\begin{array}{l}\text { - Test de Ames : NS } \\
\text { - Cellules de lymphome } \\
\text { de souris : NS } \\
\text { - Aberrations } \\
\text { chromosomiques sur } \\
\text { lymphocytes humains : } \\
\text { NS (> 5,9 mM) } \\
\text { - Test des micro-noyaux } \\
\text { sur cellules de la } \\
\text { moelle osseuse : NS }\end{array}$ & $\begin{array}{l}\text { Rat po: NS } \\
\text { Lapin sc : NS }\end{array}$ & $\begin{array}{c}\text { Rat : } \\
\text { NOEL : } 15 \mu \mathrm{g} / \mathrm{kg} / \mathrm{j}\end{array}$ & $\begin{array}{c}0,075 \mu \mathrm{g} / \mathrm{kg} \\
\text { soit } \\
4,5 \mu \mathrm{g} / \text { ind. }^{1}\end{array}$ \\
\hline Luprostiol $^{2}$ & $\begin{array}{l}\text { Rat : } \\
-\mathrm{DL}_{50} \text { iv }=116-130 \mathrm{mg} / \mathrm{kg} \\
\text { Souris : } \\
-\mathrm{DL}_{50} \mathrm{im}>350 \mathrm{mg} / \mathrm{kg} \\
\text { Rat : } \\
- \text { Toxicité à } 90 \mathrm{j}: \\
\quad \text { NOEL > } 100 \mu \mathrm{g} / \mathrm{kg} / \mathrm{j} \\
\text { Porc : } \\
\text {-Toxicité à } 30 \mathrm{j}: \\
\quad \text { NOEL > } 100 \mu \mathrm{g} / \mathrm{kg} / \mathrm{j}\end{array}$ & $\begin{array}{l}\text { - Test de Ames : NS } \\
\text { - Test des micro-noyaux } \\
\text { sur cellules de la } \\
\text { moelle osseuse : NS }\end{array}$ & $\begin{array}{l}\text { Rat po : NS } \\
\text { Lapin po : NS }\end{array}$ & $\begin{array}{c}\text { Rat : } \\
\text { NOEL }>20 \mu \mathrm{g} / \mathrm{kg} / \mathrm{j}\end{array}$ & $\begin{array}{l}0,2 \mu \mathrm{g} / \mathrm{kg} \\
\text { soit } \\
12 \mu \mathrm{g} / \mathrm{ind}\end{array}$ \\
\hline Tiaprost $^{3}$ & $\begin{array}{l}\text { Rat : } \\
-\mathrm{DL}_{50} \text { po }=22,9 \mathrm{mg} / \mathrm{kg} \\
-\mathrm{DL}_{50} \mathrm{im}=2 \mathrm{mg} / \mathrm{kg} \\
\text { Souris : } \\
-\mathrm{DL}_{50} \text { po }=15,3 \mathrm{mg} / \mathrm{kg} \\
-\mathrm{DL}_{50} \mathrm{im}=9,8 \mathrm{mg} / \mathrm{kg} \\
-\mathrm{DL}_{50} \mathrm{iv}=1,6 \mathrm{mg} / \mathrm{kg} \\
\text { Rat : } \\
- \text { Toxicité à } 90 \mathrm{j}(\mathrm{po}): \\
\quad \text { NOEL }=200 \mu \mathrm{g} / \mathrm{kg} / \mathrm{j} \\
\text { Porc : } \\
\text {-Toxicité à } 90 \mathrm{j}(\mathrm{po}): \\
\text { NOEL }=12 \mu \mathrm{g} / \mathrm{kg} / \mathrm{j}\end{array}$ & $\begin{array}{l}\text { - Test de Ames: NS } \\
\text { - Test des micro- } \\
\text { noyaux: NS }\end{array}$ & ND & ND & $\begin{array}{c}0,12 \mu \mathrm{g} / \mathrm{kg} \\
\text { soit } \\
7,2 \mu \mathrm{g} / \mathrm{ind}\end{array}$ \\
\hline
\end{tabular}




\begin{tabular}{|c|c|c|c|c|c|}
\hline \multirow[b]{2}{*}{ Molécules } & \multicolumn{5}{|c|}{ Tests } \\
\hline & $\begin{array}{l}\text { Toxicité aiguë \& } \\
\text { subchronique }\end{array}$ & Génotoxicité & Tératogénicité & Reprotoxicité & $\mathrm{DJA}^{\mathrm{a}}$ \\
\hline Alfaprostol $^{4}$ & $\begin{array}{l}\text { Rat : } \\
-\mathrm{DL}_{50} \mathrm{sc}=110 \mathrm{mg} / \mathrm{kg} \\
-\mathrm{DL}_{50} \text { iv }=52,8 \mathrm{mg} / \mathrm{kg} \\
- \text { Toxicité à } 90 \mathrm{j}(\mathrm{po}) \\
\quad \text { NOEL }=100 \mu \mathrm{\mu g} / \mathrm{kg} / \mathrm{j} \\
\text { Souris : } \\
-\mathrm{DL}_{50} \mathrm{sc}=2096 \mathrm{mg} / \mathrm{kg} \\
-\mathrm{DL}_{50} \text { iv }=53,5 \mathrm{mg} / \mathrm{kg}\end{array}$ & $\begin{array}{l}\text { - Test de Ames : NS } \\
\text { - Cellules de lymphome } \\
\text { de souris : NS }\end{array}$ & $\begin{array}{c}\text { Rat : } \\
\text { NOEL }=0,2 \mathrm{mg} / \mathrm{kg} / \mathrm{j} \\
\text { Lapin : NS }\end{array}$ & $\begin{array}{c}\text { Rat : } \\
\text { NOEL }=100 \mu \mathrm{g} / \mathrm{kg} / \mathrm{j}\end{array}$ & $\begin{array}{c}1 \mu \mathrm{g} / \mathrm{kg} \\
\text { soit } \\
60 \mu \mathrm{g} / \mathrm{ind}\end{array}$ \\
\hline $\begin{array}{l}\text { Etiproston } \\
\text { trométhamine }\end{array}$ & $\begin{array}{l}\text { Rat : } \\
\text {-Toxicité à } 30 \mathrm{j}(\mathrm{po}): \\
\quad \text { NOEL }=300 \mu \mathrm{g} / \mathrm{kg} / \mathrm{j} \\
\text { Chien : } \\
\text { - Toxicité subaiguë }(\mathrm{po}): \\
\text { NOEL }=300 \mu \mathrm{g} / \mathrm{kg} / \mathrm{j}\end{array}$ & $\begin{array}{l}\text { - Test de Ames : NS } \\
\text { - Mutations du gène } \\
\text { HPRT : NS } \\
\text { - Test des micro- } \\
\text { noyaux : NS } \\
\text { - Test d'aberrations } \\
\text { chromosomiques : (+) }\end{array}$ & $\begin{array}{l}\text { Rat : NS } \\
\text { Lapin : NS }\end{array}$ & ND & ND \\
\hline $\begin{array}{c}\text { Dinoprost } \\
\text { trométhamine }\end{array}$ & $\begin{array}{l}\text { Rat : } \\
\text { - DL }{ }_{50}(\mathrm{po})=1,2 \mathrm{mg} / \mathrm{kg} \\
\text { - Toxicité à } 28 \mathrm{j} \text { (iv) : } \\
\text { NOEL > } 32 \mathrm{mg} / \mathrm{kg} / \mathrm{j} \\
\text { Chien : } \\
\text { - Toxicité à } 30 \mathrm{j} \text { (iv) : } \\
\text { NOEL > } 600 \mu \mathrm{gg} / \mathrm{kg} / \mathrm{j} \\
\text { Singe : } \\
\text { - Toxicité à } 15 \mathrm{j} \text { (iv) : } \\
\text { NOEL > } 15 \mathrm{mg} / \mathrm{kg} / \mathrm{j} \\
\text { - Toxicité à } 90 \mathrm{j}(\mathrm{po}): \\
\text { NOEL toxicologique = } \\
8 \mathrm{mg} / \mathrm{kg} / \mathrm{j} \\
\text { NOEL pharmacologique } \\
=1,25 \mathrm{mg} / \mathrm{kg} / \mathrm{j}\end{array}$ & $\begin{array}{l}\text { - Test de Ames : NS } \\
\text { - Test d'aberrations } \\
\text { chromosomiques : NS }\end{array}$ & $\begin{array}{c}\text { Rat : } \\
\text { - \# } 3 \mathrm{mg} / \mathrm{kg}(\mathrm{sc}) \\
\text { sur } 3 \text { jours } \\
\text { Lapin : } \\
\text { - \# } 3 \mathrm{mg} / \mathrm{kg}(\mathrm{sc}) \\
\text { sur } 3 \text { jours }\end{array}$ & ND & $\begin{array}{l}0,83 \mu \mathrm{g} / \mathrm{kg} \\
\text { soit } \\
50 \mu \mathrm{g} / \mathrm{ind} .\end{array}$ \\
\hline
\end{tabular}

a Dose Journalière Admissible ; b NOEL : No-Observed Effect Level ou dose sans effet.

1 www.emea.eu.int/pdfs/vet/mrls/020297en.pdf (EMEA/MRL/202/97-FINAL, avril 1997) et www.emea.eu.int/pdfs/vet/mrls/089804en.pdf (EMEA/MRL/898/04-FINAL, mai 2004); ind. : individu.

2 www.emea.eu.int/pdfs/vet/mrls/020097en.pdf (EMEA/MRL/200/97-FINAL, avril 1997).

3 www.emea.eu.int/pdfs/vet/mrls/050298en.pdf (EMEA/MRL/502/98-FINAL, février 1999).

4 www.emea.eu.int/pdfs/vet/mrls/011596en.pdf (EMEA/MRL/115/96-FINAL, juillet 1996).

5 www.emea.eu.int/pdfs/vet/mrls/etiprostontrometh.pdf.

6 www.emea.eu.int/pdfs/vet/mrls/022897en.pdf (EMEA/MRL/228/97-FINAL, juin 1997).

7 www.emea.eu.int/pdfs/vet/mrls/dinoprost.pdf.

\subsection{3 / L'impact environnemental des résidus excrétés}

\section{- Stérö̈des}

Les préoccupations des pouvoirs publics et des consommateurs en matière de sécurité environnementale sont apparues au cours de la dernière décennie quand il a été prouvé qu'un nombre important de produits toxiques retrouvés dans l'environnement pouvaient avoir un impact sérieux sur la physiologie de la reproduction de certaines espèces animales sauvages (Cooper et Kavlock 1997, Gray et al 2001, Hotchkiss et al 2002) mais aussi vraisemblablement chez l'homme (Jegou et al 1999). Le traitement des eaux usées dans les stations d'épuration ne prend pas réellement en compte l'élimination des petites molécules comme les stéroïdes, en parti- culier des substances comme l'éthinylœstradiol, qui conservent leur pouvoir hormonal, celui-ci pouvant être suffisant pour induire chez certaines espèces aquatiques extrêmement sensibles des perturbations hormonales (Purdom et al 1994).

La dégradation des stéroïdes présents dans des lisiers provenant d'élevages où les animaux sont traités avec des stéroïdes anabolisants pendant de longues périodes pose les mêmes problèmes (Soto et al 2004, Orlando et al 2004). $\mathrm{Si}$ certains tests in vitro détectent bien une activité œstrogénique ou androgénique résiduelle dans les eaux de rivière collectées en aval des aires d'élevage de bouvillons implantés, les méthodes analytiques doivent encore progresser pour caractériser la structure de l'ensemble des molécules ainsi détectées (Soto et al 2004).

Dans une étude conduite sur des lisiers provenant de bouvillons traités avec des implants à base d'acétate de trenbolone, la vitesse de demidisparition de la trenbolone est de l'ordre de 270 jours. Après épandage de lisier, l'élimination dans le sol de la trenbolone se fait assez rapidement: 8 jours après, des résidus sont encore détectés dans le sol mais pas après 30 jours. La stabilité du MGA est importante dans le sol après épandage ; elle est supérieure à 5 mois (Schiffer et al 2001).

\section{- Autres xénobiotiques}

Aucune donnée ne semble avoir été produite en ce qui concerne les 
$\beta$-agonistes, les thyréostatiques ou les prostaglandines. Ceci s'explique simplement puisque les deux premiers sont interdits dans l'UE et que les prostaglandines ne sont utilisées que par injection en traitement aigu. Les risques pour l'environnement sont a priori négligeables. Néanmoins, dans les nouvelles évaluations de xénobiotiques utilisables en élevage, la rubrique relative à la sécurité vis-à-vis de l'environnement doit être renseignée.

\section{2 / L'évaluation toxicologique des hormones peptidiques}

Les hormones de croissance recombinantes (rGH) sont les seules hormones utilisées pour modifier sur de longues périodes la physiologie des animaux d'élevage, que ce soit pour améliorer les paramètres de croissance chez le porc ou pour maintenir les performances de production chez la vache laitière. Des AMM pour ces préparations ont d'ailleurs été accordées aux USA ou en Australie. Cependant, l'utilisation de GH étant interdite dans l'UE, il a été nécessaire de développer des techniques analytiques fiables afin de détecter leur présence éventuelle dans des matrices animales (lait, viande, sang). Deux approches sont possibles pour le contrôle de l'utilisation illégale de la GH en élevage : des mesures indirectes de l'administration de ST par le suivi de marqueurs biologiques et des mesures directes de la présence de rST.

\subsection{1 / Recherche d'effets induits : le cas des IGF}

Les IGFBP, protéines de transport des IGF, et l'IGF-I sont les molécules pouvant servir de marqueurs biologiques de l'administration de GH. En effet, la biosynthèse hépatique des IGFBP et de l'IGF-I est modulée par la GH et Kicman et al (1997) ont montré que l'IGF-I et les IGFBP pouvaient être des marqueurs potentiels de l'administration de GH chez l'homme. Cette hormone induit en effet la synthèse de l'IGFBP3 et de l'IGF-I alors qu'elle régule négativement celle des IGFBP1 et 2 . Le suivi de ces molécules dont la concentration varie sous l'effet de la $\mathrm{GH}$ représenterait donc un moyen indirect de détecter une utilisation frauduleuse de GH en élevage.

\section{- Elevage bovin}

L'utilisation de méthodes immunologiques permet d'estimer la baisse de concentration sérique en IGFBP2 chez les vaches traitées à la rbST (Scippo et al 1996). De même, le dépistage des IGF-I dans différentes matrices (sang, lait, tissus) peut être réalisé par RIA (Zhao et al 1991). Cependant, et même si la littérature s'accorde généralement sur l'augmentation du taux d'IGF-I consécutif à une administration de $\mathrm{GH}$, les concentrations en IGF-I sont très variables d'un animal à l'autre et de surcroît fortement affectées par l'état physiologique de l'animal (parité, stade de lactation, etc.). Il est donc très difficile de corréler une teneur en IGF-I avec une administration de GH (Collier et al 1991, Burton et al 1994, Zhao et al 1994). De ce fait, la stratégie consistant en la mesure des IGF-I comme critère de fraude à la $\mathrm{GH}$ reste très controversée. De plus, ces techniques ne permettent en aucun cas de déterminer en élevage bovin quelle $\mathrm{GH}$, hypophysaire ou recombinante, a été utilisée.

\section{- Elevage équin}

Chez le cheval, la GH peut être utilisée frauduleusement pour tenter d'améliorer ses performances en course. Les différentes mesures réalisées sur les protéines de transport de l'IGF-I, IGFBP1, IGFBP 2 et IGFBP3, ont montré qu'il n'était pas possible de les utiliser comme marqueurs de l'administration de la GH (Popot et al 2000, De Kock et al 2001). C'est la forme libre de l'IGF-I qui est active biologiquement. Chez le cheval, lorsqu'on dose l'IGF-I, on mesure en fait l'IGF-I total, c'est-à-dire la fraction libre et celle liée aux IGFBP (De Kock et al 2001). La sécrétion de l'IGF-I n'est pas pulsatile et sa concentration reste plus ou moins constante dans des conditions physiologiques stables (Malinowski et al 1996). Différents auteurs (De Kock et al 2001, Faustino-Kemp et al 2001, Popot et al 2001) ont étudié les variations physiologiques d'IGF-I plasmatiques ou sériques et mesuré leurs valeurs après administration de $\mathrm{rGH}$ équine ou de $\mathrm{GH}$ bovine ou porcine. Les concentrations d'IGF-I plasmatiques ou sériques n'excèdent pas $550 \mathrm{ng} / \mathrm{ml}$ au repos. Quelles que soient les voies d'administration, sous-cutanée et intra-musculaire, et les doses utilisées, les concentrations maximales plasmatiques observées ne dépassent pas $1100 \mathrm{ng} / \mathrm{ml}$. Les profils d'IGF-I plasmatique après administration peuvent être différents en fonction de l'âge des chevaux (Popot et al 2001).

Selon les travaux cités ci-dessus, l'IGF-I semble être l'indicateur le plus fiable d'une administration de $\mathrm{GH}$ chez le cheval. L'article 6 de «l'Accord International sur l'Elevage et les
Courses» considère que la mise en évidence d'un indicateur scientifique prouvant une administration d'une substance prohibée équivaut à la mise en évidence de la dite substance. C'est ainsi qu'un seuil d'IGF-I plasmatique de $860 \mathrm{ng} / \mathrm{ml}$ déterminé par LC-MS a été proposé dans le cadre du contrôle antidopage chez les chevaux (Popot et al 2002).

\subsection{2 / Détection directe de l'adminis- tration de $\mathrm{GH}$}

Les méthodes indirectes permettant une détermination non ambiguë de l'administration de rGH dans l'espèce bovine ou porcine n'ayant pas fait leur preuve, des protocoles de détection et d'analyse des rGH elles-mêmes ont été développées. Des tentatives de dosages immunologiques des rGH dans le lait ou les tissus n'ont pas permis d'atteindre des limites de détection compatibles avec la recherche de ces composés dont les concentrations sont de l'ordre $\mathrm{du} \mathrm{ng} / \mathrm{mL}$ (Schams et al 1988, Fernandez et Kopchick 1990, Roh et al 1997). Certains dosages ELISA sur le plasma se sont avérés néanmoins prometteurs pour détecter la $\mathrm{GH}$ à des concentrations comprises entre 10 et 20 $\mathrm{ng} / \mathrm{mL}$ dans cette matrice (Secchi et al 1988, Zwickl et al 1990, Roh et al 1997, Scippo et al 1997) mais n'ont jamais permis de distinguer la $\mathrm{GH}$ endogène de la forme recombinante.

A ce propos, depuis une dizaine d'années, de nouvelles stratégies ont été élaborées pour différencier les formes endogènes de celles issues des biotechnologies. Dans ce contexte, la spectrométrie de masse avec des techniques d'ionisation douces adaptées à l'étude des protéines, telles l'électrospray et la désorption laser sur matrice (MALDI) ont été utilisées. Ces techniques permettent de mesurer sans ambiguïté une différence minime de masse, même à $20 \mathrm{kDa}$, entre la rGH et ses homologues hypophysaires, à condition que cette différence corresponde au moins à un acide aminé. C'est le cas de toutes les rGH bovines et porcines commercialisées à ce jour. Une alternative à cette méthode de mesure de masse de l'hormone intacte est la détermination par LC-MS, après hydrolyse enzymatique spécifique de la protéine, du fragment $\mathrm{N}$-terminal caractéristique de la forme recombinante ou naturelle. Ces techniques ont fait leurs preuves sur des préparations purifiées de bGH et de rbGH (Scippo et al 1997, Secchi et al 2001, Rochut et al 2000, Pinel et al 2004a). Néanmoins, il n'existe toujours pas à ce jour de protocole permet- 
tant d'extraire, à partir de matrices complexes (lait ou sang), et d'analyser, dans un but de discrimination, les formes endogènes et recombinantes de GH (Pinel et al 2004b).

\subsection{3 / Conséquences sur le statut rési- duel des xénobiotiques utilisés de façon réglementée}

La GH module l'activité d'un nombre important de cibles qui sont sous son contrôle direct ou indirect. Certaines d'entre elles, hépatiques pour la plupart, interviennent dans le métabolisme de détoxication. Ces enzymes, principalement des monoxygénases à cytochrome P450, des glutathion Stransférases et des glucuronoyltransférases, voient leurs concentrations profondément modifiées en cas d'administration quasi continue de $\mathrm{GH}$, que ce soit chez le rat qui a longtemps servi de modèle à l'étude comparée de la rythmicité de la sécrétion de $\mathrm{GH}$ entre mâles et femelles (Wiwi et Waxman 2004) ou chez le porc en engraissement chez lequel les capacités de métabolisation sont réduites à la moitié ou au tiers des valeurs normales (Paris non publié). Les conséquences pour la sécurité du consommateur sont importantes au regard des délais d'attentes à respecter avant commercialisation des produits animaux en cas d'administration de xénobiotiques tels que les médicaments vétérinaires utilisés normalement en élevage porcin. En effet, les normes habituelles d'utilisation de ces substances devraient ne plus être adaptées à ce nouveau contexte d'élevage, les capacités d'élimination des xénobiotiques par ces animaux étant grandement réduites. Ce sont donc les posologies et les délais d'attentes, voire même les profils de résidus de ces xénobiotiques qu'il faudrait réexaminer dans le détail (Chilliard et al 1998b, 2001).

\section{5 / Usage et restriction d'usage des substances à visée zootechnique, régle- mentation et stratégies de contrôle}

Diverses substances et préparations qui les contiennent, susceptibles de recevoir des applications thérapeutiques ou zootechniques, sont l'objet de restrictions d'emploi chez les animaux. Elles peuvent aller jusqu'à leur interdiction totale, en raison du détournement potentiel de l'usage qui peut en être fait vers des applications qui, pour des raisons éthiques, économiques ou sanitaires, sont réprouvées par l'UE.

\section{1 / Au niveau européen}

\subsection{1 / Le cadre réglementaire communautaire}

Ce cadre est fixé par la directive 96/22/CE du Conseil du 29 avril 1996 (J.O.C.E NL 125 du 23.5.1996), modifiée par la directive 2003/74/CE du Parlement européen et du Conseil du 22 septembre 2003 (J.O.C.E. N ${ }^{\circ} \mathrm{L} 262$ du 14.10.2003), concernant l'interdiction d'utilisation de certaines substances à effet hormonal ou thyréostatique et des substances $\beta$-agonistes dans les spéculations animales.

$\mathrm{Au}$ sens de cette directive, le terme d'hormone désigne implicitement les substances à activités hormonales sexuelles : œstrogène, gestagène ou androgène. Mais la directive vise en fait les substances à activités anabolisante ou anticatabolisante susceptibles d'être utilisées comme promoteurs de croissance en élevage, ce que l'UE réprouve et combat. Par cette directive, l'UE formalise sa politique d'interdiction d'administration de ces substances aux animaux et notamment aux Animaux Producteurs de Denrées Destinées à la Consommation $\mathrm{Hu}-$ maine (APDDCH).

Tenant compte des remarques de l'OMC, les substances ont été classées dans deux annexes en fonction de leurs risques respectifs.

L'Annexe I donne la «Liste des substances pharmacologiquement actives pour lesquelles une limite maximale résiduelle a été fixée».

L'Annexe II donne la «Liste des substances interdites» avec mentionnés :

\section{- en liste A :}

- les thyréostatiques,

- les stilbènes, dérivés des stilbènes, leurs sels et esters.

\section{- en liste B :}

- L'cestradiol ${ }^{1}$ et ses dérivés estérifiés,

\section{- Les substances $\beta$-agonistes.}

L'Annexe III correspond à la «Liste des autres substances interdites provisoirement», mentionnant plus particu- lièrement les androgènes, les gestagènes ou les substances à effet oestrogénique autres que l'œstradiol et ses dérivés estérifiés.

Dans un premier temps (articles 2 et 3), la directive stipule que les Etats membres doivent «veiller à interdire» la mise sur le marché des substances de la liste A - Annexe II en vue de leur administration aux animaux de toute espèce, et d'interdire la mise sur le marché, l'administration aux APDDCH y compris d'aquaculture, leur détention sur une exploitation, leur commercialisation ou leur abattage et la transformation de leurs produits contenant des résidus de telles substances.

Dans un second temps (articles 4, 5, 5 bis), elle indique que, par dérogation, les Etats membres «peuvent autoriser» l'administration à des APDDCH des substances de la liste B - Annexe II et de l'Annexe III pour quelques indications thérapeutiques ou zootechniques, sous réserve qu'elles entrent dans la composition de médicaments vétérinaires autorisés (AMM). Sont exclues de cette dérogation les formes pharmaceutiques et conditions d'emploi conduisant à un dépôt et à des temps d'attente fixés. En outre, cette dérogation n'est acceptable que si des méthodes analytiques sont disponibles permettant les contrôles de leurs résidus. Leur administration à des animaux, parfaitement identifiés, doit alors être effectuée par le vétérinaire prescripteur, exclusivement, pour l'œstradiol et les substances $\beta$-agonistes administrées aux bovins pour la tocolyse ou, sous sa responsabilité, pour les autres substances ou indications. L'usage de l'œstradiol et de ses dérivés ne peut être autorisé que, d'une part, pour le traitement de la macération et de la momification foetales et du pyomètre chez les bovins, et, d'autre part, mais jusqu'au 14 octobre 2006 seulement, pour l'induction de l'œstrus chez les bovins, les équins, les ovins et les caprins.

D'autres dispositions concernent la détention des substances, les contrôles, la circulation et les échanges d'animaux ayant reçu de telles substances, y compris les importations des pays tiers. Il est notamment imposé aux États membres d'interdire l'importation des denrées provenant des pays n'appliquant pas les dispositions de la directive.

Rappelons ici que pour devenir effectives dans chaque Etat membre, les dispositions de ces directives doivent être transposées en droit national. 


\subsection{2 / Les laboratoires de référence}

La réglementation européenne en matière de contrôle de l'usage frauduleux des anabolisants est une des plus anciennes dans le domaine de la sécurité des aliments. Ceci tient à l'usage ancien du DES en élevage. Cette réglementation organise le contrôle dans tous ces aspects techniques : substances à contrôler, plans d'échantillonnage, affectation des substances par type d'aliments, laboratoires intervenants, etc. La directive 96/23 prévoit l'existence de laboratoires de référence au niveau communautaire (LCR) et national (LNR). Les LCR sont désignés par la Commission Européenne après consultation des Etats membres, alors que les LNR le sont au niveau des Etats, mais référencés auprès de la Commission.

Les LCR sont désignés dans l'annexe $\mathrm{V}$ de la directive. Quatre laboratoires se répartissent les différentes familles de résidus et de contaminants ; leurs fonctions au niveau communautaire peuvent être comparées à celles qu'exercent les laboratoires nationaux dans chaque Etat membre. Ils interviennent également lorsqu'un différend oppose deux LNR.

Les LCR sont le RIVM (Rijksinstituut voor Volksgezondheid en Milieu, Institut National pour la Santé Publique et l'Environnement) à Bilthoven (Pays-Bas) pour les anabolisants stéroïdiens et les antithyroïdiens, le BVL (Bundesamt für Verbraucherschutz und Lebensmittelsicherheit, Office Fédéral de la Protection des Consommateurs et de la Sécurité Alimentaire) à Berlin (Allemagne) pour les agonistes $\beta$-adrénergiques et les sulfamides, l'AFSSA à Fougères (France) pour les autres médicaments vétérinaires et 1'ISS (Istituto Superiore di Sanità, Institut Supérieur de la Santé) à Rome (Italie) pour les contaminants de l'environnement.

\section{2 / Au niveau national}

\subsection{1 / La réglementation française}

Les substances hormonales sont visées par plusieurs réglementations, certaines anciennes, parfois redondantes, relatives à la santé publique et la détection des fraudes. Pour l'essentiel, elles sont maintenant codifiées.

\section{- Code de la santé publique (CSP)}

Ces substances sont visées par l'article L. 5144-1 soit expressément, par l'alinéa c) estrogènes, soit implicite- ment par les alinéas e) produits susceptibles de demeurer à l'état de résidus toxiques ou dangereux (...) et f) produits dont les effets sont susceptibles d'être à l'origine d'une contravention à la législation sur les fraudes. En outre, les substances hormonales et les médicaments qui les contiennent sont pour la plupart classés sur l'une des listes I ou II des substances vénéneuses visées au point d) du même article et soumis à ce titre aux règles particulières qui les visent. Il en découle entre autres que ces substances ne peuvent pas être remises directement aux éleveurs et surtout que les médicaments qui les contiennent ne peuvent être délivrés que sur la prescription d'un vétérinaire. Par ailleurs, les articles R. 5141-117 à -121 soumettent ces substances à des conditions particulières, notamment un enregistrement, lors de leur prescription, de leur délivrance, de leur cession, de leur détention et de leur fabrication.

\section{- Code rural (CR)}

Les plus importantes dispositions de restriction d'usage ont été prises par le décret $n^{\circ} 2003-138$ du 18 février 2003 relatif aux substances réglementées administrées aux animaux et aux contrôles des résidus dans les denrées alimentaires d'origine animale. Ce décret, transposant en droit national la directive 96/22/CE, a été rapidement abrogé et intégré dans le Code rural par le décret $\mathrm{n}^{\circ} 2003-768$ du 1 er août 2003 (J.O.R.F. du 7.8.2003) relatif à la partie réglementaire du livre II du Code rural, lui-même modifié par le décret $\mathrm{n}^{\circ}$ 2004-757 du 22 juillet (J.O.R.F. du 29.7.2004). Les emplois autorisés à ce jour en France des médicaments vétérinaires à base de substances réglementées, sont fixées principalement par les articles R. 234-6 à -8 de ce code (tableau 20). D'autres dispositions relatives aux contrôles sont fixées par les articles suivants R. 234-9 à -14 et complétées par l'arrêté du 31 mars 2003 (J.O.R.F. du 11.4.2003) décrivant la fiche de prélèvements.

\subsection{2 / La structuration des instances de contrôle}

Le contrôle de ces substances dépend pour partie du Ministère de l'Agriculture (Direction Générale de l'Alimentation, DGAL), pour ce qui concerne les denrées alimentaires d'origine animale et du Ministère des Finances (Direction Générale de la Consommation, de la Concurrence et de la Répression des Fraudes, DGCCRF), pour ce qui concerne l'alimentation animale et les produits transformés. La DGAL, en liaison étroite avec la Commission Européenne, met en oeuvre les plans annuels de contrôle; plusieurs de ses services internes sont impliqués selon les substances, les filières et les types de denrées. Elle s'appuie sur les directions départementales des services vétérinaires pour tout ce qui concerne les prélèvements, les inspections des établissements d'élevage, de transformation et de distribution des produits. Les laboratoires concernés par ces analyses en première intention sont les laboratoires départementaux d'analyse; ces laboratoires dépendent des Conseils Généraux de département et leur activité est extrêmement diversifiée. Ce sont eux qui sont en charge des analyses nécessaires à la réalisation des plans de contrôle des résidus et contaminants dans les denrées alimentaires d'origine animale. Ils reçoivent un agrément du Ministère de l'Agriculture après avoir exprimé leur souhait de participer à un ou plusieurs groupes d'étude de résidus ou contaminants. Ceci explique que la liste des laboratoires départementaux agréés accompagnant le plan de contrôle correspondant puisse être variable dans le temps. Les conditions de l'agrément sont, bien entendu, des critères techniques liés aux équipements et compétences, lesquelles sont vérifiables par les analyses circulaires organisées par les LNR. En outre, des exigences en matière d'assurance qualité et d'accréditation (norme ISO 17025) ont été récemment ajoutées aux conditions d'agrément. A titre indicatif, le plan de contrôle des facteurs de croissance en élevage implique onze laboratoires répartis sur le territoire national.

Les laboratoires régionaux de la DGCCRF participent également à ce contrôle en analysant divers contaminants et composés de l'alimentation animale. En ce qui concerne les promoteurs de croissance, il s'agit essentiellement de quelques progestagènes et des $\beta$-agonistes.

Dans le contexte de l'organisation européenne du contrôle, les Etats membres ont dû désigner des LNR dont la liste a été publiée par la décision 98/536/CE. En France, ils sont au nombre de quatre pour couvrir l'ensemble des résidus et contaminants. A ce titre, le LABERCA de 1'Ecole Nationale Vétérinaire de Nantes est en charge des substances à effet anabolisant et assimilées (groupe A1 à $\mathrm{A} 5$ de la directive susvisée).

Les missions de ces LNR sont prévues à l'article 14 de cette même directive. En résumé, ils jouent un rôle d'ap- 
Tableau 20. Emploi des substances «réglementées» autorisé par la réglementation française : articles $R$. 234-6 et $R$. 234-7 du code rural, mentionnant le temps d'attente (TA), maximum acceptable découlant de leur administration, sous réserve qu'il existe des méthodes analytiques permettant de détecter leurs résidus aux concentrations limites admissibles.

\begin{tabular}{|c|c|}
\hline Substances & Usages thérapeutiques \\
\hline $\begin{array}{l}\text { CEstradiol } \\
\text { ou dérivés estérifiés }\end{array}$ & $\begin{array}{l}\text { - Traitement de la macération ou de la momification fœtales et du pyomètre chez les } \\
\text { bovins } \\
\text { - Forme n'entraînant pas de dépôt local }+T A \leq 15 j\end{array}$ \\
\hline $\begin{array}{l}\text { Testostérone, progestérone } \\
\text { ou dérivés facilement hydrolysés à } \\
\text { partir de l'endroit d'application }\end{array}$ & $\begin{array}{l}\text { - Traitement des troubles de la fécondité. Forme injectable n'entraînant pas de dépôt } \\
\text { local, implant exclus }+T A \leq 15 \mathrm{j} \\
\text { - Traitement d'un dysfonctionnement ovarien. Spirale vaginale }+T A \leq 15 \mathrm{j}\end{array}$ \\
\hline Allyl-trenbolone (altrenogest) & $\begin{array}{l}\text { - Traitement de troubles de la fécondité, chez les équidés* (sans restriction) et les } \\
\text { animaux de compagnie. } \\
\text { - Forme orale }+\mathrm{TA} \leq 15 \mathrm{j}\end{array}$ \\
\hline Substances $\beta$-agonistes & $\begin{array}{l}\text { - Induction de la tocolyse, chez les bovins. Forme injectable }+\mathrm{TA} \leq 28 \mathrm{j} \\
\text { - Induction de la tocolyse et traitement de troubles respiratoires chez les équidés }{ }^{2} \text { non } \\
\text { destinés à la consommation humaine et les animaux de compagnie }{ }^{2} \text {. }\end{array}$ \\
\hline Substances & Usages zootechniques \\
\hline $\begin{array}{l}\text { OEstradiol } \\
\text { ou dérivés estérifiés }\end{array}$ & $\begin{array}{l}\text { - Induction de l'œstrus chez les bovins, équins, ovins et caprins. Forme n'entraînant pas } \\
\text { de dépôt local + TA } \leq 15 \text { j } \\
\text { - Permis jusqu'au } 14 \text { octobre } 2006\end{array}$ \\
\hline $\begin{array}{l}\text { CEstrogène (œstradiol et dérivés } \\
\text { estérifiés exclus), } \\
\text { Androgène, } \\
\text { Gestagène }\end{array}$ & $\begin{array}{l}\text { - Synchronisation du cycle œstral } \\
\text { - Préparation au don ou à l'implantation d'embryons } \\
\text { - Administration individuelle. Forme pharmaceutique n'entraînant pas de dépôt local + TA } \\
\leq 15 \mathrm{j}\end{array}$ \\
\hline Androgène & $\begin{array}{l}\text { - Inversion sexuelle } \\
\text { - Alevins de poisson de }<3 \text { mois non destinés à la consommation humaine }\end{array}$ \\
\hline
\end{tabular}

1 Le terme «œstradiol» dans les textes juridiques est : œstradiol 17-bêta.

2 Administration pouvant, par dérogation, ne pas être effectuée par le vétérinaire, mais par une personne placée néanmoins sous sa responsabilité, sur prescription non renouvelable avec mention par ses soins, dans le registre d'élevage, du nom et de la fonction de la personne qui administre.

pui technique auprès de l'autorité compétente en matière de contrôle et doivent assurer une activité de recherche et de développement méthodologique et la diffuser auprès des laboratoires d'application qu'ils ont pour mission de former et d'en contrôler les aptitudes. Ils peuvent être amenés à effectuer des analyses de confirmation, soit en cas de résultat suspect obtenu par un laboratoire d'application, soit en cas de litige, notamment au niveau international. Ils sont le garant de la conformité des méthodes aux exigences de qualité décrites dans la décision 2002/657/CE.

\section{3 / Au niveau des principaux pays exportateurs}

\subsection{1 / Les contrôles nationaux (Canada, USA, Argentine, Australie, Nouvelle-Zélande)}

La plupart des grands pays producteurs de denrées d'origine animale ont mis en place des systèmes de contrôle des résidus de médicaments vétérinaires. Ceci s'est bien entendu fait de manières très différentes selon le type d'élevage, selon la conscience politique de l'intérêt à gérer ce risque potentiel ; la législation en matière d'autorisation, de conditions de distribution et d'utilisation des médicaments et additifs alimentaires a été, elle aussi, très variable. Ainsi, certains pays ont pu distribuer et utiliser sans réel contrôle des hormones anabolisantes en s'appuyant sur la confiance envers les éleveurs pour le respect des temps d'attente légaux ou pour mettre en œuvre des traitements antiparasitaires externes d'une manière extensive en vertu du principe que les animaux sont traités et abattus par lots homogènes, garantissant ici encore l'absence de résidus potentiels.

Même si, dans tous ces pays, des contrôles ont été mis en place, les calculs statistiques montrent que l'échantillonnage reste très insuffisant pour mettre en évidence une quelconque mauvaise utilisation.

Ce n'est d'ailleurs que dans la dernière décennie que les instances internationales, à savoir la commission du Codex Alimentarius, a commencé à se pencher sur le problème du contrôle des résidus, d'une part en adoptant des LMR propres et, d'autre part, en fixant des exigences minimales pour les plans de contrôle; ces exigences minimales sont fondées sur la probabilité statistique de mettre en évidence les mauvais usages. Elles sont mises en œuvre dans de nombreux pays et peuvent être considérées comme le minimum légal international.

En réalité, la plupart des pays producteurs exportent une partie de leur production vers l'un des Etats membres de l'UE ; cela peut aller d'une spécialité gastronomique particulière à une exportation massive de viande ou de poissons d'élevage indispensable à l'économie du pays. Dans tous les cas, un respect des règles européennes doit s'appliquer.

$\mathrm{Au}$ niveau du MERCOSUR (Argentine, Brésil, Paraguay et Uruguay) et du Chili, une évolution de la réglementation en matière d'utilisation des substances à activité hormonale s'est opérée au cours des dix dernières années (Fernandez-Suarez 2004). Ces pays ont créé ou adapté des programmes de contrôle de présence de résidus à partir du Compound Evaluation System (CES) de l'USDA (USA) pour l'établissement des priorités en matière de contrôle de résidus et des critères définis par le JECFA et le Codex Alimentarius pour définir les LMR, les standards techniques de vali- 
dation de méthodes analytiques et de méthodes d'échantillonnage. L'utilisation des anabolisants est interdite en Uruguay, au Chili, au Paraguay et vient de l'être en Argentine (résolution 447/2004) (Fernandez-Suarez 2004).

\subsection{2 / La politique européenne vis-à- vis des pays tiers}

Cette politique est exprimée légalement dans la directive 96/23 EC. Le principe général est que tout pays exportateur doit présenter des garanties en matière de sécurité des aliments au moins égales à celles des Etats membres ; il doit pouvoir le démontrer et accepte de se soumettre à des contrôles, tant a priori qu'a posteriori. Théoriquement cela ne signifie pas qu'un pays exportateur doive avoir strictement les mêmes règles de contrôle en ce qui concerne les matrices et les composés à rechercher, ni la même pression de contrôle. En pratique, au début de la mise en place de ces exigences, cela a été plus ou moins le cas. Ce n'est que récemment que des adaptations locales argumentées ont été prises en compte par la Commission Européenne. Il est remarquable que ces exigences de relation de l'UE avec les Pays tiers sont à la base des exigences internationales, en particulier des termes de l'accord SPS de l'OMC. Ceci a été repris plus récemment dans la loi européenne alimentaire (règlement 178/2002/EC).

Les Pays tiers exportateurs doivent figurer sur une liste (décision 2000/159) et doivent pour cela présenter un dossier initial à la Commission dans lequel figurent toutes les informations légales en matière d'autorisation des médicaments (notamment le respect des interdictions prévues par la directive 96/22 concernant les anabolisants), et une liste des LMR nationales et des teneurs maximales tolérées en contaminants (métaux lourds par exemple). En outre, le pays doit fournir des éléments de sa réglementation en matière de suivi lors de non-conformité d'un produit. A cela s'ajoute une désignation des autorités responsables du contrôle associée à des indications de nature et volume de production et d'exportation. Cela constitue l'information de base.

En complément, les Pays tiers sont invités à soumettre annuellement à la Commission Européenne leur plan de contrôle. Ce plan inclut la liste des composés surveillés, la fréquence d'échantillonnage, les méthodes employées (respect de la directive 2002/657/EC), les niveaux de détection et de confirmation, le respect des limites minimales de performance requise (MRPL, Minimum Required Performance Level) pour les composés interdits ; il comprend également la liste des laboratoires agréés tant pour le dépistage que pour la confirmation et le statut de ces laboratoires en matière d'assurance-qualité car ils doivent être accrédités selon les mêmes règles que les laboratoires de contrôle intracommunautaires. L'étude et l'acceptation de ces plans donnent la possibilité d'exporter au pays demandeur.

Néanmoins, l'UE s'est donnée les moyens de vérifier localement la mise en œuvre réelle de ces systèmes de garantie de la sécurité des aliments; c'est le FVO (Food and Veterinary Office) qui est en charge de cette mission. Ce service agit dans deux directions. La première est une inspection régulière qui fait que chaque année une inspection complète de quelques pays est organisée sur la base des déclarations a priori et des plans annoncés. Tout est vérifié, les rapports sont publiés et les suites peuvent aller jusqu'à la suspension de l'autorisation d'exporter à l'UE. C'est dans ce type d'action qu'entre l'interdiction qui a été faite aux USA d'exporter de la viande en Europe suite à la découverte de résidus d'anabolisants dans les viandes exportées. Le second type d'action est occasionnel et lié à la découverte d'une non-conformité sur un produit importé. Elle prend alors la forme d'une enquête visant à comprendre l'origine du problème et à aider les autorités locales à y remédier au plus vite; les dernières actions de ce type sont liées à la découverte d'utilisations anormales d'antibactériens interdits dans les élevages aquacoles asiatiques.

En résumé, la politique européenne vise à garantir que tout produit importé présente les mêmes qualités de sécurité que les produits issus de la production européenne; elle établit des bases d'échanges avec les Pays tiers leur permettant et d'exporter, et de garantir leurs propres citoyens; cela s'accompagne d'un effort de formation important.

\section{6 / Le futur d'une zootech- nie «maîtrisée» par les hor- mones}

La qualité des produits animaux perçue par le consommateur et, en conséquence, un certain repositionnement du marché ont pu inciter les filières de production à trouver certaines pratiques d'élevage alternatives, excluant tout recours à des traitements hormonaux. A l'opposé, des «dévoiements» de résultats de la recherche dans le domaine de l'endocrinologie peuvent toujours apparaître, qui auraient pour objectif de contourner les contrôles de substances utilisées frauduleusement.

\section{1 / Les évolutions récentes en matière de réglementation de l'utilisation des substances à activité hormonale et de leur contrôle, et celles à attendre}

Dans le cadre européen actuel, plusieurs réflexions sont en cours pour améliorer l'efficacité du contrôle. La première concerne les rôles et attributions des LCR qui couvrent actuellement des gammes importantes de composés. De même, le rôle dans ce domaine des centres communs de recherche est à préciser.

La deuxième réflexion porte sur la nature des plans de contrôle, plans aléatoires ou ciblés, les premiers étant très onéreux pour un résultat discutable quand la fraude est réduite.

La troisième réflexion concerne l'harmonisation du niveau auquel se fait le contrôle des substances à usage interdit, dont en premier lieu les promoteurs de croissance. De nombreux critères ont été définis pour garantir la qualité des méthodes en usage et surtout l'harmonisation de cette qualité. Plus récemment, la décision 2002/657 a prévu pour les composés interdits le concept de limite minimale de performance requise (MRPL), définie comme une concentration fixée administrativement que tout laboratoire de tout Etat membre doit être capable de dépister et d'en confirmer la présence. Quelques MRPL ont été publiées (EC 2003/181), d'autres sont en préparation. Il s'agit désormais de vérifier, probablement à l'aide d'essais comparatifs, que tous les laboratoires européens atteignent ce niveau de performance décidé en commun. Cela peut être considéré comme une pierre ultime à l'harmonisation sur ce sujet.

\section{2 / Les nouvelles alternatives physiologiques}

\subsection{1 / Maîtrise de la reproduction en élevage ovin, caprin et bovin}

- Chez les ovins et caprins

A l'heure actuelle, nous disposons de deux techniques de maîtrise de la reproduction excluant l'utilisation d'hormo- 
nes exogènes : l'effet mâle et les traitements photopériodiques.

\section{a) Effet mâle}

L'effet mâle est une technique d'induction et de synchronisation de l'œstrus et de l'ovulation chez la chèvre (Chemineau 1989) et la brebis (Thimonier et al 2000) en anœstrus. Cette technique permet de réaliser une lutte à contre-saison et de grouper les mises bas. Elle consiste à introduire un mâle sexuellement actif dans un groupe de femelles en anœstrus anovulatoire (les femelles doivent préalablement être séparées des mâles pendant une durée minimale d'un mois). La présence du mâle conduit à l'apparition d'un pic préovulatoire de LH qui va déclencher l'ovulation dans les 2 à 4 jours qui suivent l'introduction du mâle. Cette première ovulation est suivie soit d'une phase lutéale de durée normale (cycle normal), soit d'une phase lutéale de courte durée (cycle court). Le cycle court, d'une durée de 5-6 jours, est normalement suivi par un cycle normal. Ensuite, des cycles normaux peuvent encore se succéder. A la différence de la chèvre, la brebis présente une première ovulation silencieuse ainsi qu'une deuxième qui suit un cycle court. Chez la chèvre, la majorité des fécondations se produisent au cours des 10 premiers jours qui suivent l'introduction du mâle. Chez la brebis, les fécondations se produisent entre le $18^{\text {ème }}$ et le $26^{\text {ème jour }}$ qui suit l'introduction du mâle.

L'efficacité de la réponse à l'effet mâle (taux de réponse, proportion de femelles avec cycle court, reprise de la cyclicité) dépend d'une part de la réceptivité des femelles (intensité de l'anœstrus) et, d'autre part, de la qualité de la stimulation (contacts physiques, proportion de mâles introduits dans le troupeau des reproductrices, activité sexuelle du mâle). La période de l'année la plus favorable pour la réalisation d'un effet mâle dépend ainsi des caractéristiques de saisonnalité de chaque race. Chez des races très saisonnées, l'effet mâle n'est efficace que peu de temps avant ou après la saison sexuelle.

Le degré de synchronisation de la première ovulation induite par l'effet mâle permet d'envisager la mise en place de protocoles simplifiés d'IA. Cependant, la moindre qualité du premier cycle ovarien avec une forte proportion de cycles courts rend cette approche difficile en pratique. A l'heure actuelle, la réalisation d'un traitement progestatif avant l'introduction des mâles est le seul moyen permettant de réduire l'incidence des cycles courts et, par conséquent, de considérer l'effet mâle comme une méthode alternative de synchronisation des chaleurs dans le cadre de l'IA. Les protocoles d'insémination restent toutefois à déterminer avec précision. L'utilisation pratique de l'effet mâle associé à l'insémination artificielle pose en outre des problèmes d'organisation et de conduite du chantier de reproduction aussi bien dans les systèmes intensifs qu'extensifs.

\section{b) Les traitements photopériodiques}

Les traitements photopériodiques constituent une technique d'induction de l'activité sexuelle des mâles et femelles ovins et caprins en contresaison (Chemineau et al 1996b). Chez la femelle, ils permettent l'installation d'une cyclicité. Ces traitements consistent à faire percevoir aux animaux, à des moments précis de l'année, des jours longs par éclairage artificiel ou en profitant des jours longs naturels suivis de jours courts obtenus en obscurcissant l'étable ou, le plus souvent, en appliquant un implant de mélatonine. Les mâles doivent subir le même traitement photopériodique que les femelles. Pour bénéficier d'un effet mâle, leur introduction doit se faire avant la reprise de l'activité ovulatoire spontanée des femelles : 35 et 50 jours après le début de la période de jours courts chez la brebis et la chèvre, respectivement. Chez des races très saisonnées, l'application d'un traitement photopériodique permet ainsi d'optimiser la réponse à l'effet mâle en période d'anœstrus profond.

\section{- Chez les bovins}

Chez la vache, il n'y a pas d'alternative satisfaisante pour synchroniser les venues en chaleur et induire les ovulations en se basant sur des méthodes de conduite du troupeau (effet mâle) ou en utilisant le photopériodisme. Seules, les recherches d'alternatives hormonales sont poursuivies et évaluées aux plans zootechnique et économique.

\section{a) Les alternatives hormonales}

Chez la vache, les traitements à l'aide de progestagènes restent incontournables en termes d'efficacité et de coût. Par ailleurs, leur utilisation, bien qu'étant plus sévèrement réglementée à l'heure actuelle, ne pose pas de problème majeur vis-à-vis de la sécurité du consommateur, le problème principal étant de définir des concentrations maximales résiduelles pour des produits xénobiotiques ou des valeurs résiduelles acceptables pour les hormones stéroïdiennes naturelles dont les concentrations retrouvées après traitement sont inférieures à celles sécrétées naturellement au cours du cycle.

En dépit des concentrations résiduelles d'œstradiol relativement faibles, inférieures en particulier à celles observées pendant la gestation chez la vache, il a été décidé au niveau européen de ne plus l'utiliser à terme à des fins de contrôle zootechnique de la reproduction, ce qui, compte tenu de son efficacité, pose le problème des traitements de substitution (cf $\S 5.1 .1$ ).

Les produits autorisés qui pourraient être utilisés seuls ou en combinaison avec les progestagènes en remplacement de l'œstradiol sont la GnRH et les prostaglandines (tableau 21). Pour ces deux types d'hormones, de nombreuses molécules (hormone native ou analogues) et produits déposés existent. Par exemple, la dose de $100 \mu \mathrm{g}$ de $\mathrm{GnRH}$ est généralement administrée dans de tels protocoles et celle de $500 \mu \mathrm{g}$ de cloprosténol est également utilisée comme analogue de la $\mathrm{PgF}_{2 \alpha}$.

Les traitements à base de progestatifs qui incluent l'œstradiol ont conduit presque systématiquement à l'obtention de taux de gestation plus élevés, après insémination à des temps prédéterminés, que ceux obtenus en l'absence d'œstrogène. Les différences les plus importantes ont été observées chez les femelles de races allaitantes (tableau 21). Les alternatives en matière de traitement hormonal à rechercher devront dès lors atteindre une même efficacité zootechnique

Plusieurs études avaient pour objectif d'estimer l'efficacité de différents protocoles en utilisant la $\mathrm{PgF}_{2 \alpha}$ seule ou combinée à la GnRH (tableau 22). Dans la plupart des cas, le pourcentage de vaches détectées en chaleur dans un laps de temps court après traitement ( 1 à 4 jours) est faible et ne permet pas de réaliser des inséminations à des temps prédéterminés. Les taux de gestation à l'œstrus observé sont relativement faibles, la plupart du temps inférieurs à $40 \%$, tout spécialement lorsque ces traitements sont appliqués chez des femelles allaitantes et non cyclées et utilisés en l'absence de progestagènes.

b) Conséquences prévisibles sur l'efficacité, la faisabilité et le coût des traitements alternatifs

Lorsqu'ils sont utilisés avec les progestagènes, les traitements alternatifs testés donnent des résultats proches de 
Tableau 21. Résultats de fertilité obtenus avec des traitements progestatifs alternatifs en comparaison de ceux obtenus avec le benzoate d'œstradiol chez les bovins.

\begin{tabular}{|c|c|c|c|c|c|}
\hline $\begin{array}{c}\text { Type de production / } \\
\text { Situation physiologique }\end{array}$ & Type de traitement & Référence & Pays & $\begin{array}{l}\text { Venue en œstrus } \\
\text { observée (3-4 j) }\end{array}$ & $\begin{array}{c}\text { Taux de gestation } \\
\text { (nombre d'IA })\end{array}$ \\
\hline \multirow{3}{*}{ Génisse de race allaitante } & $\begin{array}{l}\mathrm{OEB}^{\mathrm{b}}+\mathrm{PgF}_{2 \alpha}+\mathrm{MGA} \\
\mathrm{GnRH}+\mathrm{PgF}_{2 \alpha}+\mathrm{MGA}\end{array}$ & Martinez et al 2002 & Can & & $\begin{array}{l}60,7 \%(1 \mathrm{Al}) \\
47,8 \%(1 \mathrm{Al})\end{array}$ \\
\hline & $\begin{array}{l}\text { PRID + OEB + } \mathrm{PgF}_{2 \alpha} \\
\mathrm{PRID}+\mathrm{GnRH}+\mathrm{PgF}_{2 \alpha}\end{array}$ & Lane et al 2001 & $|r|$ & $\begin{array}{l}95 \% \\
69 \%\end{array}$ & \\
\hline & $\begin{array}{l}\text { CIDR-B }^{c}+\mathrm{OEB}+\mathrm{PgF}_{2 \alpha} \\
\text { CIDR-B + pLH + PgF } 2 \alpha\end{array}$ & Martinez et al 2002 & Can & $\begin{array}{l}93,8 \% \\
70,6 \%\end{array}$ & $\begin{array}{c}75 \%(1 \mathrm{Al}) \\
64,7 \%(1 \mathrm{Al})\end{array}$ \\
\hline Génisse de race laitière & $\begin{array}{l}\mathrm{PRID}^{\mathrm{d}}+\mathrm{OEB}+\mathrm{PgF}_{2 \alpha} \\
\mathrm{PRID} \mathrm{GnRH}+\mathrm{PgF}_{2 \alpha}\end{array}$ & $\begin{array}{l}\text { Deletang et al } 2004 \\
\text { Barreteau et al } 2005\end{array}$ & $\begin{array}{l}F \\
F\end{array}$ & & $\begin{array}{l}59,2 \%(1 \mathrm{Al}) \\
52,4 \%(1 \mathrm{Al})\end{array}$ \\
\hline
\end{tabular}

a IA : insémination artificielle. b OEB : benzoate d'œstradiol. c CIDR-B : «Controlled internal drug-releasing device». d PRID : «Progesterone-releasing intravaginal device» ou spirale vaginale à relargage de progestérone.

Tableau 22. Détection des chaleurs et taux de gestation observés après l'utilisation de traitements de substitution pour la maîtrise de la venue en œstrus chez les bovins.

\begin{tabular}{|c|c|c|c|c|c|}
\hline $\begin{array}{c}\text { Type de production / } \\
\text { Situation physiologique }\end{array}$ & Type de traitement & Référence & Pays & $\begin{array}{c}\text { Venue en } \\
\text { œstrus } \\
\text { observée (3-4 j) }\end{array}$ & $\begin{array}{c}\text { Taux de gestation } \\
\text { (nombre d'IA, } \\
\text { modalités d'IA) }\end{array}$ \\
\hline \multirow[t]{3}{*}{$\begin{array}{l}\text { Races allaitantes: } \\
\text { - Vaches }\end{array}$} & $\begin{array}{c}\mathrm{PgF}_{2 \alpha} \\
\mathrm{CIDR}+\mathrm{PgF}_{2 \alpha}\end{array}$ & Lucy et al 2001 & USA & $\begin{array}{l}33 \% \\
59 \%\end{array}$ & $\begin{array}{l}22 \%\left(1 \mathrm{Al}, \mathrm{obs}^{1}\right) \\
36 \%(1 \mathrm{Al}, \mathrm{obs})\end{array}$ \\
\hline & $\mathrm{GnRH}+\mathrm{PgF}_{2 \alpha}$ & Stevenson 2002 & USA & & $\begin{array}{l}30,7 \%{ }^{\mathrm{a}} \\
51,1 \%{ }^{\mathrm{b}}\end{array}$ \\
\hline & $\mathrm{GnRH}+\mathrm{PgF}_{2 \alpha}$ & Martinez et al 2002 & Can & & $\begin{array}{l}52,2 \%(1 \mathrm{Al})^{\mathrm{a}} \\
45 \%(1 \mathrm{Al})^{\mathrm{b}}\end{array}$ \\
\hline $\begin{array}{l}\text { - Génisses: } \\
\text { • Cyclées }\end{array}$ & $\begin{array}{c}\mathrm{PgF}_{2 \alpha} \\
\mathrm{CIDR}+\mathrm{PgF}_{2 \alpha}\end{array}$ & Lucy et al 2001 & USA & $\begin{array}{l}37 \% \\
80 \%\end{array}$ & $\begin{array}{l}19 \%(1 \mathrm{Al}, \text { obs }) \\
49 \%(1 \mathrm{Al}, \mathrm{obs})\end{array}$ \\
\hline - Non Cyclées & $\begin{array}{c}\mathrm{PgF}_{2 \alpha} \\
\mathrm{CIDR}+\mathrm{PgF}_{2 \alpha}\end{array}$ & Lucy et al 2001 & USA & $\begin{array}{l}11 \% \\
48 \%\end{array}$ & $\begin{array}{c}6 \%(1 \mathrm{Al}, \text { obs }) \\
28 \%(1 \mathrm{Al}, \mathrm{obs})\end{array}$ \\
\hline $\begin{array}{l}\text { - Génisses cyclées / non } \\
\text { cyclées }\end{array}$ & $\begin{array}{c}\mathrm{GnRH}+\mathrm{PgF}_{2 \alpha} \\
\mathrm{GnRH}+\mathrm{PgF}_{2 \alpha} \\
\mathrm{pLH}+\mathrm{PgF}_{2 \alpha}\end{array}$ & $\begin{array}{c}\text { Geary et Whittier } 1997 \\
\text { Martinez et al } 2002 \\
\text { Martinez et al } 2002\end{array}$ & $\begin{array}{l}\text { USA } \\
\text { Can } \\
\text { Can }\end{array}$ & $43,8 \%$ & $\begin{array}{c}35 \% \\
39,1 \%(1 \mathrm{Al}) \\
37,5 \%(1 \mathrm{Al}) \\
\end{array}$ \\
\hline \multirow[t]{2}{*}{$\begin{array}{l}\text { Races laitières: } \\
\text { - Vaches }\end{array}$} & $\mathrm{PgF}_{2 \alpha}(2$ injections $)$ & Mialot et al 1999 & $\mathrm{~F}$ & & $\begin{array}{l}32,5 \%(1 \text { IA obs })^{a} \\
53,3 \%(1 \mathrm{Al} \text { obs })^{b}\end{array}$ \\
\hline & $\mathrm{GnRH}+\mathrm{PgF}_{2 \alpha}$ & Mialot et al 1999 & $\mathrm{~F}$ & & $\begin{array}{l}36,1 \%(1 \mathrm{Al} \text { obs })^{a} \\
53,7 \%(1 \mathrm{Al} \mathrm{obs})^{\mathrm{b}}\end{array}$ \\
\hline \multirow[t]{2}{*}{ - Génisses } & $\begin{array}{c}\mathrm{PgF}_{2 \alpha} \\
\mathrm{CIDR}+\mathrm{PgF}_{2 \alpha}\end{array}$ & Lucy et al 2001 & USA & $\begin{array}{l}57 \% \\
84 \%\end{array}$ & $\begin{array}{l}37 \%(1 \mathrm{Al}, \mathrm{obs}) \\
45 \%(1 \mathrm{Al}, \mathrm{obs})\end{array}$ \\
\hline & $\mathrm{GnRH}+\mathrm{PgF}_{2 \alpha}$ & $\begin{array}{l}\text { Schmitt et al } 1996 \\
\text { Seguin } 1997\end{array}$ & $\begin{array}{l}\text { USA } \\
\text { USA }\end{array}$ & & $\begin{array}{l}26 \% \\
28 \%\end{array}$ \\
\hline
\end{tabular}

a, b Différents groupes expérimentaux dans la même publication.

1 Chaleurs observées.

ceux obtenus précédemment avec l'œstradiol. Cependant, quelle que soit la molécule utilisée, le coût des produits de substitution est pour l'instant plus élevé que celui de l'œstradiol et le coût global du traitement pourra être augmenté. En conséquence, ceci pourrait conduire, tout spécialement dans les populations de vaches allaitantes où des proportions importantes de femelles non cyclées sont rencontrées, à une diminution considérable de l'utilisation de l'IA (de - $20 \%$ à - $30 \%$ du nombre total d'IA) aussitôt que l'interdiction de l'utilisation de l'œstradiol aura pris effet. Ceci pourrait diminuer l'impact, voire nuire au développement des programmes d'amélioration génétique menés en France depuis de nombreuses années dont le but est justement d'améliorer les qualités bouchères, la qualité de la viande et les critères fonctionnels (qualités maternelles et fertilité). Ceci serait d'autant plus regrettable que la 
sélection sur ces caractères contribue significativement à satisfaire les critères de bien-être animal et de santé des cheptels par l'amélioration des qualités maternelles (facilité de vêlage et production laitière pour l'allaitement des jeunes), de la longévité des animaux et de leur résistance aux maladies. Pour l'instant, les études de traitements faisant appel à des produits de substitution visent à définir des protocoles efficaces au plan physiologique et «réalistes» au plan économique.

\subsection{2 / Nouvelles approches alimentai- res et génétiques en production de viande et de lait}

\section{- Production de viande}

En production porcine, les efforts d'amélioration des conditions d'élevage et d'amélioration génétique ont porté pendant plusieurs décennies sur des critères de production, principalement la vitesse de croissance. Aujourd'hui, même si le maintien de la compétitivité est toujours d'actualité, des efforts sont réalisés pour améliorer la qualité de la viande dans un contexte où l'usage des promoteurs de croissance n'est plus d'actualité. Les gènes responsables des défauts majeurs de la qualité technologique de la viande de porc (viande exsudative ou viande acide) ont été identifiés et pris en compte dans les schémas de sélection (Renand et al 2003). L'amélioration des qualités sensorielles de la viande de porc devient une préoccupation importante. Les stratégies d'élevage et d'alimentation peuvent constituer une voie d'amélioration des qualités sensorielles (Lebret et al 1996, 2001). L'augmentation de l'âge à l'abattage pour un poids donné est souvent considérée comme un critère de qualité supérieure. Un rationnement énergétique couplé à une diminution progressive du rapport lysine/énergie tout au long de la croissance conduit à des carcasses de composition équivalente à celle d'animaux nourris à volonté, tout en augmentant la teneur en lipides intramusculaires, composante intervenant dans la qualité sensorielle (Lebret et al 2001).

La sélection génétique constitue toujours une stratégie de choix pour l'amélioration d'un caractère de production. A ce jour, l'amélioration génétique est fondée essentiellement sur les méthodes de la génétique quantitative. Depuis le début des années 1990, les nouveaux outils de la génétique moléculaire ont permis d'accroître les connaissances sur le génome (Bidanel et al 2003). La cartographie du génome porcin est bien avancée (Milan et al 2000) et de nombreuses régions du génome présentant des loci à effets quantitatifs ou QTL (Quantitative Trait Locus) pour des caractères d'intérêt (composition de la carcasse, qualité de la viande par exemple) ont été identifiées (Bidanel et Rothschild 2002). Les travaux de cartographie fine associée à la génomique fonctionnelle devraient permettre de mieux cibler la région du génome contenant un QTL, voire d'identifier un gène d'intérêt. Ces progrès offrent de nouvelles perspectives pour la sélection des caractères de production favorables et pourraient permettre d'augmenter l'efficacité de la sélection.

En production de viande bovine, deux orientations différentes font l'objet de recherches pour proposer des alternatives à l'utilisation de traitements anabolisants. La première s'inscrit dans le même esprit et consiste à trouver des traitements physiologiques substitutifs en s'inspirant des mécanismes physiologiques et biochimiques mis en œuvre avec les traitements classiques. Ainsi, les propriétés anabolisantes de la trenbolone ont orienté les recherches sur les possibilités d'obtenir une diminution du catabolisme des protéines imputable aux glucocorticoïdes et sur une réduction du métabolisme basal. Les approches pharmacologiques ou vaccinales n'ont pour l'instant pas abouti (Sillence 2004). De la même manière, les réponses physiologiques induites par les $\beta$-agonistes ont permis d'initier des recherches sur l'utilisation des approches anti-idiotypes utilisant comme antigène un anticorps dirigé contre un $\beta$-agoniste spécifique, le deuxième anticorps obtenu pouvant mimer le mode d'action du $\beta$ agoniste. Là encore, aucun résultat probant n'a pour l'instant été obtenu (Sillence 2004). La synergie d'effet entre un $\beta$-agoniste, le zilpatérol, et l'acétate de trenbolone a été observée sur des bovins à l'engrais, mais aucun mécanisme physiologique qui aurait pu servir de base à des recherches biochimiques ciblées n'a vraiment été envisagé $^{2}$. Les mécanismes impliquant le contrôle de la sécrétion de la GH ont orienté certaines stratégies vaccinales (immunisation contre la somatostatine, anticorps anti-idiotypes $\mathrm{GH}$ ) sans qu'elles aboutissent pour l'instant (Sillence 2004). Enfin, les recherches sur les adipokines (leptine et adiponectine) permettent d'imaginer d'autres possibilités pour moduler la fonction de croissance en interférant sur l'appétit et l'efficacité alimentaire, tandis que celles conduites sur la myostatine et les phénomènes de différenciation et de croissance des myoblastes chez le fœtus permettent d'envisager une possibilité de manipulation physiologique très tôt dans la vie de l'animal (Sillence 2004). Plus pragmatique, la sélection génétique permet d'améliorer progressivement avec un pas de temps nécessairement plus long les caractères de croissance des animaux et de qualité des carcasses, diminuant ainsi l'intérêt d'un recours systématique à des pratiques pharmacologiques.

La seconde orientation de recherche n'a pas pour but de trouver à proprement parler des traitements substitutifs aux traitements anabolisants classiques mais s'intéresse plutôt aux systèmes d'élevage analysés dans leur globalité, notamment le système allaitant (Blanc et al 2004), ceci afin de mieux comprendre comment certains traits physiologiques permettent aux animaux de s'adapter à des modifications extrêmement contraignantes du milieu, en particulier en ce qui concerne la fourniture des aliments et leur qualité.

\section{- Production laitière}

En production laitière bovine, l'amélioration génétique fondée essentiellement sur les méthodes de la génétique quantitative a principalement visé jusqu'ici à augmenter la production laitière et le taux protéique du lait, à maîtriser le taux butyreux, à améliorer l'aptitude à la traite, la conformation des animaux et des caractères liés à la conduite d'élevage (Ducrocq et al 2001). Alors que la filière «lait» s'interroge aujourd'hui sur la mise en œuvre d'alternatives plus durables à la production intensive, un enjeu majeur est d'améliorer la qualité nutritionnelle, et l'image, du lait et des produits laitiers, notamment en ce qui concerne sa composition en acides gras ayant potentiellement des effets pro- ou anti-athérogènes ou anticancéreux.

Les stratégies d'alimentation constituent la voie la plus rapide (et de plus, réversible) pour moduler cette composition. De nombreuses questions restent posées quant aux effets de certains acides gras spécifiques de la matière grasse laitière sur la santé humaine, et à leurs interactions avec le reste du régime alimentaire. Dans l'attente de progrès dans ce domaine, les recherches en nutrition animale visent à étudier les nombreuses interactions existant entre 
fourrages, concentrés, oléagineux et leurs traitements technologiques. Elles visent aussi à décrire puis modéliser les lois de réponses et les mécanismes de synthèse des différents acides gras majeurs et mineurs (quantitativement, mais potentiellement bioactifs) du lait (Chilliard et Ferlay 2004).

Les nouveaux outils de la génétique moléculaire ont permis d'accroître les connaissances sur le génome bovin, dont la cartographie est bien avancée (Levéziel et Cribiu 2000, Schibler et al 2004). De nombreuses régions du génome présentant des QTL pour des caractères d'intérêt (production laitière, taux butyreux, mammites, fertilité, par exemple) ont été identifiées (Boichard et al 2003). Les travaux de cartographie fine associée à la génomique fonctionnelle devraient permettre de mieux cibler certaines régions du génome et d'identifier les gènes influençant un caractère d'intérêt. Les analyses d'expression de ces gènes candidats pourraient apporter de nouvelles possibilités d'action. On citera par exemple la $\Delta_{9}$-désaturase et les acides gras insaturés du lait (Bernard et al 2001), ou la leptine et les performances zootechniques (Liefers et al 2003). Ces progrès offrent de nouvelles perspectives pour la sélection assistée par marqueurs d'un ensemble de caractères de production favorables (Fritz et al 2003) incluant l'équilibre des différents acides gras et d'autres critères de composition fine. Ils pourraient permettre d'augmenter encore l'efficacité de la sélection en y intégrant la qualité nutritionnelle du lait.

\section{3 / Les développements phar- macologiques et analytiques}

\subsection{1 / Les développements pharmaco- logiques}

- Les nouvelles molécules à attendre et le problème de leur détection

En dépit de l'intensité des contrôles réalisés au sein de l'UE qui visent à rechercher l'utilisation éventuelle de facteurs de croissance (œstrogènes, androgènes, progestagènes, $\beta$-agonistes, corticostéroïdes et thyréostatiques), le nombre de cas positifs (échantillons non conformes) rapportés par les Etats membres dans les principales productions animales reste, ces dernières années, très limité et, en tout état de cause, en net recul par rapport aux statistiques officielles du début des années 1990. Ainsi en 2000, les résultats du contrôle de ces substances révélaient des cas positifs dans seulement six Etats membres. Pour l'espèce bovine, cinq Etats membres étaient concernés par la présence de stéroïdes et de $\beta$-agonistes et un seul pour la présence de corticostéroïdes. Pour l'espèce porcine, trois Etats membres révélaient des échantillons non conformes pour la présence de stéroïdes et deux pour les $\beta$-agonistes. Cette diminution apparente de l'usage de ces substances peut trouver différentes explications :

- certaines substances sont fortement métabolisées, les métabolites restent parfois méconnus ou bien les standards de référence correspondant à ces métabolites sont souvent non disponibles commercialement ;

- la sensibilité des techniques de détection de certaines molécules reste insuffisante pour une surveillance efficace de leur non-utilisation;

- la démonstration de l'administration exogène des hormones naturelles reste problématique ;

- les fraudeurs pourraient utiliser de faibles doses de composés ayant une même action pharmacologique mais multiplier leur nombre (cocktails de stéroïdes ou de $\beta$-agonistes) pour obtenir l'action biologique recherchée ;

- de faibles doses de molécules appartenant à des familles pharmacologiques différentes mais ayant des effets synergiques possibles (cocktail de $\beta$-agonistes et de corticostéroïdes) pourraient être également appliquées en association ;

- de nouveaux analogues structuraux appartenant aux familles classiques de facteurs de croissance ou l'utilisation de nouvelles classes de composés restent d'actualité.

Concernant ce dernier point, des exemples récents de (re)découverte de nouveaux composés sont à souligner. Pour les antithyroïdiens de synthèse, la structure du mercapto-benzimidazole n'a été découverte que très tardivement comparativement aux autres ATS. Pour les stéroïdes, certaines molécules ont été (re)découvertes depuis 1999, notamment le stanozolol (principalement en Belgique et aux Pays-Bas), ainsi que la $17 \alpha$-méthyltestostérone, la noréthandrolone et l'éthylestrénol. Des exemples récents de découverte d'acétate de fluorogestone, d'allylestrénol et d'acétate de norclostébol dans des sites d'injection ou des préparations alimentant le marché noir peuvent également être mentionnés. Le problème reste entier en ce qui concerne les hormones naturelles (testostérone, œstradiol, nandrolone et leurs esters, progestérone) bien qu'il soit connu depuis fort longtemps. En effet, la démonstration de leur administration qui repose seulement sur la détermination d'une concentration est sujette à caution étant donnée la difficulté de détermination de seuils d'action, eu égard à la variabilité de la réponse individuelle ou à celle liée aux différents stades physiologiques. En outre, la consultation de sites Internet spécialisés dans la vente de produits dopants et la lecture d'anciennes publications russes ventant leur mérite indiquent la possibilité de circulation d'ecdystéroïdes. Biosynthétisées par les insectes ou les plantes, l'activité anabolisante de ces molécules - l'ecdystérone et l'ajugastérone $\mathrm{C}$ ont été les molécules les plus étudiées dans ce sens - a été démontrée chez les mammifères (Syrov et al 2001, Syrov 1984, Chermnykh et al 1988, Slama et Lafont 1995, Bathori 2002). Ici encore, la détermination de l'origine alimentaire (présence dans les fourrages) ou pharmacologique (injection i.m.) n'est pas évidente a priori.

En ce qui concerne les $\beta$-agonistes, de nouvelles structures ont vu le jour. Il s'agit notamment de dérivés du clenbutérol identifiés dans des préparations saisies sur le marché noir en Italie. Baptisées trivialement composé A et clenmétérol, ces molécules sont caractérisées par une plus grande lipophilicité (groupement $t$-butyl de la chaîne latérale substitué par un cycle aromatique) et une activité $\beta_{1}$-agoniste plus marquée que celles du clenbutérol. Parallèlement, des composés tels que la ractopamine (Paylean ${ }^{\circledR}$ ) ou le zilpatérol $\left(\right.$ Zilmax $\left.^{\circledR}\right)$ ont été respectivement approuvés pour une utilisation chez le porc aux USA, et chez les bovins au Mexique et en Afrique du Sud. Les structures de ces deux molécules diffèrent significativement de celles des autres $\beta$-agonistes, si bien que les tests de routine appliqués par certains laboratoires (tests immunologiques) ne permettent pas de les détecter. L'usage d'autres dérivés «naturels» tels que l'hordénine ou encore l'éphédrine a également été soupçonné.

En ce qui concerne les corticostéroïdes, les structures les plus récemment mises en évidence et non encore répertoriées ont été le propionate de clobétasol, le propionate de béclométhasone et plusieurs esters de cortisol.

Au cours des années 1990, de nouvelles substances synthétiques capables d'induire la libération de $\mathrm{GH}$ après administration intraveineuse, souscutanée, intra-nasale ou même orale chez l'animal ou l'homme ont été caractérisées ; il s'agit d'oligopeptides 
appelés GHRP (Growth Hormone Releasing Peptide). Une des applications évidentes des GHRP est de servir à l'amélioration de la productivité ainsi qu'à la prévention et au traitement de l'atrophie musculaire associée à l'inactivité ou au catabolisme chez les animaux de rente. Après administration chronique sous-cutanée de GHRP-6, l'indice de consommation chez le porc est amélioré de $11 \%$ (Chang et Hickey 1999). Chez le veau mâle Holstein, l'administration sous-cutanée de GHRP-2 pendant 14 jours améliore de $29 \%$ l'indice de consommation. De même, l'administration sous-cutanée de GHRP-6 une fois par jour pendant 10 jours améliore de $6 \%$ la production laitière (Chang et Hickey 1999). Néanmoins, ces résultats ne sont pas à la hauteur de ceux obtenus lors de traitements par la GH. Des sécrétagogues de synthèse non peptidiques présentant une meilleure efficacité, une action prolongée et une excellente biodisponibilité orale en comparaison de leurs homologues peptidiques, ont également fait leur apparition plus récemment (spiro-indane MK-0677). Réservés à une utilisation thérapeutique humaine, le recours illégal à ces sécrétagogues en élevage n'est pas pour l'instant documenté.

- Les nouvelles stratégies de «manipulation physiologique» examinées au niveau moléculaire

Parmi les stratégies alternatives visant à augmenter l'efficacité des gonadotropines endogènes actuellement à l'étude, deux sont plus particulièrement envisageables : l'une fondée sur la connaissance des voies de signalisation, l'autre sur l'hormono-modulation de l'activité des gonadotropines.

Le contrôle des voies de signalisation, et en particulier de la sensibilité des cellules gonadiques aux gonadotropines, est un premier champ d'investigations. Les GRKs ( $G$ proteincoupled Receptor Kinase) et les béta-arrestines sont des effecteurs moléculaires de la désensibilisation et de l'internalisation du récepteur FSH (Troispoux et al 1999). Ces mécanismes sont particulièrement intéressants car ils conditionnent directement la disponibilité membranaire du récepteur FSH ainsi que la réponse à son agoniste. Stratégiquement, 1'inhibition spécifique des $\beta$-arrestines et/ou des GRKs endogènes en recourant aux ARNs interférence, antisens ou dominants négatifs permettrait de «détourner» les mécanismes de désensibilisation au profit d'une amplification de l'action de la FSH. De tels «adju- vants» pourraient permettre de potentialiser transitoirement les effets des gonadotropines endogènes et, ainsi, d'éviter ou de réduire l'injection d'hormones exogènes. Certains résultats obtenus in vitro semblent conforter cette hypothèse mais de nombreuses données sont encore nécessaires pour juger du réalisme de cette approche puis de sa faisabilité in vivo.

L'hormono-modulation de l'activité des gonadotropines constitue un deuxième axe de recherche. Il repose sur des résultats obtenus récemment sur le mécanisme d'interférence des anticorps anti-eCG, produits par des chèvres traitées, sur la bioactivité de la eCG injectée (Hervé et al 2004). Ces travaux ont été engagés après avoir constaté que, parmi les femelles présentant des taux élevés en anticorps anti-eCG résiduels, certaines étaient systématiquement gravides après traitement de synchronisation et IA, avec parfois une prolificité élevée. Chez ces femelles, les anticorps anti-eCG sécrétés sont capables de potentialiser les activités FSH et/ou LH de l'eCG plutôt que de les inhiber. Ces résultats conduisent à une stratégie visant à agir directement sur l'activité des hormones LH et FSH endogènes en utilisant des anticorps monoclonaux spécifiques qui auront été sélectionnés pour leur effet potentialisant la bioactivité de celles-ci. Ces anticorps seront produits et préparés de façon à supprimer tout risque immunogène. Cette stratégie d'hormono-modulation permettrait alors de s'affranchir de toute injection d'hormone exogène en agissant directement sur la bioactivité des hormones gonadotropes propres à l'animal par l'intermédiaire d'anticorps spécifiques à effet potentialisant.

\subsection{2 / Les mauvais usages et les}

Tableau 23. Corticostéroïdes possédant une AMM pour un usage vétérinaire chez les animaux de rente (bovins, ovins, porcins, caprins et/ou équins).

\begin{tabular}{|l|l|}
\hline \multicolumn{1}{|c|}{ Molécule } & \multicolumn{1}{c|}{ Forme chimique } \\
\hline Betaméthasone & phosphate disodique \\
\hline Dexaméthasone & $\begin{array}{l}\text { base, acétate, diméthylbutyrate, isonicotinate, } \\
\text { phénylpropionate, phosphate sodique }\end{array}$ \\
\hline Fluméthasone & base \\
\hline Hydrocortisone (cortisol) & acétate \\
\hline $\begin{array}{l}\text { Isoflupredone } \\
\text { (fluoroprednisolone) }\end{array}$ & acétate \\
\hline Méthylprednisolone & base, acétate, hémisuccinate \\
\hline Prednisolone & base, acétate \\
\hline
\end{tabular}

(Source : DMV 2003).

\section{détournements d'utilisation}

Plusieurs corticostéroïdes possédaient en France au $1{ }^{\text {er }}$ février 2004 une AMM pour un usage thérapeutique vétérinaire destiné aux animaux de rente (bovins, ovins, porcins, caprins et/ou équins) (tableau 23) et des limites maximales de résidus (LMR) ont été fixées pour ces molécules (tableau 24). Le statut de ces molécules reste délicat à appréhender du point de vue de leur contrôle en élevage, car des situations diverses peuvent se présenter. De nombreux corticostéroïdes de synthèse sont en effet commercialement disponibles, mais n'ont pas reçu d'AMM pour un usage thérapeutique. D'autres ont unimédecine humaine mais pas en médecine vétérinaire. L'éventuelle identification d'une substance appartenant à l'une de ces deux catégories chez les animaux de rente entraînerait par conséquent une action similaire à celles initiées pour les molécules interdites. Pour les molécules autorisées (tableau 23), leur identification doit être justifiée par un traitement thérapeutique argumenté, en considérant de plus le délai réglementaire à respecter entre la fin du traitement et l'abattage de l'animal le cas échéant. Pour certaines de ces molécules, un dosage quantitatif doit être réalisé afin de comparer la teneur de l'échantillon analysé avec la LMR.

\subsection{3 / Les nouvelles méthodes de détection}

- Les nouvelles méthodes analytiques : la spectrométrie de masse isotopique

Le développement de la spectrométrie de masse de rapport isotopique (GC-IRMS) concerne les molécules endogènes, pour lesquelles aucun seuil quement une AMM pour un usage en 
Tableau 24. Limites fixées pour les corticostéroïdes soumis à LMR.

\begin{tabular}{|c|c|c|c|c|}
\hline Molécule & Espèce & Matrice & $\begin{array}{c}\text { LMR } \\
\left(\mu \mathrm{g} \cdot \mathrm{kg}^{-1} \text { ou }\right. \\
\left.\mu \mathrm{g} \cdot \mathrm{L}^{-1}\right)\end{array}$ & Règlement \\
\hline \multirow{3}{*}{ Bétaméthasone } & \multirow{3}{*}{ Bovine } & foie & 2 & \multirow{3}{*}{$\begin{array}{c}2593 / 1999 / \mathrm{CE} \\
\text { du } 8 / 12 / 99\end{array}$} \\
\hline & & rein, muscle & 0,75 & \\
\hline & & lait & 0,3 & \\
\hline \multirow{3}{*}{ Dexaméthasone } & \multirow{2}{*}{$\begin{array}{l}\text { Bovine, } \\
\text { porcine, } \\
\text { équine }\end{array}$} & foie & 2 & \multirow{3}{*}{$\begin{array}{c}1837 / 1997 / \mathrm{CE} \\
\text { du } 24 / 09 / 97\end{array}$} \\
\hline & & rein, muscle & 0,75 & \\
\hline & Bovine & lait & 0,3 & \\
\hline \multirow{3}{*}{ Méthylprednisolone } & \multirow{3}{*}{ Bovine } & foie, muscle & 10 & \multirow{3}{*}{$\begin{array}{l}77 / 2002 / \mathrm{CE} \\
\text { du } 17 / 01 / 02\end{array}$} \\
\hline & & rein, graisse & 10 & \\
\hline & & lait & Ne pas utiliser & \\
\hline \multirow{3}{*}{ Prednisolone } & \multirow{3}{*}{ Bovine } & foie, rein & 10 & \multirow{3}{*}{$\begin{array}{c}2535 / 2000 / \mathrm{CE} \\
\text { du } 17 / 11 / 00\end{array}$} \\
\hline & & $\begin{array}{l}\text { muscle, } \\
\text { graisse }\end{array}$ & 4 & \\
\hline & & lait & 6 & \\
\hline
\end{tabular}

(Source : Mises à jour périodiques de l'annexe I du règlement 2377/90/CE).

d'action n'a été jusqu'à présent proposé. Avec l'étude des proportions des différents métabolites conjugués, ce type particulier de spectrométrie de masse est l'approche la plus pertinente qui est explorée. La GC-IRMS permet en effet de distinguer l'origine endogène de celle, exogène, de ces hormones dans l'urine en mesurant leur rapport isotopique ${ }^{13} \mathrm{C} /{ }^{12} \mathrm{C}$. La preuve analytique d'une injection d'un ester de testostérone à des bovins adultes a déjà été apportée via l'analyse de l'urine de l'animal. Cependant, cette méthode n'a, pour l'instant, toujours pas dépassé le stade du développement.

- Les nouvelles stratégies globales de repérage de disruptions physiologiques non conformes

Une nouvelle démarche analytique, la métabonomique, fondée dans le cas présent sur la recherche de disruptions métaboliques d'origine endocrinienne est apparue qui consiste à repérer, dans un premier temps, d'éventuelles utilisations illicites de produits anabolisants sans vouloir apporter immédiatement la preuve analytique formelle de leur utilisation (Dumas et al 2002a, 2002b). Ce repérage s'effectue à partir d'une base de données dans laquelle un certain nombre de signatures métaboliques obtenues sur urine, le plus souvent, et qui sont représentatives de différentes molécules utilisées comme substances anabolisantes, sont déjà inventoriées. Cette approche permet en outre d'interpréter au plan physiologique et métabolique les modifications du métabolisme général qu'entraînent ces trai- tements anabolisants (Dumas et al 2005).

Si la preuve du bien-fondé de cette approche est faite au plan expérimental, la mise en œuvre sur le terrain devra néanmoins résoudre des difficultés propres à la mise en place des bases de données, leur mise en partage et leur consolidation au cours du temps, mais aussi le coût de la mise en place technique du contrôle et la formation des différents opérateurs à ces nouvelles méthodes analytiques.

\section{Conclusion}

Le litige porté devant les instances de l'OMC, qui oppose l'UE, d'une part, et les USA et le Canada, d'autre part, a révélé ces dernières années la différence radicale de perception qui existe entre différents groupes d'experts scientifiques, mais aussi entre les différents décideurs politiques et, à un degré moindre, entre différentes populations ou groupes de pression consuméristes en matière d'évaluation et de gestion du risque de toxicité alimentaire que présentent ou présenteraient certains promoteurs de croissance utilisés en élevage. Protectionnisme déguisé de l'UE ou réel souci de la protection de la santé du consommateur réaffirmé au plus haut niveau européen ? L'avis scientifique émis le 10 avril 2002 par le CSVSP, le comité scientifique des mesures vétérinaires en charge des affaires de santé publique au niveau de la Commission Européenne, réaffirme qu'en ce qui concerne les hormones utilisées comme promoteurs de croissance, en particulier les stéroïdes ou analogues stéroïdiens (œstradiol, testostérone, progestérone, zéranol, acétate de trenbolone, acétate de mélengestrol), le risque toxique qu'elles présentent pour le consommateur ne peut être considéré comme nul (SCVPH 2002). C'est surtout et paradoxalement une hormone naturelle, l'œstradiol, qui pose le plus de difficultés pour l'évaluation de son innocuité. Cette évaluation porte sur deux points : le potentiel hormonal résiduel et le risque génotoxique.

Les calculs d'ingestion d'œstradiol présent comme résidu dans les tissus provenant d'animaux traités avec des implants contenant de l'œstradiol montrent une augmentation d'un facteur 4,6 des quantités journalières ingérées par un adulte (tableau 25), soit une quantité d'environ 20 ng d'œstradiol consommé par un adulte de $60 \mathrm{~kg}$ (Daxenberger et al 2001). Cette quantité doit être rapportée à la production journalière d'œstradiol par 1'organisme et ne devrait pas dépasser $1 \%$ de ce taux de production en considérant la fraction de la population la plus sensible $^{3}$ (FDA 2005). Une estimation de cette production endogène $(\mathrm{P})$ est donnée par l'équation suivante (Andersson et Skakkebæk 1999) :

$$
\begin{gathered}
\mathrm{P}(\mu \mathrm{g} / \mathrm{j})= \\
\text { Concentration Plasmatique }(\mathrm{CP} \text { en } \mu \mathrm{g} / \mathrm{mL}) \\
\times \text { Clairance Métabolique }(\mathrm{CM} \text { en } \mathrm{mL} / \mathrm{j})
\end{gathered}
$$

Les valeurs de CM n'ont jamais été établies chez l'enfant et celles utilisées dans les expertises produites par le JECFA (1987) ne prennent en compte que des valeurs obtenues chez l'adulte. Ce taux est soumis à des facteurs de variation tels que le rapport taille/surface de l'individu et les teneurs circulantes en protéines de liaison aux stéroïdes (Daxenberger et al 2001). Les valeurs de CM chez l'enfant sont vraisemblablement 2 à 4 fois inférieures à celles déterminées chez la femme et prises comme références (Andersson et Skakkebæk 1999). Par ailleurs, à cause de problèmes liés à la sensibilité des méthodes de dosage, les teneurs circulantes chez l'enfant ont été très longtemps surestimées. Une méthode ultrasensible de dosage biologique utilisant des cellules transfectées exprimant le récepteur $\mathrm{ER} \alpha$ a permis d'établir les valeurs de concentrations plasmatiques en œstradiol à des niveaux moyens de $0,08 \mathrm{pg} / \mathrm{mL}$ chez les garçons prépu-

\footnotetext{
$\overline{3}$ C'est ce raisonnement combiné à l'analyse des faibles concentrations hormonales circulantes chez l'enfant, pour autant qu'elles soient connues, qui a prévalu à la mise en place de la notion d'augmentation différentielle permise («allowable incremental increases») pour les hormones naturelles, celle-ci se substituant à celle de concentrations sans risques («safe concentrations») établie pour les hormones de synthèse présentes comme résidus dans les tissus animaux.
} 
Tableau 25. Augmentation de l'ingestion d'œstradiol présent comme résidu dans une ration type imputable à l'utilisation de traitements anabolisants à base d'implant contenant de l'œstradiol (d'après Daxenberger et al 2001).

\begin{tabular}{|l|c|c|c|c|c|}
\hline \multicolumn{1}{|c|}{ Paramètres } & Muscle & Foie & Rein & Tissu adipeux & Total \\
\hline Teneurs résiduelles (pg/g) & 6,4 & 10,1 & 9,4 & 17,9 & - \\
\hline $\begin{array}{l}\text { Consommation journalière de produits } \\
\text { animaux (JECFA, 1999) }(\mathrm{g})\end{array}$ & 300 & 100 & 50 & 50 & 500 \\
\hline $\begin{array}{l}\text { Total de résidus ingérés en situation normale } \\
\text { (ng) }\end{array}$ & 1,92 & 1,01 & 0,47 & 0,90 & $\begin{array}{c}\mathbf{4 , 3 0} \\
\text { (base 1) }\end{array}$ \\
\hline $\begin{array}{l}\text { Facteur d'augmentation des résidus en } \\
\text { œstradiol lié au traitement anabolisant }\end{array}$ & 3,7 & 4,2 & 6,2 & 6,4 & - \\
\hline $\begin{array}{l}\text { Total de résidus ingérés en situation de } \\
\text { traitement anabolisant (ng) }\end{array}$ & 7,10 & 4,24 & 2,91 & 5,73 & $\begin{array}{c}19,98 \\
(\times 4,6)\end{array}$ \\
\hline
\end{tabular}

1 Facteur moyen d'augmentation des concentrations résiduelles tissulaires en œstradiol après utilisation d'implants à base d'œstradiol.

bères et à $0,6 \mathrm{pg} / \mathrm{mL}$ chez les filles prépubères (Klein et al 1994). Plus récemment, un dosage similaire a permis d'obtenir des valeurs de 1,4 et 3,5 $\mathrm{pg} / \mathrm{mL}$ respectivement chez les garçons et les filles prépubères, la différence entre sexes étant significative (Paris et al 2002). A partir des valeurs publiées par Klein et al (1994), il est possible, pour les garçons prépubères qui présentent les concentrations plasmatiques en œstradiol les plus basses, de calculer une valeur $\mathrm{P}$ variant entre 0,04 et 0,1 $\mu \mathrm{g} / \mathrm{j}$. Ceci permet, pour une dose maximale acceptable de $1 \%$ de P, d'obtenir une valeur de 400 pg/j d'œstradiol ingéré (Daxenberger et al 2001). Compte tenu des quantités de résidus retrouvées dans les tissus d'animaux témoins ou implantés (tableau 25), ce seuil sera atteint après consommation d'une ration de près de $50 \mathrm{~g}$ de viande issue d'animaux témoins et de seulement $10 \mathrm{~g}$ de viande issue d'animaux traités (Daxenberger et al 2001). A partir des valeurs de concentrations plasmatiques en œstradiol établies chez le garçon prépubère par Paris et al (2002), le même calcul donne une valeur limite de $350 \mathrm{~g}$ de viande provenant d'animaux traités. Afin d'expertiser de façon plus fiable la question du «risque œstrogénique» que présente l'œstradiol, il devient urgent d'obtenir des données précises concernant :

1) les valeurs de production d'œstradiol par l'organisme, en particulier chez l'enfant,

2) les concentrations circulantes en œstradiol chez le garçon prépubère mesurées par spectrométrie de masse à des niveaux de sensibilité de l'ordre de $0,1 \mathrm{pg}$,

3) la détermination de la clairance métabolique moyenne dans cette souspopulation pouvant être la plus sensible à ce risque hormonal, surtout si l'ab- sence d'effet de seuil en matière de stimulation hormonale est démontrée.

Concernant la question du «risque génotoxique», il n'est plus possible, à la suite des travaux conduits par les équipes de Liehr et de Cavalieri, de considérer certains des métabolites de l'œstradiol, en particulier les 4-catéchols œstrogènes, comme ne présentant aucune propriété génotoxique (Cavalieri et al 1997, Liehr et al 2000). Ces dérivés électrophiles peuvent provoquer la formation d'adduits instables à l'ADN à l'origine de mutations ponctuelles (figure 20). Ceci se traduit par le développement de tumeurs détectées dans certains modèles animaux : le hamster de Syrie ou la souris (Cavalieri et Rogan 2004). Plus récemment, Bhat et al (2003) ont pu montrer chez le hamster le partage des rôles entre la formation de dérivés catéchols induisant un stress oxydant et le signal œstrogénique impliquant le récepteur $E R \alpha$ à l'origine de la promotion tumorale. Plusieurs modèles d'étude semblent impliquer les mêmes mécanismes de formation d'adduits à l'ADN accompagnée d'un stress oxydant (Cavalieri et al 2000, 2002). D'autres s'en éloigneraient, n'impliquant que la stimulation hormonale induite par les œstrogènes (Turan et al 2004). Pourtant, l'utilisation de souris génétiquement invalidées pour l'expression du récepteur ER $\alpha$ montre aussi le développement de tumeurs dans le tissu mammaire, tissu dans lequel la forme ER $\beta$ est absente (Bocchinfuso et al 1999, Devanesan et al 2001). Ceci indique que l'implication du récepteur ER ne peut être considérée comme seule cause dans l'initiation et le déve-

Figure 20. Catéchols œstrogènes, adduits à l'ADN et atteintes cellulaires (Cavalieri et Rogan 2004).
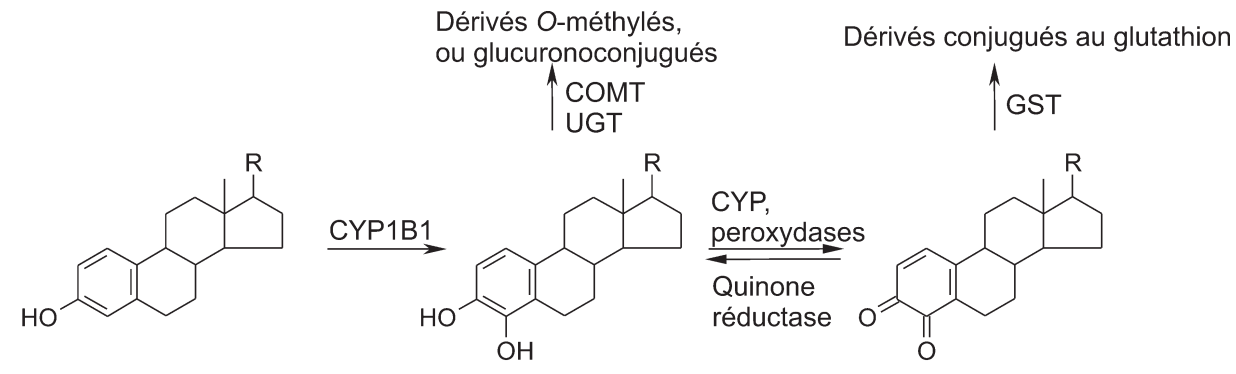

Oestrogènes

4-Catéchol oestrogènes (CE)

3,4-Quinone oestrogènes

oestradiol : $\mathrm{R}=17 \beta \mathrm{OH}$

oestrone : $\mathrm{R}=\mathrm{O}$

oestradiol- $17 \alpha: \mathrm{R}=17 \alpha \mathrm{OH}$

Développement tumoral

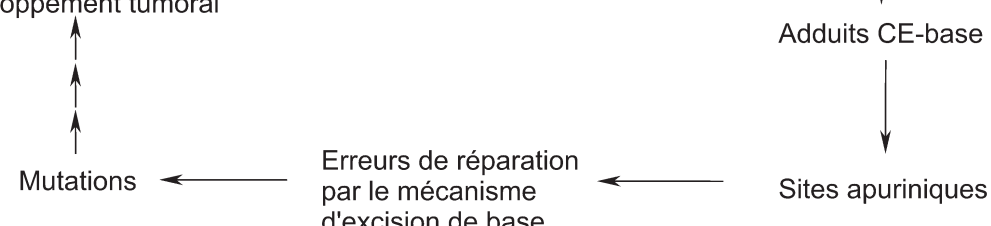


loppement de tumeurs provoqués par les œstrogènes. Ainsi, les arguments métaboliques relatifs aux catéchols œstrogènes sont de plus de plus invoqués pour expliquer la formation progressive d'altérations structurales sur l'ADN (Castagnetta et al 2002, Rogan et Cavalieri 2004, Yue et al 2005). Dans ce contexte scientifique, l'expertise devient encore plus délicate à conduire en matière d'analyse du risque génotoxique que présenteraient pour l'homme l'œstradiol et ses métabolites de type catéchol, ceci du fait de la multiplicité des voies possibles de disruptions endocriniennes et métaboliques qui seraient alors induites.

Si dans l'UE l'usage des promoteurs de croissance incluant stéroïdes, $\beta$-agonistes, thyréostatiques et hormones peptidiques reste interdit, celui des progestagènes destinés à contrôler la reproduction à des fins zootechniques est lui autorisé, à la réserve près qu'en élevage bovin l'œstradiol utilisé en association à certains progestagènes devra, dans un terme proche, être éliminé des protocoles appliqués sur le terrain. Néanmoins, les risques que présentent les résidus tissulaires des molécules destinées à maîtriser la reproduction restent en pratique extrêmement faibles du fait de la destination, zootechnique, des reproducteurs, ce qui n'est pas le cas des promoteurs de croissance utilisés tout au long de l'engraissement des animaux de boucherie et jusqu'à leur abattage.

Du fait de ces contraintes réglementaires, mais non seulement, des alternatives sont recherchées actuellement, que ce soit pour l'engraissement ou pour la maîtrise des cycles ovariens en reproduction. Si les années 60 ont vu les recherches en pharmacologie déboucher sur la synthèse de nouveaux stéroïdes destinés à renforcer l'anabolisme des animaux placés en engraissement ou à maîtriser les cycles chez les femelles, si les années 70 ont permis d'aborder une meilleure description des stades physiologiques impliqués qui pouvaient faire l'objet d'un contrôle pharmacologique, si les années 80 et le début des années 90 ont permis de réaliser des avancées importantes dans les recherches conduites en physiologie grâce aux biotechnologies, débouchant ainsi sur l'utilisation à des fins zootechniques des hormones peptidiques recombinantes, les connaissances fondamentales accumulées durant toutes ces années sur les mécanismes biochimiques sous-jacents n'en ont pas moins progressé en parallèle, et ceci de façon vertigineuse. Pourtant, sur le terrain, les méthodes du contrôle hormonal des phases de reproduction ou de la croissance sont, pour bon nombre d'entre elles, celles imaginées dans les années 60 et 70 . Elles n'ont pas vraiment fait l'objet d'une évolution radicale qui puisse s'appuyer sur les mécanismes moléculaires impliqués, en particulier tous ceux décrits dans le domaine de la réceptologie.

Ces dernières années ont vu apparaître des démarches de recherche à caractère hollistique qui tentent d'intégrer les différentes échelles de description des phénomènes physiologiques en utilisant les techniques de production de données à haut débit. On peut souligner l'intérêt d'une telle démarche qui permettrait de mieux décrire, grâce aux notions de réseaux métaboliques, les étapes biochimiques régulées ou réorientées de façon coordonnée durant ces différentes phases physiologiques. Combinée à une analyse de leur variabilité au sein des troupeaux, cette démarche pourrait renforcer les efforts de la sélection génétique qui s'appuie déjà sur l'existence de marqueurs génétiques ou moléculaires. Dans un autre ordre d'idées, cette démarche d'analyse globale appliquée à l'évaluation $\mathrm{du}$ risque subtoxique que présentent les résidus d'hormones et leurs métabolites permettrait aussi de progresser dans la connaissance des disruptions endocriniennes ou métaboliques possiblement induites par ces résidus. Cette caractérisation pourrait alors être rapportée, à la relation d'échelle près, à des phénomènes de disruption pleinement établis au plan de la toxicologie. Plus largement, la qualité des produits issus d'animaux soumis à certains de ces traitements hormonaux pourrait être documentée de façon assez analogue à ce qui commence à se faire en matière de caractérisation de la qualité alimentaire des plantes génétiquement modifiées. Enfin, ces méthodes pourraient contribuer à l'amélioration indispensable de la traçabilité de l'origine des produits animaux et des méthodes d'élevage ayant permis de les élaborer.

Il est encore trop tôt pour savoir si ce courant scientifique, encore débutant, peut apporter des réponses nouvelles concernant le contrôle physiologique de la reproduction, de la lactation ou de la croissance. S'il tient ses promesses, alors les travaux plus classiques qui se poursuivent pour acquérir une meilleure connaissance des déterminants génétiques, des contraintes nutritionnelles et celles liées à la qualité des aliments et à leur disponibilité, mais aussi celles concernant l'influence des systèmes d'élevage sur les fonctions de reproduction, de lactation ou de croissance n'en prendront que plus d'intérêt.

\section{Remerciements}

Les auteurs tiennent à remercier vivement Mesdames Danielle Monniaux, Françoise Guéraud et Nathalie Priymenko et Messieurs Michel Terqui, Philippe Chemineau et Marc-Antoine Driancourt pour leur relecture approfondie du manuscrit et les critiques et conseils avisés dont ils nous ont fait part.

\section{Références}

Addison R.S., Maguire D.J., Mortimer R.H., Cannell G.R., 1991. Metabolism of prednisolone by the isolated perfused human placental lobule. J. Steroid Biochem. Mol. Biol., 39, 83-90.

Afonso L.O.B., Iwama G.K., Smith J., Donaldson E.M., 1999. Effects of the aromatase inhibitor Fadrozole on plasma sex steroid secretion and ovulation rate in female coho salmon, Oncorhynchus kisutch, close to maturation. Gen. Comp. Endocrinol., 113, 221-229.

Afonso L.O.B., Iwama G.K., Smith J., Donaldson E.M., 2000. Effects of the aromatase inhibitor Fadrozole on reproductive steroids and spermiation in male coho salmon (Oncorhynchus kisutch) during sexual maturation. Aquaculture, 188, 175-187.

Aguilera R., Becchi M., Mateus L., Popot M.A., Bonnaire Y., Casabianca H., Hatton C.K., 1997. Detection of exogenous hydrocortisone in horse urine by gas chromatography-combustioncarbon isotope ratio mass spectrometry. J. Chromatogr. B, 702, 85-91.

Ahlquist R.A., 1948. Study of the adrenotropic receptors. Am. J. Physiol., 153, 586-600.
Ahmad N., Schrick F.N., Butcher R.L., Inskeep E.K., 1995. Effect of persistent follicles on early embryonic losses in beef cows. Biol. Reprod., 52, 1129-1135.

Alok D., Krishnan T., Salunke D., Gupta H., Talwar G.P., Garg L.C., 1994. Precocious ovarian recrudescence and induced off-season spawning of Heteropneustes fossilis by D-Lys6 salmon gonadotropin releasing hormone analog, (sGnRH-A). J. Fish Biol., 45, 909-915.

Anderson L.H., Day M.L., 1998. Development of a progestin-based estrus syn- 
chronization program. I. Reproductive response of cows fed melengestrol acetate for 20 days with an injection of progesterone. J. Anim. Sci., $76,1267-1272$

Anderson P., Edsbäcker S., Ryrfeldt A., Von Barhr C., 1982 In vitro biotransformation of glucocorticoids in liver and skin homogenate fraction from man, rat and hairless mouse. J. Steroid Biochem., 16, 787-795.

Andersson A.M., Skakkebaek N.E., 1999. Exposure to exogenous estrogens in food: possible impact on human development and health. Eur. J. Endocrinol., 140, 477-485.

Antignac J.P., Le Bizec B., Monteau F., Poulain F., André F., 2000. Collision-induced dissociation of corticosteroids in electrospray tandem mass spectrometry and development of a screening method by high performance liquid chromatography/tandem mass spectrometry. Rapid Comm. Mass Spectrom., 14, 33-39.

Antignac J.P., Le Bizec B., Monteau F., André F., 2002. Study of natural and artificial corticosteroid phase II metabolites in bovine urine using HPLC-MS/MS. Steroids, 67, 873-882.

Antignac J.P., Monteau F., Négriolli J., André F., Le Bizec B., 2004. Hyphenated mass spectrometric techniques applied to corticosteroid residue determination in biological matrices. Chromatographia, accepté pour publication.

Arch J.R., Ainsworth A.T., Cawthorne M.A., Piercy V., Sennitt M.V., Thody V.E., Wilson C., Wilson S., 1984. Atypical beta-adrenoceptor on brown adipocytes as target for anti-obesity drugs. Nature, 309, 163-165.

Arendt J., 1986. Role of the pineal gland and melatonin in seasonal reproductive functions in mammals. Oxford Rev. Reprod. Biol., 8, 266320.

Arnold D., 2004. Risk Assessments for substances without ADI/MRL - an overview. Joint FAO/WHO Technical Workshop on Residues of Veterinary Drugs without ADI/MRL, Bangkok, Thaïlande, 24-26 August 2004. http://www.fao.org/docrep/008/y 5723e/y 5723e0 d.htm\#bm13.

Astwood E.B., 1943. The chemical nature of compounds which inhibit the function of the thyroid gland. J. Pharmacol. Exp. Ther., 78, 79-89.

Astwood E.B., Bissel L.A., Hughes A.M., 1945. Further studies on the chemical nature of compounds which inhibit the function of the thyroid gland. Endocrinology, 37, 456-481.

Axelrod L.R., Werthessen N.T., 1960. The metabolism of Estrone-16-C 14 in bovine blood. Arch. Biochem. Biophys., 86, 53-55.

Auger J., Kunstmann J.M., Czyglick F., Jouannet P., 1995. Decline in semen quality among fertile men in Paris during the ast 20 years. N. Engl. J. Med., 332, 281-285.

Azuma T., Takeda K., Doi T., Muto K., Akutsu M., Sawada M., Adachi S., 2004. The influence of temperature on sex determination in sockeye salmon Oncorhynchus nerka. Aquaculture, 234, 461-473.

Baillie T.A., Brooks C.J.W., Middleditch B.S., 1972. Comparison of corticosteroid derivatives by gas chromatography-mass spectrometry. Anal. Chem., 44, 30-37.

Balthazart J., Fabre-Nys C., 2001. Le comportement sexuel. La reproduction chez les mammifères et l'homme. C. Thibault et M.C. Levasseur (Eds), Ellipses, INRA Editions, Paris, France, 611-637.
Baracaldo M.I., Martinez M.F., Adams G.P., Mapletoft R.J., 2000. Superovulatory response following transvaginal follicle ablation in cattle. Theriogenology, 53, 1239-1250.

Bareille N., Faverdin P., Hay M., 1997. Modification of feed intake response to a beta(2)-agonist by bovine somatotropin in lactating or dry dairy cows. J. Dairy Sci., 80, 52-66.

Baril G., Brebion P., Chesné P., 1993. Manuel de formation pour la transplantation embryonnaire chez la brebis et chez la chèvre. FAO, 115.

Baril G., Remy B., Leboeuf B., Beckers J.F., Saumande J., 1996a. Synchronization of estrus in goats: the relationship between eCG binding in plasma, time of occurrence of estrus and fertility following artificial insemination. Theriogenology, 45, 1553-1559.

Baril G., Pougnard J.L., Freitas V.J.F., Leboeuf B., Saumande J., 1996b. A new method for controlling the precise time of occurrence of the preovulatory gonadotropin surge in superovulated goats. Theriogenology, 45, 697-706.

Baroiller J.F., Chourrout D., Fostier A., Jalabert B., 1995. Temperature and sex chromosome govern sex ratios of the mouthbrooding cichlid fish Oreochromis niloticus. J. Exp. Zool., 273, 216-223.

Baroiller J.F., Guiguen Y., Fostier A., 1999. Endocrine and environmental aspects of sex differentiation in fish. Cell Mol. Life Sci., 55, 910931.

Barragry T.B., 1994. Drugs and the bovine genital tract Veterinary Drug Therapy. Lea and Lebiger (Eds), Philadelphia, USA, 689-716.

Barreteau S., Soulard S., Harnois G. Monlouis J.D., Driancourt M.A.,2005. Efficacité de la combinaison de GnRH et d'un implant de Norgestomet pour la synchronisation des chaleurs chez les bovins. 12 èmes Renc.Rech. Rum., Paris, France, 7-8 Décembre 2005, 166.

Bathori M., 2002. Phytoecdysteroids effects on mammalians, isolation and analysis. Mini Rev. Med. Chem., 2, 285-293.

Batjoens P., De Brabander H.F., De Wasch K., 1996. Rapid and high performing analysis of thyreostatic drug residues using GC-MS. J. Chromatogr. A, 750, 127-132.

Bauer E.R.S., Daxenberger A., Petri T., Sauerwein H., Meyer H.H.D., 2000. Characterisation of the affinity of different anabolics and synthetic hormones to the human androgen receptor, human sex hormone binding globulin and to the bovine gestagen receptor APMIS, 108, 838-846.

Bauman D.E., 2000. Regulation of nutrient partitioning during lactation: homeostasis and homeorhesis revisited. Ruminant Physiology: Digestion, Metabolism, Growth and Reproduction. CAB International, PB Cronjé (Ed), 311-328

Bauman D.E., Vernon R.G., 1993. Effects of exogenous bovine somatotropin on lactation. Ann. Rev. Nutr., 13, 437-461.

Bauman D.E., Eppard P.J., DeGeeter M.J., Lanza G.M., 1985. Responses of high-producing dairy cows to long-term treatment with pituitary somatotropin and recombinant somatotropin. J. Dairy Sci., 68, 1352-1362.

Bauman D.E., Everett R.W., Weiland W.H., Collier R.J., 1999. Production responses to bovine somatotropin in Northeast dairy herds. J. Dairy Sci., 82, 2564-2573.
Baumann G., 2001, Growth hormone binding protein in 2001. J. Pediatr. Endocrinol. Metab. $14,355-375$.

Bazan J.F. Structural design and molecular evolution of a cytokine receptor superfamily, 1990. Proc. Natl Acad. Sci. USA, 87, 6934-6938.

Beekley M.D., Ideus J.M., Brechue W.F., Kearns C.F., McKeever K.H., 2003. Chronic clenbuterol administration alters myosin heavy chain composition in standardbred mares. Vet. J., $165,234-239$.

Bell A.W., Bauman D.E., Beermann D.H. Harrell R.J., 1998. Nutrition, development and efficacy of growth modifiers in livestock species. J. Nutr., 128, 360S-363S.

Bernard L., Leroux C., Hayes H., Gautier M. Chilliard Y., Martin P., 2001. Characterization of the caprine stearoyl-CoA desaturase gene and mRNA showing an unusually long 3'-UTR sequence arising from a single exon. Gene, 281, 53-61.

Bhat H.K., Calaf G., Hei T.K., Loya T., Vadgama J.V., 2003. Critical role of oxidative stress in estrogen-induced carcinogenesis. Proc. Natl. Acad. Sci. USA, 100, 3913-3918.

Bidanel J.P., Rothschild M., 2002. Current status of quantitative trait locus mapping in pigs. Pig News Inf., 23, 39N-54N.

Bidanel J.P., Riquet J., Chardon P., Hatey F., Le Roy P., Milan D., 2003. Apport des nouvelles biotechnologies aux programmes d'amélioration génétique du porc. Journ. Rech. Porcine Fr. Paris, France, 35, 355-368.

Billard R., Bieniarz K., Peter R.E., Sokolowka M., Weil C., Crim L.W., 1984. Effects of LHRH and LHRH-a on plasma GtH levels and maturation/ovulation in the common carp, Cyprinus carpio, kept under various environmental conditions. Aquaculture, 41, 245-254.

Billard R., Bieniarz K., Popek P., Epler P., Breton B., Alagarswami K., 1987. Stimulation of gonadotropin secretion and spermiation by pimozide-LHRH-A treatment: effects of dose and time of day. Aquaculture, 62, 161-170.

Biolatti B., Bollo E., Re G., Appino S., Tartari E., Benatti G., Elliott C.T., McCaughey W.J., 1994. Pathology and residues in veal calves treated experimentally with clenbuterol. Res. Vet. Sci., 57, 365-371.

Birkelo C.P., 2003. Pharmaceuticals, directfed microbials, and enzymes for enhancing growth and feed efficiency of beef. Vet. Clin. North Am. Fd Anim. Pract., 19, 599-624.

Birkett D.J., Price N.C., Radda G.K., Salmon A.G., 1970. The reactivity of SH groups with a fluorogenic reagent. FEBS Lett., 6, 346-348.

Blair R.M., Fang H., Gaylor D., Sheehan D.M., 2001. Threshold analysis of selected doseresponse data for endocrine disruptors. APMIS, 109, 198-208.

Blanc F., Bocquer F., Debus N., Agabriel J., D’Hour P., Chilliard J., 2004. La pérennité et la durabilité des élevages de ruminants dépendent des capacités adaptatives des femelles. INRA Prod. Anim., 17, 287-302.

Blanchflower W.J., Hughes P.J., Cannavan A., McCoy M.A., Kennedy D.J., 1997. Determination of thyreostats in thyroid gland and urine using HPLC-APCI MS. Analyst, 122, 967-972.

Bloss R.E., Northam J.I., Smith L.W., Zimbelman R.G., 1966. Effects of oral melenge- 
strol acetate on the performance of feedlot cattle. J. Anim. Sci., 25, 1048-1053.

Bo G.A., Adams G.P., Caccia M., Martinez M., Pierson R.A., Mapletoft R.J., 1995a. Ovarian follicular wave emergence after treatment with progestogen and estradiol in cattle. Anim. Reprod. Sci., 39, 193-204.

Bo G.A., Adams G.P., Pierson R.A., Mapletoft R.J., 1995b. Exogenous control of follicular wave emergence in cattle. Theriogenology, 43, 31-40.

Bo G.A., Bergfelt D., Brogliatti G.M., Pierson R.A., Adams G.P., Mapletoft R.J., 2000. Local versus systemic effects of exogenous estradiol$17 \beta$ on ovarian follicular dynamics in heifers with progestogen implants. Anim. Reprod. Sci., 59, 141-157.

Bocchinfuso W.P., Hively W.P., Couse J.F., Varmus H.E., Korach K.S., 1999. A mouse mammary tumor virus-Wnt1 transgenic induces mammary gland hyperplasia and tumorigenesis in mice lacking estrogen receptor- $\alpha$. Cancer Res., 59, 1869-1876.

Bœuf G., Prunet P., Le Bail P.Y., 1990. Un traitement à l'hormone de croissance peut-il stimuler la smoltification du saumon Atlantique ? C.R. Acad. Sci. Paris, 310, 75-80.

Boichard D., Grohs C., Bourgeois F., Cerqueira F., Faugeras R., Neau A., Rupp R., Amigues Y., Bosher M.Y., Leveziel H., 2003. Detection of genes influencing economic traits in three French dairy cattle breeds. Genet. Sel. Evol., 35, 77-101.

Bonneau M., 1992. Administration exogène de GRF ou de somatotropine chez le porc et les volailles : effets sur les performances, la qualité des viandes et la fonction de reproduction. INRA Prod. Anim., 5, 257-267.

Bonneau M., 1998. Use of entire males for pig meat in the European Union. Meat Sci., 49, S257-S272.

Bonnet M., Delavaud C., Rouel J., Chilliard Y., 2005. Pregnancy increases plasma leptin in nulliparous but not primiparous goats while lactation depresses it. Domest. Anim. Endocrinol., 28, 216-223.

Borg W., Shackleton C.H.L., Pahuja S.L., Hochberg R.B., 1995. Endogenous long-lived esters of testosterone in the rat. Proc. Natl Acad. Sci. USA, 92, 1545-1549.

Bories G.F., Sutra J.F., Tulliez J., 1992. Metabolism and disposition of $\left[{ }^{3} \mathrm{H}\right]$ Zeranol implanted in the pig. J. Agric. Fd Chem., 40, 284-288.

Boulot S., Dubroca S., Badouard B., 2004. Gestion pharmacologique de la reproduction : le point sur les pratiques des éleveurs. Journées de 1'Association Française de Médecine Vétérinaire Porcine. $1^{\text {er }} 3$ décembre 2004. Actualités en production porcine-Atelier de reproduction, Maisons-Alfort, 11-14..

Boulton D.W., Fawcett J.P., 1996. Enantioselective disposition of albuterol in humans. Clin. Rev. Allergy Immunol., 14, 115138.

Brebion P., Baril G., Cognié Y., Vallet J.C., 1992. Transfert d'embryons chez les ovins et les caprins. Ann. Zoootech., 41, 331-339.

Breton B., Weil C., 1973b. Effets du LH/FSHRH synthétique et d'extraits hypothalamiques de carpe sur la sécrétion d'hormone gonadotrope in vivo chez la carpe (Cyprinus carpio). C.R. Acad. Sci. Paris, 27D, 2061-2064.
Breton B., Billard R., Jalabert B., 1973a Spécificité d'action et relations immunologiques des hormones gonadotropes de quelques téléostéens. Ann. Biol. Anim. Bioch. Biophys., 13, 347-362.

Breton B., Marcel J., Billard R., 1980. Les préparations hypophysaires en pisciculture. Obtention et emploi. Bull. Fr. Pisc., 278, 41-45.

Breton B, Weil C., Sambroni E. Zohar Y., 1990. Effects of accute versus sustained administration of GnRHa on GtH release and ovulation in the rainbow trout, Oncorynchus mykiss. Aquaculture, 91, 371-383.

Breton B., Mikolajczyk T., Popek W., 1993. The neuroendocrine control of the gonadotropin (GTH2) secretion in teleost fish. American Geophysical Union. B. Lalhou, P. Vitello (Eds)., Aquaculture: fundamental and applied research, 199-215.

Breton B., Quillet E., Jalabert B., 1996. Contrôle de la reproduction et du sexe chez les poissons d'élevage. INRA Prod. Anim., horssérie, 17-26.

Breton B., Roelants Y., Ollevier F., Epler P., Mikolacjczyk T., 1998. Improved bioavailibility of orally delivered peptides and polypetides in teleost fish. J. Appl. Ichthyol., 14, 251-257.

Briant C., 1999. Actualités en reproduction équine. Maîtrise de l'activité ovarienne chez la jument. INRA Prod. Anim., 12, 332-333.

Briant C., Ottogalli M. Morel M., Guillaume D., 2003. Use of a GnRH antagonist, antarelix, associated or not with hCG, to control ovulation in cyclic pony mares. Domest. Anim. Endocrinol., 24, 305-322.

Bricout V.A., Serrurier B.D., Bigard A.X. 2004. Clenbuterol treatment affects myosin heavy chain isoforms and MyoD content similar$y$ in intact and regenerated soleus muscles. Acta Physiol. Scand., 180, 271-280.

Broom D., Dantzer R., Willeberg P., Mepham B., Noordhuizen-Stassen E., 1999. Animal welfare aspects of the use of bovine somatotropin. Report of the scientific committee on animal health and welfare, Directorate General XXIV of the European Commission, Brussels, 10 March 1999, 1-90.

Bruneau P., Bertrand G., Chilliard Y., De Kerchove G., 1991. Somatotropine bovine (Sometribove) et production laitière. Efficacité et innocuité chez 448 paires de vaches dans les conditions de 24 exploitations françaises. Rec. Méd. Vét., 167, 859-872.

Buick R.K., Barry C., Traynor I.M., McCaughey J.W., Elliott C.T., 1998. Determination of thyreostat residues from bovine matrices using high-performance liquid chromatography. J. Chromatogr. B, 720, 71-79.

Bungartz L., Niemann H., 1994. Assessment of the presence of a dominant follicle and selection of dairy cows suitable for superovulation by a single ultrasound examination. J. Reprod. Fert., $101,583-585$.

Burke C.R., Boland M.P., MacMillan K.L., 1998. Ovarian responses to progesterone and œstradiol benzoate administered intravaginally during dioestrus in cattle. Anim. Reprod. Sci., $55,23-33$.

Burke C.R., Mussard M.L., Grum D.E., Day M.L., 2001. Effects of maturity of the potential ovulatory follicle on induction of cstrus and ovulation in cattle with œstradiol benzoate. Anim. Reprod. Sci., 66, 161-174.
Burton J.L., McBride B.W., Block E., Glimm D.R., Kennelly J.J., 1994. A review of bovine growth hormone. Can. J. Anim. Sci., 74, 167-201.

Burvenich C., Paape M.J., Hoeben D., Dosogne H., Massart-Leen A.M., Blum J., 1999. Modulation of the inflammatory reaction and neutrophil defense of the bovine lactating mammary gland by growth hormone. Domest. Anim. Endocrinol., 17, 149-159.

Butler S.T., Marr A.L., Pelton S.H., Radcliff R.P., Lucy M.C., Butler W.R., 2003. Insulin restores $\mathrm{GH}$ responsiveness during lactationinduced negative energy balance in dairy cattle: effects on expression of IGF-I and GH receptor 1A. J. Endocrinol., 176, 205-217.

Buttery P.J., Dawson J.M., 1987. The mode of action of beta-agonists as manipulators of carcass composition. Beta-agonists and their effects on animal growth and carcass quality, J.P. Hanrahan (Ed), Commission of the European Communities, Elsevier, Barking, UK, 29-43.

Buxeraud J., Raby C., Lagorce J.F., 1987. Charge transfer complexes of drugs with iodine investigation by UV/visible spectroscopy. Int. J. Pharmaceut., 35, 129-137.

Cairns T., Siegmund E.G., Stamp J.J., Skelly J.P.,1983. Liquid chromatography mass spectrometry of dexamethasone and betamethasone. Biomed. Mass Spectrom., 10, 203-208.

Calvarese S., Rubini P., Urbani G., Ferri N. Ramazza V., Zucchi M., 1994. Experimental administration of 19-Nortestosterone and dexamethasone in cattle: elimination of the two drugs in different biological matrices. Analyst, 119 2611-2615.

Caraty A., Duittoz A., Pelletier J., Thiery J.C., Tillet Y., Bouchard P., 2001. Libération pulsatile des gonadotropines, de la prolactine et de la $\mathrm{GH}$. Le contrôle de la pulsatilité de LH. La reproduction chez les mammifères et l'homme, C. Thibault et M.C. Levasseur (Eds), INRA Ellipses, Paris, France, 792-814.

Carruthers T., 1986. Principles of hormone therapy. In: Current Therapy in Theriogenology. D.A. Morrow (Ed), Saunders WB Co, Philadelphia, USA, 3-13.

Cassar-Malek I., Listrat A., Picard B., 1998. Contrôle hormonal des caractéristiques des fibres musculaires après la naissance. INRA Prod. Anim., 11, 365-377.

Castagnetta L.A.M., Granata O.M., Traina A., Ravazzolo B., Amoroso M., Miele M., Bellavia V., Agostara B., Carruba G., 2002. Tissue content of hydroxyestrogens in relation to survival of breast cancer patients. Clin. Cancer Res., 8, 3146-3155.

Cavalieri E.L., Rogan E.G., 2004. A unifying mechanism in the initiation of cancer and other diseases by catechol quinones. Ann. NY Acad. Sci., 1028, 247-257.

Cavalieri E.L., Stack D.E., Devanesan P.D., Todorovic R., Dwivedy I., Higginbotham S., Johansson S.L., Patil K.D., Gross M.L., Gooden J.K. Ramanathan R. Cerny R.L. Rogan E.G, 1997. Molecular origin of cancer: catechol estrogen-3,4-quinones as endogenous tumor initiators Proc. Natl Acad. Sci. USA, 94, 10937-10942.

Cavalieri E., Frenkel K., Liehr J.G., Rogan E., Roy D., 2000. Estrogens as endogenous genotoxic agents: DNA adducts and mutations. JNCI Monograph 27: Estrogens as endogenous carcinogens in the breast and prostate, E. Cavalieri and E Rogan (Eds), Oxford Press, UK, 75-93. 
Cavalieri E.L., Rogan E.G., Chakravarti D., 2002. Initiation of cancer and other diseases by catechol ortho-quinones: a unifying mechanism. Cell Mol. Life Sci., 59, 665-681.

Chabbert-Buffet N., Skinner D.C., Caraty A., Bouchard P., 2000. Neuroendocrine effects of progesterone. Steroids, 65, 613-620.

Cham B.E., Sadowski B. O'Hagan J.M., De Wytt C.N., Bochner F., Eadie M.J., 1980. High performance liquid chromatographic assay of dexamethasone in plasma and tissue. Therapeut. Drug Monit., 2, 373-377.

Chang C.H., Hickey G.J., 1999. Les sécrétagogues synthétiques de la somatotrophine (sST) et leur utilisation éventuelle chez les animaux de compagnie et de consommation. Le Médecin Vétérinaire du Québec, 29, 71-76.

Chemineau P., 1989. Utilization of the buck effect to stimulate ovarian and oestrous cycles in anovulatory goats. INRA Prod. Anim., 2, 97104.

Chemineau P., Malpaux B., Delgadillo J.A., Guérin Y., Ravault J.P., Thimonier J., Pelletier J., 1992. Control of sheep and goat reproduction: Use of light and melatonin. Anim. Reprod. Sci., 30, 157-184.

Chemineau P., Delgadillo J.A., Deletang F., Pobel T., Brice G., 1996b. Emploi des implants de mélatonine et des traitements photopériodiques pour maîtriser la reproduction saisonnière chez les ovins et les caprins. INRA Prod. Anim., 9, 45-60.

Chemineau P., Cognié Y., Heyman Y., 1996a. Maîtrise de la reproduction des mammifères d'élevage. INRA Prod. Anim., hors-série, 5-15.

Chemineau P., Cognié Y., Timonier J., 2001. La Maîtrise de la reproduction des mammifères domestiques. La reproduction chez les mammifères et l'homme, C. Thibault et M.C. Levasseur (Eds), INRA Ellipses, Paris, France, 792-815.

Chermnykh N.S., Shimanovskii N.L, Shutko G.V., Syrov V.N., 1988. The action of methandrostenolone and ecdysterone on the physical endurance of animals and on protein metabolism in the skeletal muscles. Farmakol. Toksikol., 51, 57-60.

Chevassus B., Blanc J.M., Chourrout D., 1979. Le contrôle de la reproduction chez les poissons. II. Reproduction différée et stérilité. Bull. Fr. Pisc., 274, 32-46.

Chevassus B., Krieg F., 1992. Effect of the concentration and duration of methyltestosterone treatment on masculinization rate in the brown trout (Salmo trutta). Aquacult. Liv. Res., 5, 325328.

Chilliard Y., 1988. Long term effects of recombinant bovine somatotropin (rBST) on dairy cow performances. Ann. Zootech., 37, 159180.

Chilliard Y., 1999. Metabolic adaptations and nutrient partitioning in the lactating animal. J. Martinet, L.M. Houdebine, H.H. Head (Eds), Biology of lactation, Collection Mieux Comprendre. INRA Editions, Paris, France, 503552.

Chilliard Y., Ferlay A., 2004. Dietary lipids and forages interactions on cow and goat milk fatty acid composition and sensory properties. Reprod. Nutr. Dev., 44, 467-492.

Chilliard Y., Bocquier F., Doreau M., 1998a. Digestive and metabolic adaptations of ruminants to undernutrition, and consequences on reproduction. Reprod. Nutr. Dev., 38, 131-152.
Chilliard Y., Colleau J.J., Disenhaus C., Lerondelle C., Mouchet C., Paris A., 1998 b. L'hormone de croissance recombinante, intérêt et risques potentiels de son utilisation pour la production laitière bovine. INRA Prod. Anim., $11,15-32$.

Chilliard Y., Lerondelle C., Disenhaus C., Mouchet C., Paris A., 2001. Recombinant growth hormone: potential interest and risks of its use for bovine milk production. R. Renaville, A. Burny (Eds), Biotechnology in animal husbandry. Kluwer Academic Publishing, Dordrecht, The Netherlands, 65-97.

Chilliard Y., Delavaud C., Bonnet M., 2005. Leptin expression in ruminants: nutritional and physiological regulations in relation with energy metabolism. Domest. Anim. Endocrinol., 29, 3-22.

Chourrout D., Chevassus B., Guyomard R., 1986. L'amélioration génétique des poissons. La Recherche, 180, 1028-1038.

Chu S.S., 1984. Bronchodilators. Part I: adrenergic drugs. Drugs of today, 20, 439-464.

Chupin D., Deletang F., Petit M., Pelot J., Le Provost F., Ortavant R., Parez M., Mauleon P., 1974. Utilisation des implants sous-cutanés de progestagènes pour le contrôle des cycles sexuels chez la vache. Ann. Biol. Anim. Biophys., 14, 27-39.

Clemens J.D., Estergreen V.L., 1982 Metabolism and conjugation of [4-14C) progesterone by bovine liver and adipose tissues, in vitro. Steroids, 40, 287-306.

Cognié Y., 1988. Nouvelles méthodes utilisées pour améliorer les performances de reproduction chez les ovins. INRA Prod. Anim., 2, 83-92.

Cognié Y., 1999. State of art in sheep-goat embryo transfer. Theriogenology, 51, 105-116.

Cognié Y, Baril G., 2002. Le point sur la production et le transfert d'embryons obtenus in vivo et in vitro chez la brebis et la chèvre. INRA Prod. Anim., 15, 199-207.

Cognié Y., Baril G., Poulin N., Mermillod P., 2003. Current status of embryo technologies in sheep and goat. Theriogenology, 59, 171-188.

Colbern G.T., Squires E.L., Voss J.L., 1987. Use of altrenogest and human chorionic gonadotropin to induce normal cyclicyty in transitional mares. J. Equine Vet. Sci., 7, 69-72.

Coleman M.E., DeMayo F., Yin K.C., Lee H.M., Geske R., Montgomery C., Schwartz R.J., 1995. Myogenic vector expression of insulinlike growth factor I stimulates muscle cell differentiation and myofiber hypertrophy in transgenic mice. J. Biol. Chem., 270, 12109-12116.

Colleau J.J., 1996. Evaluation génétique des animaux d'élevage. INRA Prod. Anim., horssérie, 27-40.

Collier R.J., Miller M.A., Hildebrandt J.R., Torkelson A.R., White T.C., Madsen K.S., Vicini J.L., Eppard P.J., Lanza G.M., 1991. Factors affecting insulin-like growth factor-I concentration in bovine milk. J. Dairy Sci., 74, 2905-2911.

Collier R.J., Byatt J.C., Denham S.C., Eppard P.J., Fabellar A.C., Hintz R.L., McGrath M.F., McLaughlin C.L., Shearer J.K., Veenhulzen J.J., Vicini J.L., 2001. Effects of sustained release bovine somatotropin (Sometribove) on animal health in commercial dairy herds. J. Dairy Sci., 84, 1098-1108.

Combarnous Y., 2004. Communications et signalisations cellulaires. Tec et Doc (Ed), Lavoisier, Paris, France, 58-234.
Cooper R.L., Kavlock R.J., 1997. Endocrine disruptors and reproductive development: a weight-of-evidence overview. J. Endocrinol., $152,159-166$.

Coulibaly S., Besenfelder U., Miller I., Zinovieva N., Lassning C., Kotler T., Jameson J.L., Gemeiner M., Muller M., Brem G., 2002. Expression and characterization of functional recombinant bovine follicle-stimulating hormone (boFSHalpha/beta) produced in the milk of transgenic rabbits. Mol. Reprod. Dev., 63, 300308.

Courtheyn D., Vercammen J., De Brabander H., Vandenreyt I., Batjoens P., Vanoosthuyze K., Van Peteghem C., 1994. Determination of dexamethasone in urine and faeces of treated cattle with negative chemical ionization-mass spectrometry. Analyst, 119, 2557-2564.

Crome P.K., McKeith F.K., Carr T.R., Jones D.J., Mowrey D.H., Cannon J.E., 1996. Effect of ractopamine on growth performance, carcass composition, and cutting yields of pigs slaughtered at 107 and 125 kilograms. J. Anim. Sci., 74, 709-716.

Cudina O., Broric J., Vujik Z., Radulovic D., Vladimirov S., 2000. Determination of fluocortolone pivalate and fluocortolone hexanoate in suppositories using reverse-phase HPLC. Il Farmaco, 55, 125-127.

Cunningham H.M., 1965. Effect of epinephrine and nicotine on protein and fat metabolism of pigs. Energy Metabolism, K.L. Blaxter (Ed), Academic press, New York, 29-36.

Dadoune J.P., Demoulin A., 2001. Structure et fonctions du testicule. La reproduction chez les mammifères et l'homme. C. Thibault, M.C. Levasseur (Eds), INRA Ellipses, Paris, France, 256-289.

Dalke B.S. Roeder R.A., Kasser T.R., Veenhuizen J.J. Hunt C.W., Hinman D.D., Schelling G.T., 1992. Dose-response effects of recombinant bovine somatotropin implants on feedlot performance in steers. J. Anim. Sci., 70, 2130-2137.

Damkjoer Nielsen M., Binder C., Starup J., 1969. Urinary excretion of different corticosteroid-metabolites in oral contraception and pregancy. Acta Endocrinol., 60, 473-485.

Danhaive P.A., Rousseau G.G., 1986. Binding of glucocorticoid antagonists to androgen and glucocorticoid hormone receptors in rat skeletal muscle. J. Steroid Biochem., 24, 481-487.

Danhaive P.A., Rousseau G.G., 1988. Evidence for sex-dependent anabolic response to androgenic steroids mediated by muscle glucocorticoid receptors in the rat. J. Steroid Biochem., 29, 575-581.

Daxenberger A., Meyer K., Hageleit M. Meyer H.H.D., 1999. Detection of melengestrol acetate (MGA) on plasma and edible tissues of heifers. Vet. Quart., 21, 154-158.

Daxenberger A., Ibarreta D., Meyer H.D.D., 2001. Possible health impact of animal œstrogens in food. Human Reprod. Update, 7, 340-355.

De Brabander H.F., Verbeke R., 1975. Detection of antithyroid residues in meat and some organs of slaughtered animals. J. Chromatogr., 108, 141-151.

De Brabander H.F., Verbeke R., 1984. Analysis of anti-hormones. Trends Anal. Chem., 3, 162-165.

De Kock S.S., Rodgers J.P., Swanepoel B.C., Guthrie A.J., 2001. Administration of bovine, 
porcine and equine growth hormone to the horse: effect on insulin-like growth factor-I and selected IGF binding protein. J. Endocrinol., 171, $163-171$.

De Wasch K., De Brabander H., Courteyn D. Van Peteghem C., 1998a. Detection of cortico steroïds in injection sites and cocktails by $\mathrm{MS}^{\mathrm{n}}$. Analyst, 123, 2415-2422.

De Wasch K., De Brabander H.F., Van Ginkel L.A., Spann A., Sterck S.S., Meiring H.D., 1998b. Confirmation of residues of thyreostatic drugs in thyroid glands by multiple mass spectrometry after thin layer chromatographic screening. J. Chromatogr. A, 819, 99-111.

De Wasch K., De Brabander H.F., Impens S., Van De Wiele M., Courtheyn D., 2001. Determination of mercaptobenzimidazol and other thyreostat residues in thyroid tissue and meat using high-performance liquid chromatography-mass spectrometry. J. Chromatogr. A, 91-2, 311-317.

De Wilde R.O., Lauwers H., 1984. The effect of parenteral use of estradiol, progesterone, testosterone and trenbolone on growth and carcass composition in pigs. J. Anim. Sci., 59, 15011509 .

DeHaan K.C., Berger L.L., Kesler D.J., et al, 1988. Effect of prenatal androgenization on growth performance and carcass characteristics of steers and heifers. J. Anim. Sci., 66, 18641870 .

Delétang F., Stazzu F., Papelard A.L., Remmy D., 2004. Comment synchroniser chaleurs et ovulation sans œstradiol avec un dispositif vaginal (PRID) imprégné de progesterone ? Journ. Nat. GTV, Nantes, 883-888.

Delpech P., Lefaucheur L., 1986. La croissance. Le Porc et son élevage. Bases scientifiques et techniques. J.M. Perez, P. Mornet, A. Rerat (Eds), Maloine, Paris, France, 121-140.

Derblom H., Johansson H., Nylander G., 1963. Thyroid hormone activity and gastrointestinal function, an experimental study in the rat. Acta Chir. Scand., 10 (Suppl. 307), 1-47.

DeRubertis F.R., Frederick R., Michelis M.F., Bloom M.A., Mintz J.D.H., Davis F.B., 1971. Impaired water excretion in myxedema. Am. J. Med., 51, 41-53.

Devanesan P., Santen R.J., Bocchinfuso W.P., Korach K.S., Rogan E.G., Cavalieri E., 2001. Catechol estrogen metabolites and conjugates in mammary tumors and hyperplastic tissue from estrogen receptor $\alpha$ knock out (ERKO)/Wntl mice: implications for initiation of mammary tumors. Carcinogenesis, 22, 1573-1576.

Devlin R.H., Nagahama Y., 2002. Sex determination and sex differentiation in fish, an overview of genetic, physiological and environmental influences. Aquaculture, 208, 191-364.

Deyo C.D., Colazo M.G., Martinez M.F., Mapletoft R.J., 2001. The use of GnRH or LH to synchronize follicular wave emergence for superstimulation in cattle. Theriogenology, 55, 513.

Dixon S.N., Russell K.L., 1986a. Radioimmunoassay of the anabolic agent zeranol. The determination of zeranol concentrations in the edible tissues of cattle implanted with zeranol (Ralgro). J. Vet. Pharmacol. Ther., 9, 94100.

Dixon S.N., Russell K.L., Heitzman R.J., Mallinson C.B., 1986b. Radioimmunoassay of the anabolic agent zeranol. V. Residues of zeranol in the edible tissues, urine, faeces and bile of steers treated with Ralgro. J. Vet. Pharmacol. Ther., 9, 353-358.

Dodds E.C., Goldberg L., Lawson W., Robinson R., 1938. Oestrogenic activity of certain synthetic compounds. Nature, 141, 247-248.

Dodds H.M., Taylor P.J., Cannell G.R., Pond S.M., 1997. A high-performance liquid chromatography-electrospray-tandem mass spectrometry analysis of cortisol and metabolites in placental perfusate. Anal. Biochem., 247, 342347 .

Donaldson E.M., 1996. Manipulation of reproduction in farmed fish. Anim. Reprod. Sci., 42, 381-392.

Donaldson E.M., Hunter G.A., 1983. Induced final maturation, ovulation and spermiation in cultured fishes. Fish physiology, Vol. IX, part B, Reproduction. W.S. Hoar, D.J. Randall, E.M Donaldson (Eds), Academic Pre ss, 351-403.

Driancourt M.A., Levasseur M.C., 2001. Cycles estriens et cycles menstruels. La reproduction chez les mammifères et l'homme. C. Thibault et M.C. Levasseur (Eds), INRA Ellipses, Paris, France, 680-698.

Drori S., Ofir M., Levavi-Sivan B., Yaron Z., 1994. Spawning induction in common carp (Cyprinus carpio) using pituitary extract or GnRH superactive analogue combined with metoclopramide: Analysis of hormone profile, progress of oocyte maturation and dependence on temperature. Aquaculture, 119, 393-407.

Ducrocq V., Boichard D., Barbat A., Larroque H., 2001. Intégration des caractères fonctionnels dans un index de synthèse pour les races bovines laitières : de la théorie à la pratique. Renc. Rech. Rum., 8, 333-336.

Dumas M.E., Canlet C., André F., Vercauteren J., Paris A., 2002a. Metabonomic assessment of physiological disruptions using ${ }^{\mathrm{H}}{ }_{\mathrm{H}}{ }^{1}{ }^{3} \mathrm{C}$ HMBC/NMR spectroscopy combined with pattern recognition procedures performed on filtered variables. Anal. Chem., 74, 2261-2273.

Dumas M.E., Debrauwer L., Beyet L., Lesage D., André F., Paris A., Tabet J.C., 2002 b. Evidencing physiological signature of use of anabolic steroids in cattle using metastable atom bombardment mass spectrometry and pattern recognition. Anal. Chem., 74, 5393-5404.

Dumas M.E., Canlet C., Vercauteren J., André F., Paris A., 2005. Homeostatic signature of anabolic steroids in cattle using ${ }^{1} \mathrm{H}-{ }^{13} \mathrm{C}$ HMBC NMR metabonomics. J. Proteome Res., sous presse. Web Release Date: 12-Aug-2005; (Article) DOI: 10.1021/pr0500556.

Dumasia M.C., Houghton E., Moss M.S., Chakraborty J., Marks V., 1986. The biotransformation and urinary excretion of dexamethasone in equine male castrate. J. Steroid Biochem., 25, 547-553.

Dunham R.A., 1990. Production and use of monosex or sterile fishes in aquaculture. Rev. Aquat. Sci., 2, 1-17.

Dunn T.G., Kaltenbach C.C., Koritnik D.R., Turner D.L., Niswender G.D., 1977. Metabolism of estradiol-17 $\beta$ and estradiol-17 $\beta$-3-benzoate in bovine tissues. J. Anim. Sci., 46, 659-673.

Dunshea F.R., Suster D., Kerton D.J., Leury B.J., 2003. Exogenous porcine somatotropin administered to neonatal pigs at high doses can alter lifetime fat but not lean tissue deposition. Br. J. Nutr., 89, 795-801.

D’occhio M.J., Jillella D., Lindsey B.R., 1999. Factors that influence follicle recruitment, growth and ovulation during ovarian superstimulation in heifers: Opportunities to increase ovulation rate and embryo recovery by delaying the exposure of follicles to LH. Theriogenology, 51, 9-35.

Edens A., Talamantes F., 1998. Alternative processing of growth hormone receptor transcripts. Endocr. Rev., 19, 559-582.

Egford M., 1995. Corticosteroid metabolism in isolated perfused rat liver and kidney. Acta Physiol. Scand., 155, 1-42.

Eisemann J.H., Huntington G.B. Ferrell C.L., 1988. Effects of dietary clenbuterol on metabolism of the hindquarters in steers. J. Anim. Sci., $66,342-353$.

EMEA/MRL/0129/96-Final, 1996. Committee for veterinary medicinal products. Medroxyprogesterone acetate. Summary Report. http://www.emea.eu.int/pdfs/vet/mrls/ 012996en.pdf.

EMEA/MRL/468/98-Final, 1999. Committee for veterinary medicinal products. Norgestomet. Summary Report. http://www.emea.eu.int/pdfs/ vet/mrls/046898en.pdf.

EMEA/MRL/780/01-Final, 2001. Committee for veterinary medicinal products. Flugestone acetate. Summary Report (2). http:// www.emea.eu.int/ pdfs/vet/mrls/078001 en.pdf.

EMEA/MRL/904/04-Final, 2004. Committee for medicinal products for veterinary use. Altrenogest. Summary Report (3). http://www.emea.eu.int/pdfs/vet/mrls/090404en. pdf.

EMEA-V-8473-03. 2003. Note regarding the establishment of maximum residue limits for norgestomet. http://www.emea.eu.int/pdfs/vet/ mrls/847303en.pdf

EMEA-V-8486-03. 2003. Note regarding the establishment of maximum residue limits for flugestone acetate. http://www.emea.eu.int/pdfs/ vet $/ \mathrm{mrls} / 848603 \mathrm{en} . \mathrm{pdf}$

Engelhardt G., 1972. Struktur-wirkungsbeziehungen in einer reihe von neuen amino-halogensubstituierten phenyl-aminoäthanolen. ArzneimForsch. (Drug Res), 22, 869-876.

Engler H., Taurog A., Nakashima T., 1982. Mechanism of inactivation of thyroid peroxydase by thioureylene drugs. Biochem. Pharmacol. 31, 3801-3806.

Erichsen S., Velle W., 1960. Studies on œstrogens in cattle. Estrogen conversions in different tissues grown in vitro. Acta Endocrinol., 37, 27-32.

Estergreen V.L., Lin M.T., Martin E.L., Moss G.E., Branen A.L., Luedecke L.O., Shimoda W., 1977. Distribution of progesterone and its metabolites in cattle tissues following administration of progesterone-4-14C. J. Anim. Sci., 46, 642-651.

Etherton T.D., 1999. Emerging strategies for enhancing growth: is there a biotechnology better than somatotropin? Domest. Anim. Endocrinol., 17, 171-179.

Etherton T.D., 2000. The biology of somatotropin in adipose tissue growth and nutrient partitioning. J. Nutr., 130, 2623-2625.

Evrard P., Maghuin-Rogister G., 1987. In vitro metabolism of trenbolone: study of the formation of covalently bound residues. Fd Addit. Contam., 5, 59-65.

FAO, 1987. Monographie on residues of some veterinary drugs in animals and foods. FAO/OMS, Rome, Italie, June 15-23, 151p. 
Fara G.M., Del Corvo G., Bernuzzi S., Bigatello A., Dipietro C., Scaglioni S., Chiumello G., 1979. Epidemic of breast enlargement in an Italian school. Lancet, 11, 295-297.

Faustino-Kemp J., Houghton E., Jackson L.S., Williams R.B., 2001. The use of IGF-I as a marker for detecting administration of growth hormone. Proc. $13^{\text {th }}$ Int. Conf of Racing Analysts and Veterinarians, Cambridge, UK, 321-323.

FDA, 2005. http://www.fda.gov/cvm/ Guidance/GFI003.htm

Federal Register, 1968. Melengestrol acetate. Fed. Regist., 33, 2602.

Federal Register, 1969. Melengestrol acetate. Fed. Regist., 34, 11, 542.

Ferlay A., Charret C. Galitzky J., Berlan M., Chilliard Y., 2001. Effects of the perfusion of beta-, beta2-, or beta3-adrenergic agonists or epinephrine on in situ adipose tissue lipolysis measured by microdialysis in underfed ewes. J. Anim. Sci., 79, 453-462.

Fernandez E., Kopchick J.J., 1990. Quantitative determination of growth hormone by immuno-blotting. Anal. Biochem., 191, 268271.

Fernandez-Suarez A. 1991. Etude comparée du métabolisme d'un stéroïde triénique : l'acétate de trenbolone, chez le rat et le porc. Thèse INP-Toulouse, 14 juin 1991, 105p.

Fernandez-Suarez A. 2004. South America's regulatory framework for the control of residues of veterinary drugs. Working paper. Joint FAO/WHO Technical workshop on Residues of Substances without ADI/MRL in Food. Bangkok, 24-28 août 2004. ftp://ftp.fao.org/ docrep/fao/008/y5723e/y5723e00.pdf, pp 57-64.

Fiori M., Pierdominici E., Longo F., Brambilla G., 1998. Identification of main corticosteroids as illegal feed additives in milk replacers by liquid chromatography-atmospheric pressure chemical ionization mass spectrometry. J. Chromatogr. A, 807, 219-227.

Florini J.R., Ewton D.Z., Coolican S.A., 1996. Growth hormone and the insulin-like growth factor system in myogenesis. Endocr. Rev., 17, 481-517.

FOIS (Freedom of information summary), 1999. Ractopamine hydrochloride $\left(\right.$ PAYLEAN $\left.^{\circledR}\right)$, NADA Elanco Animal Health, Eli Lilly and Co. December 1999, 140-863.

FOIS (Freedom of information summary), 2003. Ractopamine hydrochloride (OPTAFLEX ${ }^{\mathrm{TM}}$ 45), NADA. Elanco Animal Health, Eli Lilly and Co. June 2003, 141-221

Fontenele O., 1955. Injecting pituitary (hypophyseal) hormones into fish to induce spawning. Prog. Fish-Cult., 17, 71-75.

Forgerit Y., Martinat-Botté F., Bariteau F., Corbé H., Macar C., Poirier P., Nolibois P., Terqui M., 1995. Utilisation d'un progestagène (Régumate) au moment du tarrissement de la primipare. 1. Amélioration de la fertilité et de la productivité après un traitement progestatif court. Journ. Rech. Porcine Fr., 27, 45-50.

Forniés M.A., Carrillo M., Mañanós E., Sorbera L.A., Zohar Y., Zanuy S., 2003. Relative potency of the forms of GnRH and their analogs on LH release in sea bass. J. Fish. Biol., 63, 7389.

Fostier A., Chevassus B., 1991. Génétique et reproduction des salmonidés. Biofutur, 106, 3134.
Frank S.J., 2001. Growth hormone signalling and its regulation: preventing too much of a good thing. Growth Horm. IGF Res., 11, 201-212.

Fritsche S., Steinhart H., 1999. Occurrence of hormonally active compounds in food: a review. Eur. Fd Res. Technol., 209, 153-179.

Fritz S., Colleau J.J., Druet T., Boscher M.Y., Rossignol M.N., Malafosse A., Boichard D., 2003. Mise en place d'une selection assistée par les marqueurs dans les trois principales races bovines laitières françaises. Renc.. Rech. Rum., 10, 53-56.

Frohman L.A., Jansson J.O., 1986. Growth hormone-releasing hormone. Endocr. Rev., 7, 223-253.

Furuta T., Namekawa T., Shibasaki H., Kasuya Y., 1998. Simultaneous determination of tetrahydrocortisol and tetrahydrocortisone in human plasma and urine by stable isotope dilution mass spectrometry. J. Chromatogr. B, 706, 181-190.

Gale W.L., Fitzpatrick M.S., Lucero M. Contreras-Sanchez W.M., Schreck C.B., 1999. Masculinization of nile tilapia (Oreochromis niloticus) by immersion in androgens. Aquaculture, 178, 349-357.

Galet C., Chopineau M., Martinat N. Combarnous Y., Guillou F., 2000. Expression of an in vitro biologically active equine LH/CG without C-terminal peptide (CTP) and/or beta 26-110 disulphide bridge. Mol. Cell. Endocrinol., 17, 31-40.

Geary T.W., Whittier J.C., 1997. Modifications of the Ovsynch estrous synchronization protocol for use in beef cows. J. Anim. Sci., 75 (Suppl 1), 236 (Abstr.).

Gillet C., Breton B., Mikolajczyk T., 1996. Effects of $\mathrm{GnRHa}$ and pimozide treatments on the timing of ovulation and on egg quality in Arctic charr (Salelinus alpinus) at 5 and 10 degrees C. Aquat. Liv. Res., 9, 257-263.

Ginther O.J., 1992. Endocrinology of the ovulatory season. Reproductive biology of the mare: basic and applied aspects. Library of Congress Catalog Ed. Cross Plains, Equiservices, 233-290.

Girault J., Istin B., Fourtillan J.B., 1990. A rapid and highly sensitive method for the quantitative determination of dexamethasone in plasma, synovial fluid and tissues by combined gas chromatography/negative ion chemical ionization mass spectrometry. Biomed. Environm. Mass Spectrom., 19, 295-302.

Glasser F., Cauty C., Mourot B. Breton B., 2003. Disrupted sexual cylces in female grass carp (Ctenopharyngodon idella) raised in tropical condition. Aquaculture, 220, 857-868.

Gojmerac T., Mandic B., Lojkic M., Bilandzic N., 2000. Acute and subacute metabolic and endocrine effects of clenbuterol in female pigs. Vet. Res. Commun., 24, 179-187.

Govignon A., Rohou A. Ponsart C., Delcroix P., Humblot P., 2000. Sources of embryo production after superovulation in Prim Holstein dairy cows. AETE $-16^{\text {th }}$ Scient. Meeting, Santander, Portugal, 158 .

Grandadam J.A., Scheid J.P., Jobard A., Dreux H., Boisson J.M., 1975. Results obtained with trenbolone acetate in conjonction with estradiol $17 \beta$ in veal calves, feedlot bulls, lambs and pigs. J. Anim. Sci., 41, 969-977.

Grant A.L., Skjaerlund D.M., Helferich W.G., Bergen W.G., Merkel R.A., 1993. Skeletal muscle growth and expression of skeletal muscle alpha-actin mRNA and insulin-like growth factor I mRNA in pigs during feeding and withdrawal of ractopamine. J. Anim. Sci., 71, 33193326.

Gray L.E., Ostby J., Furr J. Wolf C.J. Lambright C. Parks L. Veeramachanemi D.N., Wilson V., Price M., Hotchkiss A., Orlando E., Guillette L., 2001. Effects of environmental antiandrogens on reproductive developement in experimental animals. Human Reprod. Update, 7, 248-264.

Grégoire F., Smas C.M., Sul H.S., 1998. Understanding adipocyte differentiation. Physiol. Re.v, 78,783-809.

Griem W., 1973. Histopathological changes in the thyroid glands of cattle and rabbits following feeding with methylthiouracil. Berl. Mün. Tierärztl. Wochenschr., 86, 50-56.

Grimard B., Humblot P., Ponter A.A., Mialot J.P., Sauvant D., Thibier M.,1995. Influence of postpartum energy restriction on energy status, plasma LH and œstradiol secretion and follicular development in suckled beef cows. J. Reprod. Fert., 104, 173-179.

Grobet L., Martin L.J.R., Poncelet D., Pirottin D., Brouwers B. Riquet J., Schoeberlein A., Dunner S., Menissier F., Massabanda J., Fries R., Hanslet R., Georges M., 1997. A deletion in the bovine myostatin gene causes the doublemuscled phenotype in cattle. Nat. Genet., 17, 71-74.

Gronemeyer H., Gustafsson J.A., Laudet V., 2004. A question of partnership: the pharmacology of the nuclear receptor superfamily. Nat. Rev. Drug Discov., 3, 950-964.

Guiguen Y., 2000. Implication of steroids in fish gonadal sex differentiation and sex inversion. Curr. Top. St Res., 3, 127-143.

Guiguen Y., Baroiller J.F., Jalabert B., Fostier A., 1996. Le contrôle du sexe phénotypique chez les poissons. Pisc. Française, 124, 16-19.

Guilbault L.A., Grasso F., Lussier J.G Rouillier P., Matton P., 1991. Decreased superovulatory responses in heifers superovulated in the presence of a dominant follicle. J. Reprod. Fert., 91, 81-89.

Guillaume G., 1999. Actualités en reproduction équine. Effet de la saison, de l'éclairement artificiel et de la mélatonine sur le rythme annuel de reproduction de la jument. INRA Prod. Anim. $12,332-334$.

Haffray P., Fostier A. Normant Y., Fauré A., Loir M., Jalabert B., Maisse G., Le Gac F., 1995. Influence du maintien en mer ou de la période du transfert en eau douce des reproducteurs de saumon Atlantique, Salmo salar, sur la maturation sexuelle et la qualité des gamètes. Aquat. Liv. Res., 8, 135-145.

Hageleit M., Daxenberger A., Kraetzl W.D. Kettler A., Meyer H.H.D., 2000. Dose-dependent effects of melengestrol acetate (MGA) on plasma levels of estradiol, progesterone and luteinizing hormone in cycling heifers and influences on oestrogen residues in edible tissues. APMIS, 108, 847-854.

Hanrahan J.P., 1987. Beta-agonists and their effects on animal growth and carcass quality. J.P. Hanrahan (Ed), Commission of the European Communities, Elsevier applied science publishers, Barking, UK, 193-197.

Hartmann S., Lacorn M., Steinhart H., 1998. Natural occurrence of steroid hormones in food. Fd Chem., 62, 7-20. 
Henricks D.M., Torrence A.K., 1978. Endogenous estrogens in bovine tissues. J. Assoc. Official Anal. Chem., 61, 1280-1283.

Henricks D.M., Gray S.L., Hoover J.L.B., 1983. Residue levels of endogenous estrogens in beef tissues. J. Anim. Sci., 57, 247-255.

Henricks D.M., Brandt R.T., Titgemeyer E.C., Milton C.T., 1997. Serum concentrations of trenbolone-17 $\beta$ and estradiol-17 $\beta$ and performance of heifers treated with trenbolone acetate, melengestrol acetate, or estradiol-17 $\beta$. J. Anim. Sci., 75, 2627-2633.

Henricks D.M., Gray S.L., Owenby J.J., Lackey B.R., 2001. Residues from anabolic preparations after good veterinary practice. APMIS, 109, 273-283.

Her G.R., Watson J.T., 1986. Electron capture negative chemical ionization mass spectrometry of chemically oxidized corticosteroids. Biomed. Environ. Mass Spectrom., 13, 57-63.

Herbst A.L., Ulfelder H., Poskanzer D.C., 1971. Adenocarcinoma of the vagina. Association of maternal stilbestrol therapy with tumor appearance in young women. N. Engl. J. Med., 284, 878-881.

Herbst A.L., Bern H.A., Eds, 1981. Developmental effects of diethylstilboestrol (DES) in pregnancy. Thieme-Stratton, NewYork

Hervé V., Roy F., Bertin J., Guillou F., Maurel M.C., 2004. Anti-eCG antibodies generated in goats treated with eCG for the induction of ovulation modulate the LH and FSH bioactivities of eCG differently. Endocrinology, 145, 294-303.

Higgs D.A., Fagerlund U.H.M., Eales J.G., McBride J.R., 1982. Application of thyroid and steroid hormones as anabolic agents in fish culture. Comp. Biochem. Physiol., 73B, 143-176.

Hinkle R.T., Hodge K.M., Cody D.B., Sheldon R.J, Kobilka B.K., Isfort R.J., 2002. Skeletal muscle hypertrophy and anti-atrophy effects of clenbuterol are mediated by the beta2adrenergic receptor. Muscle Nerve, 25, 729-734.

Hochhaus G., Mollmann H., 1992. Pharmacokinetic/pharmacodynamic characteristics of the beta-2-agonists terbutaline, salbutamol and fenoterol. Int. J. Clin. Pharmacol. Ther. Toxicol., 30, 342-362.

Hoffmann B, Evers P., 1986. Anabolic agents with sex hormone-like activities: problems of residues. Drugs residues in animals, A.G. Rico (Ed), Academic Press Inc., 111-146.

Hoffmann B., Rattenberger E., 1977. Testosterone concentrations in tissue from veal calves, bulls and heifers and in milk-samples. J. Anim. Sci., 46, 635-641.

Hoffmann B., Karg H., Heinritzi K.H., Behr H., Rattenberger E., 1975. Moderne Verfahren der Östrogenbestimmung und deren Anwendung für die Rückstandsproblematik. Mitt. Gebiete Lebensm. Hyg., 66, 20-37.

Holland H.L., 1982. The mechanism of the microbial hydroxylation of steroids. Chem. Soc. Rev., 11, 371-395.

Hooijerink H.J., De Ruig W.G., 1987. Determination of thyreostatics in meat by reversed-phase liquid chromatography with ultra-violet and electrochemical detection. J. Chromatogr. A, 394, 403-407.

Horiba M., Murai T., Nomura K., Yuge T., Sanai K. Osada E., 1984. Pharmacokinetic studies of mabuterol, a new selective $\beta 2$-stimulant. II : Urinary metabolites of mabuterol in rats and their pharmacological effects. Arzneim-Forsch. (Drug Res), 34, 1668-1679.

Hotchkiss A.K., Ostby J.S., Vandenbergh J.G., Gray L.E., 2002. Androgens and environmental antiandrogens affect reproductive development and play behavior in the Sprgue-Dawley rat. Environ. Health Perspect., 110 (Suppl. 3), 435439.

Houdebine L.M., 1997. Biologie de la lactation. Encyclopédie Médecine Chirurgicale, Gynécologie/Obstétrique, 5-008-A-30, Elsevier (Ed), Paris, France, 1-15.

Houghton E., Teale P., Dumasia M.C., Wellby J.K., 1982. The use of capillary column gas chromatography and negative ion chemical ionization mass spectrometry to confirm the administration of synthetic corticosteroids to horses. Biomed. Mass Spectrom., 9, 459-465.

Huetos-Hidalgo O., Jimenez Lopez M., Ajanjo Carazo E., San Andres Larrea M., Reuvers T.B.A., 2003. Determination of dexamethasone in urine by gas chromatography with negative chemical ionization mass spectrometry. J. Chromatogr. B, 788, 137-146.

Hunter G.A., Donaldson E.M., Dye H.M., 1981. Induced ovulation in coho salmon (Oncorhynchus kisutch). I. Further studies on the use of salmon pituitary preparations. Aquaculture, 26, 117-127.

Hunter G.A., Donaldson E.M., 1983. Hormonal sex control and its application to fish culture. Fish Physiology, W.S. Hoar, D.J. Randall, E.M. Donaldson (Eds), Academic Press, New York, 9, 223-291.

Hutz R.J., Dierschke D.J., Wolf R.C., 1988. Induction of atresia of the dominant follicle in rhesus monkeys (Macaca mulatta) by the local application of estradiol-17beta. Am. J. Primatol., $15,69-77$

IARC, 1979. International Agency for Research on Cancer, Monographs on the evaluation of the carcinogenic risk of chemicals to humans, Sex Hormones (II), IARC, Lyon, France, 21, 173.

Jalabert B., Baroiller J.F., 1989. Contribution of research in reproductive physiology to the culture of tilapias. Aquat. Liv. Res., 2, 105-116.

Jalabert B., Fostier A. 1984. The follicular sensitivity in vitro to maturation-inducing hormones in rainbow trout Salmo Gairdneri: role of estradiol-17-beta. Aquaculture, 43, 1-11.

Jalabert B., Breton B., Bruzska E., Fostier A., 1977. A new tool for induced spawning: the use of $17 \alpha$-hydroxy-20 $\beta$-dihydroprogesterone to spawn carp at low temperature. Aquaculture, 10 353-364

Jalabert B., Breton B., Fostier A., Le Gac F., Loir M. 1999. Bases physiologiques de la reproduction chez les poissons. Atelier professionnel ENITA-IFREMER, 7-8 Octobre 1998, Bordeaux, France.

Houssay, B.A. 1930. Accion sexual de la hipofisis en los peces y los reptiles. Rev. Soc. Arg. Biol., 106, 686-688.

Jammes H., Djiane J. 1988. Le développement de la glande mammaire et son contrôle hormonal dans l'espèce bovine. INRA Prod. Anim., 1, 299-310.

Jansson R., Dahlberg P.A., Johansson H., Lindstrom B. 1983. Intrathyroidal concentrations of methymazole in patients with Grave's disease. J. Clin. Endocrinol. Metab., 57, 129132.
Jansky A.M. 1983. Mise au point d'une méthode sensible d'extraction et de dosage des résidus de zéranol. Proc. Symp. OIE sur les Anabolisants en productions animales : Santé publique, méthodes analytiques et réglementation. OIE, 15-17 février 1983, Paris, France. E. Meissonnier (Ed), OIE, Paris, 467-480.

JECFA, 1987. Toxicological evaluation of certain veterinary drug residues in food. $32^{\text {nd }}$ Meeting of the joint FAO/WHO Expert Committee on Food Additives. Rome, 15-23 June 1987, 122-151.

JECFA, 2004. Joint FAO/WHO Expert Committee on Food Additives. $62^{\text {nd }}$ Meeting. Rome, Italie, 4-12 February 2004.

Jegou B., Auger J., Multiger L., Pineau C. Thonneau P., Spira A., Jouannet P., 1999. The saga of the sperm count decrease in humans and wild and farm animals. The male gamete, from basic science to clinical applications. C. Gagnon Ed., Cache River Press, McGill University, Chap. 41, 446-454.

Johansen K., Andersen A.N., Kampmann J.P., 1982. Excretion of methimazole in human milk. Eur. J. Clin. Pharmacol., 23, 339-341.

Johnston R., Simpson T.H., Youngson A.F., 1978. Sex reversal in salmonid culture. Aquaculture, 13, 115-134.

Jouanin I., Debrauwer L., Fauglas G., Paris A., Rathahao E., 2002. Adduction of catechol estrogens to nucleosides. Steroids, 67, 1091-1099.

Jouannet P., Wang C. Eustache F., KoldJensen T., Auger J., 2001. Semen quality and male reproductive health: the controversy about human sperm concentration decline. APMIS, 109, 333-344

Kambadur R., Sharma M., Smith T.P.L., Bass J.J., 1997. Mutations in myostatin (GDF8) in double-muscled Belgian Blue and Piedmontese cattle. PCR Meth. Appl., 7, 910-915.

Kampmann J.P., Hansen J.M., 1981. Clinical pharmacokinetics of antithyroid drugs. Clin. Pharmacokinet., 6, 401-428.

Karg H., 1969. Hormonale regulation. Handbuch des Tierernährung, Band I, Allgemeine Grundlagen, W. Lenkeit, K. Breirem, E. Crasemann (Eds), Paul Varey Verlag, Hamburg, Allemagne, 362-384.

Kasuya Y., Ishimaru H., Shibasaki H., Furuta T., 1998. Stable isotope methodology for kinetic studies of interconversion of cortisol and cortisone in a human subject. Steroids, 63, 122 129.

Kicman A.T., Miell J.P., Teale J.D., Powrie J., Wood P.J., Laidler P., Milligan P.J., Cowan D.A., 1997. Serum IGF-I and IGF binding proteins 2 and 3 as potential markers of doping with human GH. Clin. Endocrinol. ,47, 43-50.

Killefer J., Koohmaraie M., 1994. Bovine skeletal muscle calpastatin: cloning, sequence analysis, and steady-state mRNA expression. J. Anim. Sci., 72, 606-614.

Kinder J.E., Kojima F.N., Bergfeld E.G. Wehrman M.E., Fike K.E., 1996. Progestin and estrogen regulation of pulsatile LH release and development of persistent ovarian follicles in cattle. J. Anim. Sci., 74, 1424-1440.

King H.R., Pankhurst N.W., 2004. Effect of maintenance at elevated temperatures on ovulation and luteinizing hormone releasing hormone analogue responsiveness of female Atlantic salmon (Salmo salar) in Tasmania. Aquaculture, 233, 583-597. 
Kleemann D.O., Walker S.K. Seamark R.F., 1994. Enhanced fetal growth in sheep administered progestrone during the first three days of pregnancy. J. Reprod. Fertil., 102, 411-417.

Klein K.O., Baron J., Colli M.J., McDonnell D.P., Cutler G.B., 1994. Estrogen levels in chilhood determined by an ultrasensitive recombinant cell bioassay. J. Clin. Invest., 94, 24752480 .

Knuppen R., Breuer H., 1962. Biogenesis of $11 \beta$-hydroxyestrone and $16 \alpha$-hydroxyestrone by adrenal tissue. Biochim. Biophys. Acta, 58, 147-148.

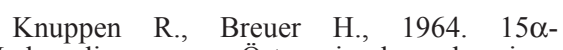
Hydroxylierung von Östron in der nebenniere. Hoppe-Seyler's Z. physiol. Chem., 337, 146-149.

Knuppen R., Behm M., Breuer H., 1964a. Biogenese von $6 \alpha$-Hydroxy-östron in der Nebenniere. Hoppe-Seyler's Z. physiol. Chem., 337, 146-149.

Knuppen R., Haupt O., Breuer H., 1964 b. Biogenesis of $7 \alpha$-hydroxyestrone by adrenal tissue. Steroids, 3, 123-128.

Kohram H., Bousquet D., Durocher J., Guilbault L.A., 1998. Alteration of follicular dynamics and superovulatory responses by gonadotropin releasing hormone and follicular puncture in cattle: a field trial. Theriogenology, 49, 1165-1174.

Kotter L., Terplan G., Schulz J., 1959. Biological demonstration of inhibitors in food stuff of animal origin. Arch. Lebensmittelhyg., 10, 145-152.

Kousteni S., Bellido T., Plotkin L.I., O’Brien C.A., Bodenner D.L., Han L., Han K., DiGregorio G.B., Katzenellenbogen J.A., Katzenellenbogen B.S., Roberson P.K., Weinstein R.S., Jilka R.L., Manolagas S.C., 2001. Nongenotropic, sex-nonspecific signaling through the oestrogen or androgen receptors: dissociation from transcriptional activity. Cell, 104, 719-730.

Krzeminsky L.F., Cox B.L., Gosline H.B., 1981. Fate of radioactive melengestrol acetate in the bovine. J. Agric. Fd Chem., 29, 387-391.

Kushinsky S., 1983. Safety aspects of the use of cattle implants containing natural steroids. International Symposium on the Safety Evaluation of Animal Drug Residues, Berlin. Soumis à la FAO par Syntex Inc., USA, Palo Alto, CA.

Lafri M., Ponsart C., Nibart M., Morel A., Jeanguyot N., Badinand F., De Mari K., Humblot P., 2002. Influence of CIDR treatment during superovulation on embryo production and hormonal patters in cattle. Theriogenology, 58, 1141-1151.

Lagorce J.F., Comby F., Buxeraud J., Raby C., 1992. Synthèse et activité anti-thyroïdienne des dérivés du thiazole. Eur. J. Med. Chem., 27, 359368.

Lam T.J., 1982. Applications of endocrinology to fish culture. Can. J. Fish. Aquat. Sci., 39, 111137.

Lands A.M., Arnold A., McAuliff J.P., Luduena F.P., Brown T.G., 1967. Differentiation of receptor systems activated by sympathomimetic amines. Nature, 214, 597-598.

Lane E.A., Austin E..J, Roche J.F., Crowe M.A., 2001. The effect of estradiol benzoate or a synthetic gonadotropin-releasing hormone used at the start of progesterone treatment on estrous response in cattle. Theriogenolgy, 56, 79-90.
Lauderdale J.W., 1983. Use of MGA (melengestrol acetate) in animal production. Proceedings of the Symposium on Anabolics in Animal Production: Public Health Aspects, Analytical Methods, and Regulation, 15-17 February 1983, Paris, France, E. Meissonnier, J. Mitchell-Vigneron (Eds), OIE, Paris, 193-212.

Laurent F., Vignon B., Coomans D., Wilkinson J. Bonnel A., 1992. Influence of bovine somatotropin on the composition and manufacturing properties of milk. J. Dairy Sci., 75, 2226-2234.

Lawrence T.L.J., Fowler V.R., 2002. Hormonal influences on growth. Growth of farm animals, 2nd edition, T.L.J. Lawrence, V.R. Fowler (Eds), CAB International Publishing, New York, 120-145.

Le Bail P.Y., Perez-Sanchez J., Yao K., Maisse G., 1993. Effects of treatment on salmonid growth: study of the variability of response. Aquaculture: Fundamental and applied research, Coastal and Estuarine Studies, B. Lahlou, P. Vitiello (Eds)., 43, 173-197.

Le Bizec B., Monteau F., Montrade M.P., André F., 1996. Promoteurs de croissance dans l'urine - Détection et identification de thyréostatiques par chromatographie gazeuse couplée à la spectrométrie de masse. Document LDH/96/T1, DGAL/SDSPA/N.96/N8136.

Le Bizec B., Monteau F., Maume D., Montrade M.P., Gade C., André F., 1997. Detection and identification of thyreostats in the thyroid gland by gas chromatography-mass spectrometry. Anal. Chim. Acta, 340, 201-208.

Le Guével R., Pakdel F., 2001. Assessment of oestrogenic potency of chemicals used as growth promoter by in vitro methods. Human Reprod., 16, 1030-1036.

Le Roith D., Bondy C., Yakar S., Liu J.L., Butler A., 2001. The somatomedin hypothesis. Endocr. Rev., 22, 53-74.

Lebret B., Lefaucheur L., Mourot J., Bonneau M., 1996. Influence des facteurs d'élevage sur la qualité de la viande de porc. Journ. Rech. Porcine Fr., Paris, France, 28, 137-156.

Lebret B., Juin H., Noblet J., Bonneau M., 2001. The effects of two methods of increasing age at slaughter on carcass and muscle traits and meat sensory quality in pigs. Anim. Sci., 72, 87 94.

Lee C.Y., Lee H.P., Jeong J.H., Baik J.H., Jin S.K., Lee J.H., Sohn S.H., 2002. Effects of resricted feeding, low-energy diet, and implantation of trenbolone acetate plus estradiol on growth, carcass traits, and circulating concentrations $f$ insulin-like growth factor (IGF)-I and IGF-binding protein-3 in finishing barrows. J. Anim. Sci., 80, 84-93.

Leffers H., Naesby M., Vendelbo B., Skakkebaek N.E., Jorgensen M., 2001. Estrogenic potencies of zeranol, oestradiol, diethylstilboestrol, bisphenol-A and genistein: implications for exposure assessment of potential endocrine disrupters. Hum. Reprod., 16, 1037 1045

Legardinier S., Duonor-Cérutti M., Devauchelle G., Combarnous Y., Cahoreau C., 2005. Biological activities of recombinant equine luteinizing hormone/chorionic gonadotropin (eLH/CG) expressed in $\mathrm{Sf9}$ and Mimic insect cell lines. J. Mol. Endocrinol., 34, 47-60.

Lemon M., 1975. The effect of oestrogens alone or in association with progestagens on the formation and regression of the corpus luteum of the cyclic cow. Ann. Biol. Anim. Biophys.Bioch., 15, 243-253.

Lethimonier C., Madigou T., Muñoz-Cueto J.A., Lareyre J.J., Kah O., 2004. Evolutionary aspects of GnRHs, GnRH neuronal systems and GnRH receptors in teleost. Gen. Comp. Endocrinol., 135, 1-16.

Leveziel H,. Cribiu E.P., 2000. Etat des lieux de la cartographie du génome des ruminants. INRA Prod. Anim., hors-série «Génétique moléculaire : principes et application aux populations animales», 103-107.

Leymarie P., Martal J. 2001. Du corps jaune cyclique au corps jaune gestatif. La reproduction chez les mammifères et l'homme. C. Thibault, M.C. Levasseur (Eds), INRA Ellipses, Paris, 479-504.

Liefers S.C., te Pas M.F.W., Veerkamp R.F., Chilliard Y., Delavaud C. Gerritsen R., Van der Lende T. 2003. Association of leptin gene polymorphisms with serum leptin concentration in dairy cows. Mammalian Genome, 14, 657-663.

Liehr J.G., 2000. Is estradiol a genotoxic mutagenic carcinogen? Endocr. Rev., 21, 40-54.

Lin M.T., Estergreen V.L., Moss G.E., Willett J.D., Shimoda W. 1978. The in vitro metabolites of [14C]-progesterone in bovine muscle and adipose tissue. Steroids, 32, 547-561.

Lindsey B.R., Maclellan L.J., Whyte T.R., Kinder J.E., D’Occhio M.J., 2002. Differential requirement for pulsatile LH during the follicular phase and exposure to the preovulatory $\mathrm{LH}$ surge for oocyte fertilization and embryo development in cattle. Theriogenology, 58, 16511662. [Erratum in: Theriogenology, 2004, 62 373].

Lone K.P., 1997. Natural sex steroids and their xenobiotic analogs in animal production: growth, carcass quality, pharmacokinetics, metabolism, mode of action, residues, methods, and epidemiology. Crit. Rev. Fd Sci. Nutr., 37, 93-209.

Louveau I., Bonneau M., 2001. Biology and actions of somatotropin in the pig Biotechnology and Animal husbandry, R. Renaville, A. Burny, Kluwer Academic Press (Ed), The Netherlands, 111-131.

Louveau I., Gondret F., 2004. Regulation of development and metabolism of adipose tissue by growth hormone and the insulin-like growth factor system. Domest. Anim. Endocrinol., 27, 241-255.

Lucy M.C., Billings H.J., Butler W.R. Ehnis L.R. Fields M.J. Kesler D.J. Kinders J.E., Mattos R.C., Short R.E., Thatcher W.W., Wettemenn R.P., Yelich J.V., Hafs H.D., 2001. Efficacy of an intravaginal progesterone insert and an injection of $\mathrm{PgF}_{2 \alpha}$ for synchronizing estrus and shortening the interval to pregnancy in postpartum beef cows, peripubertal beef heifers, and dairy heifers. J. Anim. Sci., 79, 982-995.

Lunaas T., Velle W., 1960. Estrogen metabolism in vitro in the presence of mammalian erythrocytes. A comparison study. Acta Physiol. Scand. (Suppl), 175, 95-97.

Magri K.A., Adamo M., Leroith D., Etherton T.D., 1990. The inhibition of insulin action and glucose metabolism by porcine growth hormone in porcine adipocytes is not the result of any decrease in insulin binding or insulin receptor kinase activity. Biochem. J., 266, 107-113.

Maisse G., Bonnieux F., Fauconneau B., Faure A., Gloaguen Y., Le Bail P.Y., Prunet P., Rainelli P., 1993. Impact zootechnique et socio- 
économique potentiels d'une éventuelle utilisation de la rtGH en salmoniculture. INRA Prod. Anim., 6, 167-183.

Malinowski K., Christensen R.A., Hafs H.D., Scanes C.G., 1996. Age and breed differences in thyroid hormones, insulin-like growth factor (IGF)-I and IGF binding proteins in female horses. J. Anim. Sci., 74, 1936-1942.

Mallinson E.T., Dreas J.S., Wilson R.T., Henry A.C., 1995. Determination of dexamethasone in liver and muscle by liquid chromatography and gas chromatography/mass spectrometry. J. Agric. Fd Chem., 43, 140-145.

Malpaux B., 2001. Environnement et rythmes de reproduction. La reproduction chez les mammifères et l'homme. C. Thibault, M.C. Levasseur (Eds), INRA Ellipses, Paris, France, 699-718.

Malpaux B., Migaud M., Tricoire H., Chemineau P., 2001. Biology of mammalian photoperiodism and the critical role of the pineal gland and melatonin. J. Biol. Rhythms, 16, 336-47.

Manchee G.R., Barrow A., Kulkarni S., Palmer E. Oxford J., Colthup P.V., Maconochie J.G., Tarbit M.H., 1993. Disposition of salmeterol xinafoate in laboratory animals and humans. Drug Metab. Dispos., 21, 1022-1028.

Marchant B., Alexander W.D., 1971. Concentration of 35S-propylthiouracil by the thyroid gland and its relationship to anion trapping mechanism. Metabolism, 20, 989-998.

Margat A., Martin C., 2003. Monte 2003 bilan technique de la synchronisation des chaleurs avec du regumate. Journées techniques Nationales, 12-14 novembre 2003, Blois. Les Haras Nationaux

Martin G.B., Milton J.T.B., Davidson R.H. Banchero Hunzicker G.E., Lindsay D.R., Blache D., 2004. Natural methods for increasing reproductive efficiency in small ruminants. Anim. Reprod Sci., 82-83, 231-246.

Martin R.P., 1966. Fecal metabolites of testosterone-4- ${ }^{14} \mathrm{C}$ in the bovine male castrate. Endocrinology, 78, 907-913.

Martinat-Botté F., Bariteau F., Badouard B., Terqui M., 1985. Control of pig reproduction in a breeding programme. J. Reprod. Fertil., 33, 211-228.

Martinat-Botté F., Bariteau F., Forgerit Y., Macar C., Moreau A., Terqui M., Signoret J.P., 1989. Introduction des cochettes dans l'élevage en bandes. 2. Augmentation de la fertilité et de la prolificité après synchronisation des œstrus par un progestagène (Régumate). Journ. Rech. Porcine Fr., 21, 125-128.

Martinat-Botté F., Bariteau F., Forgerit Y., Macar C. Poirier P., Terqui M., 1995. Synchronization of œstrus in gilts with altrenogest: effects on ovulation rate and fœtal survival. Anim. Reprod. Sci., 39, 267-274.

Martinez M.F., Kastelic J.P., Adams G.P., Cook B., Olson W.O., Mapletoft R.J., 2002. The use of progestins in regimens for fixed-time artificial insemination in beef cattle. Theriogenology, 57, 1049-1059.

Matty A.J., 1986. Nutrition, hormones and growth. Fish Physiol. Biochem., 2, 141-150.

Maume D., Deceuninck Y., Pouponneau K. Paris A., Le Bizec B., André F., 2001. Assessment of estradiol and its metabolites in meat. APMIS, 109, 32-38.

Maume D., Le Bizec B. Pouponneau K., Deceuninck Y., Solere V., Paris A., Antignac J.P.,
André F., 2003. Modification of 17 beta-estradiol metabolite profile in steer edible tissues after estradiol implant administration. Anal. Chim. Acta, 483, 289-297.

McAllister R.A., 1950. A new colour reaction for methylthiouracil. Nature, 166, 789.

McAllister R.A., Howells K.W., 1952. A colour reaction for certain mercaptoimidazoles using iodobismuthous acid. J. Pharm. Pharmacol., 4, 311-313.

McDougall S. MacMillan K.L., Williamson N.B., 1994. The effect of oestradiol-17ß on the rising and plateau dominant follicle in anœstrous cows. Theriogenology, 41, 452 (Abstr.).

McLean E., Devlin R.H. 2000. Application of biotechnology to enhance growth of salmonids and other fish. Recent advances in marine biotechnology. M. Fingerman, M. Nagabhushanam (Eds), Science Publishers, 17-55.

Mellin T.N. Erb R .E., 1965. Estrogens in the bovine. A review. J. Dairy Sci., 48, 687-700.

Mellon-Nussbaum S., Ponticorvo L., Schatz F. Hochberg R.B., 1982. Estradiol fatty acid esters: the isolation and identification of the lipoidal derivative of estradiol synthesized in the bovine uterus. J. Biol. Chem., 257, 5678-5684.

Ménard D.P., Martinez-Bello J.D., Iglesias A., 2000. Is it possible to increase the number of viable embryos using progestagen ear implants 1-3 days before standard superovulation (SOV) with low response cows or low fertility cows. AETE $-16^{\text {th }}$ Scientific Meeting, Santander, Portugal, 186.

Mersmann H.J., 1987. Acute metabolic effects of adrenergic agents in swine. Am. J. Physiol., 252, E85-E95.

Mersmann H.J., 1995. Species variation in mechanisms for modulation of growth by betaadrenergic receptors. J. Nutr., 125, 1777S$1782 \mathrm{~S}$.

Mersmann H.J., 1998. Overview of the effects of beta-adrenergic receptor agonists on animal growth including mechanisms of action. J. Anim. Sci., 76, 160-172

Metzler M., 1989. Metabolism of some anabolic agents: toxicological and analytical aspects. J. Chromatogr. B, 489, 11-21.

Metzler M. Pfeiffer E., 2001. Genotoxic potential of xenobiotic growth promoters and their metabolites. APMIS, 109, 89-95.

Meyer H.H., Rinke L.M., 1991. The pharmacokinetics and residues of clenbuterol in veal calves. J. Anim. Sci., 69, 4538-4544.

Meyer H.H.D., 2001. Biochemistry and physiology of anabolic hormones used for improvement of meat production. APMIS, 109, $1-8$.

Meyer H.H.D., Rapp M., 1985. Estrogen receptor in bovine skeletal muscle. J. Anim. Sci., $60,294-300$

Meyer H.H.D., Landwehr M., Schopper D. Karg H., 1984. Application of Synovex-H in veal calves: steroid release and residues. Fd Addit. Contam., 3, 261-275.

Mialot J.P., Laumonnier G., Ponsart C. Fauxpoint H., Barassin E. Ponter A.A., Deletang F., 1999. Postpartum subestrus in dairy cows: comparison of treatment with prostaglandin F $2 \alpha$ or GnRH + prostaglandin $\mathrm{F} 2 \alpha$ or GnRH. Theriogenology, 52, 901-911.
Michot J.L., Nunez J., Johnson M.L., Irace G., Edelhoch H., 1979. Iodide binding and regulation of lactoperoxidase activity toward thyroid goitrogens. J. Biol. Chem., 254, 2205-2209.

Migdalof B.H., Dugger H.A., Heiger J.G., Coombs R.A., Terry M.K., 1983. Biotransformation of zeranol: disposition and metabolism in the female rat, rabbit, dog, monkey and man. Xenobiotica, 13, 209-221.

Mihm M., Baguisi A., Boland M.P., Roche J.F., 1994. Association between the duration of dominance of the ovulatory follicle and pregnancy rate in beef heifers. J. Reprod. Fert., 102, 123 130.

Mikolajczyk T., Roelants I., Epler P., Ollevier F., Chyb J., Breton B., 2002. Modified absorption of $\mathrm{sGnRH}$-a following rectal or oral delivery to commn carp, Cyprinus carpio L. Aquaculture, 203, 375-388.

Milan D., Yerle M., Robic A., Lahbib-Mansais Y., Riquet J., Iannuccelli N., Gellin J., 2000. Etat des lieux de la cartographie du génôme du porc. INRA Prod. Anim., hors-série «Génétique Moléculaire», 109-111.

Mills S.E., Spurlock M.E., Smith D.J., 2003 Beta-adrenergic receptor subtypes that mediate ractopamine stimulation of lipolysis. J. Anim. Sci., 81, 662-668.

Montrade M.P., André F., Le Bizec B., Siliart B. 1994. Les agonistes $\beta$-adrénergiques, du mythe à la réalité. Le Point Vétérinaire, 26, 123-135.

Montrade M.P., Maume D., Le Bizec B., Pouponneau K., Andre F., 1997. Mass spectrometric study of a specific derivatization reaction between N,N-Dimethylformamide dimethylacetal and the ethanolamine moiety of $\beta$-agonistic drugs. J. Mass Spectrom., 32, 626-644.

Mugnier C., Guennoc M., Lebègue E., Fostier A., Breton B., 2000. Induction and synchronisation of spawning in cultivated turbot (Scophthalmus maximus L.) broodstock by implantation of a sustained-release GnRH-a pellet. Aquaculture, 181, 241-255.

Mylonas C.C., Zohar Y., 2000. Use of GnRHa-delivery systems for the control of reproduction in fish. Rev. Fish Biol. Fish., 10, 463-491.

Mylonas C.C., Zohar Y., 2001. Endocrine regulation and artificial induction of oocyte maturation and spermiation in basses of the genus Morone. Aquaculture, 202, 205-220.

Mylonas C.C., Tabata Y., Langer R., Zohar Y. 1995. Preparation and evaluation of polyanhydride microspheres containing gonadotropinreleasing hormone $(\mathrm{GnRH})$, for inducing ovulation and spermiation in fish. J. Control Release, $35,23-34$.

Mylonas C.C. Woods L.C., Thomas P., Zohar Y. 1998. Endocrine profiles of female striped bass (Morone saxatilis) during post-vitellogenesis, and induction of final oocyte maturation via controlled-release GnRHa-delivery systems. Gen. Comp. Endocrinol., 110, 276-289.

NADA 009-576 Suppl., 1994. Synovex ${ }^{\circledR}-S$ (estradiol benzoate and progesterone) Reimplantation of product at day 70 ; http://www.fda.gov/cvm/FOI/497.htm, 19 August 1994.

NADA 011-427 Suppl., 1999. Synovex ${ }^{\circledR}-H$ heifer finishing implants (estradiol benzoate and testosterone propionate); re: deletion of 60-day withdraw; http://www.fda.gov/cvm/FOI/504. htm, 9 July 1999. 
NADA 140-897 Suppl., 1996. Revalor ${ }^{\circledR}$-S (trenbolone acetate and estradiol); re: Category II change; http://www.fda.gov/cvm/FOI/1383. htm, 27 March 1996.

NADA 140-992 Original, 1994. Revalor $^{\mathbb{R}}{ }_{-} \mathrm{H}$ (trenbolone acetate and estradiol); http://www.fda.gov/cvm/FOI/1326.htm. 13 December 1994.

NADA 140-992 Supplemental new animal drug application, 1999. Revalor $^{\mathbb{R}}$-200 (trenbolone acetate and estradiol) for heifers fed in confinement for slaughter; http://www.fda.gov/ cvm/FOI/1325.htm, 29 November 1999.

Navegantes L.C., Machado C.R., Resano N.M., Migliorini R.H., Kettelhut I.C., 2003. Beta2-agonists and cAMP inhibit protein degradation in isolated chick (Gallus domesticus) skeletal muscle. Br. Poult. Sci., 44, 149-154.

Neufeld E., Chayen R., Stern N., 1998. Fluorescence derivatisation of urinary corticosteroids for high-performance liquid chromatography analysis. J. Chromatogr. B, 718, 273-277.

Nibart M., 1991. La transplantation d'embryons : le modèle bovin. Bull. Soc. Vet. Prat. Fr., 75, 355-373.

Nibart M., Humblot P., 1997. Utilisation des hormones gonadotropes hypophysaires chez les bovins. Les gonadotropines, Y. Combarnous ,P. Volland-Nail (Eds), INRA, Paris, France, 377394.

Nicolino M., Forest M.G., 2001. La puberté. La reproduction chez les mammifères et l'homme. C. Thibault, M.C. Levasseur (Eds), INRA Ellipses, Paris, France, 655-679.

Nieschlag E., Behre H.M., 1998. Testosterone in male contraception. Testosterone: action, deficiency, substitution, E. Nieschlag, H.M. Behre (Eds), Springer, Heidelberg, 513-528.

Noblet J., Karege C., Dubois S., 1994. Prise en compte de la variabilité de la composition corporelle pour la prévision du besoin énergétique et de l'efficacité alimentaire chez le porc en croissance. Journ. Rech. Porcine Fr., 26, 267276.

O'Keeffe M., 1984. Measuring residues of growth promoters used in beef production. Farm Fd Res., 15, 25-27.

Oksbjerg N., Gondret F., Vestergaard M., 2004. Basic principles of muscle development and growth in meat-producing mammals as affected by the insulin-like growth factor (IGF) system. Domest. Anim. Endocrinol., 27, 219-240.

Olito C., Brock I., 1991. Sex reversal of rainbow trout: creating an all-female population. Prog. Fish Cult.., 53, 41-44.

Olofsson J., Leung P.C., 1994. Auto/paracrine role of prostaglandins in corpus luteum function. Mol. Cell. Endocrinol., 100, 87-91.

Orlando E.F., Kolok A.S., Binzcik G.A., Gates J.L., Horton M.K. Lambright C.S., Gray L.E., Soto A.M., Guillette L.J., 2004. Endocrine-disrupting effects of cattle feedlot effluent on an aquatic sentinel species, the fathead minnow. Environ. Health Perspect., 112, 353-358.

Owens F.N., Gill D.R. Secrist D.S., Coleman S.W., 1995. Review of some aspects of growth and development of feedlot cattle. J. Anim. Sci., 73, 3152-3172

Palmer E., Driancourt M.A., Ortavant R., 1982. Photoperiodic stimulation of the mare during winter anoestrus. J. Reprod. Fertil. (Suppl.), $32,275-282$.
Pandey A.C., Singh R.N., 1997. Ovaprim for mass breeding of Indian major carps. Ind. J. Anim. Sci., 67, 1133-1134.

Pandian T.J., Sheela S.G., 1995. Hormonal induction of sex reversal in fish. Aquaculture, $13,115-134$

Paris A., 1987. Etude du métabolisme de l'œstradiol chez le veau. Thèse Docteur-Ingénieur INA-PG, Paris, France, 103p.

Paris A., Rao D. 1989. Biosynthesis of estradiol-17 $\beta$ fatty acyl esters by microsomes derived from bovine liver and adrenals. J. steroid. Biochem., 33, 465-472.

Paris A., Dolo L., Rao D., Terqui M. 1993. Residual estrogens in edible tissues of ${ }^{3} \mathrm{H}$-estradiol-17ß treated veal calves. EuroResidue II, Veldhoven, The Netherlands, 3-5 May 1993.

Paris A., Dolo L., Debrauwer L., Rao D., Terqui M. 1994. Analysis of $\left[{ }^{3} \mathrm{H}\right]$ estradiol-17 $\beta$ metabolites in calf perirenal fat. Analyst, 119 , 2623-2626.

Paris A. et al, 2000. GLP Study $\mathrm{n}^{\circ}$ XL/98/EUROESTR. Metabolic pathways of estrogens used as steroidal growth promoting agents. DG Sanco. Final report. 20/06/2000.

Paris A., Goutal I., Richard J., Bécret A., Guéraud F., 2001. Uterotrophic effect of a saturated fatty acid 17-ester of estradiol-17ß administered orally to juvenile rats. APMIS, 109, 365-375.

Paris F., Servant N., Térouanne B. Balaguer P. Nicolas J.C., Sultan C., 2002. A new recombinant cell bioassay for ultrasensitive determination of serum estrogenic bioactivity in children. J. Clin. Endocrinol. Metab., 87, 791-797.

Passingham B.J., Barton R.N., 1987. Application of high-performance liquid chromatography to the measurement of cortisol secretion rate. J. Chromatogr., 416, 25-35.

Pedersen T.K.H., Hansen A.M., Lund S.P., Garde A.H., 2000. Validation of a radioimmunoassay for the determination of total corticosterone in rat plasma. Anal. Chim. Acta, 413, 63-69.

Perez-Comas A., 1988. Premature sexual development in Puerto Rico. Boletin Associacion Medica de Puerto Rico, 80, 85-90.

Peter R.E., 1997. Neuroendocrine regulation of ovulation in fishes: basic and applied aspects. Rev. Fish. Biol., 7, 173-197.

Peter R.E., Lin H.R., van der Kraak G., 1988. Induced ovulation and spawning of cultured freshwater fish in China: advances in application of $\mathrm{GnRH}$ analogues and dopamine antagonists. Aquaculture, 74, 1-10.

Peterson B.C. Small B.C., Bosworth B.G., 2004. Effects of bovine growth hormone (PosilacR) on growth performance, body composition, and IGFBPs in two strains of channel catfish. Aquaculture, 232, 651-663.

Pfaffl M., Lange I., Daxenberger A., Meyer H.H.D., 2001. Influence of an estrogen treatment on the tissue specific expression pattern of estrogen receptor (ERs): quantification of $\mathrm{ER} \alpha$ and ER $\beta$ mRNA with real-time RT-PCR. APMIS, $109,345-355$.

Phipps R.H., 1988. The use of prolonged release bovine somatotropin in milk production. Int. Dairy Fed. Bull., 228.

Picard B., Jurie C., Cassar-Malek I., Hocquette J.F., Lefaucheur L., Berri C., Duclos M.J., Alami-Durante H., Rescan P.Y., 2003. Typologie et ontogenèse des fibres musculaires chez différentes espèces d'intérêt agronomique. INRA Prod. Anim., 16, 117-123.

Pickford G.E., Atz J.W., 1957. The physiology of the pituitary gland of fishes. Zoological Society, New York (Eds).

Piferrer F., 2001. Endocrine sex control strategies for the feminization of teleost fish. Aquaculture, 197, 229-281.

Pincus G., 1954. Cité dans R.I. Dorfman, F. Ungar (Eds), 1965, Academic Press, New York.

Pinel G., André F., Le Bizec B., 2004a Discrimination of recombinant and pituitaryderived bovine and porcine growth hormones by peptide mass-mapping. J. Agric. Fd Chem., 52 , 407-414.

Pinel G., Buon R., Aviat F., Larre C., AndréFontaine G., André F., Le Bizec B., 2004b. Recombinant bovine somatotropin misuse in cattle. Evaluation of Western blotting and 2D-electrophoresis methods on biological samples for the demonstration of its administration. Anal. Chim. Acta, 529, 41-46.

Plascencia A., Torrentera N., Zinn R.A., 1999. Influence of the $\beta$-agonist, zilpaterol on growth performance and carcass characteristics of feed lot steers. Proc. West. Sec. Am. So.c Anim. Sci., 50, 331-334.

Pochard M.F., 1988. Plan de contrôle anabolisants - thyréostatiques. Document DGAL/ SVHA/N88/N8057.

Pompa G., Montessissa C., Di Lauro F.M., Fadini L., Capua C., 1988. Zeranol metabolism by subcellular fractions from lamb liver. J. Vet. Pharmacol. Therap., 11, 197-203.

Ponsart C., Guérin B., Humblot P., 2002. Optimiser la production et le transfert d'embryons bovins : choix et préparation des donneuses et des receveuses. Elev. Ins., 308, 3-26.

Ponsart C., Marquant-Le Guienne B., Humblot P., 2004. Les biotechnologies de 1'embryon bovin, évolution et perspectives. 11 èmes Renc.Rech.Rum., Paris, France, 8-9 décembre 2004, 361-368.

Popot M.A., Bobin S., Bonnaire Y, Tocquet M., Fortier G., Monget P.H. Delahaut P.H., Closset J., 2000. Detection of equine recombinant growth hormone administration in the horse. Proc. $13^{\text {th }}$ Int. Conf. Racing Analysts and Veterinarians, Cambridge, UK, 98-104.

Popot M.A., Bobin S., Bonnaire Y., Delahaut P., Closset J., 2001. IGF-I plasma concentrations in non treated horses and horses administered with methionyl equine somatotropin. Res. Vet. Sci., 71, 167-173.

Popot M.A., Bobin S., Bonnaire Y., Pirens G., Delahaut P., Lyazrhi F., Tabet J.C., 2002. IGF-I concentrations measured by ELISA, IRMA and HPLC/ESI-MS. Determination of a threshold value in horse plasma. Proc.. 15 th Int. Conf. Racing Analysts and Veterinarians, Orlando, USA, 76-83.

Pottier J., Cousty C., Heitzman R.J., Reynolds I.P., 1981. Differences in the biotransformation of a 17 $\beta$-hydroxylated steroid, trenbolone acetate, in rat and cow. Xenobiotica, 11, 489500.

Prezelj A., Obreza A., Pecar S., 2003. Abuse of clenbuterol and its detection. Curr. Med. Chem., 10, 281-290.

Purdom C.E., Hardiman P.A., Bye V.J., Eno N.C., Tyler C.R., Sumpter J.P., 1994. Estrogenic effects of effluents from sewage treatment works. Chem. Eco.1, 8, 275-285. 
Purdy R.H., Durocher C.K., Moore P.H., Rao P.N., 1980. Analysis of metabolites of progesterone in bovine liver, kidney fat, and milk by high performance liquid chromatography. J. Steroid Biochem., 13, 1307-1315.

Raby C., Lagorce J.F., Jambut-Absil A.C., Buxeraud J., Cantanzano G., 1990. The mechanism of action of synthetic anti-thyroid drugs: iodine complexation during oxidation of iodide. Endocrinology, 126, 1683-1691.

Radcliff R.P., McCormack B.L., Crooker B.A., Lucy M.C., 2003. Plasma hormones and expression of growth hormone receptor and insulin-like growth factor-I mRNA in hepatic tissue of periparturient dairy cows. J. Dairy Sci., 86, 3920-3926.

Rao P.N., Purdy R.H., Williams M.C., Moore PH., Goldzieher J.W. , Layne D.L., 1979. Metabolites of estradiol-17 $\beta$ in bovine liver: identification of the 17- $\beta$-D-glucopyranoside of estradiol-17 $\alpha$. J. Steroid Biochem., 10, 179-185.

Re G., Badino P., Dacasto M., Nebbia C., Biolatti B. Di Carlo F., Girardi C., 1993. Effects of long-term administration of clenbuterol in mature female rats. Am. J. Vet. Res., 54, 438-442.

Reeds P.G., Burrin D.G., Davis T.A., Fiorotto M.A., Mersmann H.J., Pond W.G., 1993. Growth regulation with reference to the pig. Growth of the Pig, G.R. Hollis (Ed), 1-32.

Rehfeldt C., Fiedler I., Weikard R., Kanitz E., Ender K., 1993. It is possible to increase skeletal muscle fibre number in utero. Biosci. Rep., 13, 213-220.

Reiling B.A., Berger L.L., Faulkner D.B., McKeith F.K., Nash T.G., 1995. Effect of prenatal androgenization on performance, lactation, carcass, and sensory traits of heifers in a singlecalf heifer system. J. Anim. Sci., 73, 986-992.

Remy B, Baril G. Vallet J.C., Dufour R, Chouvet C., Saumande J., Chupin D., Beckers J.F., 1991. Are antibodies responsible for a decreased superovulatory response in goats which have been treated repeatedly with porcine follicle-stimulating hormone? Theriogenology, 36, 389-399.

Renand G., Larzul C., Le Bihan-Duval E., Le Roy P., 2003. L'amélioration génétique de la qualité de la viande dans les différentes espèces : situation actuelle et perspectives à court et moyen terme. INRA Prod. Anim., 16, 159-173.

Restall B.J., Brown G.H., Blockey M.A., Cahill L., Kearins R., 1976. Assessment of reproductive wastage in sheep. 1. Fertilisation failure and early embryo survival. Aust. J. Exp. Agric. Anim. Husb., 16, 329-335.

Rhind S.M., 2002. Endocrine disrupting compounds and farm animals: their properties, actions and routes of exposure. Domest. Anim. Endocrinol., 23, 179-187.

Rhoads R.P., Kim J.W., Leury B.J., Baumgard L.H., Segoale N., Frank S.J., Bauman D.E., Boisclair YR., 2004. Insulin increases the abundance of the growth hormone receptor in liver and adipose tissue of periparturient dairy cows. J. Nutr., 134, 1020-1027.

Rhodes F.M., Clark B.A., McDougall S. Macmillan K.L., 1999. Insemination at the second of two induced oestrous periods in anœstrous dairy cows increases conception rates to first service. N. Z. Vet. J., 47, 39-43.

Richold M., 1988. The genotoxicity of trenbolone, a synthetic steroid. Arch. Toxicol., 61, 249-258.
Ricks C.A., Dalrymple R.H., Baker P.K., Ingle D.L., 1984. Use of a $\beta$-agonist to alter fat and muscle deposition in steers. J. Anim. Sci., 59, 1247-1255.

Rizea Savu S., Silvestro L., Haag A., Sörgel F., 1996. A confirmatory HPLC-MS/MS method for ten synthetic corticosteroids in bovine urines. J. Mass Spectrom., 31, 1351-1363.

Rizzati V., Rathahao E., Gamet-Payrastre L., Delous G., Guéraud F., Paris A., 2005. In vitro aromatic bioactivation of the weak estrogen $\mathrm{E}_{2} \alpha$ and genesis of DNA adducts. Steroids, 70, 161172 .

Roberts N.L., Cameron D.M., 1986. Steroid levels in tissues of veal calves following implantation with Implix BM/BF and/or Revalor lactose. Unpublished report $\mathrm{N}^{\circ} \mathrm{RSL} / 686$ from Huntingdon Research Center, Huntingdon, Cambridgeshire, England. Soumis à la FAO par Roussel-UCLAF, Romainville, France. Cité dans la Monographie «Residues of some Veterinary Drugs in Animals and Foods, FAO/OMS, Rome, 15-23 juin 1987».

Roche J.F., 1977. Research report, 36-37 (Abstr.).

Rochut N., Le Bizec B., Monteau F., André F. 2000. ESI-MS for the measurement of bovine and porcine somatotropins. Analusis, 8, 280-284.

Rodchenkov G.M., Uralets V.P., Semenov V.A., Leclercq PA., 1988. Analysis of dexamethasone, triamcinolone, and their metabolite in human urine by microcolumn liquid and capillary gas chromatography mass spectrometry. J. High Resolution Chromatogr. Chromatogr. Comm., 11, 283-288.

Roelants I., Mikolajczyk T., Epler P., Ollevier F., Chyb J., Breton B., 2000. Induction of spermiation in common carp after enhanced intestinal uptake of sGnRH-A and pimozide. J. Fish Biol., 56, 1398-1407.

Rogan E.G., Cavalieri E.L., 2004. Estrogen metabolites, conjugates, and DNA adducts possible biomarkers for risk of breast, prostate, and other human cancers. Adv. Clin. Chem., 38, 135-149.

Roh S.G., Matsugana N., Miyamoto A., Hidaka S., Hidari H., 1997. Competitive enzyme immunoassay for bovine somatotropin in blood and milk. Endocrin. J., 44, 195-198.

Roy F., Combes B., Vaiman D., Cribiu E.P., Pobel T., Deletang F., Combarnous Y., Guillou F., Maurel M.C., 1999a. Humoral immune response to Equine Chorionic Gonadotropin in ewes: Association with Major histocompatibility complex and interference with subsequent fertility. Biol. Reprod., 61, 209-218.

Roy F., Maurel M.C., Combes B., Vaiman D., Cribiu E.P., Lantier I., Pobel T., Deletang F., Combarnous Y., Guillou F., 1999b. The negative effect of repeated Equine Chorionic Gonadotropin Treatment on subsequent fertility in alpine goats is due to a humoral immune response implying the major histocompatibility complex. Biol. Reprod., 60, 805-813.

Royal M.D., Darwash A.O., Flint A.P.F et al, 2000. Declining fertility in dairy cattle: changes in traditional and endocrine parameters of fertility. Anim. Sci., 70, 487-501.

Ryan D.P., 1995. Effect of estradiol subsequent to induced luteolysis on development of the ovulatory follicle and interval to estrus and ovulation. Theriogenology, 43, 310 (Abstr.).

Ryan D.P., Galvin J.A., O’Farrell K.J., 1999. Comparison of oestrous synchronization regi- mens for lactating dairy cows. Anim. Reprod. Sci., 56, 153-168.

Ryan J.J., Hoffmann B., 1978. Trenbolone acetate: experience with bound residues in cattle tissues. J. Assoc. Off. Anal. Chem., 61, 12741279 .

Saillant E., Fostier A., Menu B. Haffray P. Chatain B., 2001. Sexual growth dimorphism in sea bass Dicentrarchus labrax. Aquaculture, 202, 371-387.

Saillant E., Fostier A., Haffray P., Menu B., Thimonier J., Chatain B., 2002. Temperature effects and genotype-temperature interactions on sex determination in the european sea bass (Dicentrarchus labrax). J. Exp. Zool., 292, 494505 .

Salmon W.D., Daughaday W.H., 1957. A hormonally controlled serum factor which stimulates sulfate incorporation by cartilage in vitro. $\mathrm{J}$. Lab. Clin. Med., 49, 825-836.

Sangiorgi E., Curatolo M., Assini W., Bozzoni E., 2003. Application of neutral loss mode in liquid chromatography-mass spectrometry for the determination of corticosteroids in bovine urine. Anal. Chim. Acta, 483, 259-267.

Santos J.E.P., Juchem S.O., Cerri R.L.A., Galvao K.N., Chebel R.C., Thatcher W.W., Dei C.S., Bilby C.R., 2004. Effect of bST and reproductive management on reproductive performance of Holstein dairy cows. J. Dairy Sci., 87, 868-881.

Sauerwein H., Meyer H.H.D., 1989. Androgen and estrogen in bovine skeletal muscle. J. Anim. Sci., 67, 206-212.

Schams D., Berisha B., 2004. Regulation of corpus luteum function in cattle - an overview. Reprod. Dom. Anim., 39, 241-251.

Schams D., Winkler U., Scallenberger E., Karg H., 1988. Growth hormone and insulin-like growth factor-I (somatomedin C) blood levels in cattle from birth through sex maturation. Dtsch. Tierarztl. Wochenschr., 95, 360-362.

Schiavetta A.M., Miller M.F., Lunt D.K., Davis S.K., Smith S.B., 1990. Adipose tissue cellularity and muscle growth in young steers fed the beta-adrenergic agonist clenbuterol for 50 days and after 78 days of withdrawal. J Anim Sci, 68, 3614-3623.

Schibler L., Roig A., Mahe M.F., Save J.C., Gautier M., Taourit S. Boichard D., Eggen A., Cribiu E.P., 2004. A first generation bovine BAC-based physical map. Genet. Sel. Evol., 36, 105-122.

Schiffer B., Daxenberger A., Meyer K., Meyer H.H.D., 2001. The fate of trenbolone acetate and melengestrol acetate after application as growth promoters in cattle: environmental studies. Environ. Health Perspect., 109, 11451151 .

Schmidely P., 1993. Revue bibliographique quantitative sur l'utilisation des hormones anabolisantes à action stéroïdienne chez les ruminants en production de viande. I. Performances zootechniques. Ann. Zoot., 42, 433-359.

Schmitt E.J.P., Diaz T., Drost M., Thatcher W.W., 1996. Use of gonadotropin-releasing hormone agonist or human chorionic gonadotropin for timed insemination in cattle. J. Anim. Sci. 74, 1084-1091.

Scippo M.L., Degand G., Duyckaerts A. Michel A., Joris B., Delahaut P., Decuypere E., Maghuin-Rogister G., 1996. Antipeptide antibody against bovine IGFBP2: application to the 
detection of bovine somatotropin treated cows. Fd Agric. Immun., 8, 31-40.

Scippo M.L., Degand G., Duyckaerts A., Maghuin-Rogister G., 1997. Identification des vaches laitières traitées à la somatotropine bovine. Ann. Méd. Vét., 141, 381-390.

Scippo M.L., Gaspar P., Degand G., Brose F., Maghuin-Rogister G., Delahaut P., Willemart J.P., 1993. Control of the illegal administration of natural steroid hormones in urine and tissues of veal calves and in plasma of bulls. Anal. Chim. Acta, 275, 57-74.

SCVPH, 2002. Opinion of the scientific committee on veterinary measures relating to public health on review of previous SCVPH opinions of 30 April 1999 and 3 May 2000 on the potential risks to human health from hormone residues in bovine meat and meat products. http://europa.eu.int/comm/food/fs/sc/scv/outcome en.html, 10 April 2002.

Secchi C., Biodi P.A., Berrini A,, Simonic T, Ronchi S., 1988. A biotin avidin sandwich enzyme-linked immunosorbent assay of growth hormone in bovine plasma. J. Immun. Meth., $110,123-128$.

Secchi C., Berrini A., Gaggioli D., Borromeo V., 2001. Amino acid modifications in canine, equine and porcine pituitary growth hormones, identified by peptide mass-mapping. J. Chromatogr. B, 757, 237-245.

Seguin B., 1997. OVSYNCH: A method for breeding dairy cows without doing heat detection. The bovine Practitionner, 31, 11-14.

Setchell B., 1997. Sperm counts in semen of farm animals 1932-1995. Int. J. Androl., 20, 209214.

Shearan P., O'Keeffe M., Smyth M.R., 1991. Reversed-phase high-performance liquid chromatographic determination of dexamethasone in bovine tissues. Analyst, 116, 1365-1368.

Sheehan D.M., 2006. No-threshold doseresponse curves for nongenotoxic chemicals: findings and applications for risk assessment. Env. Res., 100, 93-99.

Shelver W.L., Smith D.J., 2004. Enzymelinked immunosorbent assay development for the beta-adrenergic agonist zilpaterol. J. Agric. Fd Chem., 52, 2159-2166.

Shibasaki H., Furuta T., Kasuya Y., 1997. Quantification of corticosteroids in human plasma by liquid chromatography-thermospray mass spectrometry using stable isotope dilution. J. Chromatogr. B, 692, 7-14.

Shiroozu A., Taurog A., Engler H., Dorris M.L., 1983. Mechanism of action of thioureylene antithyroid drugs in the rat : possible inactivation of thyroide peroxidase by propylthiouracile. Endocrinology, 113, 362-370.

Sigler D.H., Ericson D.E., Gibbs P.G., Kiracofe G.H., Stevenson J.S., 1989. Reproductive traits, lactation and foal growth in mares fed altrenogest. J. Anim. Sci., 67, 1154-1159.

Sillence M.N., 2004. Technologies for the control of fat and lean deposition in livestock. Vet. J., 167, 242-257.

Sire M.F., Vernier J.M., 1992. Intestinal absorption of protein in teleost fish. Comp. Biochem. Physiol., 103A, 771-781.

Sitar D.S., Hunninghake D.B., 1975. Pharmacokinetics of propylthiouracile in man after a single oral dose. J. Clin. Endocrinol. Metabolism, 40, 26-29.
Sitar D.S., Thornhill D.P., 1973. Methimazole: adsorption, metabolism and excretion in the albino rat. J. Pharmacol. Exp. Ther., 184, 432-439.

Skellern G.G., Stenlake J.B., Williams W.D., 1973. The absorption, distribution, excretion and metabolism of $\left[2-{ }^{14} \mathrm{C}\right]$ methimazole in rat. Xenobiotica, 3, 121-132.

Skrabalak D.S., Maylin G.A., 1982 Dexamethasone metabolism in the horse. Steroids, 39, 233-244.

Slama K., Lafont R., 1995. Insect hormones ecdysteroids: their presence and actions in vertebrates. Eur. J. Entomol., 92, 355-377.

Smith D.J., 1998. The pharmacokinetics, metabolism, and tissue residues of beta-adrenergic agonists in livestock. J. Anim. Sci., 76, 173-194.

Smith D.J., Shelver W.L., 2002. Tissue residues of ractopamine and urinary excretion of ractopamine and metabolites in animals treated for 7 days with dietary ractopamine. J. Anim. Sci., 80, 1240-1249.

Smith J.F., Tervit H.R., Good P.G., 1980 Synchronization of oestrus and ovulation in beef cows with progesterone releasing intravaginal devices (PRIDs): effect of duration of treatment and of temporary calf removal. Proc. Austr. Soc. Anim. Prod., 13, 309-312.

Smith S.B., Garcia D.K., Anderson D.B., 1989. Elevation of a specific mRNA in longissimus muscle of steers fed ractopamine. J. Anim. Sci., 67, 3495-3502.

Soto A.M., Clalabro J.M., Prechtl N.V., Yau A.Y., Orlando E.F., Daxenberger A., Kolok A.S., Guilette L.J., Le Bizec B., Lange I.G. Sonnenchein C., 2004. Androgenic and estrogenic activity in water bodies receiving cattle feedlot effluent in eastern Nebraska, USA. Environ. Health Perspect., 112, 346-352.

Source ANIO, 2003.

Source Eurostat, 2002.

SOURCE IETS (International Embryo Transfer Society), 2004. http://www.iets.org/ pdf/data retrieval/december2004.pdf.

Sprott L.R., Wiltbank J.N., Songster W.N., Webel S., 1984. Estrus and ovulation in beef cows following use of progesterone-releasing devices, progesterone and estradiol valerate. Theriogenology, 21, 349-356.

Squires E.J., 2003. Endocrine manipulation of reproduction. Applied Animal Endocrinology. CABI Publishing Ed., 154-191.

Stachel C.S., Radeck W., Gowik P., 2003. Zilpaterol-a new focus of concern in residue analysis. Anal. Chim. Acta, 493, 63-67.

Stanley S.M.R., Wilhelmi B.S., Rodgers J.P., 1993. Comparison of immunoaffinity chromatography combined with gas chromatography-negative ion chemical ionization mass spectrometry and radioimmunoassay for screening dexamethasone in equine urine. J. Chromatogr., $620,250-253$.

Stevenson J.S., 2002. Use of GnRH to synchronize estrus and/or ovulation in beef cows with or without timed insemination. Factors affecting calf crop-biotechnology of reproduction. M.J. Fields, R.S. Sand, J.V. Yelich (Eds), CRC Press, Boca Raton, 43-56.

Stoller G.M., Zerby H.N., Moeller S.J., Baas T.J., Johnson C., Watkins L.E., 2003. The effect of feeding ractopamine (Paylean) on muscle quality and sensory characteristics in three diverse genetic lines of swine. J. Anim. Sci., 81, 1508-1516.

Stouffer R.L., 2003. Progesterone as a mediator of gonadotrophin action in the corpus luteum: beyond steroidogenesis. Hum. Reprod. Update, 9, 99-117.

Syrov V.N., 1984. Mechanism of the anabolic action of phytoecdysteroids in mammals. Nauchnye Doki Vyss. Shkoly Biol. Nauki, 11, $16-20$

Syrov V.N., Saatov V., Sagdullaev S.S. et al, 2001. Study of the structure-anabolic activity relationship for the phytoecdysteroids extracted from some plants of central Asia. Pharmaceut. Chem. J., 35, 667-671.

Szabo T., 2003. Ovulation induction in northern pike Esox lucius L., using different GnRH analogues, Ovaprim, Dagin and carp pituitary. Aquaculture Res., 34, 479-486.

Szego C.M., Samuels L.T., 1943. The metabolism of estrone in surviving rabbit, bovine, and human endometrium. J. Biol. Chem., 151, 599.

Taurog A., 1976. The mechanism of action of the thioureylene antithyroid drugs. Endocrinology, 98, 1031-1046.

Taurog A., Dorris M.L., 1989. A re-examination of the proposed inactivation of thyroid peroxidase in the rat thyroid by propylthiouracil. Endocrinology, 124, 3038-3042.

Thimonier J., Cognié Y., Lassoued N., Khaldi G., 2000. L'effet mâle chez les ovins : une technique actuelle de maîtrise de la reproduction. INRA Prod. Anim., 13, 223-231.

Thomas J.W., Erdman R.A., Galton D.M Lamb R.C., Arambel M.J., Olson J.D., Madsen K.S., Samuels W.A., Peel C.J., Green G.A., 1991. Responses by lactating cows in commercial dairy herds to recombinant bovine somatotropin. J. Dairy Sci., 74, 945-964.

Tomlinson E.S., Maggs J.L., Park B.K., Back D.J., 1997. Dexamethasone metabolism in vitro species differences. J. Steroid Biochem. Mol. Biol., 62, 345-352.

Toppari J., Larsen J.C., Christiansen P., Giwercman A., Grandjean P., Guillette L.J., Jegou B., Jensen T.K., Jouannet P., Keiding N., Leffers H., McLachlan J.A., Meyer O., Muller J., Meyts E.R., Scheike T., Sharpe R. Sumpter J., Skakkebaek N.E., 1996. Male reproductive health and environmental xenoestrogens. Environ. Health Perspect., 104 (Suppl. 4), 741-803.

Tricoire H., Moller M., Chemineau P. Malpaux B., 2003. Origin of cerebrospinal fluid melatonin and possible function in the integration of photoperiod. Reproduction, Suppl. 61, 311-321.

Troispoux C., Guillou F., Elalouf J.M., Firsov D., Iacovelli L., de Blasi A., Combarnous Y., Reiter E., 1999. Involvement of G Protein-coupled receptor kinases and arrestins in desensitization to follicle-stimulating hormone action. Mol. Endocrinol., 13, 1599-1614.

Turan V.K., Sanchez R.I., Li J.J., Li S.A., Reuhl K.R., Thomas P.E., Conney A.H., Gallo M.A., Kauffman F.C., Mesia-Vela S., 2004. The effects of steroidal estrogens in ACI rat mammary carcinogenesis : 17 $\beta$-estradiol, 2-hydroxyestradiol, 4-hydroxyestradiol, 16 $\alpha$-hydroxyestradiol, and 4-hydroxyestrone. J. Endocrinol., 183, 91-99.

Van de Leemput E.E., Vos P.L.A.M., Zeinstra E.C., Bevers M.M., Vanderweijden G.C., Dieleman S.J., 1999. Improved in vitro embryo development using in vivo matured oocytes from 
heifers superovulated with a controlled preovulatory LH surge. Theriogenology, 52, 335-349.

Van den Hauwe O., Scheider M., Sahin A., Van Peteghem C.H., Naegeli H., 2003. Immunochemical screening and liquid chromatographic-tandem mass spectrometric confirmation of drug residues in edible tissues of calves injected with a therapeutic dose of the synthetic glucocorticoids dexamethasone and flumethasone. J. Agric. Fd Chem., 51, 326-330.

Vanoosthuyze K.E., Van Poucke L.S.G., Deloof A.C.A., Van Peteghem C.H., 1993. Development of a high-performance thin-layer chromatographic method for the multi-screening analysis of corticosteroids. Anal. Chim. Acta, $275,177-182$.

Veerkamp R.F., Beerda B., Van der Lende T., 2003. Effects of genetic selection for milk yield on energy balance, levels of hormones, and metabolites in lactating cattle, and possible links to reduced fertility. Livest. Prod. Sci., 83, 257-275.

Velle W., Erichsen S., 1960. Studies on estrogens in cattle. Conversion of estrogens by bovine kidney cells in vitro. Acta Endocrinol., 33, 277286.

Vos P.L., van der Schans A., de Wit A.A.C., Bevers M.M., Willemse A.H., Dieleman S.J., 1994. Effects of neutralization of pregant mares serum gonadotrophin (PMSG) shortly before or at the preovulatory LH surge in PMSG-superovulated heifers on follicular function and development. J. Reprod. Fertil., 100, 387-393.

Vree T.B., Lagerwerf A.J., Verwey-Van Wissen C.P.W.GM., Jongen P.J.H., 1999. Highperformance liquid chromatography analysis, preliminary pharmacokinetics, metabolism and renal excretion of methylprednisolone with its C6 and C20 hydroxy metabolites in multiple sclerosis patients receiving high-dose pulse therapy. J. Chromatogr. B, 732, 337-348.

Walker S.K., Smith D.H., Frensham A., Ashman R.J., Seamark R.F., 1989. The use of synthetic gonadotropin releasing hormone treatment in the collection of sheep embryos. Theriogenology, 31, 741-752.

Watkins L.E., Jones D.J., Mowrey D.H., Anderson D.B., Veenhuizen E.L., 1990. The effect of various levels of ractopamine hydrochloride on the performance and carcass characteristics of finishing swine. J. Anim. Sci., 68, 3588-3595.

Wiwi C.A., Waxman D.J., 2004. Role of hepatocyte nuclear factors in growth hormone-regulated, sexually dimorphic expression of liver cytochromes P450. Growth Factors, 22, 79-88.
Weil C., Crim L.W. 1983. Administration of LHRH analogues in various ways: Effect on the advancement of spermiation in prespawning landlocked salmon, Salmo salar. Aquaculture, $35,103-115$.

Weil C., Fostier A., Billard R. 1986. Induced spawning (ovulation and spermiation) in carp and related species. Aquaculture of cyprinids. R. Billard, J. Marcel (Eds), INRA, Paris, France, 119-137.

Weil C., Breton B., Sambroni E., Zmora N., Zohar Y. 1992. In vitro bioactivities of various forms of $\mathrm{GnRh}$ in relation to their susceptibility to degradation at the pituitary level in rainbow trout. Gen. Comp. Endocrinol., 87, 33-43.

Whittemore C.T., Tullis J.B., Emmans G.C. 1988. Protein growth in pigs. Anim. Prod., 46, 437-445.

Wiest W.G., 1968. On the function of 20 alpha-hydroxypregn-4-en-3-one during parturition in the rat. Endocrinology, 83, 1181-1184.

Wiest W.G., Kidwell W.R., Balogh K., 1968. Progesterone catabolism in the rat ovary: a regulatory mechanism for progestational potency during pregnancy. Endocrinology, 82, 844-859.

Wildanger W., 1975. Separation of caffeine, theophylline and theobromine with assistance from high pressure liquid chromatography. J. Chromatogr., 114, 480-482.

Willeberg P., 1993. Bovine somatotropin and clinical mastitis: epidemiological assessment of the welfare risk. Livest. Prod. Sci., 36, 55-66.

Wiltbank J.N., Sturges J.C., Wideman D. LeFever D.G., Faulkner L.D., 1971. Control of estrus and ovulation using subcutaneous implants and estrogens in beef cattle. J. Anim. Sci., 33, 600-606.

Wray-Cahen C.D., Kerr D.E., Evock-Clover C.M., Steele N.C., 1998. Redefining body composition: nutrients, hormones, and genes in meat production. Ann. Rev. Nutr., 18, 63-92.

Wright K., Luborsky-Moore J.L., Behrman H.R., 1979. Specific binding of prostaglandin F2 alpha to membranes of rat corpora lutea. Mol. Cell. Endocrinol., 13, 25-34.

Yamamoto T., 1969. Sex differentiation. Fish Physiology, W.S. Hoar, D.J. Randall (Eds), Academic Press, New York, USA, 3, 117-158.

Yap B.K., Johnston G.A.R., Kazlauskas R., 1992. Routine screening and quantitation of urinary corticosteroids using bench-top gas chromatography-mass selective detection. J. Chromatogr., 573, 183-190.
Yu G.Y.F, Murby E.J., Wells R.J., 1997. Gas chromatographic determination of residues of thyreostaic drugs in bovine muscle tissue using combined resin mediated methylation and extraction. J. Chromatogr. B, 703, 159-166.

Yue W., Wang J.P., Li Y., Bocchinfuso W.P., Korach K.S., Devanesan P.D., Rogan E., Cavalieri E., Santen R.J., 2005. Tamoxifen versus aromatase inhibitors for breast cancer prevention. Clin. Cancer Res., 11, 925S-930S.

Zalko D., Debrauwer L., Bories G. Tulliez J., 1997. Evidence for a new and major metabolic pathway of clenbuterol involving in vivo formation of an N-hydroxyarylamine. Chem. Res. Toxicol., 10, 197-204.

Zalko D., Bories G., Tulliez J., 1998a. Metabolic fate of clenbuterol in calves. J. Agric. Fd Chem., 46, 1935-1943.

Zalko D. Debrauwer L., Bories G. Tulliez J., 1998b. Metabolism of clenbuterol in rats. Drug Metab. Dispos., 26, 891-899.

Zhao X., Groenewegen P.P., Bride B.W., Burton J.H., Elsaser T.H., 1991. Radioimmunoassay for insulin-like growth factor-I in bovine milk. Can. J. Anim. Sci., 71, 669-674.

Zhao X., McBride B.W., Trouten-Radford L.M., Golfman L., Burton J.H., 1994. Somatotropin and insulin-like growth factor-I concentrations in plasma and milk after daily or sustained released exogenous somatotropin administrations. Domest. Anim. Endocrinol., 11, 209-216.

Zimbelman R.G., Smith L.W., 1966a. Control of ovulation in cattle with melengestrol acetate. I. Effects of dosage and route of administration. J. Reprod. Fertil., 11, 185-191.

Zimbelman R.G., Smith L.W., 1966b. Control of ovulation in cattle with melengestrol acetate. II. Effects on follicular size and activity. J. Reprod. Fertil., 11, 193-201.

Zohar Y., Mylonas C.C., 2001. Endocrine manipulations of spawning in cultured fish: from hormones to genes. Aquaculture, 197, 99-136.

Zohar Y., Goren A., Fridkin M., Elhanati E., Koch Y., 1990. Degradation of gonadotropin releasing hormone in the gilthead seabream, Sparus aurata. II. Cleavage of native salmon GnRH and LHRH, and their analogs in the pituitary, kidney, and liver. Gen. Comp. Endocrinol., 79, 306-319.

Zwickl C.M., Smith H.W., Bick P.H., 1990. Rapid and sensitive ELISA method for the determination of bovine somatotropin in blood and milk. J. Agric. Fd Chem., 38, 1358-1362.

\section{Résumé}

Au cours des cinquante dernières années, des progrès considérables dans les performances d'élevage des espèces domestiques ont été obtenus grâce à une meilleure connaissance acquise dans le domaine de la physiologie, en particulier en ce qui concerne la nutrition, la croissance, la reproduction et la lactation, et qui s'est conjuguée aux progrès génétiques accomplis dans les différentes espèces animales dans un contexte de meilleure maîtrise sanitaire des troupeaux et de maîtrise plus fine des systèmes d'élevage en place. Le recours aux substances hormonales pour mieux maîtriser les fonctions de reproduction et de croissance a pris une place déterminante dans ce progrès. Néanmoins, une tendance profonde consistant à restreindre leur utilisation à certains moments critiques de la vie de l'animal est apparue en Europe ces quinze dernières années, obligeant à rechercher des alternatives par le biais d'une meilleure maîtrise alimentaire, génétique et des systèmes d'élevage, ceci afin de garantir aux consommateurs une meilleure qualité définie a priori des produits animaux. Les fonctions physiologiques qui offrent des possibilités d'un contrôle hormonal exogène, les substances hormonales utilisables et les spéculations animales concernées sont présentées tour à tour. Un éclaircissement sur les risques toxicologiques que présentent ces substances, le contrôle et la traçabilité de leur utilisation et les réglementations en vigueur sont ensuite rappelés. Enfin, sont évoquées les recherches qui permettront de faire progresser sensiblement la question de l'utilisation des hormones en élevage dans un contexte sociétal renouvelé. 


\begin{abstract}
Hormones and growth promoters in animal breeding: from physiological end-points to risk assessment considerations

During the last fifty years, considerable progress in breeding performances of domestic species has been obtained due to a better knowledge obtained in physiology and in particular nutrition, growth, reproduction and lactation. This progress has been united with that of genetic progress accomplished in the different animal species in a context of an improved control of sanitary conditions of herds and a more accurate control of the existing breeding systems. The use of hormonal substances to better control reproduction functions and growth has become decisive within this progress. However, a profound tendency that restrains their use to certain critical moments in the life of an animal has appeared in Europe these last fifteen years, obliging researchers to search for alternatives via a better control of food, genetics and breeding systems, in order to guarantee to consumers a better, a priori, quality of animal products. Physiological functions that offer possibilities of exogenous hormonal control, usable hormonal substances and animal speculations are presented. A clarification of the toxicological risks that these substances present, the control and traceability of their use and the current regulations are given. Finally, the research that will allow making progress around the question of hormone use in breeding in a context of a remodelled society is evoked.
\end{abstract}

PARIS A., ANDRÉ F., ANTIGNAC J.-P., LE BIZEC B., BONNEAU M., BRIANT C., CARATY A., CHILLIARD Y., COGNIÉ Y., COMBARNOUS Y., CRAVED J.-P., FABRE-NYS C., FERNANDEZ-SUAREZ A, FOSTIER A., HUMBLOT P., LAUDET V., LEBOEUF B., LOUVEAU I., MALPAUX B., MARTINAT-BOTTÉ F., MAUREL M.-C., PELICERRUBIO M.-T., PICARD-HAGEN N., PINAULT L., PINEL G., PONSART C., POPOT M.-A., SCHMIDELY P., TOUTAIN P.-L., ZALKO D., 2006. Hormones et promoteurs de croissance en productions animales : de la physiologie à l'évaluation du risque. INRA Prod. Anim., 19, 151-240. 